Magdalena Zamorska

\title{
Intense Bodily Presence
}

Practices of Polish Butō Dancers

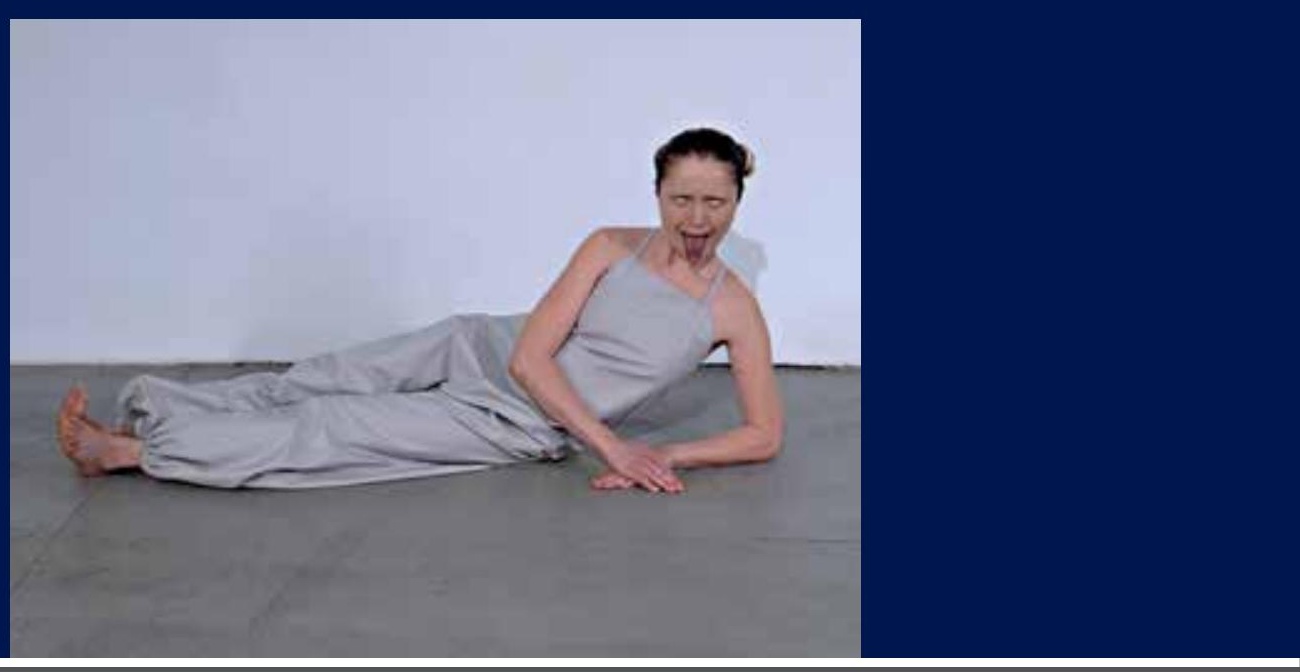




\section{Magdalena Zamorska}

\section{Intense Bodily Presence}

The author explores the practices of Polish butō dancers. Underlining the transcultural potential of the genre, she discusses in particular their individual body-mind practices and so-called butō techniques in order to produce a generalised account of butō training. Her argument is underpinned by complex field research which she carried out as an expert observer and a workshop participant. Drawing on a transdisciplinary approach, which combines insights and findings from the fields of cultural and performance studies, cultural anthropology and cognitive sciences, the book depicts the sequence of three phases which make up the processual structure of butō training: intro, following and embodiment.

\section{The Author}

Magdalena Zamorska is a Ph.D. graduate in Humanities (2012) and an assistant professor at the Institute of Cultural Studies at the University of Wroclaw (Poland). Her research interests include movement, social choreography, issues of perception and reception in choreographic performances. She also explores the intersections of humanities and science. 
Intense Bodily Presence 


\section{INTERDISCIPLINARY STUDIES IN PERFORMANCE HISTORICAL NARRATIVES. THEATER. PUBLIC LIFE}

Edited by Mirosław Kocur

VOL. 14

Zu Qualitätssicherung und Peer Review der vorliegenden Publikation

Die Qualität der in dieser Reihe erscheinenden Arbeiten wird vor der Publikation durch einen externen, von der Herausgeberschaft benannten Gutachter geprüft.
Notes on the quality assurance and peer review of this publication

Prior to publication, the quality of the work published in this series is reviewed by an external referee appointed by the editorship. 
Magdalena Zamorska

\section{Intense Bodily Presence \\ Practices of Polish Butō Dancers}

Translated by

Patrycja Poniatowska 


\title{
Bibliographic Information published by the Deutsche Nationalbibliothek
}

The Deutsche Nationalbibliothek lists this publication in the Deutsche Nationalbibliografie; detailed bibliographic data is available in the internet at http://dnb.d-nb.de.

Library of Congress Cataloging-in-Publication Data A CIP catalog record for this book has been applied for at the Library of Congress.

The Publication is founded by Ministry of Science and Higher Education of the Republic of Poland as a part of the National Program for the Development of the Humanities.This publication reflects the views only of the authors, and the Ministry cannot be held responsible for any use which may be made of the information contained therein.

\author{
ISSN 2364-3919 • ISBN 978-3-631-76512-8 (Print) \\ E-ISBN 978-3-631-76513-5 (E-PDF) • E-ISBN 978-3-631-76514-2 (EPUB) \\ E-ISBN 978-3-631-76515-9 (MOBI) • DOI 10.3726/b14546
}
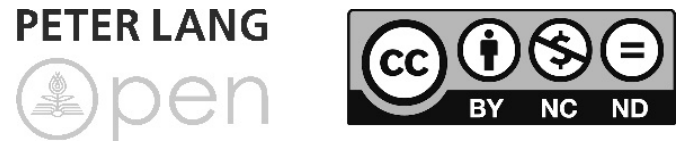

Open Access: This work is licensed under a Creative Commons Attribution Non Commercial No Derivatives 4.0 unported license. To view a copy of this license, visit https://creativecommons.org/licenses/

by-nc-nd/4.0/

(c) Magdalena Zamorska , 2018

Peter Lang $\mathrm{GmbH}$

Internationaler Verlag der Wissenschaften

Berlin 2018

Peter Lang - Berlin · Bern · Bruxelles · New York ·

Oxford $\cdot$ Warszawa $\cdot$ Wien

This publication has been peer reviewed.

www.peterlang.com 


\section{Acknowledgements}

This book grew out of my doctoral project completed at the University of Wroclaw in April 2012. My thanks go to my then academic advisor Professor Mirosław Kocur, who shared his expertise with me and gave me all possible support. I would also like to thank the referees of my dissertation - Professor Anna Grzegorczyk of the Adam Mickiewicz University in Poznan and Professor Dariusz Kosiński of the Jagiellonian University in Cracow - for their insightful and useful comments. My research would not have been possible without butō, dance workshops and, above all, without long and in-depth interviews with Polish artists who practise this art form. I am grateful to them for their openness, the time they gave me and their readiness to share their experience and knowledge with me. Last but not least, this book would not have come about without the support I received from my loved ones. A big thank-you goes to my husband Marcin, my parents and my brother. The Polish version of this book was funded by the Institute of Music and Dance in Warsaw. 

He is truly free because he is so thoroughly the Child of the Present. He lives from moment to moment, taking life as it comes and giving it up as it passes. So completely is his spirit of the Here-and-Now that he escapes altogether the crushing weight of Time and Space. [...] It is left to the Taoist to achieve the strange spirituality of ethereal diffuseness, which seems to envelop the silhouettes of Time and Space, not by vainly reaching for eternity and infinitude, but by breaking them into myriad atomic bits and fusing himself with these one by one as he chances upon them. The result is the attainment of a pantheistic repose, at once immanent and transcendental-like a fish lying listlessly on the surface of undulating waves, or a bird resting its wings on the air currents, rising and falling as the atmospheric pressure changes. There is an elasticity of adjustment in the apparent stillness of position, which definitely makes the word "static" altogether inadequate to describe the subtle relations involved.

Lin Tung-chi about a Taoist recluse (1947: 12-13) 



\section{Contents}

Introduction

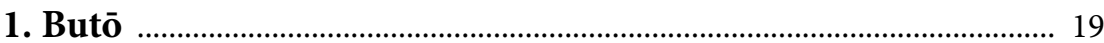

Premodern Elements of Butō .................................................................... 20

Tatsumi Hijikata: The Structure ..................................................................... 28

Kazuo Ōno: Improvisation ....................................................................... 33

Contexts: Dance, Performance Art and Physical Theatre ............................. 34

Transcultural Butō .................................................................................... 38

2. Butō Techniques .......................................................................................... 41

Kayo Mikami: Butō as a Way of Producing Neural Networks ..................... 41

Rhizome Lee: Butō as a Path to the Subbody .................................................. 43

Toshiharu Kasai: Butō as a Method of Psychosomatic Exploration ............ 45

Sondra Horton Fraleigh: Butō as an Alchemical Process .............................. 50

Polish Researchers of Butō Techniques ........................................................... 51

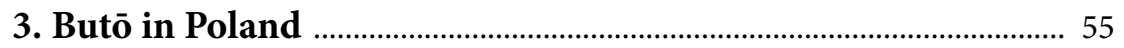

Paweł Dudziński: The Intuitive Ritual ......................................................... 56

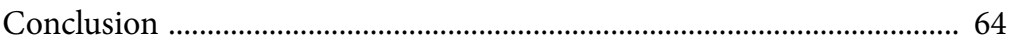

Justyna Jan-Krukowska: Sensory Sensitisation .............................................. 64

Conclusion .......................................................................................... 71

Sylwia Hanff: Transcending the Body Code ................................................... 71

Conclusion ............................................................................................ 80

Krzysztof Jerzak: Peak Experience ………………………………………... 81

Conclusion ........................................................................................ 90

The Amareya Theatre: The Body in Crisis .................................................... 90

Conclusion ...................................................................................... 100

Tomasz Bazan: Body Form Movements ................................................... 101

Conclusion ....................................................................................... 113

Aleksandra Capiga-Łochowicz: The Archaeology of the Body .................. 114

Conclusion .............................................................................................. 124 
TO-EN: The Body Shaped by Matter ..................................................... 124

Conclusion ............................................................................................ 129

Irena Lipińska: Choreographing Improvisation ........................................ 130

Conclusion ..................................................................................... 137

Katarzyna Żejmo, Iwona Wojnicka, Miho Iwata and

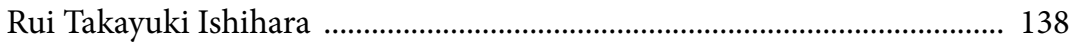

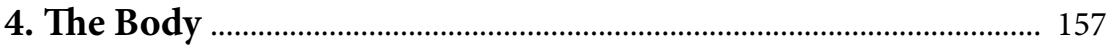

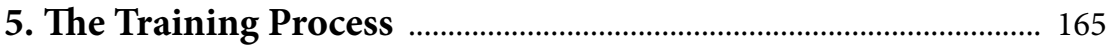

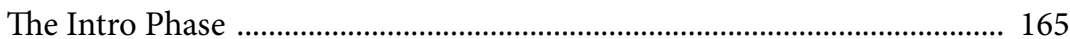

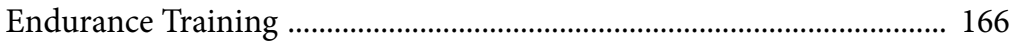

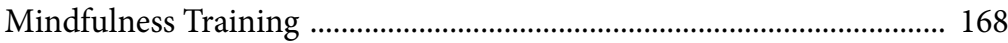

Total Presence ....................................................................................... 170

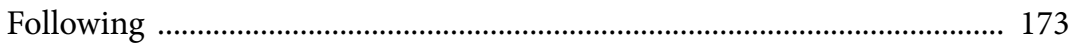

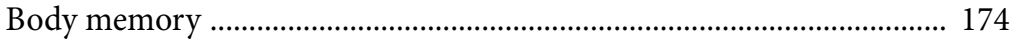

Somatosensory Changes .................................................................... 176

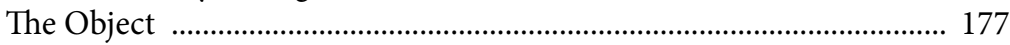

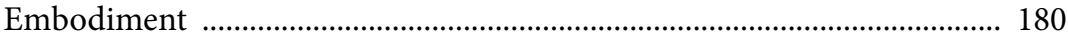

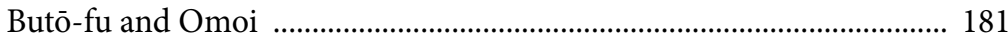

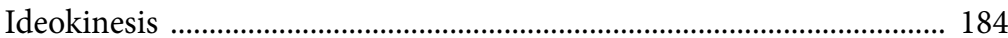

6. Transformation in the Dancer and the Audience ........................ 187

Performative Training .................................................................................... 188

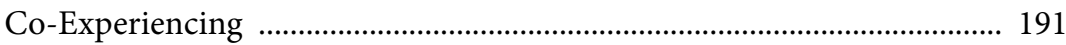

Neurobiological Empathy .............................................................................. 193

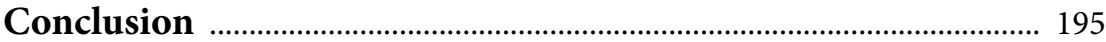

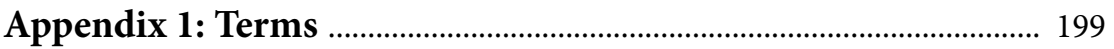

Appendix 2: Biographical Notes .................................................. 211

List of Photographs ........................................................................ 219

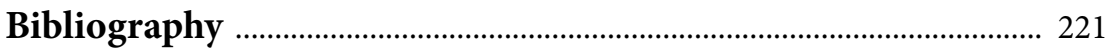

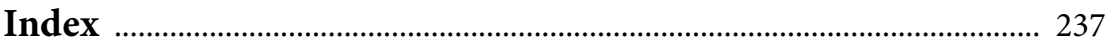




\section{Introduction $^{1}$}

1989 was a momentous year for Poland. The political transition and the concomitant opening of the borders precipitated incisive changes in visual and performing arts. Butō dance was incorporated into Polish artists' creative practices as one of the many manifestations of the artistic ferment that accompanied the socio-political transformations.

Firstly, critical art, the most important artistic movement of the 1990s, started to burgeon in the visual arts (cf. Kowalczyk 2000, 2006; Piotrowski 1999): "In Polish art, [critical art] can certainly be linked to other movements which appeared and developed in the US and Western Europe, such as 'resistance postmodernism,' 'body art' and 'abject art"' (Kowalczyk 2006: 1). Critical artists used their bodies in performative ways as simultaneously the subject and the object (material) of their art practices. In doing this, they brought body art to the audience's attention and exposed cultural blueprints used to harness and discipline the body. Piotr Piotrowski defined critical art as art which "jolts us out of automatic modes of looking and thinking” (Piotrowski 1998).

Automatisms inherent in our uses of the body were also the target of interventions Tatsumi Hijikata made as an artist. Forty years before critical art started to thrive, Hijikata had founded butō as a genre, paralleling abrupt sociopolitical changes in Japan. Hijikata was highly critical of the Japanese mainstream dance theatre of his day, which copied modern dance models "imported" from the West. However, he himself did not shun some new forms of art developing in the West (e.g. happening and performance art) and espoused, in particular, body art. Emphatically, similar tendencies were also displayed by other contemporaneous Japanese artists, such as the Gutai group. All these factors helped integrate butō, borrowed from another culture as it was, with the somatisation movement spreading across Polish arts in the 1990s.

Secondly, at the turn of 21 st century, contemporary dance started to develop in Poland (cf. Grabowska, Szymajda 2009). Its practitioners were chiefly independent artists who repudiated dance theatre aesthetics and set out on a quest for new dance forms and concepts, often inspired by postmodern, minimalist, physical, conceptual and critical dance. Previously, experimental methods of body use on stage had been pursued in Poland only within the explorations of independent

1 The Introduction to the English edition is a slightly revised version of the original Polish Introduction (Magdalena Zamorska, April 2018). 
theatre laboratories. ${ }^{2}$ In 2004, the Alternative Dance Academy (Alternatywna Akademia Tańca) was launched as one of the most important dance-related projects, in which young Polish dancers were coached in new dance and choreography methods by eminent choreographers from all over the world. Poland's accession to the European Union (2004) produced new opportunities of studying dance and choreography abroad. Two years later, the Solo Project was started as one of Poland's most important residence programmes, offering experimental dance artists both technical backup (stage infrastructure) and funding. Curated by Joanna Leśnierowska, both projects are still a vibrant part of the Old Brewery New Dance (Stary Browar Nowy Taniec) ${ }^{3}$ in Poznan. Tomasz Bazan and Irena Lipińska, two Polish dancers working with butō, received grants from the Solo Project in 2008 and 2011 respectively.

All these changes reduced the obstacles (including mental ones) to influences from a multicultural, globalised world. Diverse choreographers and dancers started visiting Poland, which helped people with an interest in butō study the genre not only theoretically but also through workshop practice.

Thirdly, non-European body- and mind-oriented developmental practices and techniques became popular with Poles towards the end of the 20th century. As meditation, yoga and martial arts teachers and instructors began coming to Poland more and more frequently, training workshops came to flourish as places for non-formal practice in body disciplines education. Concomitantly, books and articles on therapeutic somatic practices and movement therapies (such as the Alexander Technique, Bartenieff Fundamentals, Body Mind Centering, the Feldenkrais Method and ideokinesiology) appeared, followed by trainers in various techniques and methods. As a result, Polish artists obtained access to an array of body-mind disciplines (cf. Nancy 1999), both those originating outside Europe and those developed by 20th-century Western theoreticians and practitioners.

Briefly, butō dance became part of the practices and pursuits of Polish artists at the turn of the 20th century due to (1) the spread of critical art, which made the audience familiar with non-normative body performance; (2) the development of experimental contemporary dance forms facilitated by access to international laboratories of dance and choreographic techniques; and (3) the popularity of Eastern and Western body-mind disciplines, methods and techniques.

2 E.g. in Jerzy Grotowski's Laboratory Theatre in Wrocław.

3 http://www.starybrowarnowytaniec.pl [Accessed 15 July 2011]. 
What I was first intrigued by in butō was the genre's transcultural potential revealed in the universality of its psycho-somatic training. At the heart of butō lies an attempt to recover the primordial body "unspoiled by culture," a body in which mental images are embedded as the artistic process develops. Founded in the late 1950s as an avant-garde practice, butō dance has since transformed into an art genre, turning into one of many aesthetic forms emptied of subversive potential. Although butō is an aesthetically formalised dance genre today, I believe that its original, liminal and subversive power is still retained and observable in training practice.

In my view, the aesthetics commonly associated with butō, typically including the "bowlegged crouch, grotesque facial grimaces, white-coated body and rolling whites of the eyes" (Capiga 2009: 46), is not a sine qua non of butō as a genre. Butō aesthetics are not formed by reproducing generic patterns and models; rather, they are largely a side-effect of sensations and experiences through which artists go in their practice.

I believe that butōs essence lies in using specific body-mind disciplines and techniques which serve to change perceptions of the self and the world. Practices of reclaiming specific resources from body memory and/or embodying them are also quintessential.

Because in my research, I sought to understand and describe the phenomenon of Polish butō as well as to identify and trace the model of training used by Polish dancers; what I studied were not dance performances but rather "body work," i.e. the techniques that help evoke (or retrieve) specific experiences and bodymind states. I am referring to training and creative processes not witnessed by spectators as "private performance." This means that I regard the dancer's selftransformation process as a unique performance which does not require the presence of an audience. ${ }^{4}$

The private butō performance I investigated is instrumental both in devising public performances and in embracing the specific aesthetics mentioned above. Because at the core of butō lies a triadic artist-work-audience process, it is best and most efficiently studied in terms of performativity aesthetics as defined by Erika Fischer-Lichte. In her model, the audience, rather than being detached, are involved in the creative process both physically and biologically. Developed

4 In terms of performance theory, I side with Jon McKenzie's definition of performance as an action/process involving effectiveness, efficiency and efficacy rather than with Richard Schechner's broad performance-studies approach anchored in theatrical/ histrionic thinking. For this reason, in my argument I re-write Erika Fischer-Lichte's notion of performativity to adapt her concepts to training rather than stage productions. 
in private performance, butō dancers' capacity to modify physiological, motor, affective and energy states (cf. Fischer-Lichte 2008a: 67) directly affects the audience's phenomenal bodies in later public performance (shows, stage improvisation, etc.). Due to neurophysiological empathy, the dancer's inner transformation is also experienced by the viewer.

Total Intense Bodily Presence: Practices of Polish Butō Dancers concludes a threeyear research project (2008-2010), in which I studied butō techniques as inscribed in the broader context of body-mind practices used by Polish dancers. I did not investigate the intercultural transfer of butō; rather, I enquired into how Polish artists understood and defined butō as well as what psychosomatic practices and, first of all, what butō techniques they used. I believe that key to butō-ka's practice is an insight into the ways the body and mind function in highly specific training settings, about which I found out in interviews with dancers and my involvement in workshops. My book explores this training.

By Polish butō dancers or Polish butō-ka (butō practitioners) I mean Polish artists who use techniques characteristic of butō in their work, which usually involves having practised under an established butō dancer. Since the late 1990s, Polish artists have had several opportunities to participate in butō workshops and learn body-mind disciplines, devise first stagings and teach new generations of dancers.

Tatsumi Hijikata, a co-founder of butō (with Kazuo Ōno), and his students emphasised the otherness of the Japanese body. For this reason, in researching butō practices of non-Japanese bodies, I did not study the work of Poland-based Japanese artists, such as Miho Iwata and Rui Takayuki Ishihara. I did not focus either on the very interesting workshop and artistic practices of Katarzyna Żejmo, a student of Rhizome Lee's Subbody Resonance Butoh School Himalaya in Northern India, because I had concluded my preliminary research before Żejmo started to work in Poland. Another omission in my work is Iwona Wojnicka, who is currently devoted mainly to organising workshops and theatre ventures. The protagonists in my book are Paweł Dudziński, Justyna Jan-Krukowska, Sylwia Hanff, Krzysztof Jerzak, the Amareya Theatre (Teatr Amareya, i.e. Katarzyna Julia Pastuszak, Agnieszka Kamińska and Aleksandra Śliwińska), Tomasz Bazan (Maat Project Theatre), Aleksandra Capiga-Łochowicz, TO-EN (Anna Brałkowska) and Irena Lipińska.

My research aim was to produce a systematic account of butō training based on an internal process stimulated by butō techniques and other psychophysical practices. I studied basic training and training improvisation. Training practices can result both in a structured performance and in a stage improvisation. 
I did not presuppose any universal "butō method," but in the course of my explorations I realised that there were several techniques on which many butō dancers repeatedly relied. Those techniques served to achieve a body-mind state in which the dancer's body resonates both with the mental and emotional process as well as with external stimuli from the environment. They were also used to explore the contents of body memory and to embody (incarnate) mental images.

In identifying the underlying model of butō training, I drew on the data from interviews with Polish butō dancers/practitioners and knowledge acquired from butō workshops in which I had taken part. I also built on butō training models proposed by other researchers. I established analogies between structures of respective workshops. Comparing various dancers' training practice, I identified a process which served as the common axis of training. ${ }^{5}$ The stages of this process organise the butō training model I traced. Emphatically, the structuring of training (the division into consecutive stages) is in line with the Western education model rather than with the Japanese one. This issue was addressed in an interview with Katarzyna Julia Pastuszak, a butō dancer and researcher:

Japanese dancers who came to work to Europe transformed training processes to adjust them to European students. Perhaps, they wouldn't work with students in Japan in this way at all; perhaps the workshops wouldn't be as structured, with the warm-up first and other elements following. In the West, students expect an intellectual order, and this is what dancers are quite articulate about. For example in Yukio Waguri's workshop [in Japan], we first talked sitting on the floor, then he started drumming, and dancing began. Yoshito Ōno taught his workshop in a similar way [...] We are different than the Japanese, more intellectual. We need a structure to get steeped into something. [...] In Japan, you don't get all things explained to you or described, like now we'll do this and then we'll do that. Waguri transformed his workshop routine to fit Western needs. He went to the US a lot, also in order to transmit Hijikata's legacy, and created Butō Kaden. (WTA, Pastuszak).

Because what I explored was the dancer's internal process, my research method was not limited to watching performances but also included interviews with artists and active participation in butō workshops. My own practice was an important source of knowledge and helped me juxtapose the data from research with my own experience. I took part in butō workshops taught by both Polish and Japanese dancers (Sumako Koseki, Kayo Mikami, Daisuke Yoshimoto), which enabled me to compare their workshop methods.

5 Often internal and invisible, the process is the source of the dancer's observable movements in stage performance. 
In building the butō training model, I relied on an interdisciplinary approach which could effectively grasp the complexity of butō. Such eclecticism is common in contemporary scholarship as "[i]n modern science, various research areas and methods are more and more clearly interpenetrating. The traditionally demarcated disciplinary boundaries are being blurred, and new hybrid fields of knowledge are emerging, such as cognitive science, neuroscience and new humanities" (Francuz 2007: 17).

To explain subjectively experienced states, processes and phenomena that surface in butō training, I used concepts of neuroscience and its subdisciplines (neuroaesthetics, neurophenomenology), cognitive psychology and cognitive science. In these disciplines, researchers study biological processes involved in a variety of sensations and experiences. Studies using electroencephalogram (EEG), biochemical blood tests and, first of all, modern neuroimaging (MRI, fMRI, PET $)^{6}$ have contributed considerably to expanding understanding about how human beings function. Enactivism produces models of human (embodied) mind functioning in interaction with the environment. I believe that all research problems are better solved by combining different instruments of measurement and, in this case, different modes of representation anchored in various research idioms and methodologies. Concepts developed within these disciplines help comprehend and account for the experience of a butō practitioner in a language acceptable within contemporary scholarly paradigms and help present in quantifiable ways the essence of butō practices, that is, the attempt to transcend the bodily and perceptual habitus.

In this book, I attempt to accurately define the semantic field of respective terms. All specialised terms are defined either in the body of the book or in the “Terms" Appendix. Some key Japanese notions are not really translatable into Indo-European languages. Those which require detailed explanations involving cultural contexts and mental associations (e.g. $\mathrm{ma}$ ) are clarified in the course of my argument; others are included in the "Terms."

The choice of spelling and transcription of Japanese terms, not least the key notion of this book 舞踏 (butō), is another important consideration. In this book, I use the international Japanese transcription model Hēbon-shiki-rōmaji devised by the American missionary James Curtis Hepburn (Żeromska 2003: 15), in which, for example, $\bar{o}$ serves to represent the long $o$ vowel. This transcription pattern is applied to all words of Japanese origin. The butoh spelling, widespread in

6 For details of neuroimaging methods, see e.g. Jędrzejczak 2010: 131-134; BoleynFitzgerald 2010: 4-7. 
(especially popular) English-language publications, is retained in quotations and original names (of groups, festivals, etc.). Popular, internationalised foreign terms, such as aikido or yoga are not italicised, while less popular ones are put in italics. Another important choice I had to make was the way of writing Japanese names and surnames. In kanji, the surname is traditionally given before the first name. Against the Japanese tradition, I decided to reverse the sequence consistently because many contemporary butō artists live in Western countries and also tend to adhere to the first name-surname sequence. 



\section{Butō}

Butō is a dance form that came into being in Japan in the second half of the 20th century; its founding fathers were Tatsumi Hijikata and Kazuo Ōno.

In Japan, dance was originally referred to as kami-asobi, i.e. "gods at play." Towards the end of the 19th century, the term buyo, which precisely denoted "dance," came into use (Żeromska 2010a: 37). This is why Hijikata himself initially called his art Ankoku buyō, meaning "the dance of utter darkness" (“ANKOKU' means darkness, as 'AN' is darkness and 'KOKU' is black" - Kasai 2009b). Later, he replaced the umbrella term buyō with the word butō, which as early as in the Meiji epoch was used to mean ballroom dancing that had come from the West (cf. Viala, Masson-Sekine 1988: 64). ${ }^{1}$ The first decade of the butō movement was "very much focused on the ankoku side of life, full of violence, grotesquery, and madness" (Roquet 2003: 31). For example, the first performance of this genre, entitled Forbidden Colours (1959), was inspired by Yukio Mishima's short story which tackled homosexuality and the interconnections of violence and sexuality. In the show, Hijikata built on performative strategies of the happening and body art popular in the West, ${ }^{2}$ even though his goal was to create a new type of dance as an alternative to modern Western dance, which prevailed on Japanese stages in the wake of World War Two. Hijikata's Ankoku buto continued to develop "through the pre-history of notational butō (1959-1972) up to notational butō (1972-1985)" (Pastuszak 2010a: 13). ${ }^{3}$ When a second and then third generation of butō dancers entered the stage in the 1970s, the dark overtones of the name were deemed too limiting, which prompted shortening it to butō alone (舞踏) (cf. Klein 1988: 2). Even though many Japanese still employ the Ankoku butō apellation, the later, clipped version of the name has become widespread in the West.

Hijikata's and Ōno's ideas about what made up the essence of dance contributed to the invention of an entirely new genre. The artists proposed a vision of the body and dance which indeed sounded subversive in their day: Hijikata unveiled the suppressed aspects of corporeality and contested everyday practices of body use, while Ōno affirmed the spiritual dimension of bodiliness, which was tending

1 The word butō consists of two ideograms: "to dance" and "to step/tread."

2 Interestingly, in 1954-1972, Japan had its native Gutai group, whose innovative and bold pursuits were later associated with what is referred to as the happening, performance art and, even, conceptual art.

3 "Notational butō" defines dance created on the basis of $b u t \overline{-}-f u$, i.e. score or notation. 
to wane in Japan's Americanised post-war culture. Whereas Hijikata invented many butō techniques that are still widely employed today, Ōno was recognised as the master of improvisation. Both were born in the north of Japan, which was an economically and culturally disadvantaged region. Ōno was born in 1906 in Hakodate, a small fishing village; Kunio Yoneyama (later Hijikata) was born in a farming village in the Akita Prefecture, Tohoku Province. Their childhood was marked by poverty and the deaths of their loved ones. They met, probably, in 1949, when Ōno performed at the Kanda Public Hall in Tokyo.

Early in their artistic careers, both Hijikata and Ōno studied modern (mostly expressionist) dance. However, they refused to view the body as reduced to a trained and technically skilled tool. They insisted that dance should come from within the body and, in this way, re-invigorate "its structure and performance" (Gōda 1988: 86). Consequently, their stage work was "resistant to critical interpretation" and triggered the process of "direct [...] communication between the audience and the dancer" (Klein 1988: 28). Nevertheless, despite butō dancers' deep-running dislike of methods that shackled the body, several butōka (including Hijikata himself since the 1970s) have attempted to structure their dance by introducing defined movement techniques and even aesthetic agendas.

Nario Gōda differentiates between original Ankoku butō and the later, sprawling butō movement (cf. Gōda 1988: 79). Toshiharu Kasai, in turn, divides butō dance into original (the dance of Hijikata and Ōno), classical (the dance of second- and third-generation dancers of Japanese origin, such as Akira Kasai, Akaji Maro, Biskup Yamada, Natsu Nakajima, Min Tanaka and Ushio Amagatsu) and Westernised (or internationalised) butō; he also insists that there is a universal butō method, which he calls "hyper dance" (cf. Kasai 2000). The original and classical butō varieties clearly exhibit the culturally determined, Japanese mode of using the body, which vanishes in internationalised butō.

\section{Premodern Elements of Butō}

Butō tends to be classified as a postmodern dance form as it has no codified and intersubjectively comprehensible dance idiom, freely accommodating sundry borrowings and being open to interpretation. However, as Miyabi Ichikawa observes, butō seems to transgress modernity by going, so to speak, backwards and reaching back to the premodern era (Ichikawa 1988: 69).

In the aftermath of World War Two, Japan's consciousness of its native culture started to grow, including a renewed appreciation for the long histrionic tradition, which had fallen into oblivion, having been slowly ousted from communal memory by the frequently uncritical fascination with European culture rife in 
the Meiji epoch (1868-1912) and the imitation of Western (chiefly American) cultural models in the post-war years. The widespread admiration for the style of Western modern art came to be viewed as indicative of the cultural domination of Western countries. In opposition to the West's hegemony, Japan's artistic avant-garde urged drawing on Japanese traditions, customs and beliefs. Such attitudes were very popular: when in the late 1950s, students took to the streets rallying in response to the Mutual Security Treaty with the US (1951; amended in 1960) - a former enemy who had dropped atomic bombs on Japanese cities during World War Two - their protests were accompanied by street performances which abundantly alluded to Japanese myths and legends (cf. Janikowski 2008). A decade later, in 1970, Yukio Mishima, an avant-garde Japanese writer and a member of the military association Tatenokai, seized control of Japan's military headquarters and gave a speech informed by the Bushido Samurai code, calling for a coup d'etat and the restitution of the empire. As the plan failed, he took his own life, committing the ritual suicide of seppuku.

Also many Japanese scholars and intellectuals advocated going back to the native Japanese vision of individual autonomy, strongly anchored in the local community. One of them was Yanagita Kunio, a researcher of the oral traditions of the yamabito (mountain people) and the jomin (rural village folk) who never quoted works by Western scholars. He argued for dismissing modernism as associated with the individualism touted by the Western world. He sought to "give voice" to the excluded (women, old people, madmen), whom he regarded as the bearers of authentic Japanese culture. In turn, Yasuji Honda (1906-2001), a cultural scholar who focused on the study of Japan's theatre tradition,

[...] spent years traversing Japan, resolved not to pass over any temple, no matter how small, if only it had retained any traces of the theatrical glory of old. Inquisitive, meticulous and insightful, he produced an extraordinarily rich and comprehensive body of documentation, recording most performances. (Źeromska 2003: 21)

Japan's traditional theatre (Nō, Kyōgen, Kabuki) used histrionic models developed in ritual shows.

These Nativist ideas had a powerful impact on artists. As butō was being born, many avant-garde stage artists were finding inspiration in Japan's archaic traditions. The group included: Terayama Shuji (a poet and playwright inspired by folk festivals who founded the avant-garde Tenjo Sajiki group), Kara Juro (the founder of the Jokyō Gekijō group, i.e. the Situationist Theatre) and Suzuki Tadashi (the founder of the Suzuki Company of Toga, dedicated to searching for genuinely Japanese identity and relying on the "poses" of Nō, Kabuki and martial arts for his movement idiom) (Klein 1988: 17-18). This aspect of butō 
was studied by Susan Blakeley Klein (1988), who outlined her interpretation of the phenomenon in a study titled Ankoku Butō: The Premodern and Postmodern Influences on the Dance of Utter Darkness.

Pointing to traditional Japanese theatre as the source of inspiration, Klein approaches butō as a postmodern art form in which traditional theatrical techniques, forms and ideas are typically re-contextualised (Klein 1988: 20). She believes that using various performing techniques counterbalances the often unreflective adoption of Western patterns. With these assumptions in mind, Klein defines butō as a performative art form in which the Western, modern concept of the stage production is rejected, while vernacular traditions are deconstructed.

In this context, reaching back to premodern traditions (Klein 1988: 14) entails restoring the bond with the uncanny, the irrational and the unconscious. This is why violence, ritual sacrifice and/or ecstasy - experiences rooted in the collective unconscious - take place on stage. Dancers produce a vision of an anti-rational and anti-modern world. The ongoing metamorphosis unfolds outside of time, where boundaries between worlds are blurred. The critic Kiyokazu Yamamoto has called this model of time metempsychosic: "there is only process which is cyclical and endless" (Yamamoto 1978: 31). Communication is facilitated by poetic metaphors, which work by evoking vague associations and building a sense of affinity. In the world of butō, words and things are never disjoined, and beings are ubiquitously simultaneous (cf. Eguchi 1988: 89-90). Butō dancers do not seek to fashion reality and identity verbally, but expose themselves and the world in the pre-rational stage. They can operate at the level of the unconscious, both collective (communal) and individual (of a life script). What emerges from explorations of their own unconscious resources is intertwined with images anchored in the collective unconscious. According to Klein, butō dance has in this way challenged the traditionally endorsed dramatic construction of performance.

The early interest in the unconscious was accompanied by reviving the tradition of popular entertainments. The founders of butō, like many other Japanese avantgarde artists of the 1960s, turned to early 20th-centrury forms of popular theatre, such as the Asakusa opera, the circus-like Misemono shows and the Yose vaudeville revue based on comic monologues (Richie, qtd. in Klein 1988: 15). Yet Hijikata also drew on the classic Japanese performative tradition of Nō and Kabuki theatres (the latter going back to dances of actor-prostitutes; Klein 1988: 15). The butō originators combed these traditions for devices and tropes.

The mask is the oldest tool for becoming an empty shell, for casting off of individual traits and for relinquishing one's ego. Used by actors in the Japanese theatre tradition, the mask serves "to de-personalise the performer, to neutralise 
facial expression, to underscore the conventionality of the character and to divest him/her of reality [...] unlike in the European tradition, the mask never highlights the character's individuality or presents his/her face" (Żeromska 2003: 13).

The mask in Japan boasts a history of five thousand years. Over these centuries, the mask has evolved from a ritualistic prop to a histrionic one. Farming and shepherding peoples used the mask to transfigure a person into an ancestral animal, a hero, a deceased one, a spirit or a deity. The functions and meanings of the mask in mediaeval Nō theatre were largely shaped by the oldest forms of performance, such as early shamanistic practices and okina-mai dance originating from archaic shamanistic trance rituals.

The metamorphosis of the Nō actor already commences during preparations in the Mirror Room, where the protagonist, having ritualistically put on an appropriate mask, contemplates the face of the "visitor from the underworld" (henshin) in the mirror. The mask straddles the boundary between two worlds. The actor must adeptly animate the mask, which supports the "still living" body parts. Paradoxically, the mask has vivid facial expressions as it is constructed to convey an entire array of feelings, affected by the lighting, the rake angle and other factors. "The mask becomes a face and the face a mask. It is not the psychology of feelings but the anatomy of forms which is being dealt with here" (Barba, Savarese 2005: 134). Actors who use the mask insist that the face behind it must act too, lest the body belies the expression of the "face." Yet Kanze Hisao, a Nō actor, has a different view: "the mask responds to the slightest trembling of the face. And this forces the actor to immobilise the face completely" (Żeromska 2003: 188).

When the mask is donned, the face is submerged in darkness.

The light gets under the wooden surface only through "two tiny pupil-apertures, which [...] the human eye perceives as a single point. [...] actors feel regular human anxiety as, losing the sense of perspective and distance, they struggle to maintain the body balance.

(Żeromska 2003: 193)

With the stimuli which make it possible to find one's bearings in a space shut out so radically, actors must display focus and mindfulness: "On putting the mask on, the actor $[\ldots]$ can move to regions remote from the quotidian. The actor can sense, in the universe, a dimension in which s/he is not a particle and the stage with the on-stage world is no fiction" (Żeromska 2003: 188). The mask imposes special ways of bodily comportment, which is so vital in Nō. For example, because of the constraints to perception, the suriashi walk has been developed in which the feet very carefully and slowly slide on the polished floor. This step also appears in butō, in what has come to be referred to as zero walk (hokōtai) (cf. “Terms"). 
In Kabuki theatre, actors, instead of using masks, put on gaudy make-up called kumadori (which also covers the inside of the mouth) on their heavily whitened face. The actor's eyes are most important as they are vividly accentuated, bulging, squinting and gazing into the beyond: "the eyes twist as if they were about to pop out of the actor's head" (Barba, Savarese 2005: 131). Bright make-up had already been appreciated in the classic Kabuki, where the stage was traditionally dim and lit only by candlelight. The white face made the dancer more clearly visible amidst the darkness of the stage. In turn, the colourful patterns (kumadori) serve to "highlight and expose the character's features, social and occupational status, gender and age" (Hoczyk 2009b: 15).

Despite similarities, make-up in butō has a different role than the mask in Nō theatre and the kumadori make-up in Kabuki. With not only the face but also the entire body coated in white powder, the dancer can discard the visual signs of social membership and, in this way, universalise the body, helping it return to its original state (the nakedness and the shaven head can serve a similar purpose). The body transmutes into a tabula rasa which lends itself to any inscription. Initially, artists put a mixture of chalk and glue on their faces, turning them into masks, shells or carapaces. In the course of time, a make-up of rice flour and water was developed, resembling the substance used by Kabuki actors. The thick layer of flour or powder gradually peels and flakes off during the performance, which brings processes of decomposition to mind. Such make-up helps the dancer's identity disintegrate in front of the audience. The white body make-up promotes "the Butō vision of an unstable world in a state of constant flux, cyclically moving back and forth between the poles of disintegration and recreation" (Klein 1988: 48).

Grimaces, distorted facial expressions and unnatural postures serve as major tools of on-stage transformation. For this reason, mie - typical Kabuki poses - is another of butō's borrowings from the Japanese performative tradition. Mie is an utterly expressive pose accompanied by heightened facial expressions in which the actor "freezes" for a while ("the eyes bulge out and cross, the mouth stretches into an extraordinary grimace, the body seems to blow up to a superhuman size" Klein 1988: 49). Kabuki performers heavily rely on mie to highlight the climax of their protagonists' actions:

The actor halts, freezes motionless and then turns his gaze towards a certain point and stares at it with his face contorted in a grimace. Mie serves to fix the extraordinary beauty in the audience's memory by arresting - in time and space - one situation out of a stream of many minor events which make up the underlying plot. (Melanowicz 1994: 433)

Actors themselves refer to this enforced standstill as "cutting." 
The actor's pose could be described as stopping the film in that particular frame where the actor is showing a special tension: hence the meaning of cutting the action and of blocking a living immobility [...]. One could say that a kabuki performance is a transition from one mie to another, that is, from one summit of tension to another. (Barba, Savarese 2005: 130)

Butō involves moments of stoppage as well. They are referred to as beshimi kata (Iwabuchi 1988: 77), with beshimi meaning "big pursed lips" and deriving from the name of a Nō mask for powerful deities and demons of the local pantheon that converted to Buddhism and guarded Buddhist temples. The name of the mask is used to describe an excessively distorted face with rolling eyes, which is common in butō (Klein 2008). Klein refers to beshimi kata as "mie in motion" (Klein 2008). "Beshimi kata, an equivalent of mie, appear as constantly changing facial grimaces and body twists; instead of 'freezing' the body and fixing it in one pose and form, there is an ongoing flux of forms" (Hoczyk 2009b: 18).

The Kabuki tradition involved "rituals of inversion, grotesque and clownery, which the critic Masakatsu Gunji described as shuaku no bi, i.e. an aesthetics of ugliness" (Janikowski 2008: 51), "based not on the pursuit of aesthetic sublimity but on exposing human imperfection and showing human nature as ridiculous and banal" (Berestecka 2009: 28). The rituals were supposed to evoke the murky aspects of life, lay bare concealed and suppressed desires and fathom the depths of the human unconscious, which is redolent of what Bakhtin pervasively refers to as "the material bodily lower stratum" in his classic study of carnival (see Bakhtin 1984).

Typical of the grotesque are spasmodic convulsions of the body, rolling whites of the eyes, stuck-out tongues and inhumanly distorted faces (cf. Klein 1988: 28). As explained by Harpham, whom Klein cites (cf. Harpham 1982: 14-16), the grotesque is ambivalent, irrational, absurd, incongruous and, above all, elusive of any univocal interpretation. It concerns the things ousted from consciousness, provokes disgust and aversion, but at the same time fascinates, producing a blend which triggers a physical, bodily response.

Klein insists that the inclusion of the grotesque in buto is associated with the original inspiration from Kabuki. Initially, the Kabuki actor's social status was ambiguous and consequently marginal. Like itinerant priests, actors were considered divine and consecrated creatures, yet at the same time they were regarded as accursed and impure. Actors and geishas were outsiders in society though, admittedly, they were not ostracised, unlike the burakumin - the outcast group of untouchables. This classic ambivalence of the sacred and the profane had survived until the Edo era, when theatre got "domesticated." In the late Edo period, marked by the cultural emancipation of townspeople, Kabuki performances staged 
social groups that were excluded, peripheral places, marginalised situations and everything "dark, taboo and repressed" (Klein 1988: 37), breeding interest or unwholesome fascination as a forbidden fruit.

Hijikata borrowed from Kabuki its capacity to sneak through the fissures in the armour Japanese society had forged to protect itself. The buto dancer ventured into the world of the marginalised and the voiceless - of "children, the handicapped (blind musicians are especially prominent), the insane, refugees, the primitive savage, the very old, even scapegoat figures from other cultures" (Klein 1988: 38).

Another possible source of the grotesque in buto is the integration into the creative process of various elements pushed into the unconscious (socially tabooed) (cf. "The Abject" in Chapter 5). The themes of violence and sexuality surface when the actors examine their own inner fragmentation. In this process, they reclaim "the body that has been robbed" (Ichikawa 1988: 71).

Klein also discerns other borrowings. Corporeality explored in butō was a vital element of Kabuki theatre, which originally operated in entertainment districts. Kabuki was distinctly erotic, which was associated both with political censorship, which considerably restricted the subject-matter of performances, and with the very origins of the genre, i.e. the erotic dances of the Shinto priestess (miko) Okuni (Żeromska 2010b: 19-32). Kabuki theatre was very soon targeted by censorship also because performances were surrounded by practices which were deemed highly immoral. To prevent fights caused by the common trafficking of actresses' bodies, women were banned from the stage, and soon afterwards, the ban was extended to include young boys impersonating female characters (wakash $\bar{u})$. All female roles were given to grown-up males with shaven heads. In this way, an actor type specialising in female roles - onnagata - came into being. As such, female parts in the Kabuki theatre provoked playing on sexual identity off-stage. Onnagata commonly wore female kimonos and adopted the culturally ascribed female gait, which helped them behave with ease on stage. Sometimes they identified with being women so much that, in the early 20th century, an onnagata was arrested for trying to bathe in the women's section of a public bath (Keene 2001: 100). The celebrated actor Ayame Yoshizawa claimed that as soon as an onnagata realised that, on-stage, he made typically feminine gestures, he stopped being a woman and regressed into being a man (Keene 2001: 100).

In the early, aggressive and revolutionary period of butō development, crossdressing was frequent on stage and often involved homoeroticism. Unlike the culturally accepted onnagata, butō artists were socially transgressive rebels. Their manipulations of sexual identity were deliberately controversial and shocking. For example, in The Forbidden Colours (1959), historically the first performance 
classified as butō theatre, Hijikata and Yōshito Ōno (Kazuo Ōno's son) simulated homoerotic intercourse; in The Dance of the Rose Colour (1965), Hijikata and Kazuo Ono danced wearing long, flowing robes; and in the Revolt of the Flesh (1968), Hijikata, naked, fastened an enormous, golden phallus to his underbelly. Hijikata also encouraged his students and collaborators to appear in night clubs in the belief that it would help them be at ease with nakedness on stage. Butō dancers drew on their familiarity with cultural norms (and theatrical codes) in order to consciously transgress them.

The formation of Ankoku buto aesthetics was significantly influenced by the technique of representing human characters in ukiyo-e woodcuts, which flourished in the 18th century. Ukiyo-e means "a floating world" (cf. Mazurek 1994).

The master stylists of Butoh have much in common with Ukiyo-e's abstract stylizations of the human figure in motion that are still vital today. Woodcuts illustrated popular life and the original Kabuki theatre - its actors and patrons, passions and intrigues. The print colors, now dimmed through age, were once very bright. This art captured the life of Edo (the original name for Tokyo) after the Tokugawa shogunate brought stability and prosperity $[\ldots]$ in the seventeenth century. Ukiyo-e documents common life as well as the sophistication and vices of the times. [...] Its subjects are wide-ranging, but play, sex, and theatre - not work - are the serious occupations of Ukiyo-e. [...] The body is elaborately adorned in both Ukiyo-e and Butoh, or exposed and boldly colored with paint and white powder. (Fraleigh 1999: 10-11).

Finally, butō performances include, unwittingly perhaps, elements of the Japanese performance pattern called jo-ha-kyū (cf. Klein 1988: 43-46). Essentially, in jo$h a-k y \bar{u}$ on-stage activities are repeated in cycles based on a fixed sequence. Each cycle starts from a slow action (jo); the jo phase serves to capture the audience's attention and to "hypnotise" them, so to speak. Then follows the fast phase ( $h a)$, leading to the climax $(k y \bar{u})$, arrest and return to the jo phase. This pattern surfaces in butō in constant radical alternations of the pace and sudden changes in rhythm. Butō performances have also incorporated the element of applause, after which the dancer comes back on stage, this time as "him/herself." Yet in butō, the position and the meaning of this last entrance have been re-invented: the moment encapsulates the culmination and often even the essence of the performance as such.

According to Klein, butō attempts to recognise and negate the ideals of postwar, post-industrial society that prioritises finite and functional identities. The constant transformation process in which the dancer is divested of identity while "the audience are confronted with the disappearance of the individual subject" is an ultimate challenge to "the modern myth of the individual" (Klein 1988: 32). In the process of continual metamorphosis, the butō dancer reveals a fragmented, fluid self 
and forces the audience to face up to an agent who is suspended in the liminal zone, in-between the various beings s/he incorporates in turns. Identification involves not only appearance (presence), but also somatic sensations, feeling and mental states, while "becoming" marginal figures helps identify with their social position.

\section{Tatsumi Hijikata: The Structure}

Tatsumi Hijikata (born Kunio Yoneyama) moved to Tokyo at the age of twentyfour in 1952. Earlier, he briefly studied dancing with Katsuko Masumura. Deeply affected by the dance of Mitsuko Andō and Kazuo Ōno, he started to study dancing with Eguchi Takaya and Andō in 1953.

Aleksandra Capiga-Łochowicz, a Japan scholar and butō dancer, discusses Hijikata's rich life, artistic ideas and stage techniques in her study Bunt ciała. Butoh Hijikaty [Revolt of the Flesh: Hijikata's Butoh] (Capiga, 2009). In a review of the book, Katarzyna Bester observes that Hijikata

[...] repeatedly took the risk of going beyond the good-evil line. He was both a master and a pimp to his students. He inspired admiration and horror in his colleagues. Yet, in Capiga's book, Hijikata displays nothing of his demonic self. Capiga focuses on his unhappy childhood and makes the reader sympathise with and pity him, in which she tends all too easily to succumb to the artist, who skilfully manipulates his self-image. (Bester 2010b: 72)

Bester cites Hijikata’s students. Interviewed by her, Daisuke Yoshimoto said: "He was a man of unbelievable attraction, but also destruction. He was dangerous. Personally, I was afraid of him” (Bester 2010b: 72). In an interview with Bonnie Sue Stein, Min Tanaka declared: "He [Hijikata] is the devil” (Tanaka 1986: 151). It might have been this ambivalence of Hijikata's personality that powered the original Ankoku butō.

"There is no definition of butō. Some interpreters try to force butō into this or that principle, but, as the founder of butō Hijikata said, defining butō kills its nature" (Paduch 2009). Consequently, instead of defining Hijikata's butō, it makes more sense to describe it in terms of three distinctive idioms of corporeality: the primordial body, the Japanese body and the body in crisis.

At the core of the Ankoku buto was the return to the primordial, pre-cultural body, accomplished by relinquishing everyday bodiliness. In searching for the primordial body, one is submerged in the dark zone of repressed elements of the real that are hidden behind the façade of daily elegance. Therefore, the darkness that permeates Ankoku butō can be read as a subversive need to accept the body tabooed by culture. Ankoku butō performances tended to be "distinguished by their length $[\ldots]$ their intended boredom" (Richie, qtd. in Klein 1988: 25), aiming to 
comprehensively explore aspects of human life which society seeks to suppress, such as violence and sexuality. For example, the audience of The Forbidden Colours reported that confronting the usually deeply hidden aspects of bodiliness gave them "the shudder [which] resulted in a refreshing sense of release" (Gōda 1988: 81).

In Hijikata's view, the spectator's aesthetic pleasure was his greatest enemy. Hijikata's performances were inspired by the bleak and "decadent" work of Jean Genette, Lautréamont, Marquis de Sade and Aubrey Beardsley (Klein 1988), who sought to fathom the primordial, pre-cultural self, referred to as id in Freudian psychoanalysis. Hijikata's major source of inspiration was the work of Genette, one of the absurdists. The theatre of the absurd typically explores the world in chaos, and absurdist dramas often feature masks, mirrors, dreams, doubles and suggestive images of death, all steeped in a thanatic obsession. It should perhaps be added that associations of buto aesthetics with the trauma of Hiroshima and Nagasaki are as frequent as they are unexamined (at least as regards original butō). Neither Hijikata nor Ōno ever deliberately referred to these tragic events.

Rather, the relentless darkness associated with butō is related to the "praise of shadows" ubiquitous in Japanese culture, as described in Junichirō Tanizaki's likewise titled essay (2005). Another notion inherent in Japanese aesthetics that can be usefully applied to Ankoku butō is iki. The iki style reflects the preferences of the Edo-period bourgeoisie in the times when Kabuki theatre was thriving. Iki connotes first of all sophistication, typifying the wealth and lifestyle in red-light districts (geishas), expressed in stylishness, good taste and moderation combined with luxury and the play of light and shadow. I $k i$ is a thoroughly secular notion and does not refer to any alternative reality. The beauty of $i k i$ is bound up with penumbra and understatement.

Another consequence of the return to the primordial body, besides turning to the indistinct, the bleak and the tabooed, is the rise of the idea of the sexless body. Butō challenges sexualities ascribed to people, underscoring the dancer's originary asexuality: "the whitened bodies of butō dancers and their cleanshaven heads obliterate the attributes of sex, with dancers themselves becoming androgynous figures. Their bodies serve as a site of a specific sexual transgression" (Hoczyk 2009b: 16). Paradoxically, nudity, just like the mask and the white body make-up, also helps dancers shake off the attributes of sex (of course, in some performances, nakedness can be explicitly sexually loaded). The uniform white make-up - a shroud, a cocoon - facilitates bodily metamorphoses. As Carlotta Ikeda insists, "performing nude, we shed not only our clothes. The naked body makes us define our movements anew and re-invent ourselves, discovering ourselves in nakedness" (Aslan, Picon-Vallin, Amagatsu 2002: 143). 
The primordial body appears in the Revolt of the Flesh (Nikutai no Hanran, 1968); it is uncertain, soaking apart, absorbing and innocent in its return to its origin. Staging the process of the body's regression in time, Hijikata embraced the idea of searching for one's inner child, which was later to recur in his instructions for dancers of the Hakutobo group, which he choreographed. Reversion into the depths of the pre-cultural body was prompted by a childhood memory of falling down into a puddle: "I can, I know, declare that my butoh started there with what I learned from the mud in early spring, not from anything to do with the performing art of shrines or temples. I am distinctly aware that I was born of mud and that my movements now have all been built on that" (Hijikata $2000 \mathrm{f} .:$ 73-74). Hijikata's butō was based on primordial communion with the earth. "Exercises on the floor, rolling around, on the ground, all this is a matter of trust. If you feel safe, you treat the floor as a partner" (WAC).

Another idiom - the Japanese body - came to dominate Hijikata's later explorations. The butō dancer Natsu Nakajima explains that one of the early ideas behind the butō movement was to build bonds and connections in order to create a bridge between modern Western dance and traditional Japanese culture (Nakajima 1998: 48-49).

In 1967, Hijikata travelled to his native region (the northern province of Tōhoku) to show The Sickle Dish (Kamaitachi) there. In the performance, he acted - or rather turned into - an innocent fool possessed by a demon. Having returned from Tōhoku, he created a dance rooted in his experiences of childhood spent in that remote, cold, rural area of Japan. This was when he started to discover the Japanese body. Yōko Ashikawa, Hijikata's artistic partner for many years, later developed the idea of the ethnology of body movement - miburi-no minzokugaku $u^{4}$ " using original rural costumes, traditional wigs, footwear and legends of peasants from northern Japan" (Janikowski 2008).

Hijikata relied on his memories for knowledge of postures and gestures typical of rural folk. ${ }^{5}$ He evoked the images of suffering and enslaved bodies, telling of children put into uncomfortable baskets, izume, during work in the fields (Capiga 2009: 80; cf. Hijikata 2000b); children would cry, eat and defecate in the

4 From Professor Anna Grzegorczyk's review of this study (2012, pp. 5-6): "In Japan, Hijikata's work tended to be called miburi-no minzokugaku, which means 'cultivate ethnology of the body movement.' The word minzokugaku as used here designates 'ethnology as a science' and, more precisely even 'knowledge of the folklore."

5 Hijikata describes the experience of corporeality in Japan's indigenous rural population in the articles entitled "From Being Jealous of a Dog's Vein" and "Wind Daruma" (cf. Hijikata $2000 \mathrm{~b}$ and $\mathrm{f}$ ). 
baskets, left entirely to their own devices. With their feet tied, they excreted into the baskets and, waiting for their carers to return, they played with their bodies and hands. Taken out of izume, children stumbled on their cramped limbs, like "legless cripples." Hijikata recalled how, immobilised and "playing with his body like with a toy, he would stop crying and grumble against the heaven" (CapigaŁochowicz, qtd. in Paduch 2009). He wrote: "The feeling somewhere inside your body that your arm is not really your arm conceals an important secret. The roots of butoh are hidden there" (Hijikata $2000 \mathrm{f.:}$ 75). Hijikata tended to mythologise childhood, but these references are exceptionally relevant and continue to recur in many forms. As he insisted, the essence of butō lies in "taming and employing one's own darkness. What is this darkness? It is fear, pain, helplessness and hatred" (Capiga 2009: 82).

Another important theme revisited by Hijikata is the distinctness of the Japanese body. Formed from toiling in paddy fields, the body is, in his view, cut out for a different type of dance than Western dance. A characteristic pose struck by Japanese peasants is ganimata, that is, a bowlegged crouch. Nario Gōda describes ganimata in the following way: "the weight is hung on the outer sides of the two legs. When one 'floats' the inside of the legs upwards, the knees will turn out of their own accord, and the entire frame of the body sinks down" (Gōda 1988: 87). The pose ties in with an uncertain gait which metaphorically connotes existential uncertainty. "Western dance begins with feet firmly planted on the ground whereas Butoh begins with a dance wherein the dancer tries in vain to find his feet" (Viala, Masson-Sekine 1988: 189).

At the same time, Hijikata drew on certain explicit and latent assumptions of early Kabuki from before its domestication and called his dance style Tōhoku Kabuki. In 1972, he developed a series of 27 Nights for Four Seasons (Shiki no Tame no $27 \mathrm{Ban}$ ), in which he enacted his idea on the stage. Initially, butō relied heavily on the means of expression favoured by the Kabuki audience. It was only later that butō aesthetics grew more refined as butō came into contact with Western tastes. Moreover, butō appropriated Kabuki theatre's earlier fascination with the shadow zone and repressed aspects of social life, which were given an aesthetic appreciation in the creative process (Klein 1988: 37).

Hijikata's third bodily idiom is the body in crisis. Crisis is engendered when the primordial body is harnessed by social conventions which work so as to taboo the non-normative body which defies the pressures of socialisation. At the core of Hijikata's butō lies rebellion and affirmation of the rejected. The artist extolled everything that the general public found worthless: femininity, disability, insanity and, finally, death (Roquet 2003: 28, qtd. in Capiga 2009: 76). 
Hijikata's aim was to develop a form of dance to be danced by everybody - literally, by every body. He wanted to focus on taboo elements previously bracketed off from dance. Hence his focus on facial distortions and disabilities. In one of his essays, he says that a cripple, a person in a wheelchair represented an ideal dancer for him as there is truth in such an individual, and his/her movements are not disguised, not cloaked under a redundant cover. He was also resolved to address sexuality, homosexuality and, finally, death in his dance. Taboos earlier, such themes had been absent from dance. (Żukowska 2009)

The crisis is expressed in body postures that recur in butō, with a rebellion against the polish of socialisation which is often manifested in "the tensed dancer teetering on grotesquely crooked legs" (Capiga 2009: 77). Born from discomfort, dance epitomises being on the verge and reveals the supressed forms of bodiliness.

The body of the Butō dancer convulses endlessly. It is as though each fiber of the muscles has its own selfish autonomy and shudders violently as it pleases. [...] The will does not move the muscles; the muscles themselves have their own will. The trembling of the limbs infects the spectator watching, too; this will of the muscles calls forth the penetrating power of the imagination so that mutual communication between audience and dancer occurs. Rather than communicating stereotyped emotions through patterns of dance that imitate, Butō comes to have a more direct effect on the spectator. (Iwabuchi 1988: 75)

Because the body's movement is a testimony to a crisis, it cannot be fabricated only for the show. Importantly, Hijikata's oft-quoted statement that "Dance for display must be totally abolished" (Hijikata 2000c: 39-40) has tended to be grievously and profusely misinterpreted. His intended "prohibition" concerned contemporary dance in the Japan of the 1960s, where watching dance shows in theatres served to provide entertainment and aesthetic contentment. Hijikata, in turn, believed that

the dancer's body should terrorise. He explored dancing and sought to define its relation to existing reality. In fact, he loved to put the body on display, and his dancers appeared in go-go clubs painted silver all over - strippers' aim in taking off their clothes is not to please anybody but to survive. This was one of the ways to protest against commercialisation of art. Dance helps survive a crisis situation and should originate in a crisis: in the need to survive, express oneself, find one's identity. Dance should not aim simply to satisfy the audience. (WTA, Pastuszak)

Butō atomises and fragments the human body, which is symbolised in the "ash column," an image often rehearsed in workshop practice focused on embodying representations. In this context, Hijikata devoted his last years to exploring the idea of the weakened body (suijakutai). The weakened body is a state of mind characterised by complete despondency and confusion in which the only thing left for a human being is accept his fate (Mikami 2002). This was the situation 
experienced by Hijikata's first mythical dancer - Wind Daruma, a spirit of a dead man whose complaints could never be heard, muffled by whizzing wind and blizzards. Legends of Wind Daruma were common in cold Tōhoku when Hijikata was a child. In his article "Inner Material/Material" (2000c: 39) written in the Tokyo decadence period, the artist associates the ganimata pose with helplessness, vulnerability and extreme bodily wasting.

"A criminal on death row made to walk to the guillotine is already a dead person even as he clings, to the very end, to life" (Hijikata 2000e: 46). This image encapsulates the butō dancer's state of mind - hovering between life and death. The encounter with death purifies the dancer of egotism and convention, turning the body into an empty receptacle. The dead inhabit the bodies of the living, and Hijikata "found other people in himself," claims Yōko Ashikawa (qtd. in Hoffman, Holborn 1987: 20). The dead gave him a new perspective; for example, his dead sister living in him aroused his inner femininity. In fact, all butō techniques developed by Hijikata aimed to put the dancer's body in a crisis situation.

\section{Kazuo Ōno: Improvisation}

Kazuo Ōno always carved his own path. Till his death in 2009, he repudiated all attempts at defining the butō technique and always relied on individual, unique improvisation. As the major object of my research is the structure (model) of butō practice, I rarely refer to Ōno's dancing ventures. Nonetheless, his vision of dance is certainly another central pillar on which butō rests.

Ōno's first source of inspiration was a performance by the flamenco dancer La Argentina (Antonia Mercé) that he saw in Tokyo in 1929. Five years later, fascinated with a dance show staged by Harald Kreutzberg, Ono started to study modern dance with Baku Ishi and Eguchi Takaya, who disseminated German expressionist dance in Japan. Earlier he had attended the Japanese Gymnastics School in Tokyo.

Developing his Ankoku butō, Hijikata drew on Ōno's dance. Kayo Mikami observes in her dissertation that butō scholars outside Japan often refer to Hijikata as the "Father of butō" and to Ōno as the "Mother of butō." In the 1970s, the original butō split into two segments: the major one, the Hijikata-led Ankoku $b u t \bar{o}$, aimed to create performances with a particular structure, and the other one focused on improvisation and was led by Ōno, Akira Kasai and others (Mikami 1997: 18).

Unlike Hijikata, Ōno did not oppose the socialised body in his dance; nor did he seek to expose the world's concealed ugliness, as he believed that we saw enough of it in our everyday lives. Instead, Ōno thematised universal archetypes 
through dance. Similarly to Hijikata, he drafted $b u t \bar{o}-f u$ in short verse, short essays, calligraphy and drawings. The notes served to catalyse the process in which bodies were re-configured and consciousness was transformed.

Ōno's "existential questions are embodied in his dance poetry (his butoh-fu) in which his attention goes to matters of birth and death, nature, art and family" (Fraleigh 2010: 95). Those issues were reworked in an array of images, with the image of return to the womb, to pre-natal life, being the most prominent one. Sometimes during his workshops, Ōno spoke about a place called konpaku in Buddhist philosophy - the site where life and death meet, a space in which his students were supposed to dance. On other occasions, he addressed another important theme, i.e. the communion with the ancestors who inhabited dancers' bodies and whose emotions dancers were supposed to feel. With Ōno around, "one learn[ed] how to slow down and pay attention to somatic attunements of feelings" (Fraleigh 2010: 96).

His pedagogy could be summed up in a depiction he himself provided:

When a person comes to me saying they want to dance, I always tell them that it will take at least five years. In these five years, I will teach them to analyse and organise their body's gestures and, at the same time, I will raise their consciousness of life. Key to the education process is that neither of these things should be neglected and that the body itself should be placed at the core of the dilemma. (Kocur 2003)

Ono is called "the great soul of butoh" (Polzer 2004). His dance is entirely unique and, as such, it cannot be learned.

\section{Contexts: Dance, Performance Art and Physical Theatre}

Most scholars and critics classify butō as "dance" even though it could equally be regarded as a variety of physical theatre or body art. The rise of butō in the $1960 \mathrm{~s}$ coincided with a surge of radical changes in art in Europe and the US. Stage artists questioned the model of actor and dancer. Theatre based on physical actions and postmodern dance inspired by everyday uses of the body flourished. Bodiliness was also intensively explored in performance art developing at the intersection of visual and performative arts.

In the 1930s, many Japanese travelled to Europe to study dance. Both Tatsumi Hijikata and Kazuo Ōno studied modern dance with artists who had come back from abroad with many novel ideas. Hijikata's master was Eguchi Takaya, who had studied with Mary Wigman (the founder of "absolute dance") in Germany. Ōno also attended Takaya's and Baku Ishi's courses from 1934. Ishi defined his dance as poetry or haiku. Both teachers imported to Japan the ideas and techniques of German expressionist dance, which thrived in Germany in the 1920s and 30s. 
At the heart of expressionist dance lay the quest for genuine, individual expression unfettered by conventions and for the ambiguous, mysterious and non-rational. Novel as its ideas were, technically this type of dance was still grounded in classical dance models in which dancers were required to master a specific movement idiom. Klein observes that in the Japan of the 1950s and 60 s, expressionist dance "was well on its way to becoming entrenched as just one more cultivated art that young, upper-middle class women were expected to learn before they married" (Klein 1988: 12). The expressiveness in butō should thus not be identified with that of expressionist dance. Self-expression through dance is an entirely unknown concept to the Japanese mindset. Expressionism's central assumption of division into the inner and the outer is foreign to the Japanese spirit. The Japanese concept of the individual is far more "diffused and permeable" (Kasai, Parsons 2003: 258). The idea of identity or personality is a Western invention, as explained by Yukio Waguri (Hijikata's heir and butō dancer of the Kozen-Sha group) in the bulletin of the 2nd Butoh \& Related Arts Symposium \& Dance Exchange Project "Ex...it! '99."' For this reason, it is misguided to speak of individual expression of affects in the case of dancers entrenched in Japanese culture. Butō is not about a cathartic and exhibitionist articulation of stifled individual emotions. Rather, it is about the ability to get in touch with intersubjective sensations (which can be understood as an archetypal sphere, a kind of emotional matrix ${ }^{7}$ ). Even though the idea of authenticity and grotesque expressiveness certainly impacted the dancing model developed by Hijikata, butō first of all expresses the way in which young, post-war Japanese artists mutinied against the copying of Western patterns.

Butō also tends to be classified as postmodern dance. Briefly, while modern art can be said to invest in the quest for its own specificity and in defining the quintessence of respective forms of expression, postmodern art has no such aspirations. The debate on the distinctiveness of modernism and postmodernism also took place in dance theory (Carlson 2001: 126-130). Modernist dance experiments largely build on the variously comprehended ideas of pure movement or, at least, movement which no longer has to support or corroborate a narrative.

6 The bulletin is available on the symposium's website: http://butoh.us/ex-it/pamph99. htm [4.04.2011]; for Yukio Waguri's words, see http://butoh.us/ex-it/pamph/a-ee28. JPG [Retrieved 4 April 2011].

7 Emotions are similarly understood within the rasa theory as formulated in an oldIndian treatise on theatrical arts entitled Natjaśastra. Rasa designates objective emotions which the actor embodies or personifies during the performance (cf. Wielechowska 2004: 365-375). 
Postmodernist dance, in turn, is associated with severing dance's links to music and abandoning "meaning, characterization, mood or atmosphere" (Kirby 1975: 3-4), just as artistic performances relinquish techniques and conventions aimed at loading the body and movement with superimposed meanings. This kind of dance started to develop in New York in the 1990s (cf. Sier-Janik 1995). Postmodern artists dismissed the idea that dance was a pre-defined form of expression framed in patterns consisting of styles and devices (Carlson 2001: 128). New York's Judson Dance Theater dancers discarded the principle of expressiveness and technical craftsmanship, instead bringing onto the stage everyday activities, nakedness and creative improvisation (also contact improvisation). Still, no consensus has yet been reached on the dividing line between modern and postmodern dance. According to Sally Banes (cf. Banes 1992, qtd. in Carlson 2001), the experimental dance of the early 1960s relied both on minimalist ideas and multimedia cacophony, while in the 1980s and 90s it came closer to what was referred to as postmodernism in other arts.

Butō dance can be considered a product of modernity: artists are looking for the essence of dance, for authentic, organic movement originating in bodily impulses and for an autonomous formula of movement unadulterated by cultural codes. Nevertheless, the way these ideas are enacted is heavily informed by postmodernism and its instruments, as exemplified, for instance, in separating movement from rhythm and forsaking technical perfection. For example, in his Forbidden Colours, Hijikata removed all the obligatory elements of dance productions of the day: music, dancing technique and a programme describing and interpreting the performance. The literal meaning of "butō" itself $(b u$ - dance and tō - step) suggests the inclusion of normal walking into dance movements. Butō transcends the idea of dance comprehended as "beauty in motion." It also crosses the boundaries between various art disciplines. It combines elements borrowed from popular arts with esoteric explorations. And, as behooves postmodern art, it ultimately dismantles the dancer's subjectivity, stripping him/her of any stable identity (cf. Wańtuch n.d.).

Both Western and the Japanese dancing circles of the 1960s and 70s were closely associated with the community of performance, happening, minimal art and conceptual art artists.

Performance art displays an "interest in developing the expressive qualities of the body, especially in opposition to logical and discursive thought and speech, and in seeking the celebration of form and process over content and product" (Carlson 2001: 100). The body was ushered into performance arts as their key phenomenon by happening and performance, whose roots go back to body art 
(Carlson 2001: 99). Developing since the early 1960s, body art foregrounded the body and movement (cf. Carlson 2001: 101-102). With artists interested first of all in the process, the body becomes both the object and the subject of art. As the performer does not rely on a fixed stage code, s/he reveals his/her own phenomenal corporeality to the audience.

In early body art, modernism was the dominant tendency and performance "consisted only of simple actions, devoid of narrative, mimesis or aesthetic shaping" (Carlson 2001: 139). It relied on pure co-presence, which did not require the audience to take any position towards the performer's actions: "Presence [is] available in the perceptual instance" (Carlson 2001: 140). In radical body art, artists prefer to push the body to extremes. For example, Chris Burden states that "he was trying to use extreme body states to induce certain mental states" (Carlson 2001: 103). A sine qua non of performance art is intense and direct interaction with the audience. ${ }^{8}$ Thus there is an affinity between the radical ventures of body artists and Hijikata's Ankoku butō, in itself the body-in-crisis as expressed in movement.

Butō dance came onto Western stages in the 1980s, just as a transition was taking place in performance art from the high modernist, essentialist and reductive orientation of early "performance art," which viewed the body as "the privileged site of authentic presence," to the more complex, fragmentary, ambiguous, technologically innovative operations of "live art" of the 1990s, which she [Helen Spackman] relates to a shift from modernism to postmodernism in the performative consciousness. (Carlson 2001: 132)

However, the process took a different course in butō. The original austere model developed and used by Hijikata was smoothened to adjust it to a broader audience. The aesthetically refined stage poetry largely replaced the radical art of the-bodyin-crisis.

Experimentation at the intersection of visual and performative arts focused on the performer's body also affected the development of new stage-acting strategies. The laboratory work model, which appeared alongside the demands of the Grand/ Great Reform of the early 20th century, was revived in a radicalised and, at the same time, systematised, form.

The coinage of "physical theatre" is rather widely applicable. Physical theatre revolves around psychosomatic explorations in which the actor "thinks with the body and, consequently, embodies the mind" (Mond-Kozłowska 2003). Physical theatre (and, analogously, physical dance) artists search for a new formula of stage

8 Initiated by happening, the tendency to engage the audience directly appeared also in Japan, for example in the work of the Gutai group. 
movement. For example, Lloyd Newson, the leader of the DV8 Physical Theatre (like the Judson Dance Theater dancers),

[...] started from observations of everyday behaviours and introduced into dancers' practice improvisations in which natural movement was creatively reworked [...]. The process of preparation for the performance always involves issues directly concerning the actors' lives. (Fret 2000: 132)

Physical theatre uses physical and psychophysical training based on body and body-mind techniques. In Poland, the most popular training models include Grotowski training (described in Jerzy Grotowski 2007a: 123-216), Gardzienice training (depicted in Zbigniew Taranienko 1997: 130-190, and currently being studied by Małgorzata Jabłońska - 2008: 129-135, 2009: 155-174) and Eugenio Barba Odin Teatret training developed from experiences of the International School of Theatre Anthropology (researched by Katarzyna Julia Pastuszak). The fundamental principles of psychophysical practice are discussed by Philip Zarilli, a theatre theorist and practitioner, in his book Psychophysical Acting (2009: 61-115). The type of training employed in butō can be labelled psychophysical as it is based on various ways of affecting the body conceived as a unity of psychical (mental) and physical (somatic) components.

\section{Transcultural Butō}

Butō absorbs, integrates and transforms elements from multiple sources. The heterogeneity of contemporary butō is bound up with what Wolfgang Welsch describes as the "Japanese identity," which he believes to be "transcultural as a matter of course" (Welsch 2002: 7). ${ }^{9}$ Welsch is critical about Herder's concept in which identity is understood in the context of its underlying monolithic culture and claims that "traditional cultures were in fact mixed cultures" (Welsch 2002: 2). These cultures were internally diversified and offered "an ongoing potential which, in the short or long run, on this occasion or on that, some people will turn to again - with a plurality of options resulting anew, or the truly cross-cultural of the so-called 'national culture' coming to the fore again" (Welsch 2002: 2-3). Welsch cites Tsunemichi Kambayashi, who stated (at the Art in Asia - External View \& Internal Response Conference, Kyoto, 2001) that, in Japan, "there was an ongoing

9 The section on Welsch's idea of transculturality was published in a slightly revised form in "Transkulturowość butō. Japonia, Welsch i pytania o tożsamość" in Kultura Historia - Globalizacja (cf. Zamorska 2010c). 
play and interplay of two options: one modernist, one traditionalist" (Welsch 2002: 9), and develops his insight:

[I]n Japan different cultural or aesthetic or philosophic styles and models have coexisted throughout history. Once something was established it remained. Buddhism didn't outdo Shintoism, and modernism didn't outdo tradition. [...] This co-existence of different models (quite uncommon in the West) certainly paved the way to future transcultural blending. People are used to having several models, they aren't afraid of manifoldness, they don't have to acquire a new mentality in order to come to terms with contemporary plurality. (Welsch 2002: 9)

Central to my argument is Welsch's concept which sprouted when he visited Japan. The idea is that:

The Japanese identity, it seems to me, is exceptionally prepared to be transcultural perhaps it even is transcultural in its structure. One sign of - or precondition for - this is the fact that Japanese people put emphasis on things' being relevant, being close to them - no matter where the things in question originated from. Japanese people don't (as seems natural for Europeans) base their access and judgment on the distinction between own and foreign, but rather on the viewpoint of proximity [...]. To the Japanese the foreign-own distinction or, to be more precise, the foreign-own distinction with respect to origin is not relevant at all. Their basic perspective is that of proximity. If something fits neatly it is Japanese - no matter where it comes from. This is why things foreign can be considered the own as a matter of course. (Welsch 2002: 7-8)

Since the Japanese identity is structurally transcultural, whatever is absorbed by Japanese culture automatically comes to be regarded as Japanese. According to this model, foreign can be native at the same time. In this context, it makes sense to evoke the idea of the "absolutely contradictory identity" proposed by the contemporary Japanese philosopher Kitarō Nishida (see Nishida 1993). "Paradox nihilism," as his position can be defined (cf. Kozyra 2004: 277-213), assumes that reality is an internally coherent totality within which contradictions co-exist, which breaches the principle of non-contradiction central to Western formal logic. That the Japanese manner of experiencing reality is untranslatable into the Western way was discussed by the butō dancer Sumako Koseki at a butō workshop held in Srebrna Góra in 2009. The Japanese comprehend the world as a non-dual whole in constant flux. ${ }^{10}$

Welsch highlights an essential factor in relating to products of culture, i.e. a fascination that appears when we experience a thing as relevant to ourselves, as a

10 Today this kind of thinking is becoming increasingly widespread, also in the West, both in the humanities and in the natural sciences. It was pioneered in the humanities and the social sciences by, for example, Gilles Deleuze and Felix Guattari. 
result of which the thing is no longer remote or bygone. He refers to this aspect of things as presence which makes us recognise various cultural products as our "present challenges" (Welsch 2002: 5). Because the power of such products is not culturally determined, it can work across cultures: "My point is that this primary attraction obviously works independently of familiarity with the respective culture. The power of the work is [...] transculturally effective" (Welsch 2002: 7). Of course, butō dance came into being in Japan and, obviously, uses many elements of the Japanese performance culture, spiritual exercises, etc. - in short, of Japanese cultural practices (cf. Klein 1988). Nonetheless, as a result of the fascination it inspires globally, butō can be regarded as "transculturally effective." What is more, the genre is continuing to develop, for example, by absorbing existing traditions and producing new hybrid forms (e.g. Tebby W.T. Ramasike's Afro-butō; MoBu, i.e. a synthesis of ballet, modern dance, jazz dance, dance improvisation and butō, developed by Takami Mochizuki Craddock, a San Francisco-based Japanese artist; Butō Dance Therapy - a form of psychotherapy through butō dance practised by the certified choreotherapist Mika Takeuchi in Sapporo; and a combination of juggling art with butō proposed by Jean Daniel Flicker).

The practices of Polish butō dancers also fall under this "broad range of new differences" (Welsch 2002: 3). 


\section{Butō Techniques}

Butō's arcane techniques have been discussed by theorists and practitioners of the genre. At the time of writing this book, the available literature in English included translations of writings by the founders of butō, Tatsumi Hijikata and Kazuo Ōno. The English translation of a selection of Hijikata's texts was published in the Spring 2000 issue of The Drama Review. It featured four essays, two interviews, a copy of a page of Hijikata's notes introduced by Kurihara Nanako's essay and Butoh Kaden by Yukio Waguri, one of Hijikata's students (DVD-ROM), as well as a compilation of buto-fu (cf. “Terms") translated into English with a presentation performed by Waguri. Selected texts by Kazuo Ono were published in a book he co-edited with his son in 1999 entitled Kazuo Ohno's World from Without and Within (the first part contains essays by Yoshito Ōno, while the second Kazuo Ōno's lectures).

Butō techniques have also been analysed by Kayo Mikami (Hijikata's Ankoku butō method), Toshiharu Kasai (the psychosomatic exploration method) and Rhizome Lee (the subbody method). These authors drew on their own practice, examined the specificity of psychophysical training and investigated the sources of their techniques to propose their own models of the process on which formal butō training crucially relies. Sondra Horton Fraleigh (herself a dancer and a participant in butō workshops) analyses the transformative process of butō in terms of existential phenomenology.

\section{Kayo Mikami: Butō as a Way of Producing Neural Networks}

Tatsumi Hijikata's technique has been studied by Kayo Mikami, who practised butō under his supervision in the period 1978-1981. She reported on her research in her $1997 \mathrm{PhD}$ project Tatsumi Hijikata: An Analysis of Ankoku Butoh Techniques, completed at the Humanities Department, Ochanomizu University in Tokyo.

In the chapter devoted to terminology, Mikami proposes her own definitions of "technique" and "method," where the technique is a way of manipulating the body physically while the method is a way of using the body as a psychophysical entity (cf. Mikami 1997: 16). Mikami also distinguishes two definitions of the corporeal, with "flesh" designating the existential aspect and "body" conveying the cultural context (cf. Mikami 1997: 16).

My starting point will be Mikami's important observation that Hijikata, while assessing his dancing candidates, was interested in their mindsets rather than in their technical skills (cf. Mikami 1997: 87). What he required was a knowledge of 
"invisible techniques," that is, a spiritual preparedness to dance butō. Of course, those techniques were inseparable from the dancer's proficiency, which Mikami refers to as "visible techniques" and investigates in her study. She outlines a model of the training process which unfolds in consecutive stages, including standing, walking, (communicating) imaginary wordings, enforced movements and designing choreographic units.

In Hijikata, the point of entry into explorations of movement was provided by standing properly. Hijikata envisioned a dynamic balance as an alternative to the compulsory "pose" of the upright, erect body, common both in Western classical dance as well as in Nō and Kabuki. He insisted that, in butō, standing was a form of collapsing.

Comprising both the physical and the spiritual, walking is the most fundamental movement element in Ankoku butō. Movement (and the impulse to move and manner of moving) comes from (verbally communicated) imaginary wordings. Rather than resulting from a conscious decision and free will, movement is generated when the dancer's body is momentarily divested of its motion-controlling ego. ${ }^{1}$ Mikami grasps this quality in the term "enforced movements."

Movement is elicited from the body in the following sequence: verbal instructions are addressed to the trainee - imaginary wordings are triggered these images are discerned (by the trainee) - a physical transformation takes place - a movement is made in conformity with the new "character" (Mikami 1997: 100). The process is catalysed by phrases recorded in the form of the buto notation (butō-fu) which help the dancer achieve the becoming body (Mikami 1997: 104).

Walking's distinctive quality is an outcome of enacting the instructions. Training is based on an elaborate score entitled Walking of Measure (Mikami 1997: 100). Hijikata explained that he preferred the term "proper measure" rather than "mental focus" because too many feelings were stirred in the process (Mikami 1997: 101). In this "walking of measure," the body remains upright even though the dancer is neither excessively relaxed nor too strained. Central to Hijikata's entire method and still used by butō dancers, this manner of moving was also called by Hijikata the "walking of an ash column" (cf. Mikami 1997: 90). The dancer maintains his/her equilibrium and the vertical axis even though his/her body is a frail column of ash of burned-down incense kept erect by the force of gravity. Mikami conjures up several other images to describe walking in Hijikata's

1 Otherwise, we would be dealing with pantomime. 
practice, such as "folded legs" (Mikami 1997: 91), the "walking of a condemned criminal" (Mikami 1997: 92) and moving like "a legless ghost” (Mikami 1997: 94).

In Mikami's view, the cycle which commences with a verbal communication and culminates in movement produces a circuit of nerves (Mikami 1997: 103). As a result of the cycle, choreographic units are developed as minimal movement configurations.

The specific way of walking and constructing choreographic units aims to generate a new neural network in the butō dancer's body. As explained by Hijikata, the manipulation of the nervous system is sur les pointes ${ }^{2}$ for the Ankoku butō dancer (Mikami 1997: 138). The neural network is built through proper words, representations, impressions and movements. The process leads to a complete metamorphosis. Ideally, dancers are able to control interaction with particular images, which helps them manage the neural network from outside (Mikami 1997: 119).

\section{Rhizome Lee: Butō as a Path to the Subbody}

Rhizome Lee founded and runs the Subbody Resonance Butoh School Himalaya in the area of Dharmsala in India's Himalaya. He has developed a complex butō method grounded in Hijikata's Ankoku butō training and his own explorations. He dubbed his method the Subbody Butoh Method and continues to improve it, regularly posting recommendations on practice on the website of his school. ${ }^{3}$ Lee's articles from 2005-2010 have been collected, edited and published as Behind the Mirror: A Butoh Manual for Students both in print and on-line. ${ }^{4}$

Lee also builds on Hijikata's primary texts as well as on visual resources, including recordings of Hijikata's performances. Lee distinguishes three basic components of Hijikata's butō. The first one involves rejecting all typically human markings and being transformed into a weakened and collapsed body (suijakutai) (cf. "Tatsumi Hijikata: Structure" in Chapter 1), which resonates ${ }^{5}$ with the dead, the insane, the handicapped and the diseased. The second component is the capacity to turn into a creature "from another dimension."

2 Sur les pointes - literally "on the points" - is an iconic dancing technique of Western classic dance in which dancers move on the tips of their toes wearing pointe shoes.

3 http://www.subbody.net [24.07.2011].

4 Unless indicated otherwise, all quotations and references in this section come from Rhizome Lee 2010.

5 Resonating and resonance are terms often used by Rhizome Lee to refer to the process which Mikami calls interacting with imaginary wordings (cf. “Terms”). 
The third component is the ability to look at this world as a dead being. These three transformations are central to Hijikata's butō, according to Lee. Lee also insists that butō operates "beyond time and space," with the training process designed to reach this unique space.

The part of Lee's manual entitled "Practice Guide" outlines the structure of his training. Its major stages include meditation, breathing, conditioning, researching, walking and resonating. These basic psychophysical activities complement what Lee refers to as rhizoming and creating, or choreographing.

As can be seen, Rhizome Lee employs a rather idiosyncratic terminology, and his essays revolve around a handful of key notions. One of them is the subbody, i.e. "the inner body" in the sense of inner space equivalent to what psychoanalysis labels as the unconscious. Through practice, the butō dancer learns to use such resources, and as s/he listens carefully to subtle signals from the body, the subconscious meanings make their way into consciousness. The signals are activated by the flux of qualia (determinants of individual sensations) and are sensed through eight perception avenues ("body, movement, visual, audio, emotion, human relationship, world-self image and thinking”). Subjective sensations can be amplified (enhanced), as a result of which feelings transform into movement. Through resonating with inner stirrings and - later in practice - with other objects (particular body parts in a mutual relationship, things, animals, etc.), the dancer produces a subbody. The rhizome metaphor represents functioning outside cause-effect thinking and hierarchical thinking (visualised usually in the tree metaphor), which prevail in everyday life. As various subbodies resonate with each other, one resonating cobody (shared body) comes into being.

How particular elements are related to each other is explained in Lee's analysis of the training process. Various kinds of meditation serve to calm the bodymind and to switch to the subbody mode (in other words, the subconscious mode). The focus on breathing helps recognise (feel into) tiny alterations in the body that reflect the flux of qualia. In movement practices, it is possible to liberate the body-mind from hierarchical thinking and everyday physical, mental and social habits as well as to open perception channels. Explorations of one's own body-mind facilitate the discovering of subtle signals from the body and enhancing them so that they transform into a subbody and its accompanying movement. In walking, the self-world relationship is re-cast and one finds one's own, inimitable butō dance. Eventually, in resonating, one identifies a link between one's own subbody and other people's subbodies, which fosters a resonating cobody. 


\section{Toshiharu Kasai: Butō as a Method of Psychosomatic Exploration}

Toshiharu Kasai is Professor of Somatic Psychology at the Sapporo Gakuin University. Under the alias of Morita Itto, he dances butō. With Mika Takeuchi, a dancer and dance psychotherapist, Kasai runs workshops at the Studio Goo Butō Dance Institute in Sapporo.

Kasai studies butō as a psychosomatic exploration method (Kasai 1999, 2000, 2001, 2005, 2009a, 2009b, 2009c; Kasai, Parsons 2003). ${ }^{6}$ Over twenty years of training and stage practice, he has devoted himself to systematising the relevant terminology and butō-specific psychosomatic body-mind techniques: "the ongoing process of mind-body interaction is most significant in Butoh dance" (Kasai 1999: 310). At a certain moment, Kasai concluded that Western methods of body-mind integration (such as the Alexander technique, the Feldenkrais method, sensory awareness, the Gestalt method or Lowen's bioenergetics) approach the body mechanically: "its therapeutic function of mind-body entity was not well introduced outside Japan" (Kasai 1999: 310). At the same time, the body-mind is perceived as an integrated whole in the Japanese gymnastics model developed by Michizo Noguchi (Noguchi Taiso) (cf. “Terms") and in other methods instrumental to butō training (e.g. Toshiharu Takeuchi's exercises). Also butō can be employed to promote psychosomatic explorations and support internal integration.

Kasai's fundamental concept is butō-tai, i.e. the butō body or, more precisely, the butō state. It designates "a mental state trying to avoid objectifying the body and staying with the awareness of mind-body" (Kasai 2000: 358). This condition of consciousness is similar to altered states of consciousness (ASC), ${ }^{7}$ such as the hypnotic state, trance, dissociation of consciousness, state-specific memory or natural amnesia. A person that achieves the butō body is capable of integrating separated elements, such as body and mind, or subject and object. Butō-tai is a mindset, specifically a "mind-body set [which - M.Z.] plays a role of framework of movements and prepares the mental-physical space for un-predetermined things to come in" (Kasai 2000: 356).

As such, butō-tai is a state of psychosomatic readiness and openness. Ideally, such elements as the self, the outer world, the inner world and movement coalesce seamlessly in buto-tai, and, consequently, there is nobody/nothing that initiates

6 http://www.ne.jp/asahi/butoh/itto/butoh-e.htm [Retrieved 17 June 2011].

7 For more information about butō vs. ASC, see Coelho 2008b. 
movement. In this way, objectification of the body is avoided, ${ }^{8}$ which means that the body is not reduced to an instrument manipulated by a separate agent.

Butō-tai helps open up to parallel worlds, including, importantly, suppressed experiences and forgotten episodes in one's life history since state-bound (or state-specific) memory is activated. Achieving the butō body, one can release mental states inscribed in body memory but entirely muffled by consciousness. This process corresponds to Kasai's theory borrowed from Alfred Schütz's phenomenological sociology: something appears in our consciousness as one of many parallel possibilities and as the strong self seizes control of the situation, the chosen option becomes part of one's life while, at the same time, countless other options are discarded.

Aimed to achieve butō-tai, integration training helps reclaim the possibilities abandoned in earlier stages of life (Kasai 2001). The butō body can also be framed as a state of pure experience of reality as such. Through movement and resonance, the body flexibly adjusts to its changing environment. Kasai's method, called "mind-body learning by Butoh dance method" (Kasai 2001), seeks to increase proprioceptive sensitivity, i.e. to stimulate the sense of inner-bodily perception. This, in turn, promotes a desocialisation of the body (shedding whatever socialisation has instilled in the body) and a relativisation of the acquired response patterns (Kasai 2001). Kasai's method consists of three stages: playfulness, relaxation and confrontation. The playfulness phase involves the circulation of energy among the participants, triggered by pleasant and undemanding exercises. The exercises aim to dismantle the firmly entrenched "cognition-response-behaviour" system and to experience the body in the way children experience theirs (Kasai, Parsons 2003). Subsequently, various exercises lead to relaxation, which is indispensable for what is referred to as body-untying. An outcome of the slowing down and deepening of breath, relaxation helps recognise suppressed bodily impulses. As a result, one moves from social time to body time, which makes it possible to engage in more intense unconscious work. To prompt this effect, Kasai employs an exercise called the arm-standing exercise (Kasai 2005). Lying down and raising one's arms very slowly, one can feel one's weight (gravity) as well as master subtle control of the body that releases repressed bodily reactions. Called confrontation, the third stage tends to be tough, painful and possibly destructive. Such activities bring forth ideomotor movements, i.e. movements our bodies perform automatically as soon as a given image appears in our imaginations. This can involve unwitting

8 The term "objectification" was first used in relation to butō by Professor Rolf Elberfeld, who corresponded with Toshiharu Kasai. 
and involuntary body twists, unintentional motions and reflexes: "Tremors, ticks, jerks, facial and bodily distortions, falling down, or any other involuntary movements are appreciated as ways to explore and liberate the mind-body" (Kasai 2001).

As a result, the dancer begins to investigate bodily impulses which are restrained in daily life (e.g. scratching intimate body parts). Secondly, in the transformation process, one experiences all the feelings engendered when the body is naturally used - the way "people understand, feel about, and move their bodies" (Kasai, Parsons 2003: 262). Unwitting movements are a testimony of the dancer's openness to stimuli, which is referred to as passive perception (Kasai, Parsons 2003). Passive perception is defined as a psychophysical preparedness to accommodate whatever comes along. Kasai calls it a body-mind set.

Strategies that foster this type of perception consist of special ways of using one's eyes. Dancers rely on a variety of coinages to refer to them, such as nonseeing eyes, diffused focus (used by Yōko Ashikawa, Kazuo Ōno, Min Tanaka and Joan Laage) and peripheral vision (preferred by Kasai). Diffused gaze replaces the penetrating and dichotomising surveying (scanning) gaze: "[T]he eyelids lower slightly, the eyes become more relaxed, and the focus diffuses. The point of this is not to achieve a certain appearance, but to be able to perceive differently" (Kasai, Parsons 2003: 260). As passive perception sets in and one rather is in the environment than in relation to it, ${ }^{9}$ the capacity to see the void space is activated.

In Kasai's model, training consists of two stages (Kasai 1999). The first one, involving relaxation, massaging and gentle body-waving, can be called a relaxation stage. The second stage is a movement stage, which marks the release of unconscious motor reactions resulting from inner somatic stimulation or from processing a mental image.

In his article "New Understandings of Butoh Creation and Creative Autopoietic Butoh - From Subconscious Hidden Observer to Perturbation of Body-Mind System," Kasai (2009a) carefully scrutinises processes intrinsic to body-mind practices in butō. ${ }^{10} \mathrm{He}$ also attempts to "show the relationship between Butoh attitude [...] and recent theoretical developments" as well as to "understand

9 For more information on the psychological interpretation of butō processes, see Kasai 1999.

10 When I started my research on processes involved in butō training, Kasai's article had not yet been published. I studied many relationships between butō training processes and discoveries in neuroscience and cognitive sciences independently of and in parallel to Kasai. This is why some sections in Chapters 5 and 6 may seem to elaborate on his framework. 
[...] Butoh experiences as the process of self-actualization in terms of Maslow or the individualization process of Jungian sense" (Kasai 2009a). To do this, he attends to such diverse issues as a hidden subconscious observer, the mirror neuron system, the multiple controller system of body-mind, affordance, psychomotor factors, precision movements, the butterfly effect, the perturbation of the system, antagonist movements, alternative states of consciousness, schizophrenia, autopoietic structure, Maslow's self-realisation and Jung's individuation.

Kasai also draws on Freud's theory of primary and secondary processes. In the secondary process, which is governed by the rule of reality, the crucial role belongs to the controlling agent. The primary process involves dreams, fantasies and the subconscious, where what seems unreal is possible. The intensity of this process affects human inventiveness and creativity. In Kasai's view, butō embodies the primary process.

Kasai believes that "psychological knowledge works as stepping-stones, on which it becomes possible to support your body-mind and gaze into the sea of the subconscious world," and protects us against "a possible mental confusion or breakdown in the embodied primary process of exploratory Butoh" (Kasai 2009a: 26). Kasai regards psychophysical explorations through butō as a way of achieving a consciousness that helps communicate with people whose selves are jeopardised or unstable (such as schizophrenics). In butō-tai, all boundaries of the ego are malleable and permeable.

Kasai refers also to the theory of the mirror neuronal system in the context of the Japanese concept of mi-utsushi (a reciprocal relationship between body and mind as well as among various people's body-minds), where mi designates an integrated body-mind (Ichikawa 1984, qtd. in Kasai 2009a: 22). As the mirror neurons are involuntarily used, equally involuntary suggestions can appear. Kasai calls butō a somaesthetic art:

If visual stimuli created by other's bodily movements activate somatic reactions (at least surely in the brain due to the mirror neurons) of the audience, it should be recognized and appropriately defined as 'somaesthetic art' or art for bodily sensation. [...] In fact, our Butoh performance often takes a special body-mind state aiming at deepening the subconscious state of the audience by using 'mi-utsushi' or body-mind echoing, which sometimes makes the audience even to freeze as if hypnotized. (Kasai 2009a: 23)

Kasai refers here to the already mentioned state-bound memory. As Schütz claims in his multiple reality theory, people constantly adjust to new planes of reality, which he calls finite provinces of meaning. These realities include, for example, social roles and mental states. In patients with multiple personality disorder, information from one "province" is not transferred to other ones; the 
problem thus consists in a deficit of memory. Traumatic experiences involve ASC, and whatever happens while in a given state of consciousness is forgotten. Through exploring bodily states, it is possible to recall certain mental states and, consequently, events bound up with them. Kasai calls this process exploration of embodied psycho-archaeology.

He relies also on the theory of the subconscious hidden observer put forward by Ernest Hilgards, based on his investigations into hypnotic phenomena. The subjects he studied were able to simultaneously construct two different accounts in speech and in writing as if the narratives were authored by two different people. A similar split may also come forth in a trance. Other theories instrumentally contributing to butō research concern movement precision and affordances. The former says that the muscles work as sensors rather than as catalysts of movement. To construct movement, one needs sensitivity to external and internal stimuli; it is not enough to let consciousness choreograph as there are too many factors to be taken into account. Precision and focus are achieved through exercises (e.g. Noguchi Taiso) and help respond to any stimuli better and more flexibly. This ties in with the theory of affordances. Jerome Gibson explains that certain properties of objects are conducive to certain actions as possibilities to act depend on particular conditions. Affordance means "stimulus-response compatibility," that is, the ability to adjust our plan to stimuli from the physical world. It is only through movement precision training that the body-mind boundaries can be examined and, consequently, psychosomatic cognition can be improved.

Kasai draws an analogy between movement in butō and the so-called butterfly effect, a key notion in the theory of chaos. The creative movement process begins usually with trifling things, such as a minor obstacle (e.g. a splinter) and/or an unpleasant memory, leading the body in the least expected direction. Movement can also be inspired by all kinds of antagonisms. Dichotomies - such as flexorextensor, id-superego, emotional stimulation-social constraint - clash and, in this way, produce a new quality, space and energy. In "pure experience" (Kasai avails himself of Kitarō Nishida's concept), two contradictory forces make up a unidimensional space - "the absolutely contradictory identity" - which is accessible only in experience.

Practices inspired by the theory of affordances and employing perturbations (disturbances) and contradictory movements induce feelings and emotional states rooted in the collective unconscious or in the depths of the "archaeo-mind." They also enhance bodily perceptions. Butō dance as a method of psychosomatic exploration "gives performers opportunities to become aware of what is going on inside of themselves mentally and physically" (Kasai 2000: 354). 


\section{Sondra Horton Fraleigh: Butō as an Alchemical Process}

The philosopher and dance theorist Sondra Horton Fraleigh has made an important intellectual contribution to theorising models of butō training. In her Dance and Lived Body (Fraleigh 1996), the scholar outlines a philosophy of dance inspired by existential phenomenology. Studying and analysing butō in her further research (Fraleigh 1999, 2010; Fraleigh, Nakamura 2006), Fraleigh has offered a philosophical account of the dance within the phenomenological framework which highlights inner experience as a site where the specificity of dance forms is manifested. With its focus on the experiencing subject, phenomenology offers a useful underpinning for philosophical research into creative processes.

In her Butoh: Metamorphic Dance and Global Alchemy (2010), Fraleigh frames butō as an alchemical dance (as Fraleigh's language is highly poetic, scholars in search of concrete details must figure them out for themselves based on the insights gleaned from her metaphors). Butō dance appears in various forms: "staged productions, environmental dancing, community rituals, and healing dances" (Fraleigh 2010: 3).

In Fraleigh's view, butō's most essential aspects are "its shape-shifting potentials and its somatic shamanistic basis" (Fraleigh 2010: 11). Like shamans, butō dancers rely on movement to navigate between conscious and unconscious levels of life. In this, a butō-ka, similarly to a shaman, is brought in touch with ancestral spirits and the entire environment. Fraleigh refers to the butō dancer as "the last samurai" - a "fearless warrior and spiritual mendicant" (Fraleigh 2010: 35), who experiences through dancing the transformation that the contemporary world undergoes.

Butō is a dance form which is based on metamorphosis, a paradoxical imaginarium and an unending process. The verb "to morph" is derived from the Greek morphe designating a form, a shape, an outline. To undergo a metamorphosis means to change the form and the shape. "Morphology, then, is the study of forms and their transformations, including that of rocks, plants, and animals [...] The whole human life is morphology: a study of birth, death, and hope" (Fraleigh 2010: 44).

Improvisation is equivalent to transformation as it involves the cyclical acquisition of new representations (or rather images and figures) and becoming one with them. Tatsumi Hijikata's Butō-fu is a series of sixteen albums filled with cut-outs and strings of verbalised images. His student Yukio Waguri founded the Hijikata Method Study Group in 1992, and in 1996 he performed Butoh Kaden, "a journey of seven butoh-fu worlds. [...] from wet and heavy to light and airy" (Fraleigh 2010: 43), demonstrating butō-fu in action. The human body is surmounted and transcended in order to appear in a new form. The tension of conflicting elements is replaced by smooth exchange and transformation. The 
butō-tai (the butō body) is not representational but relational: "Its experimental somaticity $[\ldots]$ is widely cast to incorporate material object, images, and poetic collages" (Fraleigh 2010: 48). As such, it enables the individual to discover otherness within him/herself.

According to Fraleigh, butō's essence lies in transformation. Metamorphoses take place in "the space between," referred to by the Japanese term ma (Fraleigh 2010: 6). Designating the mental rather than the perceptual and the spatial, $m a$ is defined by Fraleigh as "an expansive state of mind" (Fraleigh 2010:6) and is a site of transfiguration. Butō dancers employ an array of means that support metamorphosis, such as, for example, hokotai, shifting the pain body, going through a spiritual transformation, being the becoming body, powdering the body white, donning costumes, etc. (cf. Fraleigh 2010:37-63). While in the West dancers fly, defying gravitation, buto dancers slump, planting themselves on the ground and, in this way, freeing the upper body. To accomplish this, they use what is referred to as hokotai - zero walk - the elementary gait in butō training. Butō dancers open themselves up to suffering, pain and bodily ugliness. At the same time, they relinquish the elements that bind the body to everyday living. As such, they abandon the social body, resorting for this purpose to several uncommon bodily techniques, such as dropping, floating, shaking, moving in the squatting position, treading unusually slowly and, when on-stage, coating the body in a neutralising layer of white. "Nudity in butoh is also an aspect of costume and another form of shedding the social body" (Fraleigh 2010:56) while costumes are metaphorical, refined and surreal, which meets the demand of giving voice to socially tabooed things. While relinquishing the social body, dancers simultaneously discard their egos by recognising them and sending them "into the middle of the universe" (Fraleigh 2010: 60).

The body which avoided "being robbed" (in socialisation) is like a blank page, which is receptive to any images. In a three-dimensional metaphor, the body becomes an empty receptacle whose shapes fluctuate under the impact of the substance it holds. The transformation process has a spiritual aspect to it as it involves cultivating "the third eye," which Western science identifies with the pineal gland - an organ that produces melatonin, regulates life cycles and is responsible for fantasising and image-making.

\section{Polish Researchers of Butō Techniques}

Butō techniques have also been investigated by Polish scholars. Such analyses can be found in the studies by Katarzyna Bester, Aleksandra Capiga-Łochowicz, Julia Hoczyk and Katarzyna Julia Pastuszak. 
Katarzyna Bester devotes the most important part of her Butō - od nazwy do istoty [Butō: From the Name to the Essence] (2010a) to butō techniques. She distinguishes the following stages: warm-up, total relaxation (relaxational attention, passive concentration) and the "my body can do everything" stage, i.e. the transformation stage (with the crucial images of the amoeba and the tree, and the climactic moment of "sleepwalking," i.e. embodiment in motion). Bester approaches the butō method she explores as "an artistic meditation and contemplation."

In her 2009 book entitled Bunt ciała. Butoh Hijikaty [The Revolt of the Flesh: Hijikata's Butoh], ${ }^{11}$ Aleksandra Capiga-Łochowicz focuses more on Hijikata's life and imagination, without methodically investigating his techniques (even though the book contains an interesting chapter entitled "Warsztat sceniczny Hijikaty" [Hijikata’s Stage Techniques]).

Julia Hoczyk's MA project on Japoński taniec butō. Historia i charakterystyka gatunku [Japanese Butoh Dance: The History and Features of the Genre] (2009a) analyses two classic butō styles: Hijikata's dark style and Ōno's luminous style. Hoczyk approaches Japanese culture within the framework of Barthesian semiotics, comparing Japanese and Western cultural concepts crucial to understanding the butō phenomenon. In her exploration of corporeality in butō, she relies on the thought of Artaud, Bataille and Derrida. Interesting as her study is, it does not tackle the training process at all.

In her PhD dissertation titled "Ankoku butö" Hijikaty Tatsumiego - teatr"ciała-wkryzysie" [Tatsumi Hijikata's "Ankoku butō": The "Body-in-Crisis” Theatre], Katarzyna Julia Pastuszak (2010a) traces the development of butō back to its genesis, from the "prehistory of notational butō" (1959-1972) up to "notational butō" (1972-1985), focusing on body techniques and the choreographic-training method. She discusses the butō-fu instructions and offers an analytical account of three Ankoku butō workshops held by Hijikata's students who work with his method.

In 2011, Iwona Wojnicka commenced her PhD project in arts devoted to Inspiracje $w$ teatrze tańca butoh [Inspirations in Butoh Dance Theatre] at the Fryderyk Chopin Music University in Warsaw. During her internship at the Codarts in Rotterdam (2010-2012), she did research into butō working methods.

Besides the scholars and researchers listed above, some MA projects at the Cultural Studies Department, University of Wroclaw, also address selected issues

11 The book was based on Capiga-Łochowicz's MA project at the Department of Japanology and Sinology, Institute of Oriental Studies, Jagiellonian University in Cracow. 
in butō training. For example, Małgorzata Barrek in her Butō i problem cielesności [Butoh and Corporeality] (2009) compares the butō method with Jerzy Grotowski's method of via negativa; Magdalena Niemczycka in her Butoh: wydzieranie ciemności z ciała [Butoh: Wrenching Darkness from the Body] (2005) and Izabela Walkowiak in her Kostium $w$ tańcu butō [The Costume in Butoh Dance] (2009) also tackle selected questions related to butō training. Additionally, in 2012, Ewa Janicka completed her PhD project on Transkulturowy charakter japońskiego tańca butō [The Transcultural Character of Japanese Butoh] supervised by Professor Juliusz Tyszka at the Department of Performance Studies, Adam Mickiewicz University in Poznan. 



\section{Butō in Poland}

The Polish butō scene has not yet been systematically studied. Information about artists is available mainly on their Internet homepages. Reviews of performances and short interviews have been published in several magazines and journals. Nevertheless, there is as of now hardly any literature either on bodily practices or on techniques used in butō training. In interviews for a wide readership, artists are usually asked to define butō and describe recent stage productions. My data on bodily practices and techniques come from interviews I conducted, from field research and from my own training experience (at workshops). Polish butō dancers characteristically draw on a variety of sources and engage in comprehensive explorations of movement and experiential bodily practices. ${ }^{1}$ Butō features in the programmes of dance festivals (e.g. Gdansk Dance Festival), performing arts festivals (e.g. Mandala Performance Festival in Wroclaw) and theatre festivals (e.g. Fortalicje Festival in Zamość). Some events are entirely dedicated to butō, for example the first Maat Festival 2009 in Lublin and, earlier, a few of the Butō Dance Festivals at the Gdansk-based Żak Club.

Any analysis of butō both as a stage form and a training method must pay attention to the genre's internal complexities.

The work of Polish butō practitioners can be examined in terms of the cultural flow and dissemination of locally formed artistic practices, among which Tatsumi Hijikata's butō can certainly be counted. Useful tools are provided by Ulf Hannerz's insights about "a pool of culture" and possibilities of accessing it (cf. Hannerz 1996). Hannerz argues that not all elements of culture are accessible with equal ease and some of them require what can be described as access pathways. This means that in cultural circulation, access to some meanings is mediated by a number of elements one has earlier integrated into one's cultural repertoire. In the case of butō, such access pathways are simply fundamental. All Polish butō dancers have earlier engaged with an array of body-mind practices (or psychosomatic practices) which combine corporeal and mental activities. In my view, these practices add up to an access pathway as defined above.

1 In his studies on body consciousness, Richard Shusterman divides bodily practices into experiential ones, which focus on somatic introspection, and representational ones, which aim to build a self-image (cf. Shusterman 2007: 78, 2008; Małecki 2009: 14). 
I believe that central to butō is special psychophysical training which fosters a more mindful self-experience and experience of the spatio-temporal world. For this reason, while describing and analysing the training used by individual butō dancers, I focus on their body disciplines.

Practices of butō dancers and artists who rely on selected elements of butō training in their projects range from contemporary dance and pantomime to therapeutic body work and martial arts, to pursuits in the visual sphere. These varied body-mind disciplines have shaped an entire generation of dancers, performers and movers (cf. "Terms") eager to investigate and experiment with their bodies. The techniques used by Polish dancers in butō training are a natural extension of their earlier explorations. Mastery of specific psychophysical methods helps augment their technical repertoire as artists. Therefore, butō dance, somato-kinetic methods (e.g. aikido and dance/movement therapy (DMT)) and other artistic techniques (e.g. mime and contemporary dance) are undoubtedly interrelated. Because butō is intrinsically intercultural, dancers can combine various body-mind disciplines. Consequently, inter-generic and somato-kinetic explorations are a natural element of Polish butō-ka.

In the following sections devoted to the experiences and practices of Polish butō dancers, I will examine body-mind disciplines which foster artists' somatic sensitivity. I will also focus on the creative process itself.

\section{Paweł Dudziński: The Intuitive Ritual}

Paweł Dudziński, with a background in sculpture and architecture, can certainly be regarded as a pioneer of butō in Poland. Dudziński's "intuitive" method took shape in the 1970s, when he was involved with the Grupa Aktywności Intuicyjnej [Intuitive Activity Group] (1974) but was not yet acquainted with butō dance as such. The Intuitive Activity Group, as well as the later Grupa Terapeutyczna Performer [the Performer Therapeutic Group] (1983), re-named the Performer Theatre in 1989, engaged in processes cultivating mindfulness to external stimuli, sensory sensitisation and intuition. Of course, their method did not come out of nowhere and Dudziński was inspired by several artists working with the visual arts, musical experimentation and direct action theatre. He was particularly interested in the experimental forms which came to prevail in various art disciplines in the later 20th century as a result of socio-cultural transformations.

A sculptor himself, Dudziński was especially attentive to developments within the fine arts. The happenings and performances of Jackson Pollock and Yves 
Klein, epitomising intuitive actions, ${ }^{2}$ are among Dudziński’s most frequently cited sources of inspiration. In her article "Inspiracje - improwizacje - intuicja. Sztuka performance Pawła Dudzińskiego" [Inspirations, Improvisations, Intuition: Paweł Dudziński's Performance Art] (2008), Joanna Sokołowska emphasises that, in Dudziński, Pollock's action painting "transmutes into body painting," where the canvas is replaced by the body, which the artist covers in paint. In the Misteria Barwy i Dźwięku [The Mysteries of Colour and Sound] staged by the Performer Theatre, Dudziński employed the dripping method in order to turn himself into a subsurface or, rather, "a painting support."

When Jackson Pollock took the canvas off the easel and out of the frame, spread it on the floor and walked on it, he established a different kind of contact with the work he was producing. With his body physically touching the canvas, he established more direct contact. As for myself, I undressed, lay down on the canvass and poured a bucket of paint over myself. I exceeded what Pollock had done. (Dudziński, qtd. in Sokołowska 2008)

Manipulating liquid and powder paints, the Performer Theatre actor is corporeally and spiritually inside the painting (the artwork), more so than was the case with Pollock, the great American painter (Dudziński 2008). In his action projects, Dudziński also took a position on Klein's anthropometries, "which were made by imprinting a model's paint-soused body on the canvass" (Dudziński 2006: 177). Dudziński's experiment took Klein's work a step further: while Klein used his models as a virtual paintbrush, Dudziński transfigured himself into a paintbrush.

By making the actor dance through butō philosophy and live music during the performance, we expanded the work of another artist, Yves Klein, who treated his paintcovered model only as a seal to make impressions on the canvas. (Dudziński 2008)

In this way, Dudziński harnessed his forerunners' transgressive experiences to enact a self-transformation during his performance, with his body becoming both a paintbrush and a canvas in the process.

The work of Jerzy Grotowski is Dudziński's other crucial inspiration.

I feel an affinity with Grotowski all the time. Seeing his Apocalypsis cum figuris was a shock which affected my development, and when I graduated, I set up a theatre which had, so to speak, grown out of my fascination with Grotowski; I've read all the literature on Grotowski published in Poland. (Dudziński, qtd. in Sokołowska 2008)

Dudziński builds on Grotowski's work both from his theatre period (the "poor theatre" idea) and from the time of Ritual Arts, which he refers to as the "so-called performative arts period” (Dudziński 2006: 180). Like Grotowski, Dudziński aims

2 The notion of intuitiveess will be described in more detail below; comp. also "Terms." 
first of all to fathom "the areas from before the birth of theatre as an institution" (Dudziński 2006: 180).

Emerging from a creative synthesis of visual (fine) arts, music and performance arts (alternative theatre), Dudziński's method was named the intuitive ritual for the purpose of the book Rytuat intuitywny. Metoda artystyczna Teatru Performer [The Intuitive Ritual: The Performer Theatre's Artistic Method] (cf. Dudziński 2004). "Grotowski cleansed theatre, turning his back on tradition and, in effect, completely giving up on theatre. I went back to theatre again. I wanted to see if I could make theatre using our new idiom" (Dudziński 2006: 180). Dudziński’s goal is to create non-literary, communal and ritualistic theatre. This pursuit actually strongly resembles the manifestoes of Antonin Artaud, a visionary reformist whose ideas of theatrical revival were familiar to Grotowski.

The actions staged by Dudziński's group

[...] are a process [...]. We don't fake anything. Unlike in theatre, we don't imitate but are in a process which, like a thunderstorm or the growing of the grass, is in and of itself direction, script and action. In fact, everything is naturally logical. As soon as you're in the process, any thought of direction or script becomes preposterous. They're obsolete and useless. (Dudziński 2006: 179)

"A performer is an unarmed actor; it's the abolition of spectacle; it's a process that can be grasped only intuitively" (Dudziński, qtd. in Sokołowska 2008).

In terms of the fine arts, a performer turns into a paintbrush while both his/her body and the space around it turn into a canvas. ${ }^{3}$ In terms of theatre studies, the Performer Theatre actors create a space by charting it by means of their bodies, which at the same time "are enveloped" in a costume of paint. "All this, called The Mysteries of Colour and Sound, aimed to bring one directly within the process, to achieve the bodily presence in the painting" (Dudziński 2006: 178).

Dudziński states that his goal is an "accurately mapped" ritual and "getting into a controlled trance" (Dudziński 2006: 180). He comprehends ritual as "going deep down into oneself and opening up" (Dudziński 2006: 180): "Ritual negates ritual and is ritual at the same time, for each performance involves the same things - there is sound, there is colour, there is an actor and there is a space" (Dudziński, qtd. Sokołowska 2008). The ritual "that stood at the beginnings of theatre" (Dudziński 2006: 181) cannot possibly be reproduced with any precision because performers "are always entangled in different time- and space-determined circumstances” (Dudziński 2006: 181).

3 In this way, Amrita - the world's biggest painting - came into being in 1994. The 17,830-square-metre painting was listed in the Guinness Book of Records in 1997. 
The idea behind the intuitive ritual is that the artist makes the work here and now. He does not know what it will turn out to be, which helps him augment his artistic self in the creative act, for if he enters uncharted territory, he expands this territory himself. (Sokołowska 2008)

The intuitive ritual does not consist in replicating productions practised in rehearsals. It is a ritual of opening which differs each time, depending on time, location and energy in order to create consciously but also to remain alert and let oneself be created by the situation and stage energy as they emerge. (Dudziński 2008)

Dudziński also refers to his action projects as "mysteries." They are a conquest

[...] of an unknown space which, when activated, would help activate the unused regions of the mind. We know of events suggesting that humans harbour unknown capacities. I mean, for example, dervish dances and voodoo rites, revealing unknown forces which enable the human-artist to function at deeper levels. (Dudziński 2006: 178)

Dudziński explains: "In our theatre, actors were steeped in a controlled, creative trance. One much deeper than is the case in the stagings of traditional, or for that matter, alternative theatre" (Dudziński 2006: 182).

The intuitive ritual should thus be understood as a performance (since "the artist performs the artwork here and now," and his supreme task is to "create consciously but also to remain alert and let himself be created by the situation and stage energy as they emerge"). What matters in this ritual is not only the artistic process ("which helps him augment his artistic self in the creative act") but also self-development ("activating the unused regions of the mind") and the spiritual process that corresponds to a shamanistic experience ("unknown forces which enable the human-artist to function at deeper levels") (cf. Dudziński 2006).

The Performer Theatre's method fundamentally involves such elements as intuition, improvisation, augmented consciousness, training sessions, reliance on inner resources and an opening to impulses from the outside.

Each action staged by the Performance Theatre takes as its starting point immersion in "the intuitive sphere of the imagination" (Dudziński 2006: 181)

Intuition, the subconscious, people refer to it differently, but we've got this thing within and we should reach down to it in order to experience it. The artist is close to nature, chaos, space, disorderly energy, unfathomed depths, taboo; this gives him a power to determine vectors of societies [directions in which societies are moving]. (Dudziński, qtd. in Sokołowska 2008)

"Thus the actor has a rare opportunity to penetrate his mental regions very deeply, augmenting his artistic self” (Dudziński 2006: 183). 
In outlining the historical development of intuitive pursuits, Dudziński lists several artists and refers to a range of disciplines (cf. Dudziński 2006: 181). Most relevant to him are music and sound-focused experiments. Free jazz, harmolodics (cf. “Terms"), dodecaphony (cf. “Terms") - they neither used musical notation (score) nor cared about traditional harmonic sound divisions (convention). Also in painting there have been artistic pursuits based on intuitive performance. In this context, Dudziński enumerates, besides Pollock of course, Wassily Kandinsky, Stanisław Ignacy Witkiewicz and even Pablo Picasso, who said: "Painting makes me do what it wants." And in theatre, Juliusz Osterwa "talked about the fourth and highest degree of actor initiation," in which the actor becomes a repository and placeholder of Supreme Beings and a guarantor of their will. In this position, the artist engages only in "a certain process and, with utmost sensitivity to its impulses, is open to what is visited on him from beyond - we refer to it as creative afflatus" (Dudziński 2006: 181).

Dudziński emphasises the histrionic aspect of his group's practices, but at the same time repudiates the entire theatrical tradition. He believes that "whole theatre, even the most modern and alternative theatre, remains stuck in secure conventions and re-enacts a well-trained score" (Dudziński 2006: 182). The Performer Theatre, on the contrary, relies on improvisation.

There is no theatrical staging, rehearsed and replicated; instead, there is fashioning in front of the audience, the fashioning of an internal reality [...] We never rehearse in the traditional sense of the term; everyone rehearses alone for themselves. And as we meet during the performance, the encounter is an event and a clash in which a structure is forged out of individual training (Dudziński, qtd. in Sokołowska 2008).

Because the performers' goal is "total creation" (cf. Dudziński 2006: 182-183), they must be comprehensively trained. As Dudziński says, they must be "multioccupational” (Dudziński 2006: 185). Actors should do play-acting exercises focused on the body and the voice, be acquainted with the basics of fine arts (e.g. composition) and be versed in the practices of the visual arts, such as performance, body art, installations and graffiti. Besides, they must also educate themselves in audio art, music improvisation and contemporary dance.

As training is supposed to foster the capacity of intuitive insight into the subconscious (a skill by no means inborn), it crucially comprises also "sensitivityand intuition-oriented personality-building practices [...] promoting the development of the creative potential" (Dudziński 2006: 185). Personality formation is the fundamental objective in the education of Intuitive Ritual actors. In the ritual,

actors can attain genuine subjectivity as, in being creators, they have an obvious impact on the unfolding of on-stage situations, dynamics and the quality and pulsations of the 
pace. The depth and frequency of actors' breathing are in themselves basic determinants of rhythm. So is their fitness. Its ebb and flow serve as a natural and credible means of giving rhythm to the performance. [...] This takes more attentiveness and sensitivity than with actors who are acquainted with the score of the production and, thus, know its structure. Consequently, Intuitive Ritual actors must be far more mentally resilient. (Dudziński 2006: 183)

Instead of a set of physical exercises, training revolves around improvisations "on a different theme each time and aimed to solve a problem the trainer poses" (Dudziński 2006: 183). The problems often concern abstract notions, such as

[...] weight, evanescence, contrast, interpenetration [...]. The themes serve only as impulses, as triggers igniting a joint action in which everybody solves their own problems - ideas, feelings - and alleviates some stress, mindful of other people. You could call it permanent improvisation. (Dudziński 2006: 185-186)

The third component of training consists of field trips, that is, outings into the wilderness, which aim to

[...] still the mind and reduce negative stimuli [...]. After a few days of such a sojourn, one's perception is re-configured. The senses are heightened, sight, hearing and even smell. [...] You must be always mindful and open to what is going on around and what can come about. (Dudziński 2006: 186)

The performer Justyna Jan-Krukowska calls such involvement with the natural environment "sensory sensitisation."

Such training helps actors attain a unique state of mind while being involved in art-making. "Everything takes place in a specific spiritual atmosphere. It is a mental state - an ecstasy or a trance - where the aroused consciousness changes and expands, ready to receive other, non-quotidian, extra-terrestrial signals" (Dudziński 2006: 180). Such sensitisation helps actors respond to external and internal stimuli non-automatically. "Listening attentively to their feelings, actors have enough time to identify and externalise them" (Dudziński 2006: 183). Dudziński describes the process of accumulating an inner "reservoir" to be used later in artistic pursuits. Actors become

[...] extraordinarily receptive to impulses from the outside, and focused. A landscape outside the bus window, an event underway, our conversations "about it," all that goes into the making of the "inner material" from which we draw during the performance.

4 The term "inner material" was also used by Tatsumi Hijikata to refer to his life experiences that provided him with resources for his dance philosophy and stage work. In his usage, the word "material" itself designated a specific physical matter (e.g. various distinct bodies) in which the inner content was clad (cf. Hijikata 2000c). 
The ability to focus and act in all settings - after all we are an outdoor theatre - helps us consciously become immersed in the staging process. (Dudziński 2006: 180-181)

During an action event, the inner material is activated by interactions between the actor and the musician. Actors identify with impulses both from within and from without. As Dudziński explains: "Instead of avidly imitating becoming a source, we've become a source. Instead of avidly imitating a process, we've become a process" (Dudziński 2006: 188).

Despite retaining the histrionic paraphernalia alongside theatrical terminology ("actors," "staging"), the Performer Theatre engages in fact with action art. Interactions between the actor and the musician (two performers), as well as interactions with the audience (participants) and the space (stimuli from the environment), are founded on an autopoietic feedback loop. What comes into being is "a spatial, cybernetic - that is, self-regulating and self-constructing - performance" (Dudziński 2006: 188).

The intuitive ritual is anchored in body-mind practices which strongly resemble the corporeal and mental training of butō dancers. It is an improvisation grounded in being here-and-now and responding to stimuli from exteroceptors and interoceptors beyond conscious reflection. A feedback loop arises between performers and the environment as their consciousness literally merges with the world. On his first encounter with butō, Dudziński realised that the aesthetic similarity of his projects to the dance must result from the analogous method undergirding the creative process.

First of all he was fascinated with the ostensible motionlessness on stage.

Dancing on paintings, I actually danced butō, without even knowing that there was anything like that in the world until I saw butō on TV. Kazuo Ōno danced The Ocean. I was immensely impressed as he was motionless. A professional dancer who does not move at all - it came as a shock to me. He exuded such enormous energy that I started to work with butō theatre in earnest. (Dudziński, qtd. in Sokołowska 2008)

As far as the actors' movements are concerned, what was most useful was finding out about the philosophy of butō dance, which highlights consciousness of the body and its impulses and the imagination, which help make art in a conscious and controlled fashion while the score is missing (which is the essence of butō). The ostensible negation of all movement in butō dance must trigger other processes in the dancer's body and awareness; and this is indeed the case, while slowing movement down to a minimum affords the dancer the time to realise and enact these processes. (Dudziński 2006: 184)

To obtain a more comprehensive insight into butō, Dudziński took part in workshops taught by butō artists Joan Laage and Daisuke Yoshimoto. $\mathrm{He}$ combined his experience of movement stemming from the fine arts with the 
aesthetics and body training proposed by the two dancers. "When I dance - have an inner experience of - butō amidst the creative process, I augment butō with body art and body painting" (Dudziński, qtd. in Sokołowska 2008). Tellingly, a similar coupling of dance and painting was attempted by Atsushi Takenouchi, who organised workshops in butoh-painting or painting-butoh: "Darkness and light, depth and surface, rhythms and cold and hot with all appended sensations and feelings are evoked by colours and translatable into colours." ${ }^{5}$

Affinities between the intuitive ritual and butō are also addressed by Julia Hoczyk, who discusses Dudziński's artistic practice as a source of inspiration for artists in the Maat Project Theatre:

The name [intuitive ritual] can sound rather hermetic, but it is closely related not only to butō but also to the creative process as such, to the freedom and joy of creation. It involves improvisation that originates from the activated intuition. The aesthetic dimension of the artwork is thus transcended, and the unknown is embraced. Intuitive dance consists in being here and now, in the particular time and space, anew each time, so as to use them in the conscious creation process and, at the same time, open oneself up to the formative power of the arising on-stage situation. Such dance is predicated on the opening of all senses, sensitivity and being a unique seismograph of time and place. It is worlds apart from a meticulously designed choreography patterned upon external repetition of fixed sequences of movements. This is where I believe its kinship with butō lies. In both cases, the essence resides in an encounter with the unpredictable. (Hoczyk 2013b)

Tomasz Bazan (Maat Project Theatre) calls Dudziński a continuator of the tradition founded by Grotowski's physical theatre. In Bazan's view, Dudziński hails from the same school though he chose to go a different path:

[...] he dedicated himself to exploring and developing intuitive art, to seeking art in the most candid sense of the term. Pursuing the experience of the-here-and-the-now [...] He was the first to stage typically intuitive and, methodologically speaking, highly orthodox actions [...] His work focuses on what is referred to as butō-tai, the butō body. He has colossal experience. (WTB)

According to Bazan, Dudziński paved the path for butō in Poland.

There's nothing razzle-dazzle about him. He doesn't use all that stage machinery, a huge stage, amplified sound, lighting, new media experiments. But in his ideas, ideology and practice, he's one of the most important pioneers of this genre in Poland. At the core of his work lies total presence, and nothing else. Just like in butō. Dressed in a stage construct, but a sparse one. He works with the matter resembling dance theatre, but he selects the most fleshy things: colour as paint, skin. (WTB)

5 Takenouchi's manifesto, a passage reprinted in Mond-Kozłowska 2010: 27. 


\section{Conclusion}

Dudziński is the founder of the intuitive ritual, a here-and-now practice based on opening up to stimuli and flows while keeping consciousness fully alert. The intuitive ritual should be understood as a performance in which not only the artistic process matters, but also a spiritual process which corresponds to going through a shamanistic trance or a mystery experience. The artist himself often speaks of "a controlled trance."

The creative method of the Performer Theatre involves such elements as intuition, reliance on the inner material, opening up to external impulses, improvisation, training and states of augmented consciousness. Intuitive intelligence helps employ the inner material and respond to the impulses from the outside world. As a result, the performance (Dudziński continues to use this term to emphasise the histrionic nature of his work) is based on improvisation instead of on a structured score. Themes for and triggers of improvisation are provided by the accumulated inner material and the only pre-determined element of the venture, i.e. the title of the performance.

In order to open up to "the flow," the Performer Theatre actors prime their body-minds in training which enhances their creative potential and sensitivity. The technical training consists of creative improvisations which often revolve around an assigned theme. Another form of sensory sensitisation is offered by trips "into wilderness," where perception is gradually re-modelled. This kind of training serves to attain a specific state of mind during a performance.

Opening oneself to the "images of the floating world" was originally and still continues to be central to butō. Such opening helps literally "embody" elements of reality (i.e. identify with them by means of bodily and mental integration with them) and, at the same time, enact the inner processes. The creative process structured in this way is analogous to the process in which buto dancers engage. Given this analogy, Dudziński's butō experience cannot be reduced simply to a fascination with the extraordinary, the unknown or the exotic to be domesticated and absorbed. Rather, his is a realisation that the intuitive ritual and butō are predicated on identical principles of bodily and mental artistic practice. As a result, Dudziński's performances can be referred to as butō dance augmented with body art and body painting.

\section{Justyna Jan-Krukowska: Sensory Sensitisation}

Justyna Jan-Krukowska studied fine arts (visual arts). While still a student, she started to denounce the mainstream idea of "putting artworks on display" as "a 
commercial ritual" (WJK). ${ }^{6}$ At the opening of her MA project in painting, she invited the examination panel and the audience to take part in "a happening which cracked down on the form and substance of the vernissaging farce." When she went to Western Europe after graduation, she got involved in collaborative happenings with various artists. In Jan-Krukowska's view, performance "lifts the millstone of objectivity." After all, the beginnings of performance art go back to ventures of visual artists, even though performative actions generally (and body art in particular) engage the entire body as a medium of performers' practices.

As artists work on their projects, their intentions and ideas are "translated into movement, into a visual quality" and encoded as "a sequence of motions," which ultimately results in a performance or a performative object. Performance aims to trigger a bidirectional "energy transfer" (a feedback loop as defined by Erica Fischer-Lichte) and, thereby, to establish a relationship with the audience. In this way, the performer transcends the virtuality which currently pervades individuals' contacts with other people and the world (the virtual is the opposite of the present). Hence Jan-Krukowska not only explores the performative uses of "the moving body, the body in action," but also studies the settings in which such a body functions.

Jan-Krukowska believes that artists quintessentially "make visible that which is imperceptible to the eyes," that is, materialise the invisible. The invisible world comprises feelings rooted in the body and so-called spiritual reality. "Through their bodies, performers communicate with higher realities."

In 1993, Ryszard Nieoczym, an actor/director of the Toronto-based laboratory theatre LeTHAL ${ }^{8}$ and a student of Jerzy Grotowski (at the turn of the 1960s), came to Wroclaw's Centre of Studies of Jerzy Grotowski's Work and of the Cultural and Theatrical Research ${ }^{9}$ to teach a five-day workshop. The Soundings workshop was a turning point in Jan-Krukowska’s development as an artist. She realised how much "the body affected her as a visual artist." After another workshop in 1995, she decided to take part in a five-year-long project on Ritual \& Healing: Women's Rituals (1995-1999), alternating between Germany and Canada. As "the project delved into the origins of art as a vehicle" (Jan-Krukowska n.d., "Kobiece rytuały"), it was conceptually indebted to Grotowski's late work, where he was gradually giving up on theatre and focusing instead on the development

\footnotetext{
6 Unless indicated otherwise, all quotations in this section come from WJK.

7 Jan-Krukowska 2009.

8 Le Théâtre de L'Homme Actor's Laboratorium LeTHAL/Theatre Research \& Performance Ensemble LeTHAL

9 The present-day Jerzy Grotowski Institute in Wroclaw.
} 
process. "For a doer, an artwork is a tool of self-work, and there is no need to show it; the audience may and may as well not be around" (Jan-Krukowska 2009; cf. Grotowski 1990).

"In one specific respect, Nieoczym surpassed his master. He ventured into a territory forgotten or unknown in our culture. He dedicated himself to studying the woman, her nature and her creative powers." Jan-Krukowska addressed the issues of femininity, bodiliness and communion with the object in her texts "Kobiece rytuały. Rytuał. Uzdrawianie. Wspólnota" ["Women's Rituals. Ritual. Healing. Community”] (n.d.), "Toaletka damska" ["A Lady's Dressing Table”] (n.d.) and "Ciało i obiekt. Kluczowe odkrycia w procesie pracy z ciałem i przedmiotem" ["The Body and the Object: Key Findings in Working with the Body and the Object"] (n.d.). She explained: "A public showing has never been the aim of my ritualistic practices. They have essentially been about me wrestling with myself."

Like Grotowski, who in his last art-and-research project on vibration songs (Pontedera, Italy) did not create anything new but studied "the bygone, the old, the forgotten," during her retreats Jan-Krukowska explored "the potential of femaleness in a male-animated culture [...], she went back to the roots of the body and its deep-buried needs." She investigated her attitude to the body and pondered key questions for artists: who am I; why do I suffer; what is my destiny? One consequence of art being embedded in the Judeo-Christian dichotomy of the body and the soul (Jan-Krukowska refers to it as a "Manichean bite") is condemnation and renunciation of the body. What is more, it is accompanied by a fear of bodiliness and of the woman, who is purportedly closer and more intimately related to this realm. "The body is enmeshed in multiple stories and negative connotations, so focusing on body disciplines is a risky business. I am aware of the consequences."

The body- and object-focused practices within the Women's Rituals project resulted in "challenging the culture codes inculcated by Catholic education." For Jan-Krukowska, "Catholic education" also includes passive Catholicism, such as the cultural transmission of values outside of the Catholic church's formalised and institutional teaching. The project aimed to "pierce through rationalisations and cultural conditioning."

Jan-Krukowska also learned to shuffle off the learned approach to creating art.

I had a rather specific notion of professional work [...] It seemed to me that success depended on the right selection of an effective and powerfully expressive object and, then, the presentation of this object alone or by means of properly directed activities and gestures. [...] A long time passed before I understood that artistic experimentation is, in its very essence, the manipulation of an object or a human being used to enact it. It consists in appropriating a body or a thing. (Jan-Krukowska n.d., "Ciało i obiekt") 
Jan-Krukowska believes that, in contemporary art, the word "object" is one of "the so-called buzzwords, [...] calling an artwork an object produces an unemotional and dangerous distance between the human being and the world of objects." During object-focused practices within the Women's Rituals project, the artist had to revise her beliefs completely. She found out that through "objectalisation" artists break apart from the object/person they work with. But what Nieoczym expected the participants to do was to establish genuine, unfeigned contact, to bond and, finally, to unite with the object. Working with the earth was a breakthrough moment. Nieoczym made Jan-Krukowska realise that "coming in touch with the earth is like talking to a grandpa's ghost." He emphasised the imperative of "birthing a human." This vividly suggestive metaphor made the students grasp how challenging and painful working on the self was.

During the project's second - Canadian - stage devoted to Wilderness (1997), Jan-Krukowska focused on fire and consolidated her approach to working with that elemental object. Initially, she treated fire functionally and tried to tame it; however, she soon realised that she had developed a special bond with fire, which gave her a sense of collectedness and at-homeness. Finally, she felt at one with fire and "embodied" it, so to speak: "Fire started in my body" (Jan-Krukowska n.d., "Ciało i obiekt"). Such an embodiment process promotes inner transformation. In butō, the same procedure is applied while working with imaginary wordings. "In Wilderness, the transformation of the body was completed swiftly, almost abruptly. My belly, flat previously, clearly rounded; my back and shoulders straightened up. My body's inner cavities filled with air."

In 1996-1998, Jan-Krukowska took part in several of Nieoczym's other projects. The experience from the Women's Rituals retreat and subsequent projects provided "the basis of body training," but the artist needed "an idea - that which saturates art." "The human psyche deeply needs to play and to perform. Learning to play is a discovery of the psyche's real needs" (Nieoczym, qtd. in Jan-Krukowska n.d., "Kobiece rytuały").

Jan-Krukowska first saw butō at Tanaka's dance performance I Sit staged at the Centre of Studies of Jerzy Grotowski's Work and of the Cultural and Theatrical Research in 1996. During the performance, she had an irresistible impression that Tanaka incarnated "a coherent vision of man-and-artist," an issue she was grappling with in Nieoczym's projects.

To find out more about butō, she went to Tanaka's Body Weather Farm in Hakushu, Japan to take part in the summer Body Weather Workshop as a Mina Tanaka School of Love-Dance Foundation (Ren-ai Butō-ha) grant-holder in 1999. At the same time, the town hosted the Dance Hakushu (a butō festival). 
Training at the Farm ${ }^{10}$ was very intense, including formal technical practice and farming chores. "It is connected with the earth and with the body," which resembles the practices of the Women's Rituals participants. The trainees got up at five every day and spent the following two hours working in the fields, with the livestock or in the orchard. "Formal training"11 began at nine with a warmup and took about three hours. All exercises were based on formal and informal breathing drills (as Jan-Krukowska argues, control of breathing is a prerequisite of any physical activity in the hot and humid climate of the subtropics). Intense warm-ups took place at the Earth Stage, a rectangular site covered with rough wooden boards, which often hurt the feet. The extremely fatiguing warm-ups consisted of exercises based on repeated steps. Their aim was to "activate the body parts one by one" and to enhance focus, coordination, sense of rhythm, the suppleness of the body and attentiveness to others. It was "endurance training which required vivid consciousness of the body in order to tag the limits to one's physical capacities and, thereby, to avoid injury. The participants had to give up on showing off and forego any quick success."

After a break, around noon, another technique-focused session would start. This part of daily training was devoted to mental images and sensory sensitisation. An heir to Hijikata, Tanaka used butō-fu, that is, "a primer of embodied images, Hijikata's alphabet." The representations it contains "must not be mechanically repeated or imitated. It is not a pantomime. Movement must be born within, inside, in the mind, in your subconscious. You can immediately tell the movement from within from an imitation."

The embodied images are then "associatively combined in chains of representations." People work in pairs where one person embodies images and the other relates what they see. The master (teacher) supervises and guides the students and offers them clues and hints.

The major objective of sensory sensitisation is to transfer active perception from the dominant sense of sight onto the other senses. To this end, for example, "space is explored while blindfolded." Trainees again work in pairs, where the blindfolded person goes along a demarcated route on the Earth Stage and across the Farm while the other person safeguards. The safeguarding partner can also carry the blindfolded one, lay him/her down in various places and on various surfaces. This is a "continuation of earlier practices: body contact, untypical perception, being

10 Unless indicated otherwise, all information about the Farm comes from Jan-Krukowska n.d., Body Weather.

11 I use the term "formal training" as an analogy to Buddhist practices, in particular Zen, where formal (meditation) sessions alternate with everyday chores. 
here-and-now - they're all very important tasks." At the core of these exercises lies "surrendering, yielding, entrusting." Sensitisation was also accomplished by stimulation: the trainees, their eyes closed, animated each other's movement using touch and imaginary wordings. At this stage, they also did exercises with objects in order to understand "how the object works, and how it can be used."

After lunch, the participants continued their farming chores and in the afternoon they took part in the Dance Hakushu events: stagings, performances, talks (for example, by Nario Gōda), film screenings, slide shows, etc. Such a training schedule engaged them both as individuals and as dancers in order to help them cross from "virtual reality" (intellect, computer, discussions) to "the reality of physical action." Essentially, training aimed firstly to give the trainees grounding through physical work in proximity with the earth and so-called bottom-level practice and secondly to hone their sensors.

The climax of the workshop was a trip to a volcanic hill in the Haka-Yama range. To reach the top enveloped in lush greenery, the trainees went up a steep path, following the instruction "to go focused, in good pace and to cumulate energy." In the lunar-like scenery of the summit, they had their familiar sensor-focused practice on the volcanic soil. They examined the impact of the environment on their bodies and movement. The return was highly challenging as they were supposed to run down the slope "like a chamois, schussing with the knees high up" (running of this kind is used in workshops by Katarzyna Żejmo, a student of the Subbody Resonance Butoh School Himalaya). Only fluid movements and relinquishing conscious control made it possible to "alight, to flow down this mountain," taking in a stride such obstacles as suddenly appearing rocks. The sought-after "organic" quality emerges when, at a certain moment, after a longlasting and intense training cycle, one no longer feels fatigue. "You break through it, you reach upper regions with energy, and everything is rearranged, your entire hormonal, immunological system."

Having returned to Poland, Jan-Krukowska set up an association called Gromady Pogody Ciała [Body Weather Clusters] devoted to augmenting the knowledge of the human body and applying, among others, Tanaka's group work with images. She also took part in workshops run by Atsushi Takenouchi (2003-2005). Like Tanaka, Takenouchi engages in bodily explorations of nonurbanised settings and investigates the relationship between "the mechanized urban environment and nature." He borrowed the practice of "creating worlds" from his master Kazuo Ōno, a dancer who believed that "the entire world is magical." Jan-Krukowska distinguishes two major pillars of Takenouchi's practice as an artist: "the imagination plus a kid's energy." His training also includes 
imaginary wordings, though he works with them in a different way. Instead of focusing on structures, the dynamic, fast-paced process is based on a constant flux of shapes (as already mentioned, butō scholars often point to the ukiyo-e woodcuts with their renderings of a floating world as a butō inspiration). Such spontaneity can produce "formal chaos." Before working on imaginary wordings, a series of exercises are done to "activate all the body parts one by one" (the same warm-up is also used by both Tanaka and Daisuke Yoshimoto, another Japanese butō dancer whom Jan-Krukowska has met). To compare the technical repertoires of Takenouchi and Tanaka, Jan-Krukowska resorts to the Chinese philosophical concepts of yin and yang. She sees Tanaka's art as "synthetic, formally sophisticated, albeit unembellished" and the artist himself as "a macho type" (yang). Takenouchi, in turn, is "gentler" (exhibiting, as mentioned above, "a kid's energy"), and his art is "organic, visually and aurally fine-tuned" (yin). Both kinds of energy are necessary in workshops and performances: "at a certain stage, artists can explore their duality, going beyond their ascribed sexualities," for the performer is "a dual figure in being neither a female nor a male ... or being both a female and a male."

Jan-Krukowska's own creative practice also follows two trajectories, comprising what she refers to as "luminous" and "dark" pursuits. The former include "being with the body in a natural, erotic, unhurried way, working on sensors, charging the batteries and nourishing the body," all of which serve to achieve a total presence in being here-and-now. "Exploring space, placating it, collaborating with it, establishing a relationship, dialogue - I give my body up to the space I communicate with - trance running, meditation running - I am here and now, I merge with the place - making contact with the earth, free movement on the ground, with or without music."

Sexual identity is one of the prevalent issues Jan-Krukowska delves into. This unfolds mainly in practices she calls "dark," as they centre on fathoming the conflict between "nature and culture" and between "the individual (unique) and the collective." The conflict is directly experienced through "activating conflict sources in the body and handling the body differently." Since the artist believes that gender theories "are fixed and programmatic and don't take existential suffering into account," she explores the meanings of masculinity/femininity through and in her own bodily practice. She seeks to scrutinise and unravel femininity stereotypes fuelled by the social need to organise the world in binary oppositions. As early as during Nieoczym's workshop, she caught the first glimpses of her "inner boy" - her male alter ego. Such knowledge processes inclined her to look into transsexuality, transgender and third sex. "It is all very comfortable 
to explore abstract issues - the form, the colour, the technique - but the artist is there to topple stereotypes." This is a particularly challenging mission in the current neo-conservative realities. "Ours is the time of counter-revolution (against the body)." "Tightening the screws breeds perversion," and society are fed two dichotomous models of corporeality: a de-eroticised, medicalised one and an ostensibly liberated while in fact pornographised and prostituted one, where the body is a commodity on sale and "a stimulant of pleasure in the audience" (JanKrukowska 2009). This is why in her work as an artist Jan-Krukowska contrasts the "seductive body" with innocent bodiliness in "a pristine bodily intercourse."

\section{Conclusion}

"I'm not, I don't feel a butō dancer; I've incorporated butō into my work," insists Jan-Krukowska. Her basic practice is sensory sensitisation. She hones her sensors in the natural environment, where the senses are not assaulted by a barrage of stimuli. She relies on a very slow walk typical of butō. The artist explains: "What does slow/quick mean? Away from the city, we start moving organically, we assume a rhythm which is slow only when compared with the pace of urban life." Jan-Krukowska studies various properties of movement: she juxtaposes the slow, organic movement (largely resembling small dance, ${ }^{12}$ developed and explored by Steve Paxton, the initiator of contact improvisation) with vivid bodily gestures and jerks. This improvised movement - both luminous/organic and dark/conflictridden - forms the basis of her performances, actions and presentations. "The body becomes part of the environment and, as a display, remains art at the same time. Without display, there is 'art as a vehicle." Stage action originates in impulses as artists investigate "where the body takes them. And a performance appears when that structure of impulses has been consolidated."

\section{Sylwia Hanff: Transcending the Body Code}

Ever since childhood, Sylwia Hanff has been interested in various forms of body-focused practices. "Ever since I can remember, the body has been my basic medium and communication channel. My body is me; it is myself" (WSH). ${ }^{13}$ Because the artist has never thought of the body as separated from the mind, she

12 For the theory of small dance (S. Paxton), see http://vimeo.com/1731742 [13.04.2011]; for its practice, see https://www.youtube.com/watch?v=6sJKEXUtv44 [12.07.2014].

13 Unless otherwise indicated, all quotations from Sylwia Hanff in this section come from WSH. 
finds it difficult to relate to the notion of integrating body and mind. "My body is the total me. It has always been my channel of self-expression. So far, it has been my way of communicating: of self-expression and reception."

Hanff studied philosophy at the University of Warsaw.

To me, philosophy is a perfect preparation for butō and meditation. [...] It deconstructs the structures of the intellect so thoroughly that it makes you ready to meditate. You come to take a distanced view of theories because you know you can always challenge any of them. Those years of philosophy made me feel split into body and intellect, but theatre helped me come back to myself at the right moment.

As a student, she researched theories of ritual and shamanism, at the same time exploring the philosophy of art and the creative process, the anthropology of theatre and contemporary experimentation in the performance arts. She studied the theory of an array of concepts, focusing especially on the anthropology of theatre as developed by Eugenio Barba's International School of Theatre Anthropology (ISTA), devoted to the study of the actor's art and technique. These pursuits inspired her to develop $W$ strone Orientu [Towards the Orient], a project including a series of guest performances and master classes taught by invited dancers. She also presented a lecture entitled Aktor obdarty ze skóry [A flayed actor] (n.d.), in which she philosophically re-interpreted Antonin Artaud's idea of the theatre of cruelty.

When still in primary school, Hanff practised rhythmic gymnastics combined with acrobatics and dance. The method she used later was developed within the ISTA.

Physical training included Eastern and Western body disciplines, such as ballet, modern and contemporary dance, Indian dance forms (Bharatanatyam and manipuri), Aztec and African dances, dance improvisation, body symbolism, corporeal mime, dance therapy, Nō theatre and martial arts. [...] Meditation practices (Zen, Hatha and Kundalini Yoga, Kum Nye, Tao and labyrinth meditation) have been and still are an important part of my training; they serve to develop a special type of focus and mindful awareness of all mental and bodily processes. (HTL)

Rather than achieving mastery of any of the techniques, the aim of the training is to fathom the various ways in which the body functions at the energy level. All the techniques

[...] offer a specific experience, a kind of energy which can be entirely strange and unfamiliar to me. It is a method of opening up to this bodily energy. [...] later, I can use all these various energies as they are part of my experience, are my resource. Even if I don't dance in a given way any more, the energy bound up with it still remains. It can emerge spontaneously. 
Work with the body-mind is a key aspect of Hanff's creative pursuits and life as an artist.

Her body consciousness has been greatly improved by what is known as corporeal mime (cf. "Terms"), which she learned at Stefan Niedziałkowski’s Studio Mimów [The Mimes Studio] in Warsaw. Niedziałkowski, a mime artist, director, choreographer and educator, picked up Henryk Tomaszewski's pantomimic technique based on harnessing bodily impulses and developed it by "shifting the emphasis onto transformation and authenticity of experience."

Niedziałkowski's studio work characteristically prioritises "precision in working with the body and, hence, outstanding body consciousness, awareness of each millimetre of movement." Movement is initiated by an impulse which spreads across the body. "The technique of disseminating the impulse is very accurate, but it also involves energy processing. Breathing is extremely important. As is the absolute consciousness of how the impulse flows through the body and develops into a particular movement."

Movement is simultaneous: "when I raise my hand, my toes take part in this movement." The face is only one of the body parts and, unlike in classic pantomime, by no means the most important one. Corporeal mime is not just a modern pantomime form; given that it involves a unique body discipline, it can be considered a variety of physical theatre. In Niedziałkowski, all pursuits - even the production of a stage illusion - had a metaphysical grounding.

We didn't work on illusion a lot; rather what was emphasised was the body's plasticity and very intensive physical training, which actually was never purely physical, but always combined with expression. At the same time, we monitored the flow of energy at the level of the simplest motion.

This is one reason why breathing is such an important element as it directs energy and is, simultaneously, a vehicle for the body's communication with the outside world: it makes "the body alive and makes it work as something more than technical and muscle-driven."

Corporeal mime involves "many abstract forms of movement, and this is what interested me most," confesses Hanff. "They were only externally abstract, for internally each movement was worked out in detail and encoded a number of things." For example, in one exercise, the actor becomes "a tree with the energy of sand sliding off a scarp." The key task is "to become it and to feel all this in your body." The point is to go through a process in which the actor identifies energies of actions, people or objects in his/her body. Individual work on the consciousness of the body and its plasticity is a prelude to group exercises focused on metaphorical images and transformation. Even though the Studio practices 
are undoubtedly multi-layered, they ultimately boil down to "a metaphorical application of something to express something else, that is, for example feelings, a person's life story, an individual's pain." This is a very important observation as it helps pinpoint the difference between working with images in corporeal mime and in butō.

On stage, the mime-actor is very meticulous. S/he must both be acutely aware of what is going on in each part of his/her body at a given time and must communicate accurately with the audience. "When on stage, we had to be aware how each viewer saw us. To know exactly our position and have each element very precisely, meticulously arranged [...], to realise how all parts of our bodies moved at every moment."

The difference between mime and butō lies in the illustrative character of the former, its emphasis on technique and, first and foremost, the domination of the self.

In mime, you constantly improve the technique and you must always know what's going on. [...] Basically, the thought or idea of what you want to do, what is to appear, comes first. This impulse in the body is a symbol of me wanting, me doing, me starting. [...] There are just a theme, an impulse and the self that directs the energy. This is just the opposite of butō.

Still, Hanff believes that some elements of mime training can be instrumentally used in butō despite the fundamental differences between the two art forms. These elements are, first of all, "spatial awareness and, in effect, an enhanced consciousness of one's body. Moving your arm, you can't forget about your foot. This is very powerful training in being. [...] The same can be said about feeling, about identifying various things in your body."

Compared in terms of other facets of the creative process, corporeal mime turns out to have "some of those facets in common with butō." Besides cultivating the body's plasticity, which enhances body consciousness, what crucially matters is identifying, discovering or "feeling the energy of various phenomena, things, people, etc. in your body."

"The mime training includes elements of several techniques, for example, ballet, acrobatics, gymnastics - broadly conceived physical training." To enlarge her technical repertoire with other means of expression, Hanff studied a variety of performative techniques, mainly dance. Her explorations turned towards practices which she refers to as physical theatre (cf. "Terms"). "What I wanted to do was transcend corporeal mime and contemporary dance."

In that period, Hanff had already embarked on regular individual training sessions, initially in rooms she hired during holidays, where she improvised 
to, mainly, electroacoustic music, constructing sound spaces favourable to explorations of movement. As she explains, this resembled "meditation in motion. [...] Being here-and-now and, at the same time, in another space. Within and without." Hanff believes that it was the experience of slipping into this space that formed a link connecting her earlier practice as an artist with butō.

Back then, Japanese butō dancers, such as Kazuo Ōno, Masaki Iwana and Atsushi Takenouchi, began to visit Poland (cf. Hoczyk 2009a). Hanff started then to formally learn various butō styles and the body disciplines the dancers used. Her butō teachers were Ko Murobushi, Daisuke Yoshimoto, Carlotta Ikeda, Atsushi Takenouchi, Tadashi Endo and Yuko Kawamoto. Yet, she insists that butō is not associated with any instructor or transmission of knowledge. "For example, I found butō for myself even before I formally came in touch with it," concludes Hanff.

Butō dance is always a culmination of individual explorations. There are no universal techniques through the mastering of which the dancer achieves the butō quality. "It's difficult to talk about butō, for either it happens at a certain moment, you cross a threshold and it clicks for you or it doesn't, and that's why it's difficult to learn butō." But this threshold, whatever it is and wherever it lies, is not crossed once and for all: the crossing must be repeated all over again. This is where the butō process dovetails with the individual initiation ritual, as Hanff emphasises. "Dancing, you approach the threshold time and again and catch yourself repeating clichés. You get stuck in a rut and keep repeating the same thing over and over again. That's why I must constantly search for something new in order to transcend my body code."

Butō is a forever renewed process of crossing one threshold after another. The Latin word for "threshold" is limen. It is no coincident that Hanff called the theatre she founded in 2002 Teatr Limen [Limen Theatre].

Liminality and liminoidality were thoroughly examined by Victor Turner (cf. Turner 2008: 94-130; Deflem 1991). In the liminal (threshold) stage of a rite of passage, anti-structures are produced which help the group test potential alternatives to the social and cultural structures in place. In his later works, Turner developed the notion of the liminoid, which is associated with less conservative cultures and, unlike liminal situations, promotes interrogating and overthrowing cultural norms.

The liminoid diverges from the liminal in several ways [...] Liminoid phenomena [...] take place in the complex industrial world; they are the products of individual or particular group efforts and are generated continuously [...] outside the boundaries of the economic, political or structural process, and its manifestations often challenge the wider social structure. (Deflem 1991: 194) 
Liminality involves the transgression, that is, the violation of cultural norms. At the core of transgression is the desire to penetrate the mystery of being. The human being is supposed to experience such aspects of his/her self which are marginalised in rationalised, utility-oriented society. In transgression, the person familiar with the normative system upheld by a given cultural system deliberately contravenes its prohibitions. Transgression leads to the inexpressible, to the limits of language and beyond discourse.

Butō dancers perform social transgressions (breaching social conventions) and bodily transgressions (for example, overcoming habitual ways of moving and responding). To this aim, they employ various techniques which catalyse inner processes. One method for transgressing one's own body involves

[...] over-fatiguing the body; one crosses limits not only in butō, but also in many kinds of training, in Grotowski for example. [...] When improvising, we usually start from reproducing cultural clichés, relying on our well-trained bodies. [...] Such social bodies are completely unaware and, as such, cannot be transgressed at will; it works like a mechanism, an automaton. And either you break it or it dissolves. Using whatever methods you know, you'll seek to erase it, wipe it out, transcend it.

The common, quotidian body must be transgressed in butō improvisations. To this end, "purely physical methods of transcending a certain bodily state" are used. The body must no longer be constituted as "human."

"In butō, the dancer seems to the viewers to have drifted away, but in fact his/ her consciousness is actively engaged in what's going on.” According to Hanff, the state of consciousness typical of buto cannot be compared either to a trance or to being possessed. ${ }^{14}$ In a trance, the consciousness wanders beyond the body which is undergoing the ritual while in possession one's consciousness is ousted by somebody else's (e.g. deity's) consciousness so that the possessed person (his/ her conscious mind) cannot possibly remember the experience. Consequently, butō is neither a trance dance nor a dance of possession. In butō

[...] you give up on control, on planning movement and expression, that is, on using the body to talk about something else, [...] you give up on projecting, planning, control. The process goes on by itself, and impulses appear which direct me, which I yield to. But at the same time, I'm fully aware of what's going on. So it's not a trance, but rather hyper-consciousness. [...] In our culture, the mind is so narrowly conceived, only as

14 Different artists have different views on trance in butō. This difference probably depends on their different definitions of trance rather than on the individual ways in which they experience their body-minds while dancing. Trance will be discussed in more detail in Chapter 5 "The Training Process." 
controlling intellect, and, consequently, giving up on control is identified with a trance. But it's not like that: you remain a witness all the time.

The inner witness "functions like in meditation - that's why butō is a meditative dance form."

Even though butō does not involve trance and possession, it is more than just ordinary improvisation, which is, after all, a relevant element of contemporary dance. It is what happens to consciousness and the mind while dancing that is a distinctive feature of butō.

In spite of what it may look like, improvisation is not always the same thing. For example, it can be based on a particular technique. It can use any spontaneous movements. It can be based on movement that illustrates a given theme. Or it can be an interpretation of something through movement. [...] In such improvisation, the body remains the dancer's body, the private body. And it's not always present here-and-now.

In butō, the performer's identity is temporarily suspended, and even though consciousness serves as an observer and a witness, the body-mind acts with absolute freedom and spontaneity. To explain this process, Hanff recounts her work on improvisation with Sebastian Prantel, which she feels was one "of the most important experiences regarding butō."

[The trainer] tried to reverse or halt the course of thinking and, simultaneously, to free the bodily responses to the situation of being [...]. He used simple methods to activate our unconscious or subconscious - whatever appears when the thinking mind is stopped. At a certain moment, my body, before I could even think about it, did what it was supposed to do, exactly at the moment it found itself here-and-now.

This is what happens with body consciousness when dancing butō. In the experience depicted above, the body is not consciously controlled by the dancer, but she remains aware both of her body movements and of their adequacy.

A similar sensation, described earlier as hyperconsciousness, arises in several religious and spiritual practices. This is why Hanff considers practices of this kind to be very similar to butō.

The spirituality of the body is a concept used also in transpersonal psychology. Physical (somatic) spiritual practices have basically always been something I've been doing. The body is a medium through which I communicate not only with the world, but also with myself: I get in touch with different aspects or levels of my consciousness. This is the field of my broadly conceived practice, and it accommodates Kundalini Yoga as well as butō.

Hanff studies various forms of bodily expression. She engages in meditation through which the mind learns to capture what is going on with the body-mind in space at a given moment. 
In butō, the indivisible whole of the body-mind must be brought to experience what in the East is referred to as the void. To achieve this, dancers work to "kill the body" and grapple with the various layers of our bodies, for example, with what is socially or culturally inculcated in them. That's why the famous zero walk is so vital to butō.

Importantly the (zero walk) technique has a lot in common with the suriashi walk in Nō theatre and the walking meditation kinhin, which is an interlude between long periods of the sitting mediation zazen in Zen Buddhism.

I've always believed that the body is not only a body, a separate thing; that the body is something more and, as such, it holds something you can dig down to. This is where another difference between improvisation in contemporary dance and butō improvisation lies. To generalise, contemporary dance focuses on expression as psychologically understood. Through the body, dance can further explore even more distant spheres - for example, what is call the sacred and also the spiritual transcending psychological mechanisms and crossing beyond the quotidian mind. This is the continuum of experiencing.

Even if the dancer's starting point is his/her own emotionality, "a moment comes when the structure of feeling and knowing the world [...] makes it possible to grasp something more, to see another aspect of reality." Private emotions can usher one into the realm of "universal emotions" (a notion already developed in the Indian theory of rasa). Both butō and dance therapy are methods that serve to open up people through their bodies, which is sometimes easier done "through the body than through the head. Butō is self-consciousness, an encounter with oneself and the world, sensitisation"; this distinctive approach to the body can be employed in dance therapy. However, Hanff believes that butō is more ritualistic than psychotherapeutic.

The most important thing in butō is transcending. [...] That's why butō has more in common with such spiritual practices as phowa [transference of consciousness - M.Z.] and zazen than therapy. The accumulation of whatever emerges from the unconscious is a side-effect rather than the aim of these practices. [...] When it comes to an end, spiritual practice begins - and this is also where butō starts.

The set-up of Hanff's training continues to change. "I don't always train regularly, for giving yourself a total break makes sometimes for better training than holding regular training sessions." The work that butōinvolves is an ongoing process and often takes place outside any formal training hours and venues. Basically speaking, there is no dividing line between everyday life and butō practice. "In a sense, butō is the process of my life, and as such it comprises all my explorations, which sometimes means working with the body and sometimes something completely different. It can be physical training or zazen, meditation experiences." 
Importantly, the difference between butō dance and the tools promoting this state or the butō quality should not be blurred.

Sometimes, I put aside what has been the core of my butō training so far because it's completely used up. Sometimes I put everything on hold. They are all but tools that can be replaced with other ones, and that's why I claim that there's no butō technique as such. For the only technique that could always be retained is the zero walk, and this is, after all, a meditation practice shared by many Eastern traditions. You can't teach anyone butō because there are no exercises distinct to butō. Different dancers use all the techniques they chance upon, $[\ldots]$ from physical, fitness training of the body to techniques focused on body consciousness and energy.

As mentioned above, these are supplemented with physical spiritual practices, ranging from Kundalini Yoga and zazen, to spatial improvisation, to the zero walk. They can all be described as perception training, which helps artists experience various extraordinary states of consciousness. Hanff uses multiple body-mind disciplines,

[...] from running, trance running to what Atsushi [Takenouchi - M.Z.] refers to as amoeba. For example, at the beginning, I very often did just that, and after some time amoeba began to work. When it had done the trick - something had clicked in the body - I stopped using it. Now, I sometimes use it again and, when doing it, I immediately plunge into that quality that has already opened up in me.

This is also how the zero walk works. Many dancers practice it, and it is a common fixture in workshops. "This is another thing you need to go beyond. To capture this quality and be able to plunge into it again and again." Such states and such quality must simply be experienced in the body-mind, for they are the essence of butō. Since they cannot possibly be verbalised, the intellect alone is useless here. "There are no tools with which to understand this process even though records of such experiences can also be found in our culture."

Another tool different butō dancers often use is butō-fu, borrowed from Hijikata. Yet Hanff draws on it only rarely.

I believe that butō-fu is also something to transcend. Instead of images, it consists of surreal and completely illogical clusters, and as such it cannot help dancers construct any image; that is why on hearing $b u t o-f u$, everybody does something else. They cannot be translated into movement directly, but they help develop [...] a certain kind of thinking about one's own body, about what this body can be.

And what it can transfigure into. Butō is a quality, a state of the body-mind. "Butō is not a technique but a certain quality of movement, a sensibility, a state of being. [...] You keep finding butō all over again, nearly every day, as long as you try to answer the question what butō actually is." 
As Hanff claims, butō is best defined ostensively: this is butō. The same movement when performed by a mime-actor, a modern dancer and a butō dancer will have a completely different quality. No one will have the least trouble recognising a butō dancer. The greatest challenge in designing choreography for a butō performance is to achieve this specific quality and, more importantly, to retain the structure of the performance without losing that specific quality.

The choreography of a dance performance is one thing and its direction is another, which Hanff emphasises:

My performances are entirely stage-directed, but they aren't necessarily choreographed, certainly not in full. There are choreographed episodes, fragments and moments, but between these points there's improvisation. That's why every show is different: I dance something completely different within the same structural framework.

This structural framework is stage-directed: "It's intuitive direction, that's what I'd call it." Constructing a performance, Hanff is anchored in movement, and the performance is a bodily, rather than intellectual, project. "I don't rely on images, for that would render a pantomime. For me, butō is still beyond image. As long as I've got an image on my mind, it's expression, and there is a difference between expression and a state of being, being as such."

The underlying idea is that whatever goes on in and with the dancer's bodymind should be emulated in the audience: "Solo performances $[\ldots]$ generate a distilled, intimate situation between the dancer and the viewer where enhanced presence and the process unfolding in the performer's body-mind are transferred onto the viewer" (HTL).

\section{Conclusion}

Hanff regards the body as a basic channel of communication. Corporeal mime, which emphasises transformation and authenticity of experience, prepared her body-mind for dancing butō. Mime fostered her awareness of how the impulse spreads across the body and fleshes out in a particular movement. Mime also made her attend to breathing, which directs energy flows, furnished her with a consciousness of space and enhanced her bodily self-awareness. She has learned to enact body-mind transformations through identifying the energies of various phenomena, things and people in her body. To develop her repertoire of stage techniques, she studies multiple performance techniques, aiming to fathom the ways in which her body works at the energy level rather than to master any of them thoroughly.

Her spontaneous movement improvisations have proved conducive to the same quality that butō dancers seek to accomplish. The most important element in butō is the state of mind associated with crossing thresholds and entering what can be 
called a "meditation" space. Yet, there are no universal techniques to be used by dancers to achieve the butō quality. Artists employ various techniques to catalyse inner processes. At the social level, they transgress social conventions, while at the body level, they transgress their bodily conditioning. They yield to all impulses of "being" and, simultaneously, retain consciousness of bodily movements and behaviours. Hanff has used an array of psychophysical techniques linked to butō (the zero walk, amoeba and, even, butō-fu), but she considers them to be only ad-hoc tools that should be discarded when they have served their purpose. Butō is a quality, a body-mind state, a property of movement, sensibility and a state of being. The key thing in buto is to enhance presence and the process unfolding in the performer's body-mind.

\section{Krzysztof Jerzak: Peak Experience}

In his work as an artist, Krzysztof Jerzak integrates dance, performance, martial arts (aikido) and styles of Eastern gymnastics (aikishintaiso and Noguchi Taiso). They merge into an original, coherent and effective practice in which artistic freedom is combined with body discipline and intense physical effort.

Jerzak met his first butō teacher, Daisuke Yoshimoto, at a workshop organised by the Szczecin-based Kana Theatre (Teatr Kana) in 1999. ${ }^{15}$ Fascinated with Yoshimoto's artistic vision, he also attended subsequent workshops. This involvement coincided with an invitation from Zygmunt Duczyński, the legendary founder of the Kana Theatre (now sadly deceased), to join his team. Jerzak declined. In hindsight, he explains: "They were a strong and innovative theatre, but they didn't pay much attention to body disciplines, and there was no one there whom I could look up to as an authority, focused on the body as I was." Instead, Jerzak started a fruitful collaboration with Janusz Turkowski, the founder of Szczecin's alternative The Stettiners Theater, with which he performed multiple times in Samotni Wędrowcy z Labor [Lonesome Wanderers from Labor], a production (or, rather, a work in progress) directed by Turkowski (2002-2007). He also continued to cooperate with the Kana Theatre, participating twice in the Łasztownia ${ }^{16}$ project: in 2006, he supported the project's Polish-German production entitled W poszukiwaniu tożsamości miejsca [Searching for the Identity of the Place], and in 2008 he took part in its international production entitled

15 Unless otherwise indicated, all information and quotations in this section come from WKJ.

16 Łasztownia is a borough in Szczecin; the name is derived from an old unit of weight and volume representing amounts of ships' cargoes. (translator's note) 
Cztery obrazy $w$ przestrzeni [Four Images in Space]. Even though he did not perform butō dance as such in these projects, in retrospect he believes that what he was doing was indeed similar to body-mind disciplines typical of butō and, as he puts it, "it very much headed inwards."

"In Daisuke's workshop in 1999, I burst into tears, dancing, when we were doing solaris. ${ }^{17}$ I really got on the same wavelength with Daisuke," recalls Jerzak. Then, he took part in other workshops led by Morita Itto, Atsushi Takenouchi, Kan Katsura, Yoki Muronoi, Minako Seki and Imre Thormann.

Paradoxically, Jerzak's first meeting with Yoshimoto inspired him not so much to do butō on stage as to enhance his self-training in aikishintaiso, a practice that harmonises the energies of the body and the mind ( $A i$ stands for harmony, $K i$ for energy, Shin for the spirit, Tai for the body and So for body movement). Practising aikishintaiso

[...] you can notice considerable changes in your body already after a few months of training; the body is stronger, softer, charged with energy and sensitive, becoming a tool for communicating with yourself and others, with the material environment which surrounds people. [...] Aikishintaiso is useful for everyone who wants to start or continue physical exercises, as well as for artists, dancers and actors, because it helps them optimise their creative capacities and express art in its spiritual dimension. (KAAK, Aikishintaiso tab)

Since 1987, Jerzak has practised aikido. Currently, he trains with Patrick Matoian (himself a student of André Cognard Shihan), under whom he was promoted to consecutive degrees, including 3rd Dan in 2012. Since 2002, Jerzak has taught aikido to adults and children, and since 2003 he has run his own dojo. He is also a teacher at the Krakowska Akademia Aikido Kobayashi Hirokazu (KAAKH) [Kobayashi Hirokazu Cracow Aikido Academy].

Aikido is a traditional Japanese martial art founded by Morihei Ueshiba (1883-1969).

Training does not involve rivalry, and teaching is based on the principles of energy balance and respect for the partner. [...] The trainee first learns basic components of martial arts, such as evasion techniques, shifts, grabs and distance. As he progresses, he masters body techniques (taijutsu aiki), such as immobilisations and throws, and weapon techniques (aikijo, aikiken). (KAAK, Aikido tab)

Essential to aikido are mental balance and the fluid application of techniques that have been learned. As the aikido practitioner comes to understand his/her

17 Solaris is a group exercise often used by Yoshimoto in workshops and performances. It consists in building "a breathing sea" of bodies. 
own capacities, force becomes redundant. Besides aikishintaiso, Jerzak also grew interested in Noguchi Taiso, a gymnastic style developed by Michizo Noguchi. Noguchi taught his courses in the same period in which Tatsumi Hijikata worked at Tokyo's Asbestos Studio. Jerzak found out about Noguchi Taiso from the butō dancer Imre Thormann, a practitioner of several martial arts and the Alexander technique. Briefly, Noguchi Taiso is a system of bodily exercises developed in Japan in the second half of the 20th century. It builds, among others, on the Chinese meridian method (cf. Masunaga 1987, 1997), which is essentially informed by the idea of the "unconscious subject" (Mikami 1997: 144). In body activities, smooth movements are preferred and attention is paid to muscular-skeletal comfort. The body is a live lump that easily yields to the force of gravity and is experienced as "a kind of water bag in which bones and muscles and viscera are floating" (Kasai 2001). While the body is generally relaxed, minor tensions are produced in some body parts. The energy flow induced in this way brings about optimum flexibility. The Noguchi Taiso method has been and still is widely used by butō dancers. It helps achieve superb economy of movement by utilising the force of gravity. Its basic exercises improve bodily perceptions, enhance the monitoring of body-mind processes and, thus, help accurately grasp what is going on with other dancers' body-minds.

The multiple affinities and overlaps between body disciplines in martial arts and the dancer's practice include:

Studying the body's natural movement [...], working on the fluid application of techniques which help better generate and control energy [...], defining one's self in relating to another person instead of in clashing and competing with them [...], ways of discovering one's individuality without confrontation. (KAAK, Teksty tab).

And what is the connection between butō and aikido? As the aikido master André Cognard puts it, "the body remembers events in our lives as muscle tensions or deformations which represent, in fact, potential energy" (AAK). Working with the body memory in buto dance is underpinned by the same assumptions: the dancer's body "becomes a text, a record of human experience revealed by movement" (Jerzak 2009).

Jerzak performed on stage as a butō dancer in 2002, when he danced a solo part in a staging designed collaboratively with Turkowski. Originally titled Petersen odkrywanie gestu [Petersen: Discovering a Gesture], the staging mutated into a constantly evolving project in progress, re-named as Szczery? [Sincere?]. Since that time, Jerzak has taken part in several butō-related performance projects (cf. "Performances of Polish Butō Dancers"), among which particularly important is Aite, produced with the Do-Teatr (2008) and combining the traditional martial art of aikido and butō dance. 
Jerzak regards butō as more than just a dance form and a performative art. Butō is founded on an internal process, while bodily practice expressed in dance is a kind of spiritual practice. For this reason, a true teacher of butō (like a sensei in aikido) should be a guide and a moral authority to the dancer. All the psychosomatic disciplines embraced by Jerzak (aikido, butō, Zen) derive from the Japanese tradition. "I don't make the East vs. West division. Japanese culture, which I use, is lively here and so, in a way, it ceases to be Japanese." According to Jerzak, Zen and butō share certain elements: "the unity of body and mind, Nirvana, Satori... Though I don't know how far they [Hijikata and Ōno] actually progressed in butō." Indeed, butō's basic exercise, called zero walk, can be compared to Zen's kinhin (walking meditation), while the process of embodying imaginary wordings is analogous to the process of identifying with the kōan.

Jerzak readily admits that many teachers have shared their knowledge with him, inspired him with their fervour and, thus, made him develop as an artist. But he finds it difficult to name one as his true butō master:

I miss a bit an indisputable authority of the kind I find in aikido, the certainty that I'm heading in the right direction without any doubt. But it may also be a good thing because I'm still vividly alive, searching, inquiring. [...] Perhaps Kazuo Ōno might be such a person for me. I'd very much like to know what point Hijikata actually reached, what point Ōno reached. I mean, how far it can go in the first place. How much did they transcend the form? What does it mean that the ego dies? Can it really happen on stage? What does it mean to be in unity with everything, to be complete and authentic, not to lie to the audience, but to give, to offer up yourself, your soul, your gesture of creation, that thing which is spiritual yet is expressed through the body? In this context, I wonder what point they reached and how far butō can actually go. I keep testing... testing myself.

Jerzak believes that there are many similarities in the explorations of butō dancers and of actors in Jerzy Grotowski's poor theatre. Butō practices resemble, both externally and essentially, actors' practices in the Laboratory Theatre (so-called via negativa). As the ultimate goal is an act of offering rather than the mastery of technical means, the actor is utterly denuded and fuses the collective and the individual in his/her total act, thereby drawing on the mythical. As such, the actor's creative practice unveils the strata of human nature which remain latent or suppressed in everyday life. In the total act, the actor grasps the deepest layers of the mind (Jung's archetypes and Durkheim's collective representations) and relies on the "dialectics of ridicule and apotheosis" (Kudliński 2006) to perform transgression in what can be understood as a specific para-trance. Grotowski emphasised the imperative of bringing together free creative processes (spontaneity) and the enframing constraints of theatrical form (discipline). A similarly tense complementarity pervades butōss relationship between training 
and choreography (i.e. the performance as a form). Other analogies can be found between inner processes that lie at the heart of training in butō and the focus on the performer's organic process in Grotowski's Ritual Arts period. At that stage, Grotowski was preoccupied with the essence of the performer's activities and the organic process unfolding in the doer (the term "actor" was deliberately abandoned).

I believe Grotowski' would have liked to do what Hijikata and Ōno did. [...] Not in any external sense, but he [would have liked] to get where they did. The human being on stage should be able to do it using as few devices as possible. He should meet another human being and offer up a gesture, an act of creation, a touch, an encounter with the most important thing.

Performative practices aim to produce a particular experience, which can be achieved by using both Grotowski's techniques and butō. Jerzak believes that "the poor theatre actors worked on the same experience, but butō dancers have gone a step further. [...] They embody and transcend what Grotowski was looking for." Grotowski's theatre failed to foster further transformations based on experience, while Grotowski himself "sealed himself off from the spectator. He didn't take responsibility for his words," concludes Jerzak.

Practising butō promotes experiencing one's own self and the world in a unique and intense way. It produces extraordinary states by unblocking energy flows.

Energy traverses the body and is clogged at many places, depending on emotions, the organism's psychophysical condition, karma, etc. What will happen to the mind when this energy is unblocked? Initially, we can be inundated by emotions, which is rarely a pleasant thing to feel. We must face it, let go of it, let it happen. Later, we can see that whatever we do and whatever happens outside, the mind calms down [...]. We use some of the body's energy as a springboard to touch something beyond the body. This is the starting point.

For this purpose, various techniques are used which, in this case, can be called butō techniques. But, ultimately, "we do not know whether we make butō or, perhaps, butō makes us. Certainly, it can be viewed in this way." These techniques serve as a preparation for processing emotions, such as fear, anger, joy and sorrow.

To be a butō dancer on the stage, you must settle your affairs and patch up the holes so that you don't spew your histories and emotions on people, but use the performance as an opportunity to address difficult issues [...]. There must be a balance between unloading and presence in space.

Butō employs psychosomatic techniques which can serve as tools for such cleansing. Jerzak insists that for butō dancers the phase of workshop, studio or laboratory practice in isolation is absolutely vital. 
This is where we handle what hasn't been handled yet, issues which are often bound up with our unexpressed emotions. Workshop practice helps dig down to them and bring them to expression in a gesture, in dance. The emotions tend to be very strong, and because training is not for display, they can be easier revealed. A moment when their intensity subsides. [...] This also involves working on the ego in the broad sense. As a sole of a shoe wears off after some time, so the power, or "shadow," of the unconscious runs out. This happens because we switch on and let in light, consciousness, where they haven't come yet. When we accept this something in us, it no longer paralyses us and isn't unconscious and threatening anymore. This is a new and liberating experience for us.

This is one reason why butō works perfectly as a form of dance movement therapy. "The most important aspect of butō dance is getting closer to yourself and other people, developing, enrichment," says Jerzak, while a participant in the project he coordinates ("Integracja w terapii tańcem"/“Integration in dance therapy") adds: "Butō dance has taught me to externalise hidden feelings, to show emotions. Butō is not only body training but also training in understanding your own soul" (Chanczewska 2004).

Every somatic discipline which respects the human being as a psychophysical, emotional and spiritual being and values all these aspects equally will be beneficial for the individual's emotional state. Mental and emotional problems are always linked to a stoppage of energy in the body. We put this stagnated energy in motion and obtain a positive psychological outcome. I've noticed this pattern both in aikido and in butō.

Workshop training consists of a physical part (warm-up) and psychophysical exercises, including butō-specific techniques which develop into improvisations. The subsequent phases alternate and interpenetrate smoothly.

Jerzak's warm-up is comprised of aikishintaiso exercises, which serve to stretch joints and warm up muscles. He also employs Noguchi Taiso, in which the force of gravity is used. For example, the body in auto-balance (cf. "Terms") is jerked off balance and "dropped," with the upper part flopping inertly. The depth of the tilt depends on which joint or vertebra controls the movement. The body is brought back into the erect position in a wave-like motion starting where the impulse is born. Counterintuitively, the technique takes a lot of physical effort. As mentioned, Jerzak heavily relies on aikishintaiso and employs, for example, its five basic poses. The participants arrange their bodies in aikishintaiso-derived patterns explained in detail by Jerzak and then break these postures, following their inner impulses. In this way, the energy accumulated in bodily setups is set in motion, while their symmetries fall apart under the pressure of individual, internal stimuli. As the structure is unhinged, movement is saturated with an interplay of oppositions. The exercise can result both in frozen, grotesque figurations and in dance born from disruptions of symmetry. This kind of workshop practice 
bred the idea of choreography for Aite (2008), which synthesised the traditional martial art of aikido, aikishintaiso and butō. In this production, Jerzak proved that body disciplines used by dancers as a warm-up, stretching exercises or relaxation exercises could form the texture of a performance. Aite brings together entirely different body disciplines. Aikido is founded on patterns of pre-arranged movements which "work" only if they have been repeated multiple times, and, as such, it represents "a kind of enclosure in a form." Given this, it is associated with the conscious, the mental and the patterned. Butō, on the other hand, involves "opening to a form beyond a form" and relies on individual, unconscious scripts and archetypes, which tend to be rejected by consciousness.

The warm-up is followed by exercises aimed at accustoming the body to a space and to the presence of other bodies and objects. For example, workshop participants play in pairs with an imagined, live energy cloud which changes size and shape between them. They also establish contact by means of visualised antennae protruding from various parts of their bodies. The same antennae can turn into ropes hooked up in the sky which manipulate the body like a puppet which has no will of its own.

Butō's central technique is the zero walk, i.e. neutral step, which is quintessentially about a specific perception of the world which can be achieved through diffused vision. Dancers move by gliding, placing the entire foot on the floor and aware of its contact with the surface. This kind of gait derives from the way the shite, the main actor in the Nō theatre, moves across the stage (suriashi walk; cf. "Terms"). The movement can start from the "zero position," or auto-balance mentioned above, in which the body is naturally relaxed but at the same time stands firmly on the ground. Such movement can also ensue from exercises revolving around the experience of differences between natural walking and neutral walking ("zero walk"). Natural walk is our "everyday" step slowed down nearly to the point of motionlessness, while neutral walk denotes fluid movement across space with our eyes not fixed on anything and the mind "focused in diffusion." Colloquially referred to as "zombie," such movement can be developed in several ways. For example, the person doing the zero walk must respond to impulses (tactile stimuli) from another (leading) person. In this way, movement is derived from an external impulse, while the body becomes a medium channelling the flow. Another possibility is for the dancer to move following his/her internal impulses, as is the case in the aikishintaiso five-poses exercises. Also, people moving in the zero walk can come across each other and react mutually.

The most important stage of buto workshop activities is practice in embodying (incarnating) images. The body in auto-balance or in the zero walk is a "transparent 
receptacle" becoming that which fills it. The aim of butō training is transformation. In his workshops, Jerzak proposes certain images which the participants are expected to embody. Such images include, for example, a blooming and wilting flower, water flowing at various paces and life-cycle moments, ranging from the embryo, to birth, growth and development, to dying. Every workshop participant is supposed to find in his/her bodily and mental experience an individual and unique representation of a given image; this produces his/her walk and dance.

Practices such as the zero walk (serving to mute the colloquial mind by diffused focus) and image-embodying (serving to discover the yet-unknown qualities of movement) can be regarded as butō techniques.

They aren't an aim in themselves; rather they're instruments you use to strike chords in yourself which you may have never touched before and to express this in body gestures, realising at the same time that the chord is indisputably there. This results in becoming more complete and richer.

Using an array of techniques, the dancer learns to achieve a state of intensified presence. "You can enter the space of your body and mind and be more reconciled with yourself and with others." The artist must delve into and inquire about what s/he is experiencing: "What is it actually? What access do we have to our bodyminds? What is it that happens then in fact? What does it mean to us that we touch it, that we experience it?" Butō is a form which can help us demonstrate our own experience of the augmented body-mind.

Such practice brings the dancer closer to an experience which can be called peak experience [...] or trance. The experience has been triggered by [the already described] body disciplines: by extracting a lot of energy from the body and externalising it. Without that energy, we can't possibly experience this state of mind. It is similar to meditation: we learn to be here-and-now by doing things very accurately and to the end, focused on what we're doing. In unity with what is going on in our head and in our body.

The changed or enhanced perception helps retrieve information encoded in body memory, while somatic experiences and emerging images are the source of movement and dance. Workshop and studio practice is an entirely different thing than the stage production in that the former is a process of opening up. The dancer improvises and builds movement in constant interaction with an internal stream of images and sensations: "When the laundry has been done, the inner and the outer are no longer divided by such a chasm." When the dancer releases the repressed elements in laboratory and studio practice and embraces energy flows, s/he can use this experience to begin "to create, give direction and juggle in order to show creatively and productively the dark side of human personality. The spectator should be affected by our authenticity and ease of performing." 
The dancer lays bare the part of him/herself in which s/he is most at ease with him/herself, in which "the gaze and perception are at their broadest. This is the space I show to the audience. [...] For I think that this is the most difficult and most precious thing." Jerzak views training as a process of exploration, while he sees the performance as a test of authenticity and openness. "Today, when I prepare for a workshop or develop a performance on my own, I do it differently than I did it, say, eighteen months ago. This evolution pushes me to create a new performance." Such differences notwithstanding, designing a performance invariably involves a deep, internal process.

Developing a performance is construction and destruction. The performance is, so to speak, a product of it. What is redundant has been cut off. I want to show that which is most valuable, most precious and most difficult both physically and mentally. This shows in a kind of concentration, in other words, in opening to what lies deep down in our consciousness, in the mind and the soul.

Movement which emerges as a result of a continually repeated improvisation process can provide the basis for choreography. In the performance, the dancer reproduces this pattern:

Getting into a movement from the outside, we can stir up what it causes inside. If we're focused on it (here-and-now), if while making this movement we don't think of the next one, this movement will continue live and vibrant. If I know in advance what the final effect will be, the thing is dead from the start.

Emerging experiences help construct only a partly structured or repeatable stage form. "Hijikata worked with choreography, Ōno with image, and movement itself was produced spontaneously. I find the latter school more appealing." The key factor is sustained interaction with the live texture of imaginations and sensations. "A butō performance as such resembles a ritual. You strive for a peak achievement, experience through producing the frames [of the performance]." Because the performance is grounded in experience, it will be different each time it is performed.

There are certain points in the performance through which I pass (as Stanislavski did in his theatre), I undergo a physical, emotional and spiritual process to get from one point to another point. I am supposed to perform one or a few activities in a pre-arranged way, but between them there's room for something unplanned to appear.

Jerzak emphasises the flow between the dancer and the audience and the imperative of exchange - of "the transfer of gifts." The performance arises from a need to give, to offer up something "[...] because it may be that we get something from others because we give. [...] I believe that it [butō] should be useful and beneficial both in workshops and on stage. That's the role of art." 


\section{Conclusion}

Jerzak's primary practice is aikido. The martial art is based on the fluidity of learned techniques, mental stability and the recognition of one's capacities, which makes recourse to force redundant. In aikido, as well as in aikido-derived aikishintaiso gymnastics, the emphasis lies on firm groundedness (stability and contact with the ground), manipulation of energy circulation in the body and a resolve to understand how one's mind functions. Jerzak also employs elements of Noguchi Taiso, i.e. exercises which promote smooth movement and muscularskeletal comfort. These body-mind disciplines can be an effective foundation of butō dance.

According to Jerzak, central to butō are internal processes while bodily practice expressed in dance is an equivalent of or a complement to formalised spiritual practice. Practising butō fosters a unique and intense experience of one's own self and the world by unblocking energy flows, which helps achieve extraordinary states.

Drawing on his own experiences, Jerzak devised a formal training routine which consists of a physical part (warm-up) and psychophysical exercises, including butōspecific techniques which develop into improvisations. In the warm-up, Jerzak uses aikishintaiso exercises (serving to stretch the joints and warm up the muscles) and/ or elements of Noguchi Taiso. Basic aikishintaiso poses are also used, which can be transformed into grotesque figurations or dance under the influence of inner impulses. The warm-up is followed by exercises that aim to familiarise the body with space and with the presence of other bodies and objects. One of Jerzak's very important techniques is the zero walk, i.e. neutral step, which involves very characteristic movement combined with wide-angle vision. The starting point is provided by the zero position derived from auto-balance. This is supposed to bring the body-mind into a special state of "diffused focus," which can be viewed as peak experience, trance or meditation. This state makes it possible to start embodying images and, consequently, implementing butō's most important process, i.e. bodily and mental transformation. Induced in training, these processes aim to ameliorate emotional ferment and thus to make space for creation.

\section{The Amareya Theatre: The Body in Crisis}

The Gdansk-based Amareya Theatre (Teatr Amareya) was founded in 2003 by Katarzyna Julia Pastuszak, Agnieszka Kamińska and Aleksandra Śliwińska. Julia Pastuszak, the theatre's spiritus movens, is a dancer, director, choreographer, researcher and the author of three books on performing arts. Tracing the Essence 
of Odin Theatret, her first study, which sprang from the Odin Week in Holstebro, Denmark (2003) where she came in touch with Eugenio Barba's Odin Teatret, discusses performer training within the framework of theatre anthropology. She wrote her second study, Wprowadzenie do butō [An Introduction to Butō], under the supervision of Dr Beata Kubiak Ho-chi, and in 2010 she completed her doctoral project on "Ankoku butō" Hijikaty Tatsumiego teatr "ciała-w-kryzysie" [Tatsumi Hijikata's "Ankoku butō": "Body-in-Crisis" Theatre], which analyses the classic butō of the genre’s founder Tatsumi Hijikata. Agnieszka Kamińska is a dancer, singer, educator and voice instructor; she also teaches at voice-andmovement workshops for young people and adults. She has studied body and movement disciplines under several eminent educators; she also has a background in vocal techniques and voice therapy. Aleksandra Śliwińska is a dancer. She has acquired and developed technical skills and experience in contemporary dance, improvisation, contact improvisation and expressive dance at many international dance workshops. The three artists share a fascination with practical aspects of theatre anthropology and an interest in butō.

The choice of amareya for the name of their theatre is revealing about the dancers' approach to artistic practice: "In old Japanese, amareya means heroic devotion, unconditional sacrifice" (HTA). Pastuszak had the ethos of complete commitment instilled in her by the actors of the Odin Teatret, whose training method she learned in practice during the Odin Week in Holstebro.

This was a breakthrough moment for me because I saw how terribly serious those people were about their work, that they had a code of conduct in theatrical space and deeply believed that the space must be pure, that it and our work must be respected. Simply a strong actor's ethos. The Japanese are the same. (WTA, Pastuszak) ${ }^{18}$

Founded in 1964, the Odin Teatret has developed its training method over many years of collective training and stage practice under the leadership of Barba. The method has been regularly fed by experiences acquired at meetings of the International School of Theatre Anthropology (ISTA), which have been held regularly since 1980. In the early 1960s, Barba studied under Jerzy Grotowski and described his experiences in Land of Ashes and Diamonds: My Apprenticeship in Poland (1999). The way the Polish theatre reformer approached the body and the mind had an immense effect on Barba's further explorations.

Training offered in workshops implements in practice the principles of the actor's art as defined within theatre anthropology.

18 Unless indicated otherwise, all quotations in this section come from WTA, Pastuszak. If another artist is quoted, her name follows WTA after a comma. 
Certain rules can be learned from texts theoretically and quickly grasped. Yet to develop a physical awareness of what each principle implies, for example, what it means to be off balance and how opposing forces work, takes a very long process. Such awareness is a highly important tool in itself, but the principles must also be consciously applied on stage or in training.

In the ISTA sessions, actors and researchers tackle the key problem of the actor's stage presence. Theatre anthropology studies biological and socio-cultural aspects of the performer's art. It investigates the ways of "using the body" employed in various performing traditions, that is, it delves into the biological and physiological level of stage-acting, which tends to be neglected by traditional theatre studies, which are focused on the psychological and semiotic analyses of theatrical impact. Attending to its own concerns, theatre anthropology resorts to such notions as "pre-expressivity" and "energy." The former refers to the performer's "strong presence" in the show, which requires the mastery of techniques serving to achieve specific energy concentration. It is the ability to accumulate energy that attracts the audience's attention to the actor even before s/he begins his/her performance.

Pastuszak suggested that Kamińska and Śliwińska used the type of training she had done at the workshops in Holstebro. "In our training sessions over there I found that thing - energy, the sacredness of work" (WTA, Śliwińska).

The actor's ethos she preached was contagious. We trained together even before our theatre came into being. [...] Each of us felt the need to create something of her own. The dance community in Gdansk was firmly established by that time [...]. At the beginning, the audience were confused about what we were doing. The first show, Sen Ikara [Icarus' Dream], was a bit of butō and a bit of contemporary dance, with our faces painted white. They asked: what is that? Something between mime theatre and ritual. (WTA, Kamińska)

In their work, the Amareya Theatre build on the training method of the Odin Teatret actors and the ISTA investigations. The dancers use a set of exercises composed of "butō, physical theatre techniques, contemporary dance, the Martha Graham technique, African dance, singing, yoga, Kalaripayattu and psychosomatic relaxation techniques" (HTA). Śliwińska recalls: "We also tested various techniques of contemporary dance; we would practice together after workshops" (WTA, Śliwińska). "Movement in contemporary dance is based on the body's natural dynamics."

The technique developed by Martha Graham [a modern dancer] takes as its starting point the dancer's recognition of the motor capacities of his/her body; this is where consciousness and control of muscles and joints in each motion comes from, and the point is that they must function within their natural limits. (Tyborowska 2009) 
In contemporary dance, the dancer's individual limitations are taken into account, while the dancer's responsibility is to understand his/her body's anatomy and kinesthetics through practice. Movement is based on a constant interplay of opposing impulses. The dance technique is supposed to serve first of all as a tool of expression. The most important aspect of dance is the spontaneous and intuitive expression of the dancer's sensations and feelings in movement. This happens through "controlled contraction and relaxation of muscles, with movement originating from the centre of the torso (located around the diaphragm) and heading outward" (Tyborowska 2009). The diaphragm area is the body's most important region in many psychosomatic techniques, meditation modes and Eastern martial arts (in Japanese the point is called hara). An important role is also attributed to improvisation, which consists in "putting the trained body to individual uses, unfettered by fixed schemas, and in creating new dance combinations" (Tyborowska 2009).

Improvisation and exploration of the possibilities offered by the body are also building blocks for physical theatre artists. They question the utility of conventional patterns and codes of movement; instead, they rely on the natural human way of moving to generate a new physical idiom in each project.

In its purest form, physical theatre makes the human body into the major and fundamental sign in the transmission of meaning and communication with the world. [...] In such a context, we talk of an artist, an actor or a dancer (a performer in English) who thinks with the body and, consequently, embodies the mind. (Mond-Kozłowska 2003)

The key elements include physical risk and confrontation with oneself. Choreography/direction only complement them (Rea, qtd. in Fret 2000: 132). "In this framework, close physical contact is absolutely natural and indispensable. [...] The body contemplates its presence through the presence of the Other; the Other's existence is a necessary condition of the human being's self-determination" (Fret 2000: 134).

The three artists have also studied contact improvisation (CI), a technique serving to enhance group improvisation skills. CI attends both to the physical components of movement and to the state of mind, to complete presence hereand-now, which makes it possible to react creatively to whatever is happening at a given moment. CI is a product of a symbiosis of Western dance and movement traditions with the Eastern approach to working with the living system of the body-mind. "Sometimes wild and athletic, sometimes quiet and meditative, it is a form open to all bodies and enquiring minds," as Ray Chung characterises CI. The "small dance" formula created by Steve Paxton, the founder of CI, resembles the ways in which butō applies body disciplines and stimulates the imagination: 
"small dance" $[\ldots]$ the small reflexive movements that happen while standing still. $[\ldots]$ We worked all day, practicing [...] the small dance, during which Steve suggested different images of the skeleton, the flow of energy, the expansion of lungs, identifying small sensations [...] Steve led us in standing still, the small dance. (Smith 2006)

This resembles practice in embodying mental images in butō.

The Amareya Theatre dancers also used elements of African dance in training. The philosophy of African dance highlights the foetal experience,

[...] for the foetus lives in a world saturated with inner sounds, listening to its own and its mother's heartbeat. Before birth, the child lives in an overwhelming world of syncopal sounds. This environment of sounds and rhythms which we inhabit even before we are born indicates that sound and rhythm lie at the beginning of life. (Pawlik 2008: 32-33)

Butō dancers are similarly interested in personal "pre-history," i.e. in foetal life. First, the human being carries the entire universe within, as the developmental history of the human species (phylogenesis) is encoded in the body's neural system. Second, the division into the self and the external world is not yet part of a foetus's consciousness; hence, the embryo/foetus is one of the most important mental images in butō.

Studies of African bodily disciplines use the notion of somatic modes of attention (cf. Csórdas 1993), which designates entrenched somatic ways of reacting to sensory stimuli. Because the body constantly interacts with its environment, it cannot be regarded as independent; rather, the body and the world function as communicating vessels. The body comes to know the environment through the organism's inner states and internal receptors. Bodily sensing and mental knowing are inseparable, while feeling with one's "inside" is a source of knowledge about the world. In Western psychosomatic terms, the phenomenon is referred to as "somatic knowledge" or "body wisdom." In this kind of cognition, sensory appreciation, emotions and personality predispositions are interwoven and kinesthetics and speech belong to the sensory sphere. African dance has a cognitive function and additionally is "a great stamina exercise. Very good for the centre" (WTA, Kamińska).

Sensing and knowing are similarly unified in the Body Mind Centering method (BMC), which the three artists also learned in workshops. In BMC, the focus is on

[...] identifying, articulating, differentiating, and integrating the various tissues within the body, discovering the qualities they contribute to one's movement, how they have evolved in one's developmental process, and the role they play in the expression of the mind. (Cohen 2012). 
The most important thing is being fully conscious of one's body and all its layers, starting from cells, to the skeleton, ligaments, muscles, organs and glands, to the nervous system, muscles, fascia, fluids and skin, and finishing with the interconnections of these systems. The method develops mindfulness and awareness of how movement originates from various levels of the body. BMC employs, among others, primary movements.

Underlying the forms of our expression through the body systems is the process of our movement development, both ontogenetic (human infant development) and phylogenetic (the evolutionary progression through the animal kingdom). (Cohen 2009)

Butō dancers often refer to the body's ontogenetic and phylogenetic memory.

All these forms of bodily practice combined with dance and movement experiences help understand how particular techniques can be employed to use the energy available in the body. Training based on the ISTA-inspired exploration method aims to achieve the state of pure stage-presence,

[...] the performer's psychophysical presence. We want to go back to the primordial to the body, its limitedness and infinite creative potential, in the belief that the actordancer's total presence radiating from beneath the costume of form and technique has the power to move the audience and lead them deep into themselves. (HTA)

Detailed and discussed by Barba in his founding texts of theatre anthropology, the basic principles and mechanisms of the performer's art also appear in butō. "All butō dancers of Hijikata's school are very concrete in their work. The workshops of Yumiko Yoshioka, Ko Murobushi and Yukio Waguri are precisely structured, and the principles Barba talks about are undoubtedly there." This concerns first of all the alternations of tension and relaxation, the interplay of opposing forces and tipping the body off balance. Butō means putting the body in a crisis situation time and again, which the genre's founder Hijikata emphasised repeatedly. The Amareya Theatre artists have adopted this as their motto and consider Hijikata's students and heirs (e.g. Yumiko Yoshioka, Seisaku and Ko Murobushi) to be their most important teachers. The have also studied under other dancers, such as Morita Itto, Mika Takeuchi, Minako Seki, Marie-Gabrielle Rotie, Yuri Nagaoka, Daisuke Yoshimoto, Joan Laage and Atsushi Takenouchi.

The three artists believe that butō has changed considerably ever since Japanese dancers came to Europe and the US. Learning particular techniques without fathoming their cultural context and the meanings unconsciously encoded in movements is like "learning elements of classical ballet" (WTA, Kamińska). One may learn them, but that does not make one yet a ballet dancer. For this reason, the Japanese dancers modified training formulas in Western countries. 
Japanese dancers [...] transformed training processes to adjust them to European students. Perhaps, they wouldn't work with students in Japan in this way at all; perhaps the workshops wouldn't be as structured, with the warm-up first and other elements following. In the West, students expect an intellectual order, and this is what dancers are quite articulate about. For example in Yukio Waguri's workshop [in Japan], we first talked sitting on the floor, then he started drumming, and dancing began. Yoshito Ōno taught his workshop in a similar way [...] We are different than the Japanese, more intellectual. We need a structure to get steeped into something. [...] In Japan, you don't get all things explained to you or described, like now we'll do this and then we'll do that. Waguri [...] wanted to transmit Hijikata's legacy, and created Butō Kaden. He didn't talk so much about what we were going to do, we just did that.

What is actually the essence of butō? Pastuszak has no doubts about it: the essence of butō lies in getting the body into crisis time and again. "I can ask myself what it is I miss that I can't call this thing butō yet/already and what makes me conclude: yes, that's certainly it. Because I embrace Hijikata's butō, this thing is putting the body in crisis all the time. That's what I'll be looking for." Pastuszak means not only the technical and physical devices, such as pushing the body off balance or manipulating tensions, but also designing costumes and lighting and arranging the body on stage so as to,

[...] keep the body indeterminate. For the body not to be the body all the time. To foment situations in which the audience ask: what is it? What is emerging out there? Appearing? Hiding? What isn't there? Transforming the body concealed under the costume, the process of pulling the audience into this body's world.

In butō, the body is continually transformed, deformed, altered and disembodied, but the dancer enacts all these processes consciously. Given this, butō can by no means be regarded as trance dancing, for the dancer is fully present here-andnow and never loses the sense of reality. Butō tends to be associated with trance probably because, in training, butō dancers state repeatedly: "you're not there." "I'm not there, but not in the sense of fundamental awareness. My everyday self is not there. My controlling, deciding, calculated self is not there" (WTA, Kamińska).

[The dancer] imagines an image and embodies it, heading in a given direction. This image is joined by additional images, words and also music, to which you respond. [...] Because so many elements co-exist on which you must focus [...] attention is dispersed; hence, I guess, these associations with trance. [...] You can indeed get yourself into a trance and use it ritualistically, but this process involves particular stages (getting into a trance, the trance, getting out of the trance) and physiological reactions. In butō, like in other forms of physical theatre, borderline trance states do appear, states of very intense being. [...] But rather than a lack of awareness, it is an entirely different awareness. 
Ideally, awareness should not control what is going on with the body: "If an image appears, let it move your body. Don't think - don't control - don't stage-direct." This means yielding to the flow. The butō dancer finds him/herself in "a meditation state. It is a different form because it takes place in a different, extraordinary situation. But the dancer's duty is to remain conscious" (WTA, Kamińska) and sustain his/her inner active observer. The idea of eyes gazing from above or from the side constantly recurs in Hijikata's butō-fu. Butō is based on the flow instead of on an aesthetic effect which tends to result from the confluence of the audience's needs and the dancer's technical possibilities. Discrediting "dance for display" was a critique targeting the commercialisation of Japanese theatre in the second half of the 20th century. Hijikata wanted dance to serve as a tool for processing reality and a support in a crisis situation. This idea was one of the pillars of his philosophy from the very beginning of butō.

What does training look like in the Amareya theatre? The artists meet three times a week for a few hours and have very intense training sessions. "The body gets so relaxed that it's easy to start imaging or practising butō. For this purpose, we use sequences of African dance, Kalaripayattu and even running" (WTA, Kamińska).

This resembles the way in which Daisuke Yoshimoto, Ko Murobushi and Yumiko Yoshioka train: "At the beginning there's a hard workout, intense warm-up with the body all strained. This releases the body and prepares it for further work" (WTA, Kamińska). The butō training sessions in which the artists have taken part are very similar. Analogies can be found not only in the external likeness of the exercises, but first of all at the level of principles explicated in theatre anthropology. "If you analyse each training session in terms of particular exercises, you'll see that each exercise activates another quality, that is, in each of them you work on another principle, another aspect or another area of the body."

Dancers who teach workshops use different ways to make the body relaxed and prepared. For example, Mikami Kayo relies on massage and self-massage, Daisuke on push-ups and fatigue, and Atsushi on Noguchi Taiso. We employ, for example, African dance. The common element is leading the participants through images and various states, but warm-up routines differ widely. However, their ultimate goal is the same: readiness, presence, relaxation of the body, preparation for embodying imaginary wordings, fluid movement and tensions. The aim is the same, the centre is the same. We simply use different tools. (WTA, Kamińska)

Since the very beginning, the training routine of the Amareya Theatre has consisted in smooth transitions from one element to another. For example, gymnastics transitioned into African dance, the pace of which gradually slowed down to segue into an animal's movements. Exercises have changed as a result 
of workshops with various Japanese butō dancers. "The things that had earlier been part of the training cycle were transforming in this or that way, taking on a new quality."

For example, the first part of workshop training with Yoshioka focuses on the centre. Various concrete physical exercises are used, for example sitting and bouncing on the sitting bones, followed by hip eights, with the focus on the centre all the time. Ko Murobushi does the same but standing rather than sitting. The following exercises serve to get the dancer off balance.

"It is a physical way of awakening the imagination. It's the imagination transposed onto the entire body, onto each cell" (WTA, Śliwińska).

The aim of physical training is to prepare the body for improvising and working with images, a process in which the imagination and the body cooperate. They explore "how images affect movement, how they awaken it." "My body transforms in relation to the assigned image so that I feel I'm something or somebody else, I disperse in space or condense into a stone." For the Amareya Theatre artists, this process is usually catalysed by word sequences. In the improvisation stage

[...] image embodying appears, but we not only work with particular phases of Hijikata's butō-fu, but also build our own sequences. Sometimes the improvisation is so interesting that the word sequence which contributed to it is repeated. This verbal structure replaces choreography.

The person in charge, usually Pastuszak, proposes images that suit the process she sees. "All the workshops we've participated in have had common points, or recurring images [imaginary wordings]" (WTA, Kamińska). For example, one image popular with butō dancers is an image of worms swarming on the body and getting inside it through orifices and skin pores, derived from Hijikata's butō-fu. "I really felt it in these exercises. You can't do anything about these worms moving your body. But when a pause, a freeze comes, the worms disappear and that body returns, either empty or filled with something" (WTA, Sliwińska). The images are not closed entities "like an icon, you can search inside them" (WTA, Kamińska).

In butō improvisation, private emotions are not involved. "In these images there are hardly any emotions. There are processes which take place not only in the body, but also in various beings, objects, creatures that's why private emotional states don't matter, they are out there, so to speak."

At the same time, "there is cellular memory in the body, everything accumulates in the body: tensions, childhood experiences, traumas" (WTA, Kamińska) and, while dancing, one comes in touch with these accumulated resources and integrates them through movement. In this way, one recovers the suppressed or forgotten part of the self, which can then be creatively used in the most important process, i.e. in 
transformation. For example, during the Butoh Barter 2005, Atsushi Takenouchi "evoked strong images: the child, the cripple, the sick" (WTA, Kamińska). Pastuszak recalls: "I was down after the performance, it smashed me. It contained improvisations based on experiences very painful to me." Even if the choreographer uses universal images, the bodily experiences can be very personal. However, it is by no means the aim of training to evoke and re-live private emotions. Emphatically, what matters most is using such experiences creatively as the texture of the performance instead of going through a therapeutic process.

Working with fear was an important stage for the Amareya Theatre dancers. When you engage with fear-based structures and terrifying, dark images, "you feel like in a black tunnel, you are genuinely scared. You don't know what will happen next. For example, you hear there is an arrow drilling your eye. You really feel preparedness then" (WTA, Kamińska).

Another technique involves "prolonging, protracting the situation in which the body finds itself. This makes the body very focused and sensitive" (WTA, Sliwińska). However, precedence is given to working with the centre, balance, jolting off balance and overcoming one's own automatic reactions. "Such discontinuity is a practice in surprising yourself. This is the legacy of Odin and Grotowski, the imperative of going beyond somehow. Beyond the balance of reality." Pastuszak believes that choreographers who do not do butō also sometimes use such methods and combine the imagination and words with movement. But not all practices of this kind can be called butō. The trademark of butō is putting the body in a crisis situation.

In their further creative pursuits, the artists build several different structures. "The sequence, the structure, the para-choreography come into being in this way" (WTA, Kamińska). Technique and structure serve to continue the show even when the dancer is extremely moved emotionally when getting on the stage.

This is the question of presence. If you've mastered basic principles, you're able to transpose your inner flutter onto a structure. Because the body is my mainstay, my safe island. And the image itself and the movement that appears in the transformation process give me a sense of security. During the performance, I enact what is inside me. The structure remains the same, but my body's movement within this structure will be different.

Certain points of reference are fixed, but the remaining things - what happens between them - depend on a number of factors: events, emotional states, various stimuli. "The body is well trained, it can respond to words, images and can return to them at any moment. This is simply movement memory, but there's also room for latitude and explorations" (WTA, Śliwińska). 
During the performance, a situation or a body-mind state experienced in rehearsals can be called back.

It's already been inscribed in body memory, this is not just intellectual remembering. It's a state of the body, you generate it in you through training, you learn how to enter it, this image. For example like in our latest staging [Ocaleni/The Saved], where I have a very dark episode, and I use in it the dark tunnel from a few years ago written in my body. (WTA, Kamińska)

On stage, the most important thing is candour and genuine bodily transformation. "For example, we play Inskrypcje [Inscriptions] very close to the audience, and this is an entirely new quality: it's impossible to escape into a mask or a technique. When there's distance, you think also in aesthetic terms: of the stage, of the whole." Whether the dancer shows his/her face to the audience, looks the spectators into the eye, composes movement sequences having in mind the viewers' presence or deliberately turns away, ignoring the audience, depends on the dancer and can differ from performance to performance.

Butō can be shown as a stage production or an improvisation, but it "can also be private dance, a body discipline" (WTA, Kamińska). What matters is "body consciousness, truth of the body (or in the body) - butō helps you yield, you are in your body. This concerns the whole of life, every experience" (WTA, Kamińska).

In Polish theatre studies there is no literature in which the phenomenon is explained as a whole. There is a French book with $b u t o \bar{s}^{19}$ - the plural number - in the title, so simply let's give ourselves a chance! Either we'll be constrained by some conventions and ideas about butō, or we'll create it ourselves based on what we know.

\section{Conclusion}

In their creative practice, the Amareya Theatre artists rely on the principles of the actor's art as developed by theatre anthropology and the Odin Teatret. Training includes such elements as alternating contraction and relaxation of the muscles, the interplay of opposing forces and becoming off balance. Multiple techniques help work with various energies in the body. Still, the key element of buto practice is putting the body in a crisis situation. This requires getting rid of the everyday self, which is chained to a cultural matrix. Consequently, butō training essentially aims to disrupt automatic movement routines. As artists grapple with themselves, their attention can become dispersed. Hence, butō is often associated with trance, yet such an interpretation of the performer's state of awareness seems mistaken:

19 Cf. Aslan, Picon-Vallin, and Amagatsu 2002. 
although the performer often finds him/herself in a meditative state, s/he cannot relinquish his/her inner active observer.

Training starts with an intense warm-up which relaxes the body and prepares it for further practice. Each exercise activates another quality as various principles, aspects and areas of the body are involved. The focus is on working on the centre, balance and pushing the dancer off balance, which mobilises different properties of the body. In this way, the tool which is the dancer's body-mind is supposed to be primed for improvisations and engagement with images. In this process, images (imaginary wordings) are embodied and, consequently, initiate movement and transformation. At this stage, the Amareya Theatre artists also employ images proposed by Hijikata, though they design their own image sequences as well. Rather than processing private emotions, they attend to processes that take place in the object: the body and, also, various beings, things and creatures. The bodymind undergoes constant transformation, which results in sequences, ministructures and para-choreographies that are used later to design the framework of the stage performance.

\section{Tomasz Bazan: Body Form Movements}

In 2004, Tomasz Bazan initiated the establishment of the Maat Project Theatre [Teatr Maat Projekt] in Lublin. The theatre's aim is to "attempt to find and create a pure language of the body" (HTMP) through "exploring broadly conceived body form movements" (WTB).$^{20}$ In their laboratory and stage practice, Bazan and other actors of the Maat Theatre (cf. HTMP) draw on their experience in visual and performative arts. They employ various body disciplines and contemporary movement and dance techniques to seek "energies that put the body's texture in motion. [...] Over the years, the Theatre has presented a number of projects: stage productions, happenings, collective installations and performances [...], forging its own signature style" (HTMP).

Bazan is a stage-director and a choreographer who also develops the installations, exhibitions, happenings and performances of the Maat Theatre. Since 2009, he has curated the Maat Festival, an international event dedicated to forms of experimental dance and movement.

The very name of the group hints at the characteristics and goals of Bazan's approach to art: "Maat is a word which was coined in ancient Egypt. It designates a philosophical attitude in which one looks for order and an autonomous path.

20 Unless indicated otherwise, all quotations in this section come from WTB. 
That is why the word is very important to us" (Kawa, Kawka 2008). The website of the Theatre states: "Maat is a right and legitimate state of nature and society, established in the act of creation and immanent to the being and becoming of things; as such, it is that which is righteous and valid: law, order, justice and truth" (HTMP).

Maat determined the fate - i.e. the right place in the world - of all elements of being. Hence, deities of prosperity, good harvest and destiny belong to its realm and, according to the sages, were its aspects. The Egyptians believed that Maat came into being together with magic. [...] Magic and Order jointly represent two sides of divine operations in the world: the former stands for active deeds which transform reality according to the will of the pantheistic heart, and the latter stands for passive being which produces the world's harmony. As understood by the Egyptians, Maat was a passive complement to the active operations of the pantheistic being's mind. As such, it contained the ideas of all goddesses. [...] Maat was also a philosophical way of conduct, a spiritual path which involved a constant search for one's own order and one's own mode of action. (Morenz, qtd. in HTMP) $)^{21}$

The central goal to which the Maat Project Theatre is dedicated is thus searching for harmony, individual order and a proper human path. The principle of maat that informs such explorations can also be traced in other cultures: in China (tao) with its martial arts, Confucianism, Taoism and dzen, and in Japan (do), where butō, Zen and aikido originated.

As the word tao (do) is highly ambiguous, below I focus on those of its meanings which tie in with the maat principle. "In pre-Confucian texts, the word denotes a way, a path or to lead, to guide while in The Analects of Confucius it takes on a new meaning, i.e. a way of acting, a principle of conduct" (Żbikowski 1988: 40). Tao also designates a principle that motivates the human being to selfimprove. The Neo-Confucian doctrine (11th - 13th centuries) holds that all laws concerning individual things come down to one main law. While things change, laws are eternal. Tao embodies this fundamental principle and, as such, means a regularity, a rule that is binding to all things. Tao is unchangeable, as the key text of the Taoist tradition Tao Te Ching repeatedly and emphatically insists. This is indisputably analogous to the maat principle, which assigns a proper place in the world to each element of being and founds order and harmony. Tao is discernible in its manifestations, i.e. in te. While tao is the generative principle, te is a mode in which things function in the world "Tao breeds a multiplicity of things, nurtures

21 The artists cited these insights of the eminent Egyptologist Siegfried Morenz on the already discontinued website of the Maat Project Theatre. 
them, develops, cultivates, constitutes and puts them to an end" (Bykow 1988: 35; cf. Lao Tzu 1987: 54). Te is an embodiment of tao; it is tao made present.

Defining the goals and methods of the Maat Theatre, Bazan also builds on the idea of intuitive dance. He understands intuitive dance as resulting from the operations of the unified body-mind. "For me, butō is so-called butō dance techniques and intuitive dance. So, it's linked to live improvisation in the creative process that is unfolding here-and-now."

Bazan has used a variety of body disciplines. He has tried, for example, the Gardzienice method and various contemporary dance forms. Yet, as he claims, Eastern martial arts have always been his primary basis, and their philosophy has deeply affected his work as an artist.

He collaborated with the Gardzienice Theatre Association [Stowarzyszenie Teatralne Gardzienice] and learned their methods and techniques: "I was deeply involved with them and studied their ways a bit, the actor's, performer's practice." Besides fitness training, the Gardzienice-inspired exercises are used to "stimulate constrained movement, arrested by habits of stereotypical bodily carriage" (Taranienko 1997: 160). ${ }^{22}$ For this reason, they include drills which produce borderline trance states (e.g. whirling dances). In the Gardzienice model, the performer is part of the collective body. The movement of the interacting group is combined with constant singing, and in this natural way performers practise breathing, diaphragm control and energy flows. Włodzimierz Staniewski, the founder of the Gardzienice group and their training style, compares their singing method to joik, an Old Scandinavian method of reflecting and relating to the world through sound. The Gardzienice exercises bring the dancer closer to the natural melodics of movement. Training sessions have no fixed structure and aim to expand the participants' perception capacities. A training session usually starts from a "night run" in darkness, where the group breathe in the same rhythm. Besides standard exercises, training includes a practical assignment module aligned with the show the actors are developing. Like in butō, the actor/trainee is supposed to relinquish his/her "everyday body," i.e. the mechanical patterns of movement and reaction.

Contemporary dance workshops have afforded Bazan entirely different experiences. Their major aim is, as he claims, to learn and "imprint the trainer actor's language in yourself." To identify the point where contemporary dance and butō intersect, Bazan uses the coinage "I with my body here-and-now." "Contemporary choreographers don't focus on arrangements or sequences, they

22 All information about the Gardzienice training comes from Taranienko 1997: 145-160. 
don't try to squeeze the body into a technique (or to pump a technique into the body), or at least it's not their supreme goal. I perceive an uncanny similarity between contemporary dance and butō."

Even though butō initially delved into the subconscious while modern dance was at the beginning strictly physical, even mathematical, today, as Bazan believes, the two art forms have come closer to each other, which, in Poland, is perfectly illustrated in Anita Wach's work. "She is making a dance revolution happen in Poland." Wach's stage work resembles butō in terms of both psychophysical explorations and aesthetics (which is not a coincidence).

Bazan believes that for each contemporary dancer contact, and in particular dancing contact improvisation, is an important experience. Contact contributes to "the development of the dancer's presence in the process - in the relationship." "Contact improvisation is a very difficult technique. Contact between people on stage is difficult. The solo attitude is a completely different thing, a different space, a different reality."

In contact, one forfeits control over one's body, so it is more difficult to "put on an act, to play, to fib." Like any other dance technique, whether "ballroom dance, contemporary dance, ballet or more recent styles of hip-hop and jazz," contact improvisation "can help the butō dancer acquire and hone movement competence." According to Bazan, butō is naturally based on the act of contact. This contact is specific, and at its core lies a co-appreciation of the "floating world" at the level of physiology.

Still, the key point, as well as the starting point, of Bazan's movement practice is the Eastern body discipline of martial arts, with their techniques and philosophy. Martial arts

[...] are closely linked to butō: they're supposed to imprint something in you, to prime you for something. I believe that butō is also such training. The state of butō involves opening up to certain possibilities; it's a certain sensibility. Training imprints these possibilities in you, and primes you. When you evoke this state in you on stage, it happens, in a way, automatically and, thanks to it, you can progress in this full presence. Automatism must be consciously developed, accepted and used. This takes a lot of focus and work.

Training seems thus to be the common ground for martial arts and butō: the body learns certain automatic responses; it learns to achieve a certain state of bodymind automatically (as Bazan says, "at your beck and call"). This skill enables the dancer or the martial arts practitioner to "further explore here-and-now."

Bazan has worked with a few Eastern body disciplines, including the Chinese martial system wushu, the Tang Lang style and the Vietnamese Viet Vo Dao system. 
Chinese martial arts have come to be referred to generally as kung-fu in the West. However, kung-fu designates not so much a martial art as advanced proficiency in any field achieved through long and arduous learning, As far as Chinese martial arts are concerned, they are better defined by the term wushu, which is used in China and means literally military arts. The word wushu is written by means of the same signs as the Japanese word bujitsu. (Bushido)

According to Bazan, martial arts are not really about achieving technical precision, but first of all about the very process of learning. Given this, through training martial - or military - arts, he practised the skill of evoking the learned preparedness in his body-mind.

In kung-fu, the emphasis lies not only on perfecting the skills of fighting barehanded or with weapons, but also on the student's comprehensive development. The exemplary kung-fu warrior is not only proficient in combat, but also erudite in various fields of knowledge. [...] Many schools teach not only martial arts, but also traditional healing methods (acupressure, acupuncture, herbal healing) and health-cultivating exercises (neigong, qigong). Some kung-fu systems are famous for their salutary qualities. [...]. The ethical attitudes of students are also prioritised as wude (literally: the warrior's virtues). The saying goes: Learning martial arts, you learn first of all how to be a good man. (Bushido)

The wushu system which Bazan practised was the Tanglang Men. (Praying Mantis)

Tanglang Men is a classic Chinese martial system. It is supposed to have been created by Wang Lang of Shandong after watching a fight between a mantis and a cicada [...] [The system] is guided by the mantis's fighting spirit rather than by the imitation of its movements. Having absorbed the major techniques and principles of the Northern combat styles, the Praying Mantis style has become a very comprehensive system. Tanglang Men uses a whole range of blows, grabs, sweeps and throws as well as attacks on vital points. All blow and throws are performed in a lightning-quick series, starting from low, strong and dynamic positions. Footwork in Tanglang includes fast-paced and constantly changing steps, which promote devastating attacks and quick, dodging defence. Although the Tanglang Men came into being and developed first among the Taoists from the Laoshan Mountains, it exhibits close affinities with Shaolin boxing. The Shaolin influence is visible when comparing the jiben gong (basic exercises) of the two systems. Yet these similarities decrease as more advanced Tanglang Men techniques are mastered. (Modliszka)

In turn, the philosophy of the Viet Vo Dao - a martial art which originated from the centuries-long tradition of martial arts but was codified in 1945 - builds on Buddhism, Confucianism and Taoism. Essential to Buddhism is the individual's ongoing self-improvement in pursuit of an ever higher and more perfect state of being, wherein the Buddhist follows the Master's teachings. Confucius's programme focused on perfecting human personality, human co-existence and 
modes of governance. His theories presupposed that everything that was must conform to the order of heaven. Philosophical Taoism assumed the material unity of the universe regulated by nature's impersonal order - i.e. tao - and disseminated the principle of not contravening that order in nature and society (Vietvodao).

Viet Vo Dao emphasises human moral development and improvement. The Vo maxim is: To be strong means to be useful. Making a bow, the Viet Vo Dao student expresses his/her non-violence. The main principles include: constant Development of body and soul, Balance between man and nature, and Harmony with the entire world. (Vietvodao)

Many notions concerning martial arts and religion (or, in broader terms, spirituality) contain the tao morpheme, which in Japanese is pronounced as do or to. So is the Vietnamese dao. As Chinese philosophy spread and permeated boundaries, the term tao started to be broadly and popularly used in Japanese, for example in: judo (the tao of gentleness, which differentiates this martial art from other ones, which are based on hardness, i.e. on physical strength), kendo (tao of the sword), shinto (tao of spirits) and bushido (tao bushi, i.e. tao of warriors). The morpheme is also used in the lexicon of Buddhism, which appeared in Japan at the beginning of our era. It was used to designate a way, path, principle, logos, cosmic energy but also the way of enlightenment and the state of nirvana, steeped in freedom which fosters action for the sake of all sentient beings (Żbikowski 1988: 42-43). "I got involved with martial arts because I saw in them a determination I needed in body and movement [...] After a while, they indeed imprinted a certain quality in my body."

In martial arts, practice is based on a basic pattern which is used to devise new movement configurations in response to the needs of the moment. "There's a good reason why they are called martial arts. They are a great site of creation! You face certain challenges and have a logically unlimited system at your disposal [...] This makes for great mental training."

In his first contact with butō, Bazan felt as if he was entering a territory which was not entirely unknown to him. He explains: "I'd already visited this world, I'd seen a tiny corner of it."

Butō is quintessentially about "full presence." It is above all "an attitude rather than choreography or aesthetics." The attitude entails self-development: learning control over one's perception processes and mental states.

Talking about butō, I always tell people to read Herbert's Dune. It is about issues of identity, body memory, hyperconsciousness, super-consciousness, control, lack of control and the mind, all of which are very important in butō [...] For me, butō means so-called butō dance techniques and intuitive dance. I mean, live improvisation in the creative process unfolding here-and-now. 
Butō training aims to foster the ability to achieve openness or, in other words, "permeability," whether it is later used in a choreographed staging, a stage-directed one or in improvisation.

Butō is a dance form, and dance entails various things, various ways of using the body: synchronisation, mathematical algorithms, using the body in complete ignorance. Art can be made in various ways, there's, for example, Sankai Juku's complete, perfectly calculated, indeed, chiselled choreography $[\ldots]$ and there's Atsushi Takenouchi's improvisation-based work.

It is from Atsushi Takenouchi that Bazan learned butō, working with him during the Butoh Barter 2007. He also learned a lot from Sylwia Hanff, Poland's leading butō dancer, with whom he collaborated in 2005-2008. Bazan's most esteemed dancer, Daisuke Yoshimoto, captivates him "because of the details he uses in dancing."

The Maat Project Theatre works to explore what Bazan refers to as "butō's European context" (HTMP). He insists that in investigating butō's dissemination in Western countries, the cultural context cannot be ignored.

Chasing the Japanese dimension of butō makes us blind. [...] Attempts to squeeze Ōno's or Hijikata' experiences into our bodies are by definition futile. It'll always be fake, artificial, a remote reflection of the true essence. You can learn training methods, you can borrow handfuls of theory, but art happens only when you process it in and through yourself. [...] I went through a period of being completely stuck in the Japanese structure - I mean aesthetics, the total outline. Only when I went back to the basics and started to work on my own self, using those methods step by step, did I really start to discover butō.

According to Bazan, Western and Japanese cultures have only very few things in common. He obtained a lot of valuable knowledge about the Japanese mentality from the linguist Shoji Okada (a Polish Studies student at Tokyo University), who collaborated with the Maat Theatre on the Teika project, helping translate Japanese literary texts and advising on a Nō play entitled Teika. Bazan observes that the Japanese are more likely to understand butō because it is rooted in their culturally entrenched perception of reality. For a European, butō is

[...] fundamentally Oriental, with odd mystical overtones. Many people reduce butō to mystical sensations - the most extraordinary and bizarre ones. The homo religiosus comes into play [...] while butô’s provenance is, in fact, histrionic. [...] [There is] a risk of getting embroiled in Orientalism, transplanting on our soil their work, symbolism, lithograph, calligraphy. [...] It's like taking in an Oriental bird, not only with the feathers, the beak and the talons, but even with a bar on which it sits. It can turn out that there's no bar because at home the bird simply flies around. And here it can live only in a zoo. 
In Bazan's opinion, Zen is a "cultural key" to Japan. Butō is interwoven with the Japanese lifestyle: ways of sleeping, walking, dressing and with popular culture, design, architecture and painting: the way people handle their bodies and the way they relate to the world. "The point is what externalises and what internalises me."

Butō is not founded on any particular technique. Technique is a makeweight. It is the cultural context that matters. What is called butō technique in Poland is what the Japanese think of as body discipline [...] The Japanese are formed differently and differently conditioned by their bodies. These techniques help them get rid of blockages. Besides, the history of theatre in Japan is important. For example, in the No theatre, suriashi is linked to the polished floor (the gliding movement) and the constraining kimonos. Certain movements and gaits result from particular external conditions. Forgetting about that produces infantile, even ignorant approaches.

Consequently, it is not enough to learn Japanese techniques and approaches. If artists did only that, they would not go beyond mere "academism."

Bazan believes that the point lies in using the skills and techniques one learns to create a new quality, and in his view, the only person in Poland who has succeeded in it is Sylwia Hanff.

With immense experience in dance, theatre and, first of all, pantomime, Hanff developed her own, elaborate style and, only then, took up butō. Her success resulted from consistency, an uncompromising attitude and constant development of technique, which has been part of her life for years.

According to Bazan, the butō method was pioneered on the Polish stage by Paweł Dudziński.

In his view, at the core of butō lies a specific practice which engages the dancer's body-mind and aims to foster the capacity to merge completely with the flow of reality. This dance form is universal and nobody should attempt to monopolise it. "Butō is only coming into being. You can't say it's dead if there are continuators still." Hijikata laid the foundations of the genre, but then "the wheels were put in motion, and the ripples on the water have run out so far that they only vaguely reflect his ideas." At any rate, Hijikata's words "are often wrenched out of context, as Grotowski's are. Attempts are made to steer this river though it flowed by a long time ago."

Bazan believes that "butō will spread and make itself at home in the world as Zen has" and that various "schools" will form as even now specific body disciplines and approaches to image and movement are distinguished in the work of Ushio Amagatsu, Kan Katsura and Daisuke Yoshimoto. Techniques, body disciplines and "language codes" distinct to particular dancers will be established and consolidated as, in Bazan's view, there is no universal butō technique and, consequently, it 
is impossible to establish one school based on it. There are only individually developed body disciplines which Bazan refers to as "body form movements." "Dance is conscious, and I call it body form movements [...]. This formula helps avoid strict terms, such as 'method' and 'technique.' I don't say that I dance; I say that I guide my body in a form." This is also how he called one of the workshops he taught using body disciplines borrowed from Eastern martial arts "that serve first of all to enhance breathing capacity, motor coordination and conditioning. Workshops include complete sets of exercises which activate and stimulate all regions of the body (relaxation techniques, stretching, fitness exercises)" (HTMP, Warsztaty tab). Bazan himself says: "We work on fitness, physicality, kinetics; we're interested in physical body theatre [...] it's very concrete, physical work."

In the Formy prowadzenia ciała [Body form movements] workshop, the participants focus on body consciousness, while the Buto workshop (which Bazan taught together with Justyna Jasłowska in the first years of the Maat Project) included more advanced explorations. The participants were invited to engage in internal experimentation with perception and be prepared for side effects, such as sudden (pleasant and unpleasant) insights and, first of all, deep psychosomatic exploration.

Butō workshops require a lot of prior preparation; you need to realise what dance and movement mean to you. Otherwise you'll notice only one aspect of these workshops that something is being pumped into your body. In this way, you only regress. Copying can do you harm, physically and mentally.

"It is an ongoing journey, constant change, and it defies definition. I call it Butō only as a point of reference" (HTMP, Warsztaty tab). Currently (2012), a similar workshop entitled Peryferie ciata [Peripheries of the Body] is being offered.

The Butō workshop was based on a processual structure which developed from physical exercises (warm-up) to psychosomatic practices improving the ability to listen to one's own body and, consequently, to experience full presence. The artists also used so-called butō dance techniques (techniques used by various butō dancers). They developed the method in their own experimentation with the body-mind.

I use what I've tested and know is safe. I don't propose exercises I've learned from my teachers if I'm not certain that they're mine, that I've processed them. The workshop I teach is a synthesis of various workshops. [...] I show people what I've experienced myself, what was important to me, and where I am now [...]. I show things that help me achieve a certain state, ways I've tested on myself. I assume that they may help others as well.

The Butō workshop began with physical preparation of the body. The structure devised by Bazan was geared to fitness conditioning. For example: "bouncing for 
twenty minutes until everybody drops. Then we lie for fifteen minutes and then go on bouncing. For an hour. After this hour, we begin to walk, enriched with an entire array of experiences."

Walking (zero walk based on the already mentioned suriashi) starts from the zero position in which the body is relaxed and sight is diffused or, rather, focused "on everything" (which Bazan refers to as "wide-angle vision"). In this position, the mind is emptied out and rid of all thoughts. Bazan emphasises the importance of the Japanese theatrical tradition: "You must filter such techniques as suriashi through yourself in a creative process and discover your own context of this walk. Otherwise, the technique will be empty like a jug."

Adopting the zero position and doing the zero walk, we open to the "stream of the floating world." We are fully conscious and do not focus our attention selectively.

When he talks about butō, Bazan often evokes the notion of "full presence,"23 which he has probably borrowed from Hanff. He explains that "this is one of the key words which I believe stems somewhere from Hijikata [...]. Somewhere from Japan." At this stage of training, images are usually introduced, taken from Hijikata's manual (butō-fu). Bazan believes that the focus on images and visualisation support kinetics, but in his practice, he concentrates first on the body and then proceeds to the imagination. He is not enthusiastic about embodying imaginary wordings, which is so typical of butō. Instead, he tries to "look in the body for such forms which images compel." "I prefer sketching a situation rather than particular objects or states. What involves us most are situations where behaviour, completion and reception are individual."

Whether one works with embodied images or with bodily forms evoking images, the aim of psychosomatic transformation is the same. Irrespective of the direction our process takes, we are dealing with the body and the image (a mental element). Psychosomatic transformation is the basic process, a sine qua non of butō and its essence. But Bazan stresses that the practice of embodying images (or, as is the case with him, projecting the image from the body), which is the culmination of butō workshops, is not the most important element in this dance form as an on-stage performance. "It seems to me that dance itself is often confused with what happens in training, where you indeed focus on internal visualisation, on projection." In the context of the body-image relationship, "body

23 The notion of "total presence" (an equivalent of "full presence") appears in Eugenio Barba's theatre anthropology. This was a likely source of the expression for Sylwia Hanff. 
memory" is frequently evoked. "Body memory" is an ambiguous term. On the one hand, the body remembers its interrelated muscular-skeletal configurations, energy flows and experiences that can be later reproduced (muscle memory). On the other, the body is a reservoir of repressed memories. Inducing in the body a state in which it was in a past situation, we stimulate body memory, which makes it possible to re-live forgotten situations. ${ }^{24}$ Bazan was investigating the latter understanding of "body memory," yet he has not identified any traces of such a process in his body. "Perhaps people aren't able to distinguish some states they evoke themselves and haven't got enough experience to verbalise and name them properly [...]. They come across a notion and link it to what they don't understand."

Bazan believes that the term "body memory" is often misused and abused, just like the concept of body consciousness.

Body memory is involved in every movement, in every dance, because when dancing you discover various regions of your body, and they teach you to function and give you new answers [...] While dancing, receptors are suddenly awoken which have long lain dormant. Children explore their bodies, which close off as they age.

The transformative element which appears in butō invites associations with trance, ecstasy and possession, in which consciousness sets off on a journey outside the body, abandons the bodily realm or is replaced by another, external (e.g. a deity's or a spirit's) consciousness. Yet according to Bazan, "dance is not about surrendering to trance." Dance is "a closed code, an ensemble of ways of guiding the body through certain processes. Loss of control over the body, in my opinion, precludes dance." To Bazan, trance is identical with a lack of awareness, and, consequently, he insists that such formulations as a "dance of possession" or a "dance of frenzy" in fact do not refer to dance but to quite a different category of body-related phenomena. "In biological terms, loss of consciousness contradicts the healthy operation of the body-mind. In such a case, we can ask 'Am I still a human being?'” On stage, Bazan remains conscious of "walls, floodlights, the floor. If he left the body, it would fall down limply like a piece of cloth. Our bodies are guided by neural impulses [...]. If such impulses are cut off, the body stops functioning."

Using some body or mind disciplines requires preparation and needs to be learnt gradually. In this context, Bazan points to mediation and prayer practices used in psychophysical training.

24 This issue will be discussed in more detail in Chapter 5 "The Training Process." 
If you throw your mind into the deep end without having any experience with it, it's like doing a back flip without any practice. With a back flip, you can break your spine, with the techniques I mention, your mind. [...] In introspection, you can go too far and come to believe that you are on a mission, that it's about a calling or mysticism ... Mystical attitudes are always dangerous, and butō indeed explores such regions very intensely. It pushed me into problems; a few times I felt I was going the place I wasn't prepared for.

"You're not there," a formulation often used in workshops with Japanese dancers, is explained by Bazan as follows: "When I'm dancing, I dedicate my activities to a concept, to an idea, I surrender my own self a bit, I sacrifice it. This concept becomes the centre, the core, and my entire life, my experiences revolve around it. I step back in a way, but I don't disappear, of course." If the phrase is taken literally, Bazan considers it "mysticism in the scholastic, medieval sense of the term, related to the belief that our souls are visited by some demons, forces, or qualities which command us." Interpreting the statement literally, one can perceive the buto-specific technique of filling the empty body with images as "magic, the supernatural." For example, Daisuke Yoshimoto "says that he dances all deaths, and there's a lot of truth in it. But it must be remembered that even though it's a poetics of sorts, this poetics is supported by immense experience and massive practice."

Metaphors used by artists and dancers should not be taken too literally because, in fact, "butō is a very conscious process of applying body disciplines, of engaging with your own self [...]. It is a way based on the here-and-now."

During the performance, there's somebody else on the stage: me, but functioning in other dimensions. It's impossible to say what you are out there, where you are, what you see $[\ldots]$. This concerns not only butō [...] Many dancers suddenly experience illumination and find [themselves] in an entirely different place. This is the mystery of dance, I guess. It's not me, so there must be something more; other things appear which are to be found only out there.

In butō, one works on one's own mind, perception and psyche. The process forms a foundation on which the physical, artistic and aesthetic layers of dance are mounted. The staging is a culmination of the creative process which involves two components: training and choreographing.

Bazan's training is based on "finding challenges and setting the bar high for yourself," which happens through "using techniques which are terribly boring to me. Or, for a while, impossible to get hold of. [...] I hope this keeps me constantly alert."

At a certain moment, there was a clear shift in his work: "I moved most of my training from the ballet mat into my head. For a year or so, I've more thought about dance than moved in it." Consequently, his experimentation is mainly 
conceptual. "I go out to the mat only when I've figured things out and really try to face up to them." The performance emerges when many elements involved in the texture of the artist's daily life come into sync.

I start to think on several levels at the same time, in partitions. I live with a colour which is reflected on stage, with aspirations to something, with a form of skin; and I am also intellectually engaged: I ask myself questions and draw conclusions. The stage effect is just the tip of the iceberg.

In Bazan's performances, movement is stage-directed based on improvisation. It involves interpolating orientation points which make up a grid serving as the structure. This grid replaces choreography. "I retain the contours of direction and choreography, and the rest simply happens [...] Idiota albo trans [An Idiot or a Trance] is an exception to this pattern as it has meticulously detailed choreography. The remaining ones are $90 \%$ based on improvisation."

Dance is a process in which the body is involved. It does not have to follow the same course every time.

I always need to be somewhat of a mystery to myself. I never know exactly what will happen. And as long as this is so, my performances are alive. When I lose this perspective, I can't act or dance; I don't want to anymore. The problem has been defined and ended a certain stage, its lifetime [...] To play performances years later is interesting because they're a completely different thing. [...] In each performance, I leave gaps to be filled. Either I fill a gap, or it overwhelms me [...]. Rounding everything off precisely would kill the vitality of the staging, the possibility to dialogue. [...] This is where butôss essence is as I see it: in the mystery of this state.

\section{Conclusion}

Bazan's initial and primary body disciplines included Eastern martial arts: the Chinese Tang Lang and the Vietnamese Viet Vo Dao. In them and, likewise, in butō, training teaches the body to respond in certain ways and helps achieve a certain liminal state of the body-mind. Martial arts training demands enormous discipline, focus, determination and mental practice. It emphasises not only the mastery of combat skills, but also the student's comprehensive development.

According to Bazan, lying at the core of butō is full presence, which can only be achieved through self-control of perception processes and mental states. The state of openness is achieved by using so-called butō dance techniques and live, hereand-now improvisations. Zen provides a cultural key to the Japanese mentality (and, consequently, to butō). Butō is not based on any universally effective method, and individual techniques are developed by artists, who employ them to produce a new quality. Bazan refers to their various practices as body form movements. 
Butō training begins from intense physical preparation of the body. In further stages, the practitioner strives to achieve full presence (which is similar, albeit only superficially, to trance and ecstasy). One of the techniques that help attain this state is the zero walk, which is very popular with buto dancers and whose first step can be called the zero state. Training is processual as it progresses from physical exercises (warm-up) to psychosomatic exercises which develop the ability to listen to one's own body. This is followed by practice focused on mental images. In Bazan's original version, it starts from bodily forms and only later involves the mind and the imagination. The ultimate aim of the training is psychosomatic transformation or, rather, an uninterrupted flux of changes.

Currently, Bazan's artistic pursuits start from conceptualisation, defined as the mental coagulation of all experiences. Physical practice is a materialisation of this internal process.

\section{Aleksandra Capiga-Łochowicz: The Archaeology of the Body}

Aleksandra Capiga-Łochowicz, a graduate in Japanese Studies, was an interpreter during Atsushi Takenouchi's workshops in 2003. This gave her an opportunity to spend long hours discussing dance and the body. Her theoretical fascinations developed into bodily engagement in weekly meetings at a dance studio founded in Joan Laage's home in Cracow (October 2005 - May 2006), which gave her first insights into butō, though she admits in retrospect that she was completely unprepared for such practice.

Laage's warm-ups included contact activities and rhythm routines, followed by exercises focused on an assigned theme. They relied, for example, on the dead body/hanging body exercise, in which the body, pictorially speaking, resembles a marionette which is not being manipulated, as it dangles relaxed with the head falling to the sides like in a puppet kept straight only by a wire attached to the neck. This image or, rather, this bodily form was used in practices by the Hakutobo company led by Yōko Ashikawa, a follower of Hijikata. While staying in Japan, Laage collaborated with the group.

At the meetings in Laage's studio, Capiga-Łochowicz felt ill at ease: "[Laage] showed us a form to achieve, but did not tell us at all how to go about it" (WAC). ${ }^{25}$ She had a sense of being constantly assessed (though she admits it may have been a wrong impression). In that period, she was newly fascinated with butō and expected a lot from the meetings, which is why she was disappointed in a way. "I

25 Unless otherwise indicated, all quotations in this section come from WAC. 
grasped some of the things [Joan] had shown me only in Sapporo. Then I could try them anew and felt I was in touch with myself."

Butō consists in wrenching the body out of routine movement and is a revolt against movement conventions. "Movement does not always result from the dancer's will, but often defies it and imposes itself. [...] Butō means searching for the truth about your own body as the dancer doesn't act, doesn't imitate the world and doesn't change into somebody else, but the other way round, becomes more him/herself."

It is no coincidence that Capiga-Łochowicz's vision of butō is deeply anchored in Hijikata's world of movement. She has authored Bunt ciała. Butō Hijikaty [The Revolt of the Flesh: Hijikata's Butō] (2009), the first Polish biography of the artist. Working on her MA project from which the book grew, she could build on Hijikata's original vocabulary because she knew Japanese. It was when collecting her resources that she felt she had discovered her purpose in life.

This was the most powerful moment. I had a few epiphanies about butō. For example, it would suddenly dawn on me when analysing a passage in an essay what it was that Hijikata was talking about - I would suddenly realise what a metaphor concerning his life or a particular show really meant. I did that intuitively; I wondered where this or that gesture came from. And then I had that feeling.

Capiga-Łochowicz believes that butō is a dance form for everybody who is prepared to look into the depths of their body's darkness.

Butō is dancing your own authenticity. You know what the body's like: it will reveal every lie, that you cheat, that you're beginning to play games. If you don't feel the centre of your body, it'll show that you don't. If you've no access to it, you'll make only peripheral movements. You can know you're making them and use this knowledge. But you may also not know it. For me, butō is about being intimately in touch with myself. And then you start looking for a way to express truthfully what you discover in this contact.

Consequently, the first stage, the training stage, is a process of arriving at authentic movement embedded in the body, the entire body. In the second stage, this newly discovered movement is extracted outside, used and shown.

At Sapporo's Studio Goo, where she practised from November 2006 to April 2007, Capiga-Łochowicz was reasserted in her belief that butō was not only a modern art form but also a method of psychosomatic exploration. Her teachers were Toshiharu Kasai, Professor of Somatic Psychology at the Sapporo Gakuin University (who performed on stage as Morita Itto), and Mika Takeuchi, his collaborator, a dancer and dance psychotherapist. The course taught her techniques that add up to the "Kasai butō method" (cf. "Toshiharu Kasai: Butō as a Method of Psychosomatic Exploration" in Chapter 2). 
Capiga-Łochowicz spent half a year in Sapporo, studying butō in practice "as a method of psychosomatic exploration." First, she practised alone and then was joined by other people (three women). She met with the trainer two or three times a week for a few hours.

The sessions had a fixed structure: they always started from tea-drinking and a conversation, when Itto talked a lot about buto. Then a warm-up followed which always looked the same with very lazy, very slow stretching, with no strain, no excess, no reaching and going beyond your limit. The exercises focused on breathing, which we paid lots of attention to. Most of the warm-up consisted of exercises done while lying on the floor. We relaxed the whole body, starting from the feet. The point was to develop body consciousness, to find out about the body and play with it. [...] For example, when lying down, you raise your leg and test how its parts can move: flexing, stretching, manipulating. Now I know, though Morita never called it so, that it's about noticing so-called qualities of movement (compact, free, fast, slow). About feeling the movement and trying out very different possibilities. About not closing yourself against other, new movements. There is no predefined form you must achieve, and as far as the trainer's intervention is concerned, Itto showed me only starting points. The sessions also included butô’s characteristic walk and very slow movement, where what mattered was less to show movement and more to feel that it was there.

A lot of emphasis was put on working with movement's polar qualities, which was based on the "starting points" shown by Morita Itto. The points are particular figures, arrangements of the body, from which the exploration process begins. The poses were associated with various images used by Hijikata, such as, for example, the child (when the artist felt that her body was becoming estranged, then it intrigued her and forced her to explore it) or the hanging body (described above as a marionette), i.e.

The whole body's dangling as if hung from a strong thread attached to the nape, a position in which the nape, the neck work. [...] Itto showed me different starting points and I worked on them. Sometimes he used music, sometimes he placed bells on me. [...] He very rarely interfered with my explorations, but when he did, he would say, for example, "lift your leg and try the balance." [...] I usually danced with my eyes closed.

There was also pair work in which we helped the other person relax and unclench. They also did exercises borrowed from the Noguchi Taiso system, exercises for "the arms, the head, supporting somebody else's head, the legs," which Kasai describes in his articles. From such initial exercises or techniques, Capiga-Łochowicz proceeded to improvisations. "Although Itto didn't comment and didn't correct my movement, without him I wouldn't have known that you could improvise in this way. He showed me how to find movement in various places." The artist often refers to knowledge acquired in her conversations with 
Morita Itto though, as she admits, sometimes it is difficult to relate the exercises described in his articles to real practice.

Over twenty years of training and stage practice, Morita Itto, a dancer and Professor of Somatic Psychology, had systematised butō-related terminology and described its psychosomatic body-mind disciplines. He concludes that "the ongoing process of mind-body interaction is most significant in Butoh dance" (Kasai 1999: 310). He has described the method of psychosomatic exploration in multiple widely shared articles (cf. Kasai 1999, 2000, 2001, 2005, 2009a, b and c; Kasai, Parsons 2003). His fundamental concept is butō-tai, i.e. butō body or, specifically, butō state. This state of consciousness is often construed by the audience as a trance. "Dance is a medium in which you either can let yourself go into a trance and induce other voices, another nature, or not. It's your call. You can let something speak, but you can also keep it at bay."

Although Capiga-Łochowicz has not opted for trance as her own method, she realises that there are situations in butō where the dancer's consciousness is ousted by the unconscious, internal impulses or by the consciousness of the figure being danced (e.g. a tree, a child, etc.). There are also situations in which the individual consciousness is retained in dancing, which does not necessarily entail stage-directing the movement. She regards "butō as a conscious dance form, taking place in full presence. There's no room for trance here." Butō-tai is a state of psychosomatic readiness and openness. Having achieved the butō body, one can release mental states imprinted in body memory and erased from one's consciousness. Capiga-Łochowicz agrees with her teacher that some people cannot attain this state.

They stumble upon obstacles, for example, the carefully selected attire, the striving to present an impeccable style or difficulty with being natural. [...] Some people are constrained by tension or stress. To get rid of fear, they often giggle or watch others. Sometimes newcomers to my classes can't fully focus on dance, and when they have no idea how to move, they don't believe you can do very well without such an idea. When they wonder what their next gesture should be, they fall out of their rhythm and emotions. (Paduch 2009)

Resulting from the slowing down and deepening of breathing, relaxation helps discern the repressed body impulses. This is when the transition from social time to body time happens. The most important exercise is arm-standing (while lying down, raising the arm very slowly to the "erect" position), which CapigaŁochowicz uses in her workshops. It helps feel the weight of arms, learn tiny movements which relieve tension and master subtle body control to release suppressed bodily responses, involuntary movements and reflexes. 
The artist stresses:

People have their genuine movements, and dance should try to unveil them, to get rid of all masks and show the truth. That's why every person's buto will be different. It doesn't depend on the sense of musical rhythm. Everybody has their own inner rhythm, and it is to this rhythm that they should dance. If you don't feel the music's rhythm, don't force yourself to do so, just dance to your rhythm, to the tune you have in you. And if you don't feel any tune at a given moment, don't dance at all. (Capiga-Łochowicz, qtd. in Żukowska 2009).

"I believe there is something like the spirit of butō. For example, Keith Jarret is butō for the piano, to me. It's truth that originates in the body and flows from the very centre."

Authentic movements testify to the dancer's openness to stimuli and readiness, which is referred to as passive perception.

Butō inspired Capiga-Łochowicz to become involved in body performances on stage. The artist does not hold regular daily training sessions, but spends time preparing before workshops and stage appearances. Since 2007, she has danced "butō improvisations in the form of spectacles," which is what she calls her mode of stage expression. While there are butō dancers and groups that meticulously choreograph their performances down to the second (e.g. Kanazawa Butoh Kan), Capiga-Łochowicz's butō never relies on the classical choreographic structure. Instead, she performs movement improvisations. "The movement is not stage-directed. I remain aware in dancing, but it has nothing to do with stagedirection." Capiga-Łochowicz cannot even imagine completely choreographing her butō shows, though she does not consider "butō choreography" to be an oxymoron.

The starting point for her on-stage movement is images derived from the body, while the scenic framework for her Improvisations - the structure of reference points - is provided by space, music, lighting and costume. The artist sometimes listens to the music composed for particular performances just before the performance begins, but sometimes she hears it first only when she enters the stage.

Using music in butō can be risky insofar as you can be tempted to cling to it strictly. If this happens, we stick to its rhythm and pace, repeating one movement without moving on, without looking for new gestures. An important thing is to dance consciously with or against it. Music can serve as a background, but it shouldn't be the only thing that motivates our dance. (Paduch 2009)

Lighting is a similar: "you can play with it, go into or out of its beam"; as is the floor "which can be both an obstacle and a support" (Paduch 2009). The costume 
is either minimalist or "random, picked at the last minute. Only those remain that offer impulses and stir ideas." Capiga-Łochowicz's approach to the theatrical trappings of the spectacle is well expressed in her pithy statement: "For me, less is more."

The audience are witnesses rather than "critics" of what she does.

Certainly, it isn't a dance you dance for show or to entertain anybody. [...] you can dance with somebody or with something, with the place, with the floor, with the light, with emotions, but not in order to endear yourself to people or to please them [...] what you look like doesn't matter. [...] I simply allow somebody to look at me. I'm interested in what it was in my dance that moved you in this or that way. That's what I'm curious about. (Paduch 2009)

Capiga-Łochowicz interprets Hijikata’s injunction that "butō is not for display" literally. She believes that dance is an intimate thing: "I won't dance with my face turned to the audience only for them to see it all the time. [...] I am the first person for whom it is to be true. The audience only come second." She regards the performance as successful and creative if while dancing she feels firmly rooted in herself and if she senses that "there was truth there and I felt it."

The artist values butō's spiritual, even religious, aspect:

Butō is not rooted in religion. On the other hand, I'm certain you can't possibly dance the truth about yourself in separation from what you believe in. I'm a Catholic and the truth that is at the core of butō is associated, for me, with striving for truth also in the Christian sense. (Paduch 2009).

Ever since Capiga-Łochowicz took up dancing, she has danced alone. Recently, however, she has been absorbed by contact improvisation originating in contemporary dance. "I've come to the conclusion that I prefer dancing with somebody to dancing for somebody. There's an enormous potential in improvising together. [...] For me, the most intimate contact in dance is the hand's touch combined with a look into the eyes, for without eye contact, hands are impersonal." Yet she also believes that dancing within one technique of contemporary dance can be a trap:

You start to assess other dance forms by your criteria. Contemporary dance is a broader notion in the world than in Poland. In Poland, it's approached very technically and evaluated in terms of technique rather than expression of emotions, etc. But this is changing. [...] As I see it, contemporary dance is based on the weight-lightness binary.

Although several techniques are used in butō, they do not serve to achieve sophisticated technical mastery. "In butō, master dance is not an issue at all because there are no degrees of initiation. You can learn about figures [images], and there 
are a few of them, but the way we dance will be an effect of our explorations" (Paduch 2009). "Some people believe that there are such degrees. We might ask if they do so because they're able to distinguish them, or because they believe they've achieved a higher level themselves."

In butō, no official certificates are issued to confirm artists' readiness to start doing their own art individually, and dancers do not need a teacher's permission to perform on stage using his/her methods. Capiga-Łochowicz believes that interpreting a butō show as a critic is a bold thing to do. A critic must largely discuss him/herself because the audience relate to what is happening on stage through bodily empathy based on the co-presence of the dancer and the viewer. This is a distinctive quality of the reception of butō. All misunderstandings about butō result "from critics' ignorance and dancers' presumption." Knowing nothing about the genesis of butō, critics try to interpret the dance in semiotic categories, while artists who use only its aesthetics describe themselves formally as butō dancers.

At the core of Kasai's method (cf. "Toshiharu Kasai: Butō as a Method of Psychosomatic Exploration" in Chapter 2) lie techniques of the body-mind as an integrated whole. They help the dancer enter "the time of his/her own body" and discard the socialised body. For this reason, butō can be regarded as a variety of body psychotherapy, somatotherapy (cf. "Terms") or dance movement psychotherapy. ${ }^{26}$

If you think that butō and dance therapy don't go hand in hand, you don't get in touch with yourself fully when dancing. If you did, you'd know perfectly that all elements, first of all looking for the truth about yourself, gave butō a therapeutic aspect. And looking at Hijikata's work, you can say that, in his dance, he examined and told of his own darkness, of his own painful experiences, utilising its therapeutic potential in this way.

Capiga-Łochowicz applies butō as a psychotherapeutic method. She runs dance improvisation workshops based on techniques borrowed from butō. "My workshops are very much like the training sessions in Sapporo. Open-ended. You can join, you can leave." "When dancing butō, we can make slow or abrupt movements, motionlessness is also allowed and can be the beginning of a new exploration" (Paduch 2009). Capiga-Łochowicz declares: "I never say that I teach butō; I teach improvisation, using butō training; I teach how to approach dance in an unconventional way" (Capiga-Łochowicz, qtd. in Żukowska 2009).

Her workshops are attended by elderly people and people with mild or moderate intellectual disabilities. She learned how to work with more demanding groups in

26 For more information on the relationship between butō and DMT, cf. CapigaŁochowicz 2011. 
the butō-as-a-method-of-psychosomatic-explorations training series conducted by Kasai. "In my workshops, I rely on his exercises; they make up more than a half of what we do. The rest are my own ideas which I tested first myself."

Currently, Capiga-Łochowicz is a professional dance movement therapist. In 2009, she enrolled in a post-graduate programme in DMT. Initially, she was accompanied by a certified psychotherapist when teaching her classes. Now (2012), she works with adult schizophrenia patients and adolescents with various mental disorders at Warsaw's Psychiatry and Neurology Institute.

$\mathrm{DMT}^{27}$ is not a psychotherapeutic method complementary to verbal psychotherapy. In DMT, the psychotherapeutic process addresses the same issues with which verbal psychotherapists deal (transference, countertransference, projective identification, etc.). Since

the 1980s, DMT has been recognised as one of the four sub-disciplines of arts psychotherapy (in the British classification); it is also classified as a form of movement psychotherapy and action-oriented psychotherapy (together with arts, music and theatre therapy, psychodrama, Gestalt therapy, psychomotor therapy and bioenergetics) (cf. Pędzich 2009: 20). DMT consists in psychotherapeutic applications of movement and dance to "promote emotional, cognitive and social integration in the person," and its links to psychotherapy imply that DMT is separate from dance as a form of artistic expression, therapeutic dance and dance education (Karkou, Sanderson 2005: 238).

Depending on their background and preferences, dance movement psychotherapists employ a wide array of body and movement practices, including improvisational movement, spontaneous movement, touch, simple movement, symbolic movement, communicating dance, organised movement sequences and such methods as mirroring and exaggerating. DMT presupposes that "body movement reflects the person's internal emotional state while changes in movement can effect mental changes, supporting the person's development" (Pędzich 2009: 7).

The working procedure begins from an initial (verbal) interview with the patient/client. Then contact is established and the sense of security is bolstered, which is followed by the key phase of the therapy called incubation. Incubation is the core of the therapeutic process as, in this phase, emotions and thoughts are expressed through movement which the therapist analyses using, as a rule, the Laban Movement Analysis (LMA) or the Kestenberg Movement Profile (KMP).

27 All information about DMT in this section comes from Karkou, Sanderson 2005; Pędzich 2009; and DMT. 
Subsequently, the therapist interprets movement at the somatic level (e.g. patterns, phrasing and mirroring) and, finally offers a verbal interpretation which, ideally, helps the patient/client develop an insight, i.e. understand what has surfaced during the session.

Because the process unfolds somatically and is observable from the outside, the method is very effective in the case of patients/clients who are not very amenable to verbal psychotherapy (due to, for example, autism, schizophrenia, etc.). DMT's exceptional value lies in the fact that dance and movement can also express experiences involved in situations which "cannot possibly" be told as well as sensations from the pre-verbal period, in which experiences and traumas are encoded somatically. For this reason, the method is particularly useful for people whose intellectual and/or emotional disorders date back to early childhood. "One of the dancers I admire, with whom I had an opportunity to talk through a few long nights - Atsushi Takenouchi - uses butō in workshops for alcohol addicts and for prisoners" (Paduch 2009).

Kasai, Capiga-Łochowicz's main teacher of butō, is "a psychologist and a psychotherapist who employs butō in the treatment of patients with both physical conditions and mental disorders." Paradoxical though it may sound, CapigaŁochowicz considers butō unsuitable for children.

I've worked with kids, and I think that butō requires a kind of focus that is hard for a child to achieve. Children find it difficult to understand why there's no music or jumping now if they just feel like doing it. In such situations, telling children to focus or explore things in silence, when they have quite different needs, could be a constraint. And this would contradict the nature of butō.

While the method serves to investigate people's bodily limitations resulting from body socialisation and movement habits, children only teach their bodies to meet social expectations.

Employing butō techniques, you must be a conscious butō dancer, and when you use them for therapy, you must also be a conscious therapist. It's your responsibility to realise whether using them involves any risk for your client group. For example, you don't used metaphors and visualisations with people with schizophrenia because it's dangerous. Consequently, in the case of people with this disorder, you can use only elements of physical training, such as exploring polar qualities of movement, or focusing on the body image or the integration of emotions, thought and movement.

"Dance movement therapy methods are designed not only for people with mental problems, but also for healthy people who are looking for ways of selfdevelopment." Butō helps reduce muscle tension and relieve stress. 
Capiga-Łochowicz emphasises the somatotherapeutic quality of this method. The therapy works

$[\ldots]$ at the level of the body rather, and its major aims are strain-relief, relaxation and the development of body consciousness. [...] We are looking for a gesture, and the gesture leads us; in dancing, we often wrestle with ourselves and become more aware of our bodies. We must find courage to expose what's inside. [...] Butō is a dance of metamorphosis which is supposed to show the truth about the dancer. It requires shedding the mask. [...] There're no ugly movements in it. You have tics? Great! Tics are your resource. Try to use them. (Paduch 2009)

Butō is not about expressing or releasing repressed individual emotions but about getting in touch with the intersubjective and objective layer of emotions. "The darkness which each of us bears inside is the substance of butō. This darkness is made of all our anxieties, anger, frustrations and grievances. Making a gesture, the dancer can explore or expunge these dark emotions and, having got rid of them, head towards light" (Paduch 2009).

Dancers do psychosomatic exercises in an attempt to recover experiences which are inscribed in the body and affect how they move. The exercises aim to objectify the experiences and to go through them in movement. As a result, dancers obtain better insight into how experiences and emotional states are associated with the ways their bodies function.

Such knowledge can be employed in performances.

Butō helps express the truth about oneself and eliminate inner checks and tensions. In dancing, one can draw on difficult emotions and experiences, translate them into movement, and this movement can help one unwind, fend off these emotions and transition into "light" dance. (Żukowska 2009)

Like in DMT sessions, in butō dancers become aware of their bodies and get anchoring in them. "One issue in butō is identifying the limits; you must clearly feel where your limits lie. I've learned to say 'stop', to know what I want and to do things the way I want. There are no 'musts' in butō."

In Capiga-Łochowicz's workshops, the line between dance and therapy is indeed hard to find. Only the target group and the context determine the nature of sessions. "DMT presupposes that every safe movement is good. As a therapist, you accompany the person in movement, without imposing anything. And you watch. That's the difference from butō: you do the watching. To see whether the centre or only the periphery moves in the person. To see whether, accompanying, you can embody this movement yourself." 


\section{Conclusion}

Butō is not only a strictly histrionic performative art. Also, it is a method of psychosomatic exploration. This aspect of butō is of special interest to CapigaŁochowicz. The essence of butō as a method of psychosomatic exploration lies in butō-tai. Having achieved this state of body-mind, the butō practitioner no longer objectifies the body, i.e. no longer uses it as an instrument employed by a separate agent. As such, butō is a specific archaeology of the body which involves delving into long-forgotten layers of bodily experiences. The suppressed experiences resurface when the organism finds itself in a state analogous to that which was involved in the past events. Consequently, the method helps release the repressed bodily reactions in series of involuntary movements. Also, unplanned movements take place as an automatic response to images that appear in the mind. Movement results from an exceptional openness and sensitisation to all stimuli. Techniques involved in Kasai's method bring about the desocialisation of the body (i.e. the discarding of bodily routines imposed in socialisation) and enhance its proprioceptive sensitivity (inner body consciousness). At the sensory level, it is associated with passive perception, which is also referred to as unseeing eyes, diffused vision, peripheral vision and non-objectifying gaze.

Capiga-Łochowicz as an artist dances improvised performances (though, admittedly, seldom now) while Capiga-Łochowicz as a therapist uses DMT combined with Kasai's method of psychosomatic exploration. In December 2009, she co-chaired (with Pastuszak of the Amareya Theatre) a panel discussion about the history and therapeutic applications of butō at the Oblicza butō. Bunt ciałataniec - terapia [The Facets of Butō: Revolt of the Flesh - Dance - Therapy], an event organised to commemorate the 50th anniversary of this performative genre.

\section{TO-EN: The Body Shaped by Matter}

TO-EN (Anna Brałkowska) was born in Gdansk, where she also got a degree in Scandinavian Studies. She believes that her choice of degree was motivated by a fascination with otherness and the exotic. Europe's Northern reaches fulfilled her dream of the unknown.

As a grant-holder, she went to Sweden in 2002 and participated in butō workshops taught by the butō dancer and choreographer SU-EN (Susana Akerlund) in Haparand. SU-EN found a place for her group SU-EN Butoh Company in Almunge (Haglund Skola) near Uppsala, and in 1997 started a studio, where the group practice and where open workshops are held. SU-EN is the group's artistic director and dance teacher; her students look up to her as a guide, 
a master and a sensei. SU-EN lived in Japan from 1986 to $1994 .{ }^{28}$ She studied for five years with Tomoe Shizune, artistic director of Tomoe Shizune \& Hakutobo (the Hakutobo company was founded by Tatsumi Hijikata), and worked with the Gnome group, led and choreographed by Yöko Ashikawa, the chief dancer of Hijikata's group. In this sense, she was a pioneer because Japanese butō groups only started to accept foreigners in the 1980s.

Building on her experience with Shizune's and Ashikawa's methods, SU-EN developed her own body-mind approach, called the SU-EN Butoh Method:

Through re-defining the body and space, possibilities for movement are found. A specific quality/tension of the body which will be able to communicate to the audience is the artistic goal. The body is pushed beyond personal limits and re-constructed, thus developing new tools for making dance.

Her method underpins a structured training cycle, within which open workshops give an opportunity to learn the method and talented dancers are invited by SUEN to practice with her group. They take part both in the group's artistic pursuits and in everyday work at the Haglund Skola. Those who complete the training process ("apprenticeship") are licensed by SU-EN to teach body disciplines based on her butō method and use elements of her choreographies in their shows.

TO-EN came to the studio again in 2004 to take part in a workshop. She had developed an interest in dance before, but the many various workshops she had attended had not made a lasting impression on her. Only in Haglund did she get a feeling that she had found the dance form she had been looking for. In 2005-2009, she completed the full five-year apprenticeship in SU-EN's group, combined with stage performances in Sweden. Invited by SU-EN to collaborate on a project, she remembers that it was "a truly deep dive" (WTE). ${ }^{29}$ The maxim of SU-EN Butoh Company is: "To dance, you need the courage to challenge your body." As part of the group, TO-EN had to let go of her individual identity: "Our earlier existential and bodily experiences do not matter anymore." The person's artistic and existential history is produced anew in the creative process: "As soon as I crossed the threshold of the Haglund room, I started building everything from scratch," concludes TO-EN. Like in the Japanese tradition, the moment one finds one's master (SU-EN), one must commit fully to the community of practitioners (TO-EN refers to the Swedish group's activities as "practising"). Working together round the clock, in and outside the studio, is supposed to produce permanent

28 All information about SU-EN comes from SU-EN Butoh Method.

29 Unless indicated otherwise, all information about and quotations from TO-EN come from WTE. 
performative readiness in the dancer: "Woken up in the middle of the night, the butō dancer must be ready to go out on the stage and perform."

The intense and very demanding training culminates in a solo performance. The "diploma performance" is developed in collaboration with the entire group and supervised by the teacher. The solo show involves an important symbolic act, i.e. receiving a name which serves as one's artistic name henceforth. Brałkowska was named TO-EN, which means the Earthly Garden. She has used the name ever since. The artist regards the diploma solo performance as the butō dancer's actual birth because an anonymous person who has been part of the group becomes artistically "complete" then. The moment is embedded in the traditional apprenticeship procedure. A prospective student finds a master and trains with him/her with absolute dedication. After years of training, the master (sensei in Japan) bestows on the student a name and the right to pass for an heir to a given tradition (craft, philosophy, religion, etc.). In this way, the tradition is passed down in unbroken continuity. Given this, TO-EN, when looking for an apt expression to convey the meaning of the act chooses to call it "anointment." Preserving the line of transmission intact is of key relevance to connections between subsequent bodies, which are links in this chain. At the moment of anointment, each "initiated" butō dancer becomes entitled to develop his/her own butō method, drawing on the master's method. The teacher guides the student's bodily process, which continues despite physical separation as the student's body is a development on and a continuation of the master's body. In this way, continuity is retained.

There is one process, but it is realised in various bodies. That is why it is important to choose one teacher, as participating in many short workshops offered by different dancers interrupts the process and destroys continuity. TO-EN is currently (2010) the only continuator of SU-EN's line. She is developing her own method based on SU-EN's method.

SU-EN spent several years in Japan, perfecting her mastery of Hijikata's butō method in Shizune's and Ashikawa's groups. Hijikata insisted that the Japanese body had an entirely different anatomy than the Western body (cf. "Tatsumi Hijikata: Structure" in Chapter 1). Importantly, what he specifically had in mind was the traditional Japanese body entrenched in the hardships of rural life. This insight has led SU-EN to conclude two things. First, bodily explorations in the West must concern "the Nordic body" (in more general terms, the European one); and second, a type of physical training must be developed which will help Europeans overcome limitations caused by their different bodily setup. As a result, she developed a two-layered method suited to the needs of Westerners. 
The SU-EN butō method involves basic training and so-called body materials. Basic training aims to prepare individual body parts (e.g. joints, the spine, the hips) for further work. "[T] he focus in on researching the body. Through exercises involving breathing, gravity, flexibility, strength and balance we challenge our habits and structures." TO-EN puts it more directly and vividly: "We have to dismantle our bodies into parts to put them back together again."

First the trainees assume the so-called initial posture with the centre of gravity located below the navel, which appears in terminologies of various Japanese disciplines (e.g. aikido and Zen) as hara. To describe the effect, TO-EN talks of belly power. Dancers practise so-called cuts, i.e. vigorous cutting of the body at the hip level which results in lowering the gravity centre. Muscles involved in breathing are trained, the diaphragm region strengthened and the dormant muscles (used for example to blow up a balloon or to retain urine) activated.

Such exercises produce a firm grounding characteristic of the Japanese body. It is connected with bodily awareness of how gravitation affects our bodies. Metaphorically, in Japan "the soul is in the belly" while in the West the personal core (that is, the self, mind, soul) is located where the heart is, in the chest; it is not a coincidence after all that pointing to ourselves, we touch the chest. This is reflected in Western dance forms (ballet, contemporary dance, etc.), in which movement is usually directed upwards and dancers fly in the air, often quite literally.

In using the SU-EN method, one focuses on particular qualities of the body, including resonance, spread and emptiness. This involves very intense activity of the body-mind. Artists grapple with their bodily habits and routines, challenging themselves as they seek to locate their weaknesses and work on what causes most problems. It is "an ongoing revolution, ongoing torpedoing of your own body. [...] crisis and pain are the daily bread of all buto dancers. Often we land at the bottom of the crisis in the body, where it seems that something is impossible and then you have to start building anew... and it can take a year or five years."

The mind finds itself in perpetual crisis. However, this crisis is the "private business of each dancer," who must take into account the group and the situation of other people. Consequently, everybody should handle their crisis all by themselves. Dance demands discipline: TO-EN "works in silence, focused and respectful of the space when dancing with other co-present bodies."

The process of metamorphosis starts from the erased/empty body, that is, the body stripped of any record. Emptiness is popularly associated with nothingness, lack and passivity, yet in this case "the void is a very active process [...], in this void you can experience a kind of tension which is not to be confused with strain, 
straining" of, for example, the muscles. "Tension" and "strain" are not to be conflated. TO-EN defines tension as the body's specific, internal activity, that is, a concrete physical state or process. Consequently, relaxation practices certainly do not serve to achieve the empty body. According to the artist, tension is "an inner activity resulting from the fact that something is emptying out; subsequently, this void resonates in a natural way." Achieved through intense effort, this state "must be reproduced in the body time and again." The empty body is "a state in which the body contours cease to exist and, by the same token, the person's identity vanishes. Anna Brałkowska is not on the stage."

Every dancer goes through a bodily transformation, learning to discover other models of his/her body's functioning. Though the process unfolds differently for every person, it is invariably lengthy. Predispositions to butō can be seen as early as in the first workshop sessions: "the body can alter so much that you can see the change after three days." Butō is quintessentially about metamorphosis, which can take place only if identity is given up. Transfiguration in butō is both a mental (representational) and a physical (bodily) act. For transformation to take place, first an appropriate state of the body mind must occur (erasure of contours, emptying out).

Body materials, the other level of SU-EN's method, needs an explanation. Generally, at this stage "the body is changed into various kinds of organic and inorganic materials." The body materials, anchored in the body primed in basic training, form the basis of butō choreography. "Body materials involve the transforming of the living body into other matter. [...] Choreographic processes, improvisations and structure are developed from this work."

Materials and images are something literal and tangible. It can be a crumpled sheet of paper, a tangle of roots, an anthill, mucus, a monkey running around, etc. Each element of reality finds itself in constant change, and the same sheet of paper never looks the same. The dancer's body-mind, likewise, flexibly undergoes an organic process. The body transforms into a type of matter and for this reason, in order to dance butō, one must always study matter, learning about how it functions, what it looks like, what weight, structure and texture it has. "Matter is the teacher!"

At this stage, language is used quite extensively, but the words do not serve to instruct. Rather, "the body is torpedoed with words which are supposed to effect something themselves, [to trigger] a transformation." The choreographer manipulates the body with words which catalyse metamorphosis. "There is a basic terminology which is constantly changing"; words are also organic. Japanese (which is also used in training by SU-EN) is a specific language with its own, 
distinctive imagery. TO-EN employs Japanese onomatopoeias which, as she insists, "are fuller and more telling." Notably, the Japanese used by Hijikata, the method's founder, was based on paradoxes and metaphors.

The body materials stage at Haglund involves very important outdoor training sessions. Dancers are involved in "perception and reality research. This work is done outside in the surrounding landscape, season or weather." Put into practice, the philosophy of nature also lies at the core of activities during Atsushi Takenouchi's Jinen Butoh summer workshops (cf. "Irena Lipińska: Choreographing Improvisation" in Chapter 3) and at Min Tanaka’s Body Weather Farm in Hakushu, Japan (cf. "Justyna Jan-Krukowska: Sensory Sensitisation" in Chapter 3), where artists study, work and dance together.

A staged event is the crowning point of training. It can take the form of a choreographed dance show, improvisation based on available materials, ephemeral actions, site-specific events, art in a public space or a multimedia event. The choreography of TO-EN's performances comprises a basic structure (of images and materials rather than of movements) which the dancer develops in the studio. Instead of a fixed, rigid form, the structure offers a frame within which images, objects and associations can flow freely.

Butō dance is first of all art, and the dancer's aim is to perform. "Woken up in the middle of the night, the butō dancer must be ready to perform. [...] You don't dance for yourself, but for the audience, for the viewer." This assertion can be confronted with Hijikata's insistence that "dance for display is not interesting" (Capiga 2009: 20). ${ }^{30}$ Because butō is essentially informed by the desire to express the body's truth, dance should not be approached as an aesthetic formula which seeks to please the audience. At the same time, the injunction to "express the body's truth" compels artists to expose themselves. The guiding idea is that "through the body on stage, through the fact that the dancer (his/her body) is dancing, the audience should be able to see themselves." For this reason, the artist believes that encounters with the audience are always vivid and organic. The ideal viewer "engages with art not only though the intellect or reason."

\section{Conclusion}

Butō is a dance of bodily candour. Individual physical and mental predispositions make the dancer choose a dance form that suits him/her (his/her body) best. "My body trains itself as a matter of course" (Hijikata 2000 f.: 76). SU-EN's method,

30 Hijikata's statement is sometimes understood to mean that dance designed to cater to the audience's tastes is not creative and, as such, not interesting. 
as well as TO-EN's method now, is based on a tripartite process, including: (1) erasing the body; (2) body materials (embodying matter) and transformation; and (3) constructing choreography. Training serves to make transformation into a given matter as comprehensive as possible and aims to overcome the body's inbuilt checks. The more restrictions there are that have been imposed by cultural codes, the more intense and radical the training must be.

\section{Irena Lipińska: Choreographing Improvisation}

Ever since she was a child, Irena Lipińska has craved to perform on stage: "As far as exercising my body is concerned, something has always been happening in my life" (WIL), ${ }^{31}$ she concludes. She practised ballet between the ages of six and eleven. As an adult, she studied acting for a year at Poznan's Akademia Sztuk Wizualnych (School of Visual Arts) (1996-1997), took part in dance and physical theatre workshops at Wroclaw's Centre of Studies of Jerzy Grotowski's Work and of the Cultural and Theatrical Research, ${ }^{32}$ practised yoga and participated in contemporary dance workshops organised, for example, by Bytom's Silesian Dance Theatre. Initially, in courses and workshops, she learned mainly contemporary dance, which she describes as "swinging your arms and legs in sync, full of movement sequences which are a pain to remember." Disappointed, she continued to look for another form of stage expression that suited her expectations more.

She first saw butō performed by Daisuke Yoshimoto at the Jerzy Grotowski Institute ${ }^{33}$ in the 1990s. She remembers: "I didn't think then that my body could do something like that." It was only in 2008 that she first decided to take part in a butō workshop. The course taught by Atsushi Takenouchi in Pondera, Italy, took a month (cf. "Justyna Jan-Krukowska: Sensory Sensitisation" in Chapter 3). Even though the project was intended for professional dancers while Lipińska had hardly any prior stage experience, Takenouchi agreed to admit her. The very intensive workshop deeply affected her understanding of butō.

In the early 1980s, Takenouchi as a young man (aged 18-24) was involved with Hoppo Butoh-ha, a company led by Ippei Yamada (Bishop Yamada), where he underwent very difficult and physically exhausting training founded on Tatsumi Hijikata's injunction "kill your body." It took years of dancing butō before Takenouchi discovered his own specific practice, as Lipińska relates his memories.

31 Unless indicated otherwise, all quotations in this section come from WIL.

32 Now the Jerzy Grotowski Institute in Wrocław.

33 Then called the Centre of Studies of Jerzy Grotowski's Work and of the Cultural and Theatrical Research. 
Before that, discouraged by the radical model of butō, he engaged with its milder form which he learned from Kazuo Ōno, the master of improvisation. Having trained and explored butō for years, Takenouchi developed his own philosophy and method called Jinen Butoh and founded his first school "Dance with Nature" (1986).

Jinen is the word that describes the universe, its origin and the natural course. All things connect to this river, and are part of the river of Jinen. [...] The Jinen view of nature exists in the art forms created by ancient people. (Fraleigh, Nakamura 2006: 131) ) $^{34}$ [I began working] with children, parents, and young people, teaching them in very simple ways how to dance, cook, and make natural dyes from plants - how to make sculpture, pictures, calligraphy and visual artefacts from natural materials [...] I also used a lot of natural movement as butoh does, but freely choreographing in my way. (Takenouchi, qtd. in Fraleigh, Nakamura 2006: 131)

Takenouchi's art is often referred to as ritualistic and rooted in Japanese animism. His movement originates in the universal expression of nature and ancient wisdom (Fraleigh, Nakamura 2006: 129). His method is founded on the Jineninspired worldview. ${ }^{35}$

During the workshop which Lipińska attended, three groups of six people each worked ten hours a day. Each day began with four-hour warm-ups, in which two sets of exercises alternated. Both were based on Hatha Yoga, exercises borrowed from Hijikata's training and meditation techniques. It was inherently a group practice: "The group is like a family. The necessary energy is accumulated and the rest follows by itself," concludes Lipińska. Training did not aim to overcome bodily limits and was interrupted when the limit of physical endurance had been reached (the limit tended to be transgressed by the upholders of the training method used by Hijikata in his Tokyo studio). The warm-up was followed by improvisations around assigned themes, which ranged from the natural world to emotions to mental disorders. Improvisation often started from butōs characteristic zero walk (cf. “Terms").

Lipińska considers Yumiko Yoshioka (cf. „Biographical Notes”) her other important teacher. Yoshioka, a co-founder of the TEN PEN CHii Art Labor, creates performances where dance is enveloped in the context of visual arts, which results in what can be called butō installations. Yoshioka has developed the body resonance method, which is grounded in the idea of a constant resonance between bodies and objects:

34 Jinen (Japanese) - everything, the whole universe and entire nature.

35 For descriptions of techniques used by Takenouchi, see also Fraleigh, Nakamura 2006: 132-133. 
Our life consists of continuous interactions between nature, society, energy, and ourselves. [...] The world, including our body and soul, consists of vibrational waves [...]. When we tune our body to a certain frequency, we consequently get a resonance [...]. In order for this to happen, we need to first get rid of unnecessary tension. (Yoshioka, qtd. in Fraleigh, Nakamura 2006: 118-120).

In her studio practice and training, Yoshioka uses elements of yoga, tai chi and, first of all, Noguchi Taiso (cf. "Terms"; "Krzysztof Jerzak: Peak Experience" in Chapter 3). The dancer learned the latter method first from its founder, Michizo Noguchi. Noguchi's gymnastics is based on "the body's dialogue with gravity and integration of the body with image and feelings (the senses)" (Fraleigh, Nakamura 2006: 120). Yoshioka also shares his belief that both movement and language originate in the body and are rooted in it. In the ideograms, language (meaning) is linked to image (form) and "that is why it's difficult to translate Noguchi's work into foreign languages" (Fraleigh, Nakamura 2006: 120; Koseki 2009).

Like Takenouchi, Yoshioka puts the act of transformation at the centre of her philosophy and practice. "We make a white canvas of our body in order to paint new color on it. I teach this as neutralization" (Yoshioka, qtd. in Fraleigh, Nakamura 2006: 120). Her preferred transformative form of training (preceded by relaxation and energising exercises) is the "hanging body" or "water bag." 36 Dancers create a mental image in which their bodies are bags filled with rocking water; the "bags" suspended from a rope stretching from "the center of the sky" (Fraleigh, Nakamura 2006: 121) and attached at the other end to their heads, ears, elbows, etc. while their feet take root in the ground. This image is then embodied in movement. The bag of the body is shaken, exposed to impulses from within and without, stretched and squeezed; the water inside moves and circulates, making the body pulsate and billow. Dancers feel the flow (or, rather, become the flow), play with the possibilities offered by the water and juggle with its properties, as the water can be thin, dense, clean or polluted. At the beginning, they move consciously, but then they let the wave surge. This is where movement - dance is born.

We have so many different states of energy within; they may look like contradictions or contrasts, but actually they are all organically connected. [...] Butoh (dance) for me activates divergent body energies that are usually not seen or permitted in our daily life. In other words, as our body is a receptacle of time, we can evoke its forgotten memories through dance. (Fraleigh, Nakamura 2006: 122-123)

36 For details of the exercises, see Fraleigh, Nakamura 2006: 121. 
The warm-up comprised of relaxation, energising and "water bag" exercises is followed by interactive exercises with partners, which continue and expand on the wave formula.

Lipińska considers Yoshioka's butō to resemble very much and, at the same time, to complement Jinen Butoh. As Lipińska sees it, Yoshioka's butō consists in "identifying points in the body through water or air..." The points form a body frame, which is our point of reference.

Lipińska's third important teacher of butō is Daisuke Yoshimoto. He offers an entirely different model of training. Yoshimoto seems to subscribe to Hijikata's demand to "kill your body." Physically crossing the limit of the body's endurance, dancers can go beyond the dedication to their own identities and egos. This enables them to transform fully into another form of being.

In her butō, Lipińska employs methods she learned when studying under Takenouchi, Yoshioka and Yoshimoto. Within a collaborative project with the Jerzy Grotowski Institute, she went on a research trip to Japan in the footsteps of female butō dancers.

It is important to practise butō with various dancers. In this way, your blinders fall off, and new impulses appear. They make us re-think many things. The process is important: not only taking and giving, but also opening up to something.

According to Lipińska, whichever practice model works for us, "training is a must if something is to happen in the body at all. The body must be prepared. Whether it's yoga combined with tai chi, like in Atsushi, or killing the body, like in Daisuke. It is due to training that the body doesn't lose the neutral state."

Lipińska's training is based on regular running, though she has also practised Hatha Yoga, Ashtanga Yoga and meditation. They all help her prepare the body-mind for movement improvisation which aims to explore how her bodymind functions. Her training can be described as integral as she also considers preparatory activities, such as cleaning the room, to be part of her training practice. Three-hour-long warm-ups also include her own configuration of yoga asanas with or without music, energising and relaxation exercises and meditation. In the butō workshops she teaches, the artist uses the techniques she learned earlier, such as slow and quick falling and raising, zero walk and water bag, which enhance focus and consequently prepare for body-mind explorations.

Focus-enhancing techniques serve, according to Lipińska, to "empty out the body-mind," that is, to strip it of all the points of reference, psychological and social influences, habits and blueprints, to go back to the child's - or, rather, the infant's - consciousness, to the time when the human being does not divide the world into what $s /$ he identifies with and what $s /$ he finds foreign. Dancers must 
first of all get rid of all automatisms: actions and responses which they like and find obvious, yet which appear not because they are suitable but because they are habitual.

The fundamental and desirable state in butō is natural flexibility and openness. Emptiness in butō

$[\ldots]$ is the purity, the honesty that emerges there. When you start meditation, you don't presuppose you'll be a void. And that's the honesty of being. You don't become an empty receptacle because of assumptions or will; no, this simply happens. It's about getting into the situation, into what's going on, without calculating, without interpreting.

Being an empty receptacle, the dancer can take in everything that is happening within and around him/her. But it is not "about filling the receptacle; it is about pouring things through it." Obviously the pouring (of ideas, images, visions) into the receptacle (the body-mind) is not subject to conscious control because "if you assume that you can do something, for example put something into this voided body, it means you're actually not voided." This state (the neutral state) promotes "getting closer, communication between my world and somebody else's/different/another world." A relationship evolves between dancers in the act of self-transformation

[...] their worlds communicate. This just happens, and verbalisation is not necessary. [...] Dancers don't receive the impulse consciously, they just do it [respond]. [...] Both an individual dancer's action and the group's action are based on impulses from the body. [...] The impulse is above your intellectual or para-intellectual assumptions.

You can call this situation continuous communication. "Both the (individual, closed) monad and group actions matter." For this reason, interaction with various artists is vital. "When you study only with one teacher, it more closely resembles therapy, where we work with just one therapist."

According to Lipińska, the neutral state (zero state) does not involve trance, i.e. the loss of self-consciousness.

Trance is complete abandonment, where you reject consciousness. [...] It's rather a kind of oblivion. It involves, for example, simultaneous being and not being on stage. But, for me, butō dance doesn't consist in getting into a trance on stage [...]. I'm present on stage, but at the same time I forget myself. I'm a vehicle, it's linked to theatre, I'm a medium between what I want to communicate, the world that is going on somewhere within me, and that which is happening in the intersubjective space at the moment $[\ldots]$ It's not that I deliberately get my body into a trance; I don't use any techniques that would lead to that $[\ldots]$ Obliviousness comes unplanned.

After the warm-up, which fosters focus and openness, Lipińska proceeds to improvisation exercises, experimenting with her body. She looks for movement: "I start from the point I set for myself and look for movement; sometimes I put 
down my discoveries, but it's not related to designing a performance." In butō improvisation, an inner transformation takes place, but it has nothing to do with a conscious therapeutic practice.

I still don't accept the word "therapy" in the context of butō - dance doesn't serve me to heal my problems. [...] Dance therapy is completely different than training in butō. [In butō, the body] is a tool [for] touching something, finding something. [...] I'm not even trying to find any terms to express what is happening there [in butō], but it's certainly not self-healing.

Lipińska views therapy as based on a pattern of identifying a problem to be solved and then taking steps make it possible to solve it. In butō, on the contrary, patterns are not taken into account; there is only an opening to the unexpected, to "what comes from beyond us and to what we have within (which doesn't have to be a trauma or a problem)." For this reason, common openness is more useful. "If a person comes to the workshop all tied up, isolated from his/her inner process, nothing will come to pass in fact and everything will be happening in one point only." At the same time, Lipińska does not deny that butō dancers get in touch with emotions. However, they do not evoke individual memories, images, the experiences they remember or emotions as buto is not based on the material that can be consciously and intellectually brought out of oblivion. When dancing butō, the body is rather a vehicle and a medium.

When I dance death, for example, [...] I certainly don't evoke any memory images [...], I don't evoke any specific emotional situations from my life, such as the death of a loved one, but I simply let death appear. [...] we've got this within whether it appears in our tissue now or did once, somewhere.

Resulting from training, the body's openness to flows and impulses makes "butō more like a colourful jelly in which autistic children bathe than like antidepressants." According to Lipińska, butō usually uses "improvised choreography or choreographed improvisation":

It's not a calculated choreography, but still choreography. [...] Choreography [in butō] has some assumptions and fixed points, but movement is not arranged in sequences, which is the case in contemporary dance. It's still improvisation because at each moment [movement] emerges from the body.

Importantly, in his later period, Hijikata choreographed each second of the performance by means of imaginary wordings (recorded in the butō-fu).

Lipińska explains: "The impulse emerges spontaneously, independently of our will or even consciousness, in the body, also during the staging based on a prior choreography." "During and after training, a theme or a story appears which can 
be worded to a degree. [...] I've danced some stories, narratives which I've had in my head." For example, her hydrohypno (2009) was inspired by a specific state of mind which occurs while falling asleep.

I'm fascinated with my body in the in-between moment, in the moment of suspension. I began to work with it, explored it, and various images, various stories appeared, from which movement emerged and then choreography. [...] I develop choreography but don't devise concrete movements in advance. Obviously there'll be movements which I'll repeat in the same way, moments [fragments] which I'll use in the show [...]. I find a certain starting point, I have certain images, representations and the rest happens as I engage in action [...] My work is not about remembering everything. I note down some fleeting, important things so as not to lose them.

Both in a stage production and in an improvisation, continuity is the most important aspect, which means that images should change in a continuous way. The artist does not approach images literally: "If I'm, say, a tree, I'm a tree as a whole, I don't divide my body into the trunk, the branches. I try to feel the process taking place in me, for example, sucking in water." According to Lipińska, "what is being danced" (e.g. a tree) does not find itself on stage alone as there is also the dancer-observer there. "This effort switches off the personality state in me, but I am still Irena, a human being who has entered the stage and wants to communicate something. On stage, I'm Irena here-and-now, my body, but not Irena's life history or identity.'

Transformation does not concern the identity the dancer has outside of the performance, but reaches beyond his/her personal history with temporal relationships and memory structures. "Butō has the power to make the reader appreciate something that is above and beyond, something that all those present share. It transmits something that is common to us all, something that exists even at the level of biology."

Butō is associated with "what I feel, with honesty [...]. As such, butō does not only appear in shows of butō dance"; it also represents a universal quality that can be found across various dance aesthetics. For Lipińska, butō dance was just a starting point for explorations of body-mind, movement and dance.

In 2010, Lipińska completed the Stage Choreography Course at the Artistic Alternative Art Studio [Artystyczna Alternatywa Art Studio] (AA) in Cracow. The course included classes in theory and practice. At the end of the course, the students staged a dance show with their own script, choreography, lighting, music, etc. Lipińska presented line, a performance based on the philosophy of butō dance with elements of contemporary dance and verbalisation (a story of dance in the glossolalic mode). Also in 2010, she received an Alternative Dance Academy (AAT) scholarship. AAT is an arts-and-education project of Poznan's Old Brewery New Dance (Stary Browar Nowy Taniec) curated by Joanna Leśnierowska and 
targeting professional dancers. AAT involves a series of intense workshops during which invited teachers - dancers and choreographers associated with the recent styles of contemporary dance - coach participants in their respective working methods. Lipińska got to learn the methods used by Arkadi Zaides (Israel), Ria Higler (Netherlands), Chris Haring (Austria), Peter Pleyer (Germany), Simone Aughterlony (Switzerland), Isabelle Schad (Germany), Jonathan Burrows (UK), Michael Schumacher (Netherlands/US) and David Zambrano (Venezuela/ Netherlands). The dancers and choreographers explore movement, develop new methods/techniques based on minimalist and conceptualist formulas and integrate in their work elements of somatic education and improvisation methods used in dance movement therapy (authentic movement). Lipińska also took part in other contemporary dance theatre workshops (taught, for example, by the dancer and choreographer Meg Stuart at the ImPulsTanz in Vienna, 2010) and in a nine-month internship project at the ZAR Theatre (Teatr ZAR), ${ }^{37}$ which cultivates psychophysical theatre (2010/2011). The artist claims that various methods used in contemporary dance and various ways of understanding it help her "open up to other possibilities, especially because such practice isn't based on mechanically repeated sequences. You also talk for hours on end and engage in various somatic practices."

In March 2011, Lipińska became a Solo Project ${ }^{38}$ resident and created the performance DNACE as part of her residency.

\section{Conclusion}

Lipińska started her career as a dancer from butō. She learned about the philosophy and training of butō at workshops taught by Takenouchi (Jinen Butoh), Yoshioka (Body Resonance) and Yoshimoto, who represent various approaches to and schools of the genre.

37 The participants have an opportunity "to take part in the ZAR Theatre's daily work and to witness the artistic process develop; [...] to attend the winter Studio spanning over two weeks of precious meetings and experiences in collaboration with other students and practitioners from all over the world, [...] during the internship, the ZAR Theatre will organise three practical seminars devoted to the group's explorations and musical sources of inspiration" (Sta $\dot{z} w$ Teatrze ZAR n.d.).

38 Within the project "artists receive funding, rehearsal space and publicity as well as [...] they get an opportunity to develop a fully professional solo dance show. [...] the project's main emphasis is not so much on completing the product-performance but on the creative process itself [...]. The project is guided by the words of the British choreographer Jonathan Burrows: 'To make dance, you need two legs, two arms, and first of all - a head"” (Solo Projekt 2011). 
According to Lipińska, butō practise is crucially grounded in physicality, i.e. in training which involves long-distance running, Hatha Yoga, tai chi, meditation, elements of Hijikata's training and Noguchi Taiso. Such training primes the dancer's body-mind for "yielding to" improvisation. In her opinion, irrespective of which technique one prefers, practising butō aims crucially to induce a neutral state in the body-mind and prepare it for profound exploration, which culminates in transformation. This is what she thinks "emptiness" in butō is: opening up to what the body-mind does not know, being a blank page, acting as a medium. While openness and mindfulness of everyday experience are important factors, the impulse for movement originates in the body and, ultimately "improvised choreography or choreographed improvisation" is produced.

Currently, the artist's major source of inspiration for body disciplines is the work of contemporary dance choreographers who engage in somatic explorations and experiment with the concept of performance as such. Butō, though a very important starting point, is already a closed chapter in her life as an artist.

\section{Katarzyna Żejmo, Iwona Wojnicka, Miho Iwata and Rui Takayuki Ishihara}

Katarzyna Żejmo has a background in fine arts. She graduated from Professor Stanisław Wieczorek's Multimedia Studio at the Faculty of Graphic Arts, Academy of Fine Arts in Warsaw, and obtained a BA degree in fashion design from the Faculty of Textile Art and Fashion Design, Strzemiński Academy of Art in Lodz.

She has used various opportunities to learn an array of body disciplines: she took part in drama-focused educational workshops organised by the Forum Theatre and in mime workshops taught by Stefan Niedziałkowski and his guests. She studied at the Gardzienice Academy for Theatre Practices (2005). She has practised yoga since 2005. She spent two years in India, where she learned Ashtanga Vinyasa Yoga at the Sri Krishnamacharya Institute (2008) and completed a course for instructors in asanas, pranayama, philosophy and mudra taught by Bellur Krishnamachar Sundararaja Iyengar (2009). "Yoga is all about breathing. It's a practice of the fullness of life. In yoga, I look first of all for internal harmony, calm, relaxation and keeping my body healthy and fit." ${ }^{39}$

She learned butō at the Subbody Resonance Butoh School Himalaya (SRBSH) founded by the Japanese butō dancer Rhizome Lee in Dharamsala, India. She also took part in workshops taught by Atsushi Takenouchi and Daisuke Yoshimoto.

39 http://izabelin.pl/centrum/ index.php?wpis=wpis_20110105093613 [4 June 2014]. 
Żejmo defines butō as "leaving behind all conditions that constrain the individual; it's transformation into the suijakutai, the so-called weakened body, and entering other dimensions that differ from the human world, it's becoming a being from another world." 40

Żejmo is interested in "synthesising the idiom of Western performance art, contemporary theatre and wild, raw, primordial improvisations of movement in traditional butō dance."

The most important element of my work is integrating apparently random elements found objects, dreams, visions - into movement and dance. Time is an inseparable component of my work. I treat it in a multidimensional and multi-layered way. Natural weather conditions (light, temperature, etc.) and emotional states make time an autonomous element of compositions which open up to chance and change.

Żejmo uses the subbody method (SRBSH, "What is subbody?" tag), which was briefly outlined in "Rhizome Lee: Butō as a Path to the Subbody" in Chapter 2. The most important themes of the Body in Resonance workshops she offers include: subbody ("It designates other bodies, subbodies that inhabit the dark corners of our bodies. It's a creative and communicative body. It's a great creator of the imagination, dreams, fantasies and dance"), cobody ("It means several subbodies united into one whole") and resonance ("It stands for a force which makes the subbody move with others and communicate with the entire world").

Currently, besides teaching Body in Resonance workshops and yoga classes, she is a Thai massage nuat tai instructor and designs theatre costumes.

Iwona Wojnicka is a curator, a performer and a researcher of human body movement. She develops arts education projects focused on dance, especially as part of the Zero Format Association [Stowarzyszenie Format Zero], which implements EU projects in artistic dance. With a degree in sociology, she also graduated from the postgraduate programme in Dance Theory at the Fryderyk Chopin Academy of Music ${ }^{41}$ in Warsaw and is a certified instructor of Hatha Yogabased movement recreation. She is theoretically and practically involved with the Laban Movement Analysis (training at the moment as a movement analyst and studying at the Fortbildung Basic in Laban/Bartenieff Bewegungsstudien, EUROLAB Fortbildung \& Zertifikatausbildung in Berlin).

In 1998-2000, Wojnicka performed in productions staged by the Mimes' Theatre [Teatr Mimów] founded by Stefan Niedziałkowski at the Na Woli Theatre

40 Unless indicated otherwise, all quotations from the artist come from Katarzyna Żejmo's CV (courtesy of the artist).

41 In 2008 the school was re-named the Fryderyk Chopin University of Music. 
[Teatr na Woli] in Warsaw. She refers to her pantomimic acting when describing her first experiences with butō:

For a few years I danced a dying tree for Niedziałkowski, and in Takenouchi's workshops we were supposed to dance a tree's life-cycle from the seed to the ash. It was an enormous challenge, and it took me a few years to process my inner tree. Body memory proved stronger than theory and practice combined. (Wojnicka 2011)

In 2002-2010, Wojnicka collaborated with Takenouchi on the Globe Jinen Butoh projects, including performances and master classes. She danced in her original productions Butoh Body Chlewiska (2003) and also in Tanz Cooperativa (2004), Butoh Barter with Takenouchi (2005-2010), Butoh Buzz with Joan Laage (2006), a "butō opera" Taniec lasu [Forest Dance] with Kan Katsura and Tomasz Rodowicz (2006), Ciało i głos [Body and Voice] with Katsura and the Chorea Theatre (2007) and in a few stagings by the Limen Theatre.

In 2006, Wojnicka started her own research project on Body Poetry, inspired by Japanese poetry and painting, and staged a solo show entitled $R i$, in which she used fragments of music scores of the Chorea Theatre. At the same time, she started an internship at the Synergasia Theatre in Athens (2007). In 2007-2009, she coordinated a Ki Mu Studio project within which she organised dance workshops and herself taught butō workshops using the original KI MU method (BIW).

Studying inspirations, I came to develop two basic methods which organise my work. They're $K i$, i.e. flow, and $M u$, i.e. emptiness. They derive from the artistic concepts of ink painting and Buddhist aesthetics [...] In the Ki (Qi) flow concept, body movements, like the movements of a paintbrush, don't imitate the life of nature but are, as it is itself, life as such, nature as such. Dance can revive the minds of the contemplating audience and make them able to resonate the vitality it conveys. [...] This unity is founded on emptiness. (BIW)

Wojnicka develops all her projects in collaboration with the Zero Format Association (founded in 2003) and other institutional partners. Most of her butō projects have been realised jointly with Warsaw's Pracownia Wschodnia [Eastern Studio].

In 2011, Wojnicka started a PhD project in arts at Warsaw's Fryderyk Chopin University of Music. ${ }^{42}$ She did her research on working methods in butō dance theatre ${ }^{43}$ at the Codarts in Rotterdam (2010-2012), a leading school of modern dance in Europe which continues the artistic tradition of Rudolf von Laban. In 2012, she began to study human body movement at Ex Nunc, a school of modern dance in the Hague.

42 Previously Fryderyk Chopin Academy of Music.

43 I found out about the project only when the book was already in print. 
Her most important performances related to her butō practice include Taniec lasu [Forest Dance] (2007), Mierzeje [Spits] (2008) with Elżbieta Piasecka and Katarzyna Orowiecka, and AOI (2008) with Anna Achimowicz (contemporary dance, physical theatre).

Miho Iwata was born in Ichinomiya-shi, Japan, in 1962. She studied architecture at the Kyoto Prefectural University. She first came to Poland in 1984, and two years later she settled in Cracow.

As a child, she learned classical dance techniques and later also studied jazz and modern dance. Though Japanese by birth, she discovered and learned butō dance only in Poland, when having met the dancer Daisuke Yoshimoto in 1991, she developed a fascination with this performative genre. She also saw Kazuo Ono's and Min Tanaka's performances in Poland.

She develops all her shows and performances, from choreography to stage design, by

herself. [...] In her performances, a considerable role is attributed to numerous references to archetypes and cultural clichés. They combine constructs typical of Western civilisation with notions and metaphors of the East (e.g. butō and others). As a result, Iwata's works attempt to create a transcultural and universal, though at the same time very intimate, idiom which, balancing between movement and gesture, engages in a conversation with painting aesthetics and its action practices. (Lewandowski 2008)

Iwata's performances include Nogi gotębia [Legs of the Pigeon] (1994), Granat (1996), Księżyc i kark rybi [The Moon and the Fish Neck] (1998) and Utsusemi (2001). Since 2002, she has worked on the Tysiac snów [A Thousand Dreams] project (improvisations, shows performed in silence without theatrical light and sound effects in natural settings, using the place's natural ambience). Besides, she creates performances that accompany art exhibitions (sculpture, installations and video installations) and collaborates on multimedia projects and improvisations with musicians from the Improvising Artists ensemble. She engages in art inscribed in spatial contexts. Similarly to Justyna Jan-Krukowska, she uses body practices to study artist-object relationships. She cooperates with Cracow's Open Studio [Otwarta Pracownia] gallery.

Rui Takayuki Ishihara was born in Kyoto in 1976. He studied at the Faculty of Agriculture, Kyoto University, and graduated presenting "a thesis on The Zone of Nature, devoted to a retro-interpretation of the Shizen (nature) concept from the perspective of holism." ${ }^{4}$

44 Unless indicated otherwise, all information about and quotations from Ishihara come from Internet websites: http://www.winda.gda.pl/aktualnosci_177.html [3 April 2011]; 
As a student, he got involved in theatre and fine arts. Inspired by actors such as Megumi Nakamura (classical and contemporary ballet), Min Tanaka (butō), Kazuo Ōno (butō) and Simone Forti (postmodern dance), he started to research dance and the body. He studied butō dance under Masami Yurabe and Tanaka. At the same time he practised meditation and trained Budō Waraku (a Japanese martial art).

His career as an artist started in 2001, when he performed with the Arrow Dance Communication group (Kyoto). Later, he performed, for example in the trilogy Life-Size Universe in Kyoto, Ku-dai/Untilted (2003) and the improvisation series Experiences in a Body Dancing, no. 1-no. 4 (Tokyo, 2003-2006). His most famous project is Kanademai, a dancing pilgrimage across Italy, Ireland, France, Poland and Serbia, which commenced in 2006 (Wilk 2011). His other performances include Uta no sasagemono (2006), First Reaction (2008), Hospitality for Darkness (2008), Kappa (2009), Tsuki moribito, hi-moribito (2009), Legenda bez legendy [A Legend without a Legend] (2009), Sen pszczoly [A Bee's Dream] (2010) and Spektakl ulotnych cieni [The Spectacle of Fleeting Shadows] (2011). Ishihara creates improvised shows in natural and artificial settings.

He runs workshops in which he shares with the participants his vision of butō, which resembles Atsushi Takenouchi's Jinen Butō:

Butō is a word that describes a dance of the beginning. Butō is an authentic attempt to reach the place your dance originates in. In the process of arriving there, you'll find out about your entire life, the one you really live, the one that breathes within you. You will touch your environment anew and you'll taste the world. You'll discover harmony of your fragile existence with all beings. Butō includes all these processes and dance that cuts across them.

Within his workshops, Ishihara offers relaxation and breathing exercises, meditation, exercises in arm and chest movement, voice practice and dance with and without imaginary wordings.

Listen carefully. You'll find something that you can only do in this very moment. Feel it deeply and with your mind at peace. Look without thinking at all. Touch as slightly as possible. In the body, here-and-now and in the environment, you'll rediscover brightness, darkness, warmth, cold, a variety of sounds, colours, tastes and smells of desires and memories (the future and the past), and yourself (the present).

http:// butōh.dreamhosters.com/?page_id=2 [3 April 2011]; http://teatrnawoli.pl/ home/2259/ index.html [3 April 2011]; http://www.fundacjapompka.org.pl/artysci/ rui-takayuki-ishihara,6.html [4 July 2014]. 
Photo 1: Paweł Dudziński, photo Gabriel Obolewicz

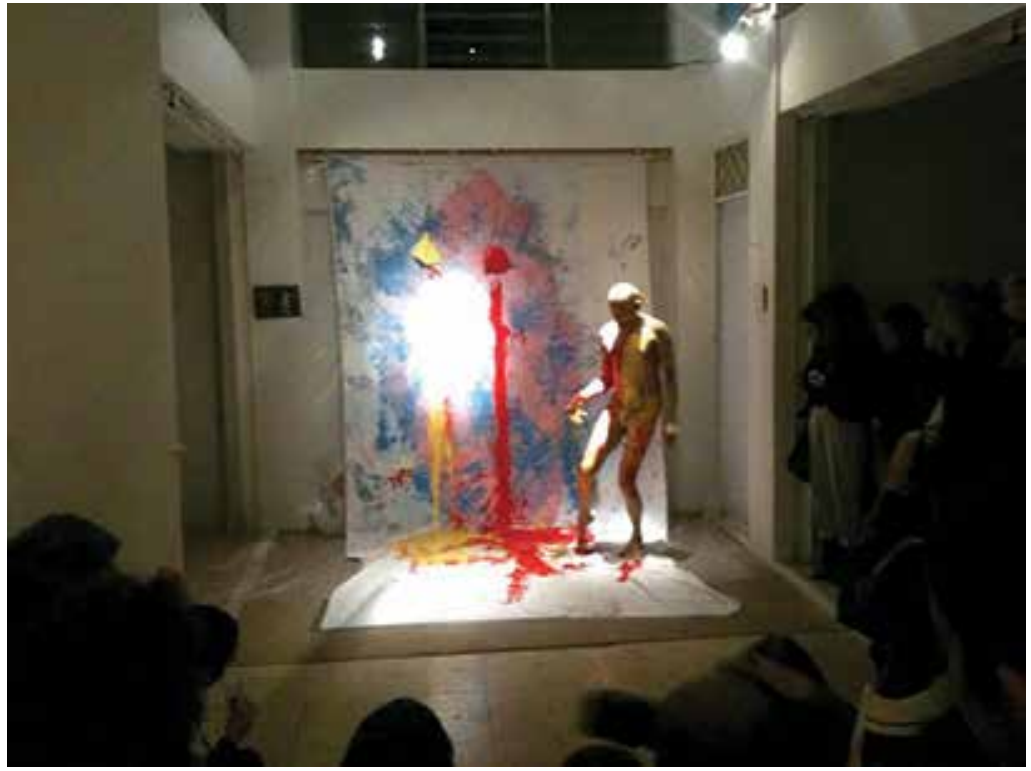

Photo 2: Paweł Dudziński, photo Piotr Mazurek

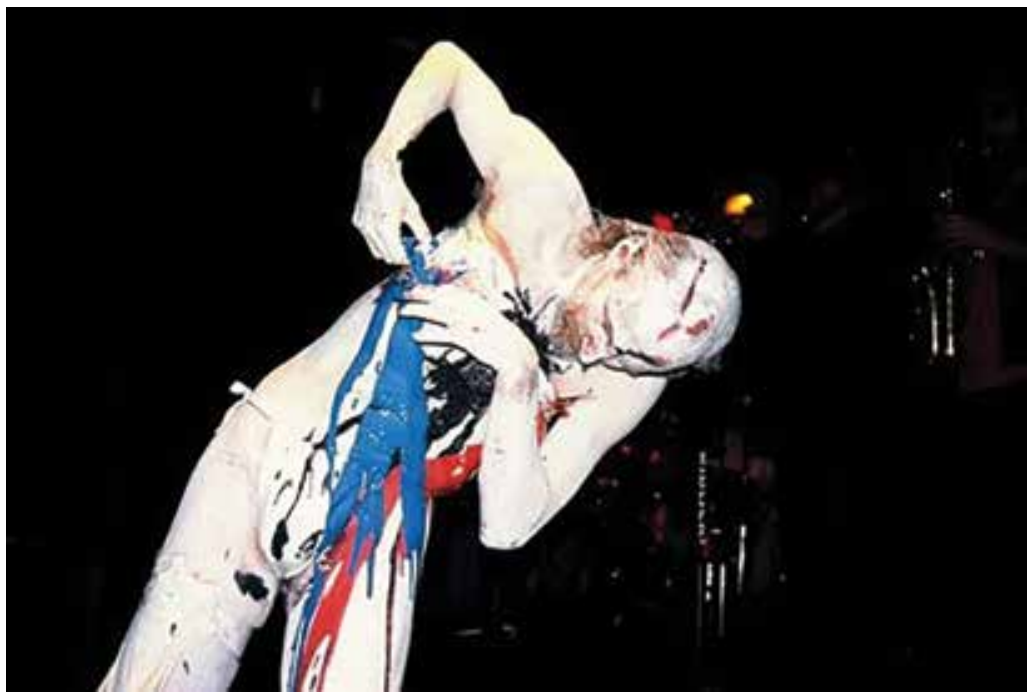


Photo 3: Paweł Dudziński, Incantation 2, photo Michał Popiel-Machnicki

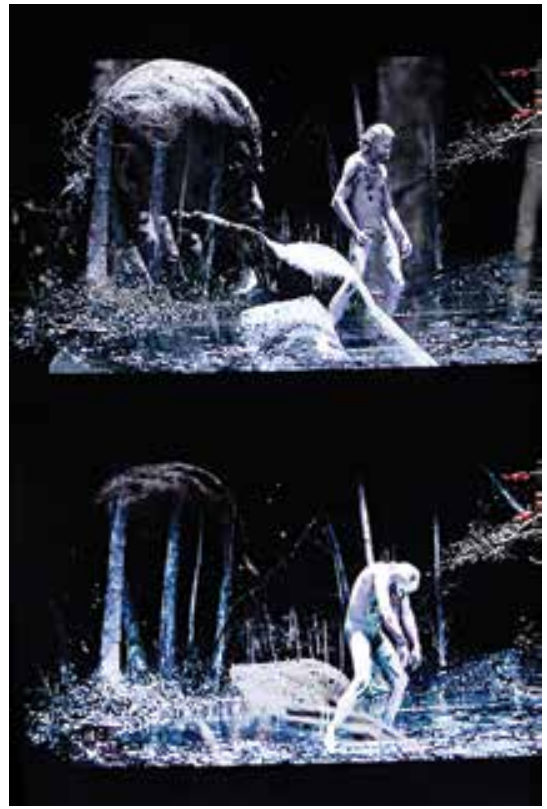

Photo 4: Justyna Jan-Krukowska, Water \& Fire Ritual, photo Kamil Zaremba

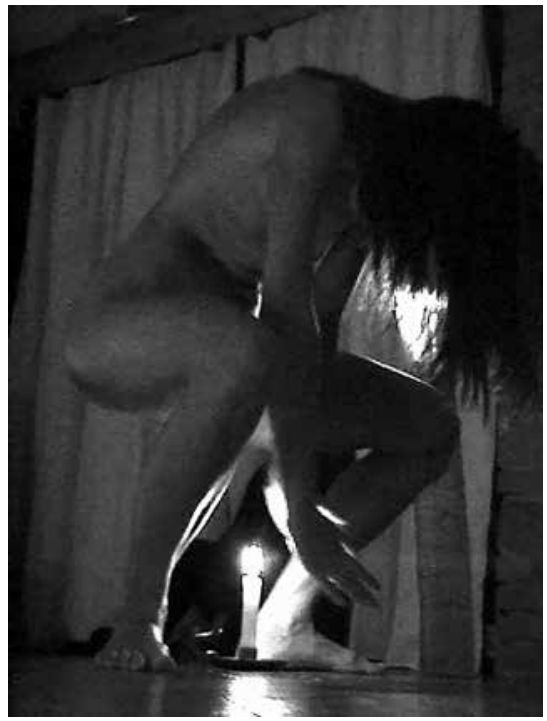


Photo 5: Justyna Jan-Kurkowska, A Lady's Dressing Table, photo Kamil Zaremba

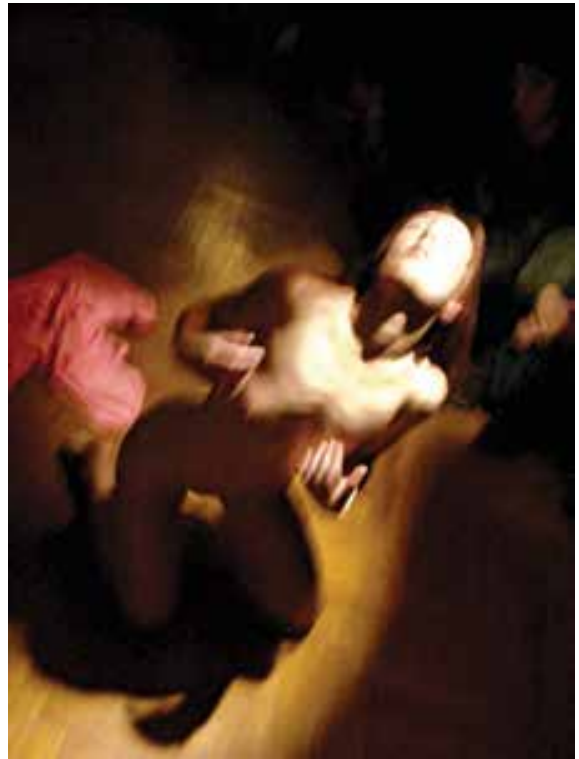

Photo 6: Justyna Jan-Kurkowska, A Lady's Dressing Table, photo Kamil Zaremba

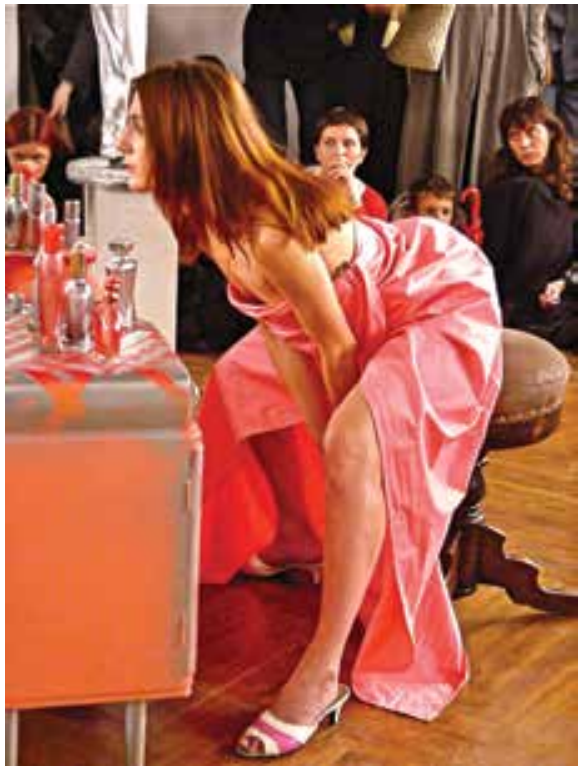


Photo 7: Sylwia Hanff, 8 Deserts, photo Arkadiusz Rączka

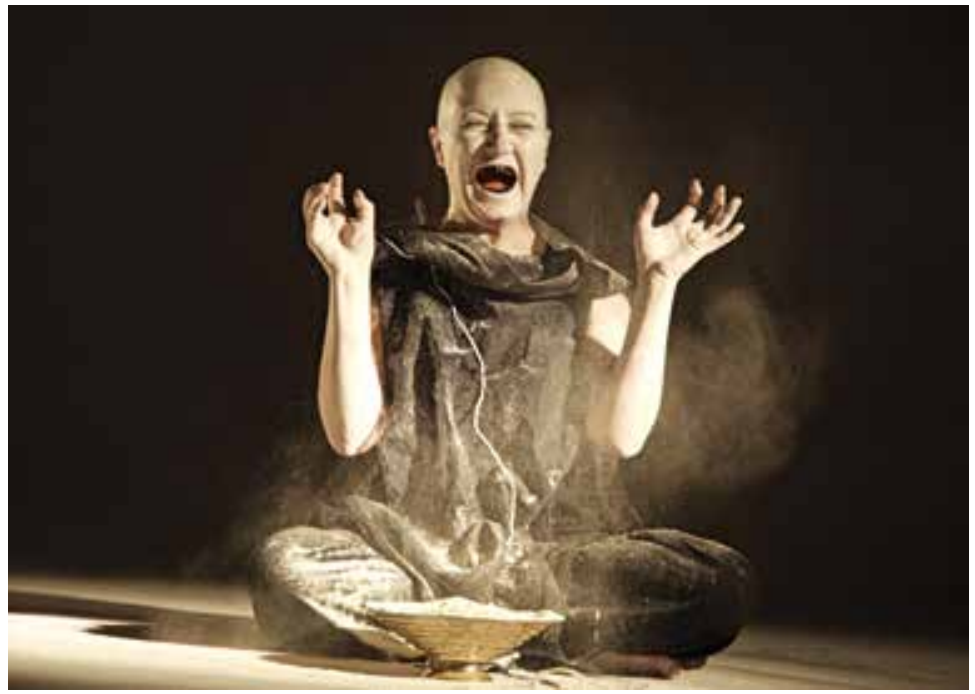

Photo 8: Sylwia Hanff, 8 Deserts, photo Arkadiusz Rączka

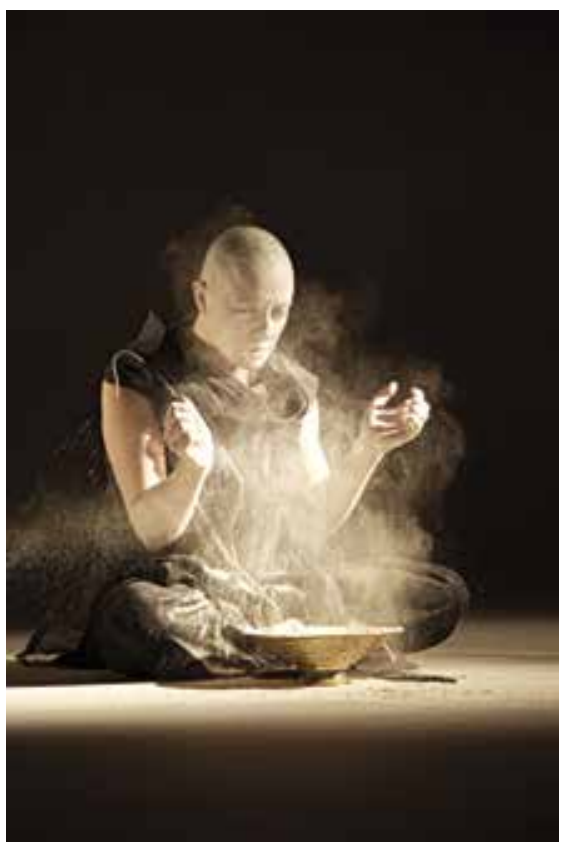


Photo 9: Sylwia Hanff, The Ocean's Dreams, photo Marta Przybyło

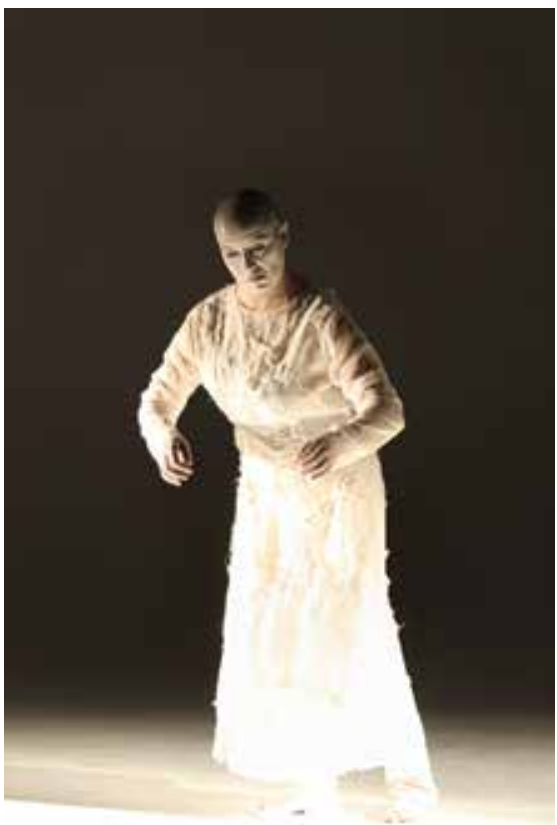

Photo 10: Krzysztof Jerzak, Straw-butō, photo Monika Cichocka

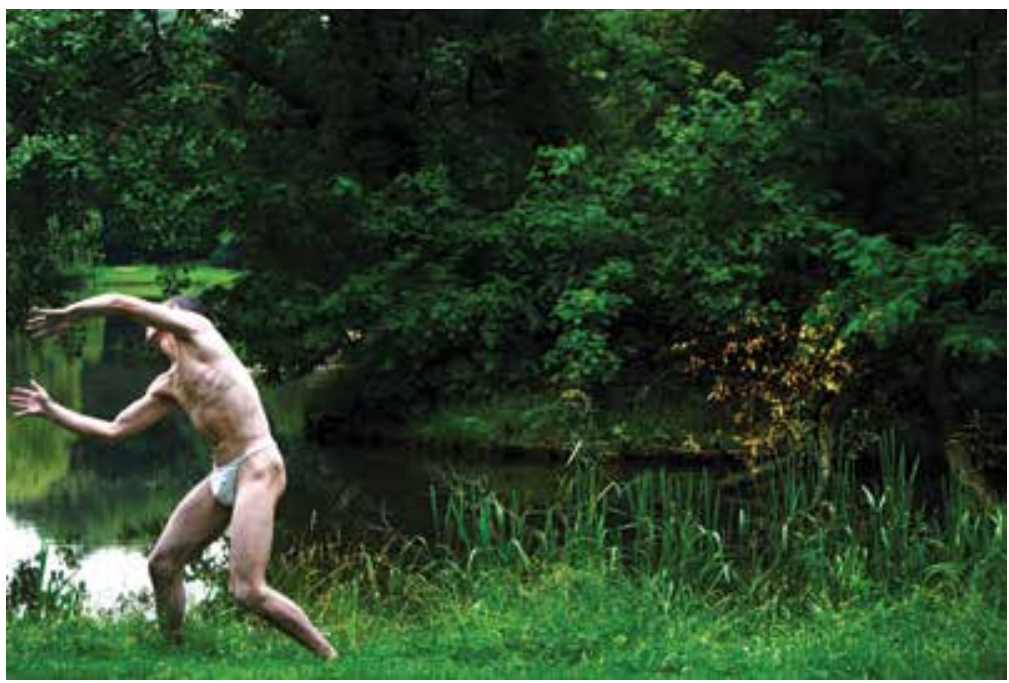


Photo 11: Krzysztof Jerzak, Straw-butō, photo Monika Cichocka

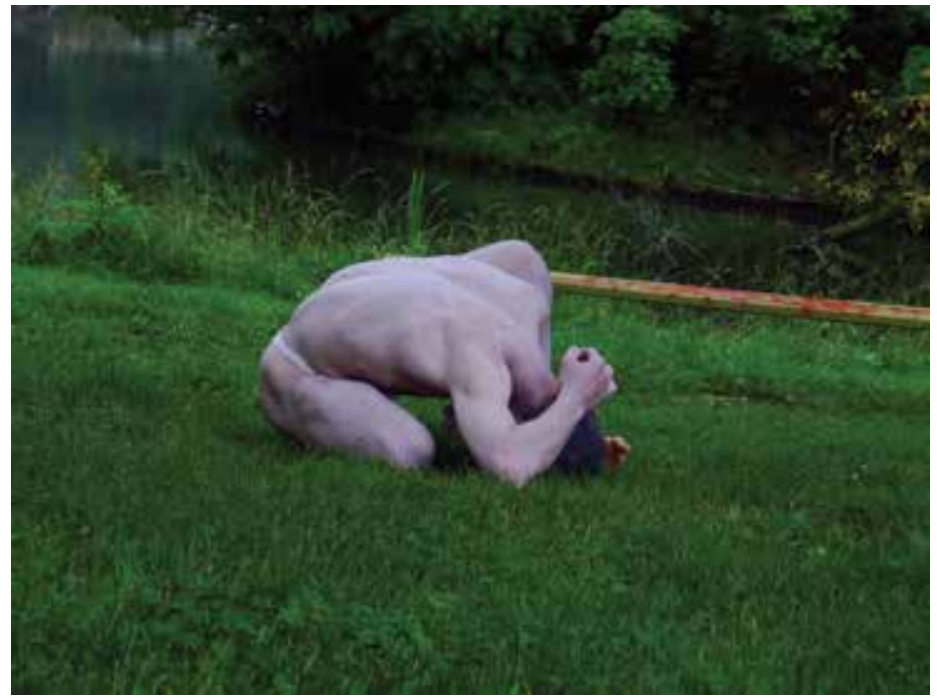

Photo 12: Krzysztof Jerzak, Aite, photo Barbara Songin

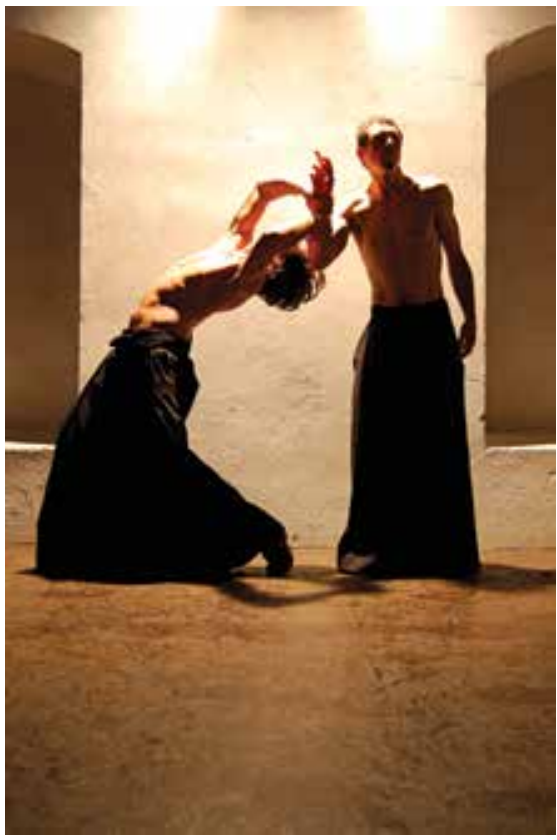


Photo 13: Amareya Theatre, Haiku for Three Bodies, photo Jerzy Nowak

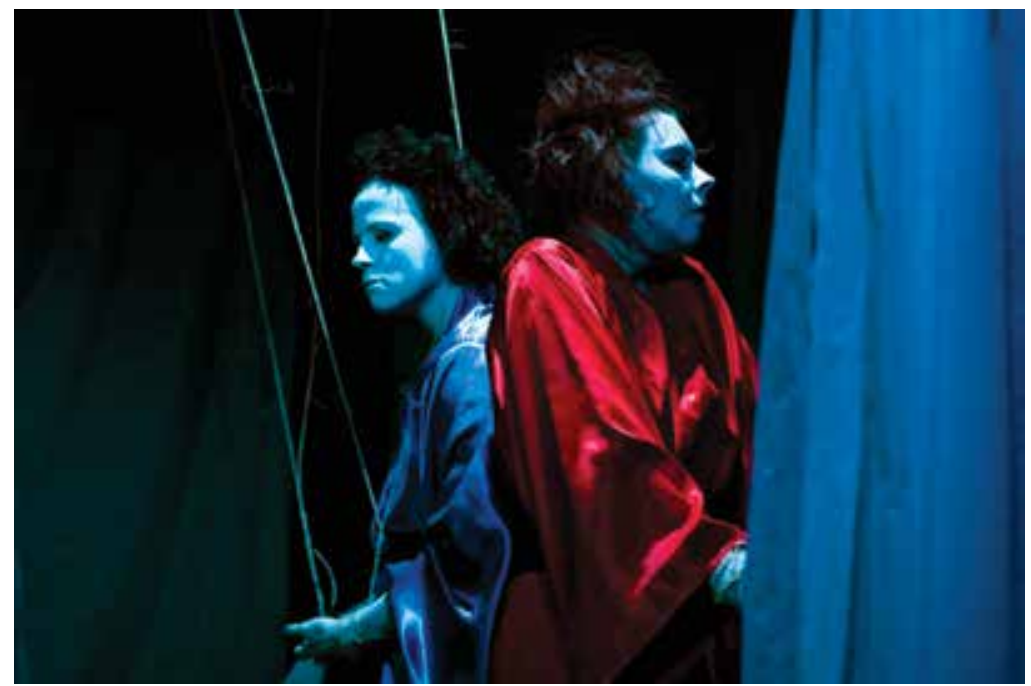

Photo 14: Amareya Theatre, The Empty Home, photo Jerzy Nowak

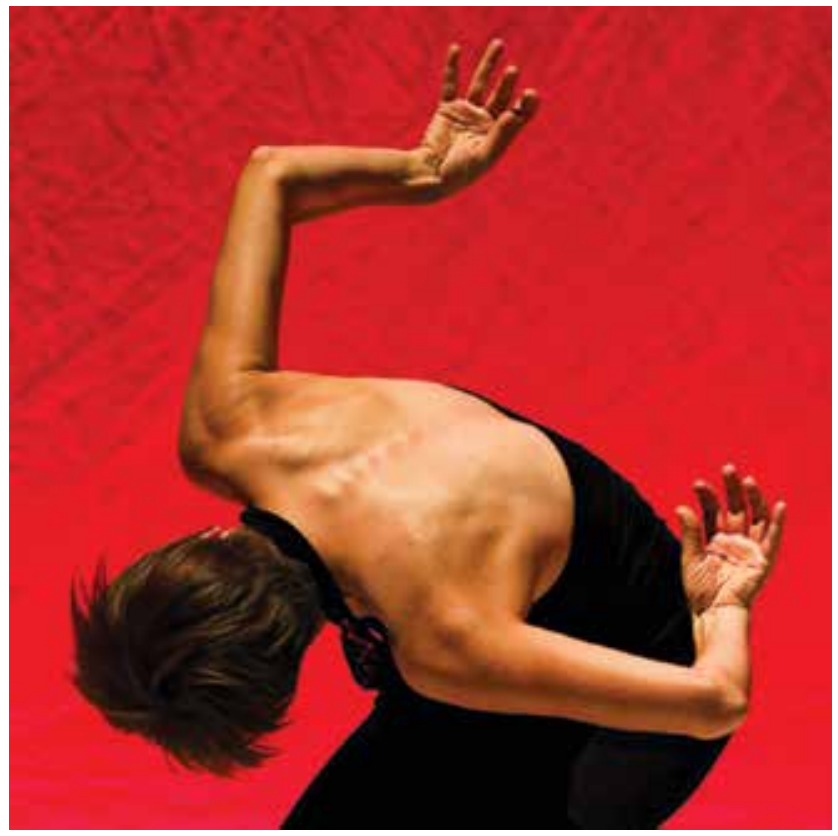


Photo 15: Amareya Theatre, Anatomical Theatre, photo Jacek Sobociński

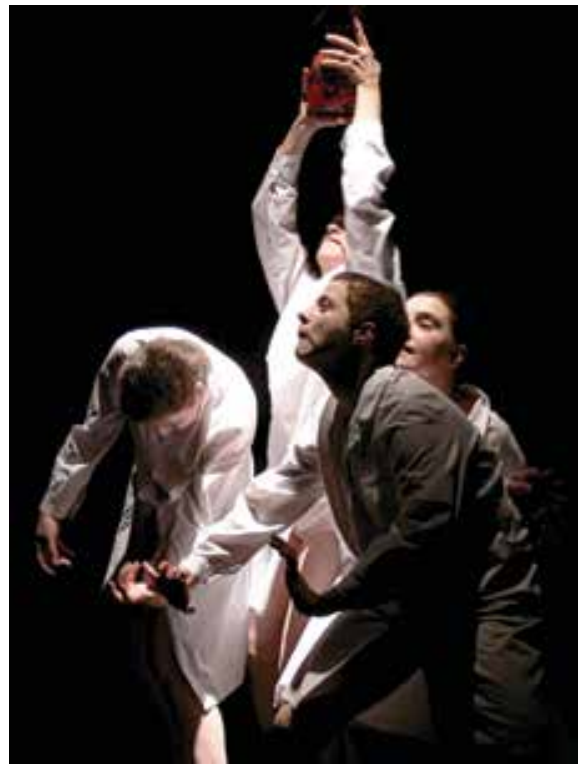

Photo 16: Amareya Theatre, Xenos, photo Agnieszka Kubińska

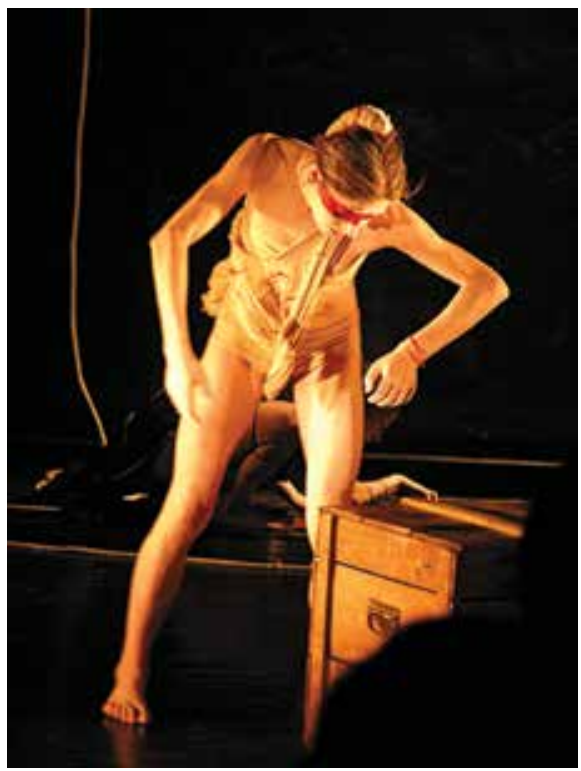


Photo 17: Aleksandra Capiga-Łochowicz, Improvisation 2008, photo Andrzej Janikowski

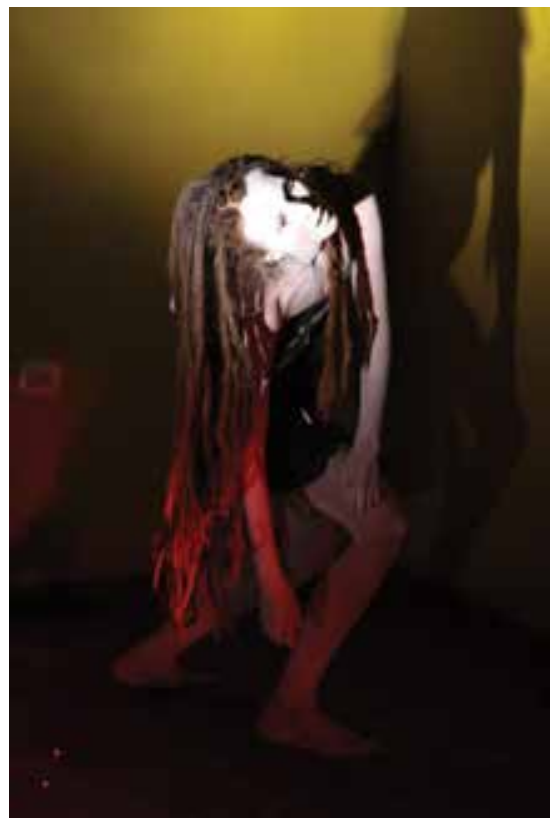

Photo 18: Aleksandra Capiga-Eochowicz, Improvisation 2009, photo Andrzej Janikowski

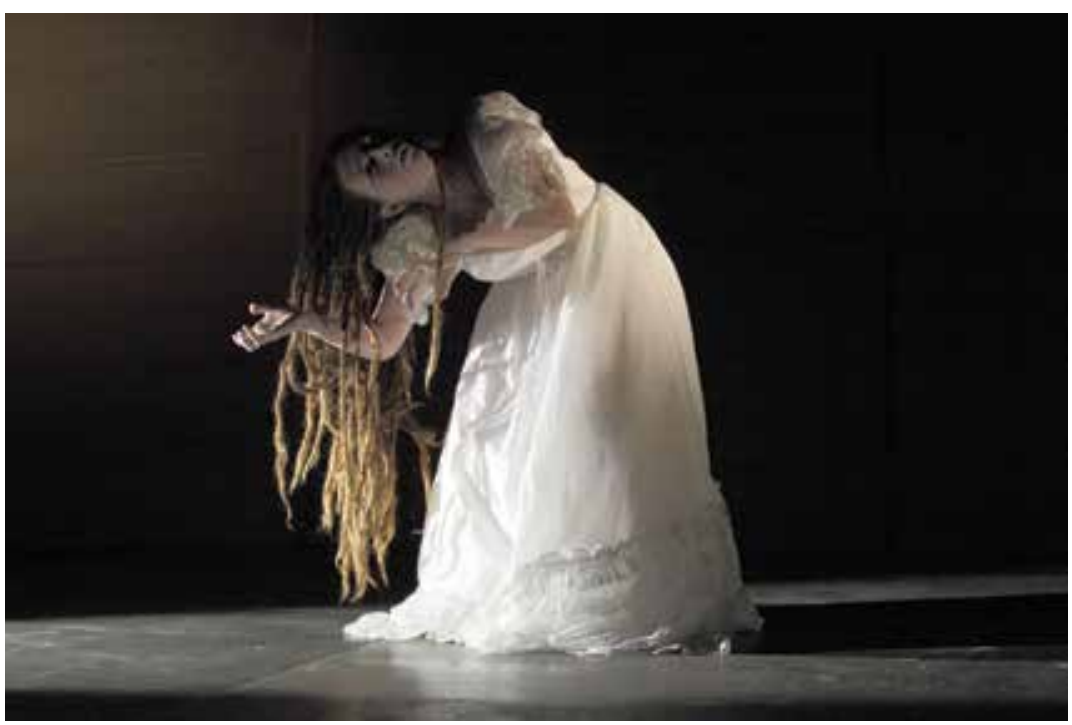


Photo 19: Aleksandra Capiga-Łochowicz, Improvisation 2010, photo Andrzej Janikowski

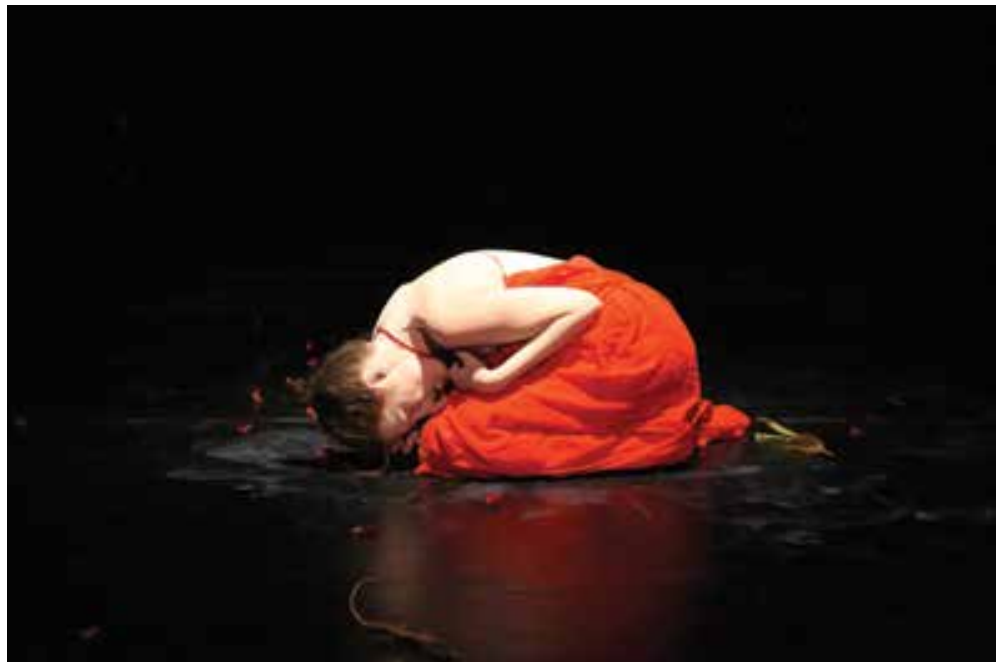

Photo 20: Aleksandra Capiga-Łochowicz, Improvisation 2010, photo Andrzej Janikowski

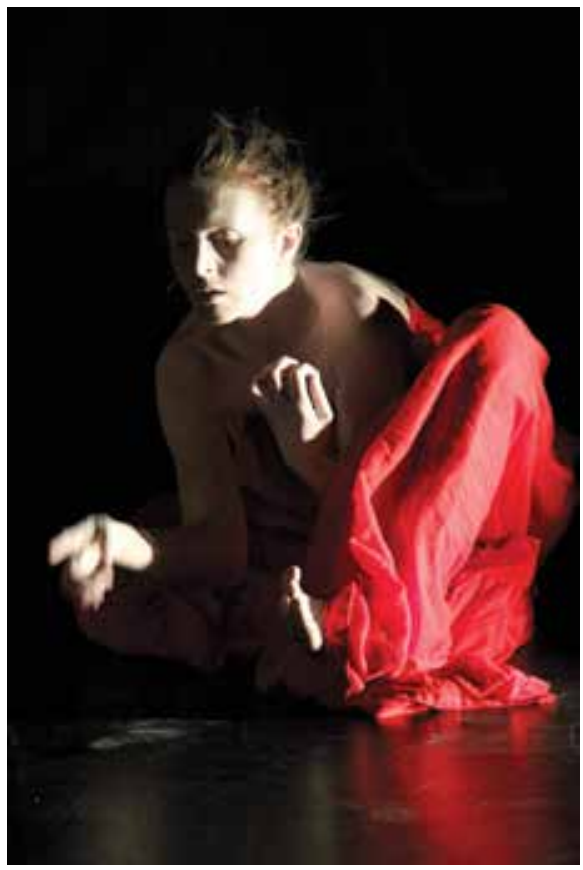


Photo 21: TO-EN, Melange, photo Małgorzata Taraszkiewicz

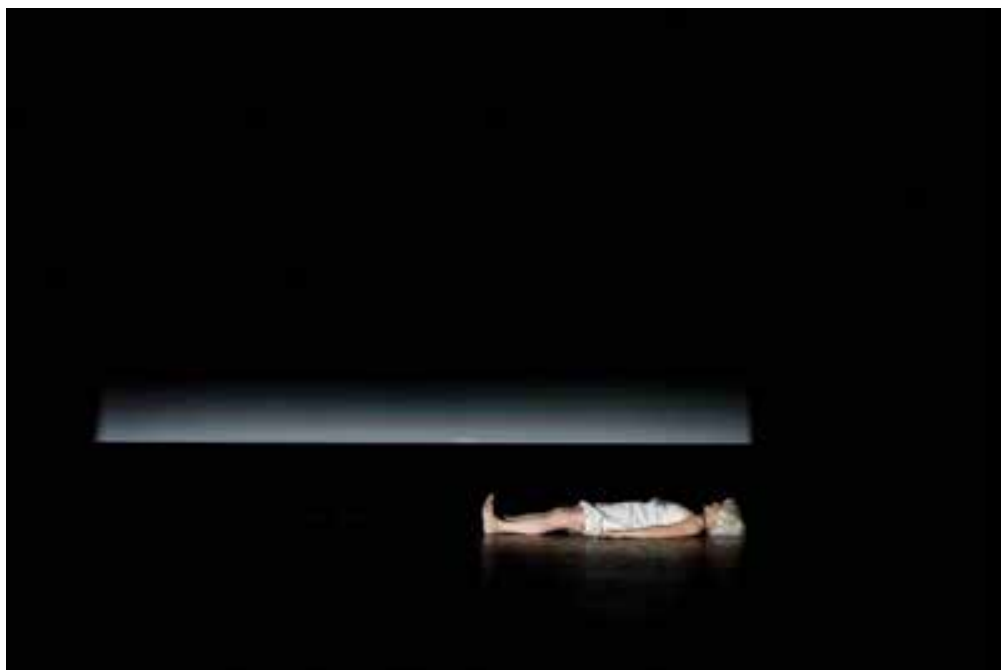

Photo 22: TO-EN, Melange, photo Małgorzata Taraszkiewicz

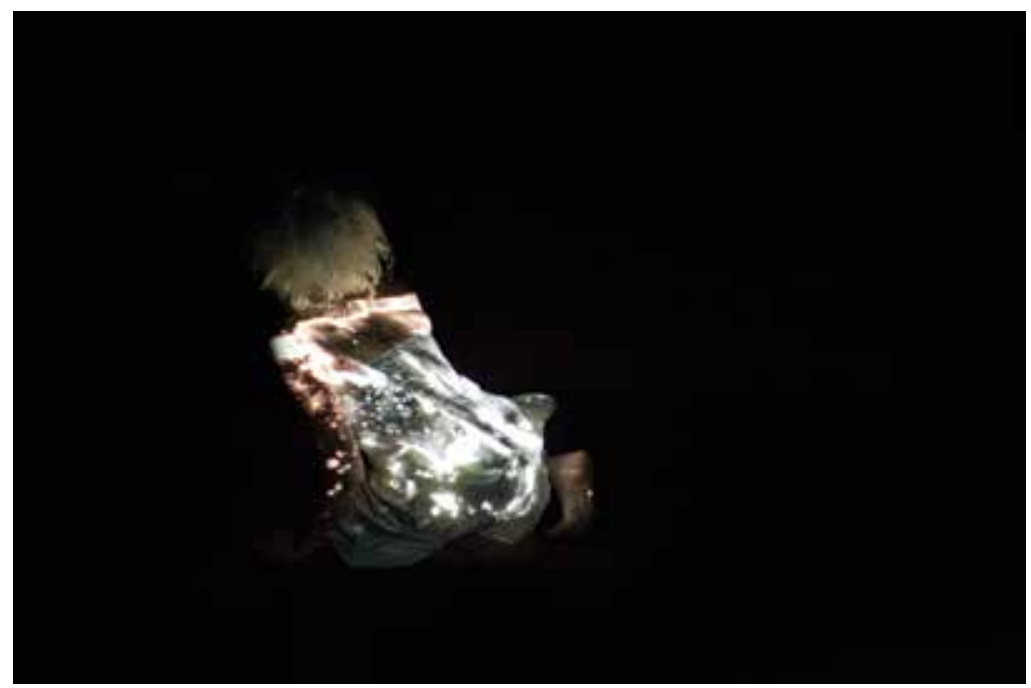


Photo 23: TO-EN, Embers, photo Małgorzata Taraszkiewicz

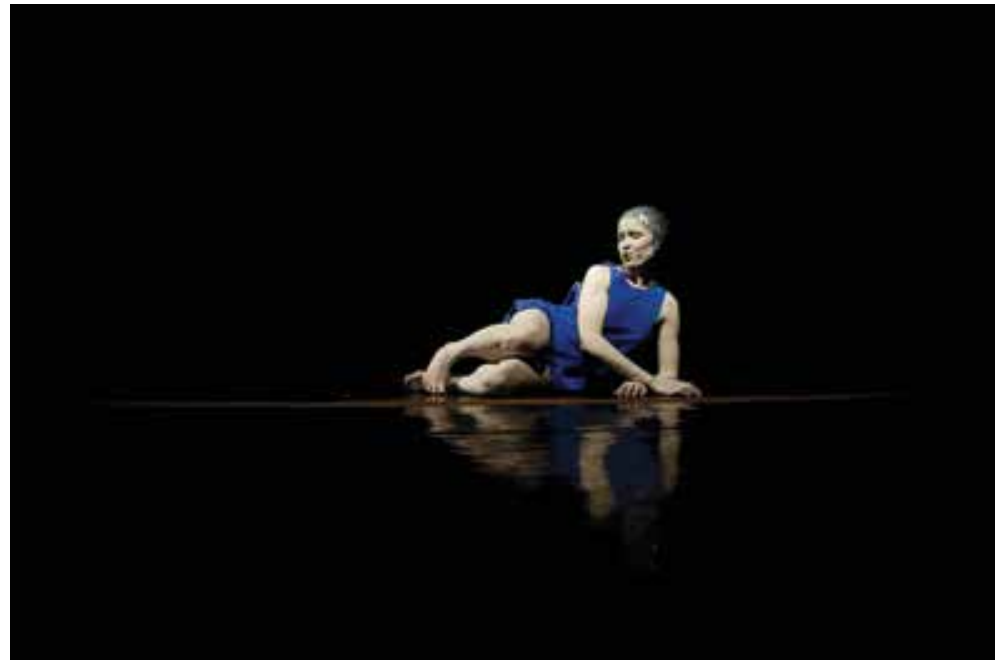

Photo 24: TO-EN, Embers, photo Małgorzata Taraszkiewicz

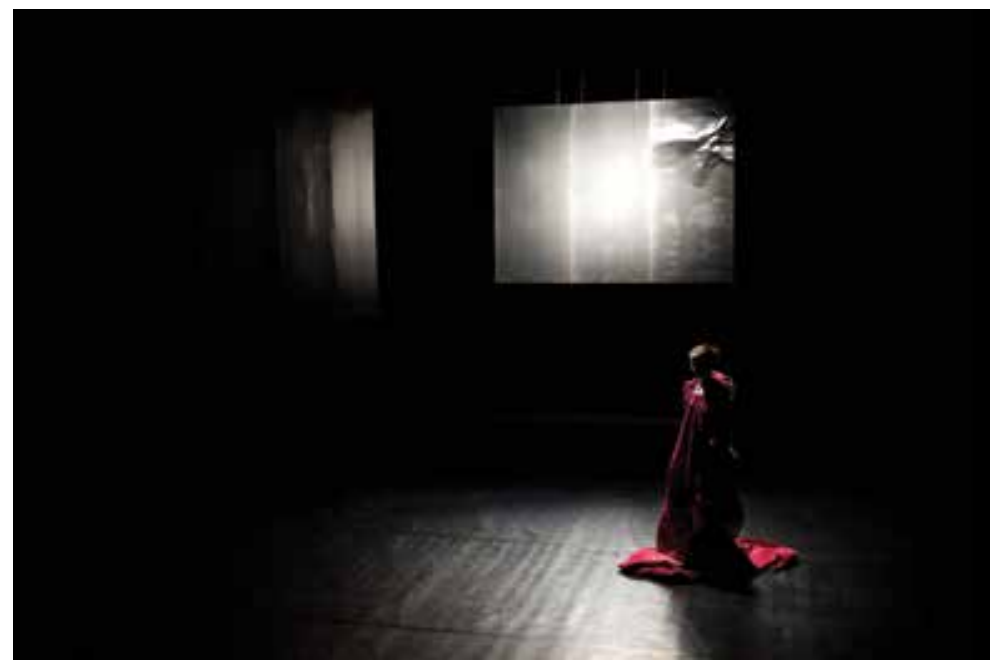


Photo 25: Irena Lipińska, line, photo Paweł Pych

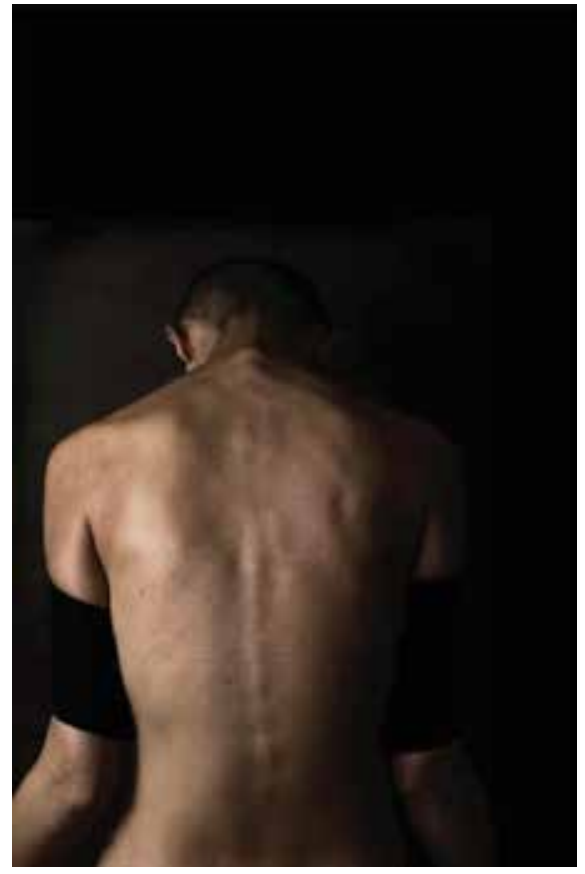

Photo 26: Irena Lipińska, DNACE, photo Kailai Chen

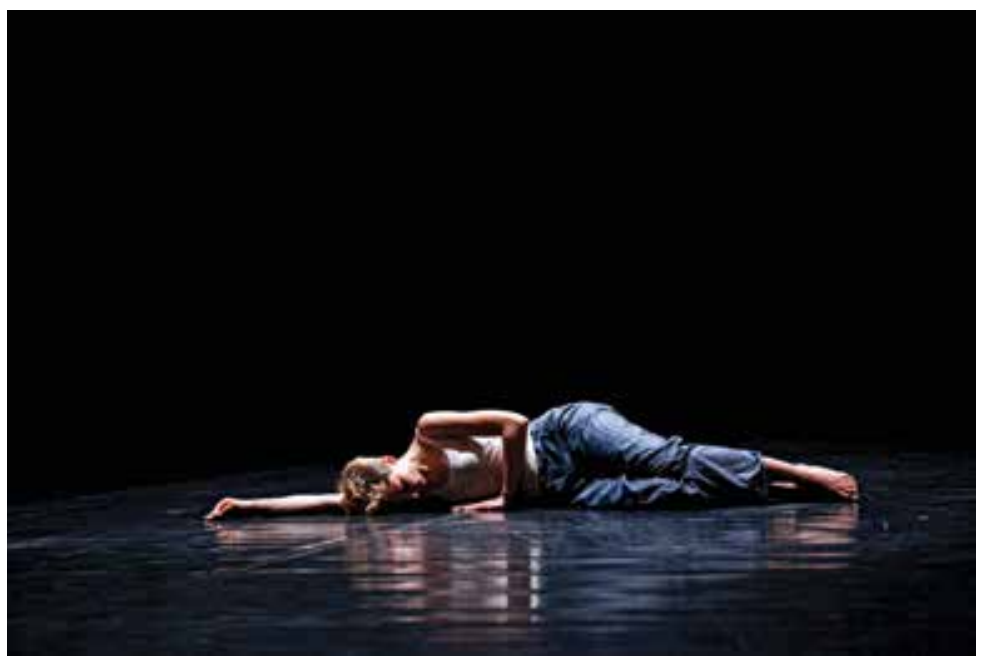


Photo 27: Irena Lipińska, DNACE, photo Kailai Chen

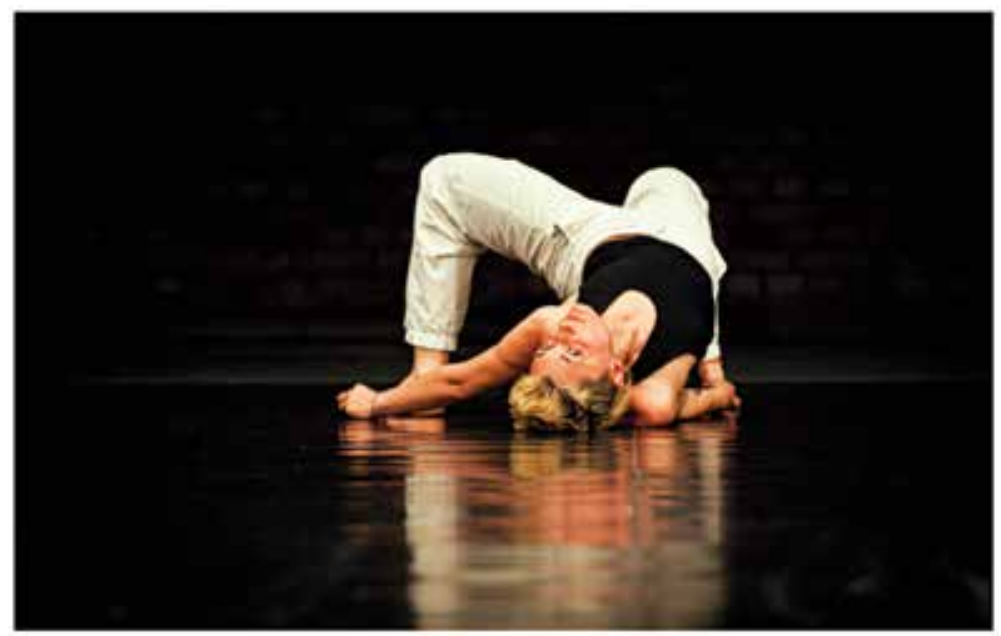




\section{The Body}

To give lucidity to my argument, I would like to introduce a distinction between "private performance" and "public performance." In butō, private performances take place while training and developing a project, as a rule without the audience in attendance. This is where they differ from public performances, i.e. shows, stage improvisations and other events involving spectators. I realise that this terminological division is controversial; nevertheless, it enables me to study training "as performance."

My interpretive framework is based on the research I conducted among Polish butō-ka. My account of the training model is based on the workshops in which I took part myself (whereby I conducted participant observation of the training and artistic practice) and on my interviews with Polish butō artists. Butō practitioners as a rule do not analyse phenomena that emerge in their training practice and are not aware of the grammar of their own activities. Nor do they use the concepts and notions on which I rely; instead, they employ "operative, applied knowledge." Producing my account of the training model, I identify, name and classify elements of this practical, embodied knowledge.

In exploring processes and phenomena, I have adopted a multi-layered interpretive approach and an interdisciplinary analytical framework. I draw on interpretive paradigms of such disciplines and fields as performance studies, theatre anthropology, philosophy of the mind and consciousness, existential phenomenology, aesthetics, somaesthetics, neurobiology, neurophenomenology, neuroaesthetics, cognitive studies, somatic psychology, psychoanalysis and kinesiology. Putting together the model of Polish butō dancers' training, I identify pivotal moments in the respective stages of training, outline an overall framework of references and propose further research directions.

Crucial to the art of dance is how bodiliness is perceived. Consequently, to explore creative processes in butō, we must define its perception of the body, body-mind relationships and the connections between the body and sensory perceptions on the one hand and movement on the other.

Because artists use tacit operative knowledge, their position on the so-called psychophysical problem (i.e. mind-body relationships) can be re-traced on the basis of the activities they use to target the body, the mind or the body-mind. Butō-ka tackle the psychophysical problem through their practice. They dismiss body vs. mind dualism, and their training and workshop practice is informed by the notion of not only psychophysical (body-mind) but also sensorimotor (perception-movement) unity. 
The history of philosophical enquiries into the psychophysical problem is outlined by Józef Bremer in his Problem umyst-ciało. Wprowadzenie [The MindBody Problem: An Introduction] (2001). As Bremer explains, "[g]enerally, scholars understand 'body' as an anatomical and functional structure of the nervous system, while 'mind' is understood as spiritual states, which are also called 'mental states' (thoughts, perceptions, sensations)" (Bremer 2001: 10).

The basic dividing line between mental and bodily phenomena is demarcated by means of predicates serving to describe phenomena. The main pairs of mutually corresponding predicates are: subjective (private, unobservable by the third parties) vs. objective, qualitative (e.g. the perceived quality of red) vs. quantitative (e.g. the chemically testable components of red) and intentional (focused on real or imagined objects, representational) vs. unintentional.

"Arguably, the history of philosophy provides two 'standard' solutions to the body-mind problem, which are broadly referred to as dualist and monist versions" (Bremer 2001: 12). In short, dualists claim that because mental (mind-related) phenomena are given to people in entirely different ways than physical (bodyrelated) phenomena, the former cannot possibly be described by means of the language of solid sciences, e.g. neurophysiology. To this monists respond that in order to endorse this theory, we need to presuppose an $X$ factor that is a causal force in mental phenomena. Consequently, knowledge is possible in introspection alone and can only be expressed in a phenomenal, private and thus intersubjectively uncommunicable language.

The upholders of monism (in its materialist and reductive version) identify mental and bodily phenomena or, precisely speaking, presuppose their reducibility to the physical level (e.g. in classic neurophysiology). Yet, adopting this premise, we are faced with the problem of qualia, ${ }^{1}$ that is, phenomenal qualities which are hardly reducible to neuro-physical reactions.

A more moderate version of monism, i.e. contemporary naturalism (cf. Bremer 2001: 20-21), criticises some of the dualist tenets without endorsing the materialist and reductionist variety of monism. In contemporary naturalism, the brain is viewed as a syntactic rather than semantic tool, which explores an overall process instead of just information processing and intentional components of the signal. Intentionality, which draws the line between mental and physical states, ceases to be a property of mental states. Naturalists do not negate the direct awareness

1 Qualia (sing. quale) - felt or phenomenal qualitative characters apprehended in sensory experiences, e.g. hearing sounds, feeling pain, perceiving colours. "The quale is directly intuited, given, and is not the subject of any possible error because it is purely subjective" (Lewis 1956: 121); cf. "Terms." 
of intentional states, but question the cognitive value of introspection: "We have no guarantee that our intentional vocabulary ('s/he believes that...' 's/he wishes to...) describes any real thing" (Bremer 2001:21). The third person perspective is enough to describe all phenomena, including mental ones. However, the problem of qualia (i.e. private sensations) still remains unresolved.

The philosophy of consciousness is interested in whether psychophysical interactions (or, mind-body interactions) are possible and if so, how they proceed.

Donald Davidson's anomalous monism and related theories which assume the supervenience or emergence of the mental (mind) domain are perhaps best suited to the intuitive reading of body-mind relationships in butō. In brief terms, Davidson separates ontological events from language. Consequently, while mental (mind) and physical (body) events are identical, "psychological concepts are nomologically and otherwise irreducible to physical concepts" (Davidson 2002: 243). This is the reason why Davidson's position is referred to as anomalous monism (ontological monism combined with conceptual dualism). Davidson insists that "psychology cannot be understood as a solid science (e.g. physics)" (Bremer 2001: 116); a similar thing can be said about biology. Explaining his position, Davidson concedes: "But I do not know how to show that the concepts of biology are nomologically irreducible to the concepts of physics" (Davidson 2002: 241), which Bremer re-phrases into an equation rendering a psychophysical law: "Strict psychophysical laws would be expressed as 'For every person $\mathrm{X}$ it holds that $\mathrm{X}$ is in $\mathrm{m}$ state when and only when $\mathrm{X}$ is in $\mathrm{p}$ state, where $\mathrm{m}$ is a mental state and $\mathrm{p}$ is a physical state" (Bremer 2001: 116). This kind of interdependence between mental states (which Davidson understands as intentional) and physical states is defined by Davidson as supervenience. Mental events are supervenient, i.e. superimposed on and correlated with physical events.

This approach to the relationship is convergent with the emergentist framework. "Emergents are new qualities which emerge as a result of interactions at a lower level" (Bremer 2001: 128). Given this, mental events are supervenient on and, at the same time, emergent in relation to physical events. As a result, we can conclude that there are bilateral impacts and reciprocal dependences between the body and the supervenient mind. "Material reality is the primary but not the only one. Something larger than material reality arises from matter; it is consciousness. In this picture, the mind is an emergent formation which takes over control of the brain" (Janik 2011: 3).

2 By "manipulating" the mind, butō dancers may trigger changes in the body. 
Also the pragmatist philosopher John Dewey, in his Art as Experience (Dewey 2005: 21), questioned the "contempt for the body, fear of the senses, and the opposition of flesh to spirit," which came to prevail in Western philosophy. Dewey thought of the body-mind as a unity in which mental activity, comprising also aesthetic experiences and representations, arises from the biological/physical substratum. He defined the body-mind as "what actually takes place when a living body is implicated in situations of discourse, communication and participation" (Dewey 1981: 217, qtd. in Shusterman 2008: 185). Dewey insisted that the bodymind should be treated as a fundamental, indivisible entity, explaining that as any response to a stimulus was simultaneously bodily and mental, every action was always a psychophysical act. The entity of body-mind did not always function harmoniously, and its degree of integration depended on the cultural context and individual experiences. This is why various method of somatic education could be applied which relied on conscious somatic introspection to produce a balanced integration of the body-mind.

Dewey's insights and injunctions are a frequent point of reference for Richard Shusterman. Shusterman builds on them in his original project of somaesthetics, which he outlined in Body Consciousness: A Philosophy of Mindfulness and Somaesthetics (2008), devoting a separate chapter to Dewey's philosophy (Shusterman 2008: 180-217). Shusterman's close contact with dance artists was instrumental to his newly founded subdiscipline. Shusterman recalls that, influenced by encounters with dancers, he "converted" to Deweyan pragmatism, which is more experimental, activist and appreciative of creativity and fluidity. Shusterman describes this conversion as deeply physical and sensory, liberating him from a constraining psychosomatic rigidity (Shusterman 2007: 19).

The concept of somaesthetics as an autonomous discipline or a subdiscipline of philosophy was developed in essays, some of which are to be found in a volume entitled O sztuce i życiu. Od poetyki hip-hopu do filozofii somatycznej [On Life and Art: From the Poetics of Hip-Hop to Somatic Philosophy] (2007), and was then systematised in Body Consciousness: A Philosophy of Mindfulness and Somaesthetics. Importantly, Shusterman opted for "soma" instead of "body" since, as he observes, in traditional Western thought the body has been all too often contrasted with the idealised mind, while "flesh" sounds too medical: "I often prefer to speak of soma rather than body to emphasise that my concern is with the living, feeling, sentient, purposive body rather than a mere physical corpus of flesh and bones" (Shusterman 2008: xii).

Somaesthetics is defined as "a discipline that puts the body's experience and artful refashioning back into the heart of philosophy as an art of living" 
(Shusterman 2000b: 530). Shusterman insists on placing at the centre of his research (and practice) the emanating expression of the embodied subject involved in self-examination (Shusterman 2007: 12). This means de-objectifying one's bodiliness through "the critical, meliorative study of the experience and use of one's body as a locus of sensory-aesthetic appreciation (aisthesis)" (Shusterman 2000b: 532). The somaesthetics project addresses, to an extent, ways of enhancing somatic (bodily) consciousness and self-consciousness. From this perspective, soma "must be recognized as our most primordial of tools, our most basic medium for interacting with various environments, a necessity for our action, perception, and even thought" (Shusterman 2008: 4). Soma as such enables people to communicate at the non-reflective and non-linguistic level, while a reflective consciousness of the body helps augment the cognitive capacities of the human being as a mental-and-bodily whole. Shusterman underscores soma's perceptual function and, at the same time, emphasises that the embodied and experiencing self can be depicted as "essentially situated, relational, and symbiotic" (Shusterman 2008: 8).

Shusterman distinguishes (cf. Małecki 2009: 13-14) analytical somaesthetics (speculative reasoning about the nature of the body), pragmatic somaesthetics (reflection on body disciplines) and practical somaesthetics (the implementation of these theoretical concerns). Pragmatic somaesthetics encompasses representational practices (focused on the improvement of the body image) and experiential practices, which include "a wide range of practices and ideologies from the very ancient to the New Age: from Asian practices of hatha yoga, t'ai chi ch'uan, and Zen meditation to Western therapies of Alexander Technique, Feldenkrais Method, and bioenergetics" (Shusterman 2000a: 152).

Bodily manipulations and movements can profoundly affect the ways the mind works, which is the basis of a range of body-mind disciplines. Notable examples include somatic psychology, which works on the communicative totality of soma and psyche (somatopsychology, psychosomatology), various methods of body (psycho)therapy, somatotherapy, Reichian therapy, Lowen's bioenergetics, Boadella's biosynthesis, the Alexander Technique, the Feldenkrais Method, Rolfing (i.e. structural integration developed by Ida Rolf), sensory consciousness, Body Mind Centering, Gyrokinesis, body art, Cantienica, Noguchi Taiso, kinesiotherapy, dance movement therapy (DMT) and traditional Eastern techniques such as yoga, tai chi, qi-gong and aikishintaiso. All these practices fall under the umbrella term of body-mind disciplines (cf. Nancy 1999), which include non-European approaches to the body-mind and Western methods of somatic education. 
Pragmatic somaesthetics offers a useful framework for investigating butō training as an experiential practice, while butō practice as such would count as a form of practical somaesthetics in Shusterman's classification.

The French phenomenologist Maurice Merleau-Ponty highlights the functional, practical aspect of the body-mind. He considers the body to be a tool of perception, action and thinking. In his Phenomenology of Perception (Phénoménologie de la perception, 1945), ${ }^{3}$ Merleau-Ponty argues that the human being perceives and apprehends the world first and foremost through the body and is, as such, an embodied subject. One of Merleau-Ponty's central concepts is un corps vécu - the lived body, i.e. the body as actually experienced: "The body is experienced in action. Embodiment is not passive, but expressive. I live my body as a body-of-motion. [...] In this perspective, body, movement and agency [...] are not separate entities" (Mond-Kozłowska 2010: 93).

The perceptual and the motoric are interconnected and make up a sensorimotor unity. This issue is further explored by the American dancer and philosopher Sondra Horton Fraleigh. In her aesthetic studies of dance, she also builds on the concept of the lived body (cf. Fraleigh 1996), which she conceptualises as sentient, conscious and kinaesthetically intelligent. "Living, the human being experiences his/her non-dualistic body-mind, a bodily and mental being" (Mond-Kozłowska 2010: 63). Fraleigh defines the lived body as "our living body, the body that we experience, the body-in-action, the perceived body, the body experienced in the first person, the body-of-life, the subjective body that can never be an object no matter how often we try to objectify it" (Fraleigh, qtd. in Mond-Kozłowska 2010: 16).

The lived body, specifically a representation in the mind of experiences from the body, is an important focus of research within cognitive psychology. Various ways of defining the body self are discussed by Olga Sakson-Obada in her Pamięć ciała. Ja cielesne $w$ relacji przywiazania i w traumie [Body Memory: The Body Self in the Relationship of Attachment and in Trauma] (2009). Sakson-Obada investigates the ways in which the body is represented in the mind, relying on such concepts as body schema, body image, body attitude and the body experience mode. She views body and mind as separate at the level of language and analysis (body and mind are two mutually interacting entities), yet insists that ontologically they form a unified body-mind whole.

3 For an English translation, see Phenomenology of Perception, trans. Colin Smith, London: Routledge and Kegan Paul, 1965; and Phenomenology of Perception, trans. Donald Landes, London: Routledge, 2012. 
The first kind of representation she discusses is body schema, which she defines as the neural structure which monitors and coordinates the movements of individual body parts $[\ldots]$, unlike other forms of representation, body schema is not accessible to consciousness and consequently cannot be an object of self-perception or knowledge. The structure [is] built chiefly on the basis of sensations from proprioceptors (but also from the vestibular system and the sense of touch). (Sakson-Obada 2009: 19; cf. Kawai et al. 2001: 3419-3423)

Importantly, the sensations from proprioceptors are largely an effect of kinaesthetic stimulation. "For body schema to function correctly, impressions originating in motor activities must continue to flow incessantly" (Sakson-Obada 2009: 21). Since body schema cannot be consciously grasped, the individual involved in butō training is unable to report changes at this level; nor can an external observer possibly discern them. Although the concept seems very promising for the study of butō training ("how do body schemata change in the transformation process?"), possible changes (if any) could only be registered in a laboratory setting by means of advanced neuroimaging technologies (e.g. functional magnetic resonance imaging fMRI or positron emission tomography PET). Such research was not part of my project, yet I leave the question open-ended as it could be fruitfully studied under another interdisciplinary research design.

Equally important for my argument are two other modes of representing the body in the mind: representation of sensations from the body and the production of a body image. Sensations from the body include a range of impressions and excitations felt at the surface of the body (exteroception) and within the body (interoception). People differ in terms of their sensitivity to skin stimuli and their interoceptive capacities (cf. Sakson-Obada 2009: 27-36). It seems that what happens in the buto training process is an attempt to enhance the awareness of sensations from the body (in terms of perception) and to increase the body's responsiveness (in terms of motor activity). This representation type appears to be particularly important in the stage of following impressions and sensory sensitisation.

Sakson-Obada describes body image as "a perceptual image a person creates in his/her own mind [...], visual image is a significant form of representing one's own body in the mind since it helps produce a cognitive representation as knowledge or beliefs about one's own bodiliness" (Sakson-Obada 2009: 21). This kind of representation emerges when mental images are processed.

Sakson-Obada's last research concept is body attitude. Body attitude includes emotional, cognitive and behavioural components (cf. Sakson-Obada 2009: 17). Essentially, the inner process that unfolds in butō training entails questioning and transgressing the socio-cultural norms which form the framework of reference in 
forming attitudes to one's own body. Dancers discard individualised identities, and their bodies are divested of meaning as human bodies (at least as the everyday, socialised body of a particular person). For this reason, body attitude falls outside the scope of my investigations.

Sakson-Obada is especially preoccupied with the dynamic reception and processing of impulses and sensations from the body. Based on a survey of the literature on bodiliness, she offers a definition of the body self and discusses the development of "particular representations of somatic impressions" (cf. SaksonObada 2009: 97-129).

On this model, the body self is both an entity that integrates body-related experiences and, at the same time, an ensemble of representations as such [...]. The field processed by the body self is the sphere of body impressions. They can be organised through the functions the body self acquires and perfects in development. The functions include reception of stimuli both from within the body (interoception) and from activated exteroceptors [...]; their integration first into sensorimotor schemes $[\ldots]$ later to be completed with a verbal representation of the bodily state [...] and knowledge of causes and ways of handling them. (Sakson-Obada 2009: 99)

Of particular importance in exploring butō training are stimulus reception modes (interoception, exteroception) and the generation of sensorimotor schemes. I will outline the development model of the body self in the following chapter, with a special focus on the developmental aspects relevant to the study of the buto training process. 


\section{The Training Process}

The butō training process involves a series of stages. The introductory phase includes endurance conditioning and mindfulness training aimed at achieving the butō body state, referred to also as total presence. The next stage is improvisation - i.e. the phases of following and embodying - which revolves around transformation. In this process, the performer (dancer) conceptualised as a bodily-and-mental being is both the subject and the object of activity.

Butō training can be compared to hypnosis-based therapy. Hypnosis consists in inducing changes in the psychophysical body functioning of the hypnotised person through (1) recalling past states and revealing hidden contents; or (2) suggesting new behaviours and contents. In this way, a hypnotherapist intervenes in the operations of the autonomic nervous system and triggers the desired psychophysical states (e.g. by provoking trauma-related states; cf. Sakson- Obada 2009: 81). In butō training, the dancer him/herself induces self-hypnosis by means of an array of physical and psychophysical techniques. The performer's movement is a reflection of a transformed perception of reality, a changed functioning in reality and/or the rise of new images.

\section{The Intro Phase}

In the first stage of the creative process, the buto dancer seeks to alter the ways his/her body works.

Dancers who teach workshops use different ways to make the body relaxed and prepared. For example, Mikami Kayo relies on massage and self-massage, Daisuke on push-ups and fatigue, and Atsushi on Noguchi Taiso. [...] The common element is leading the participants through images and various states, but warm-up routines differ widely. However, their ultimate goal is the same: readiness, presence, relaxation of the body, preparation for embodying imaginary wordings, fluid movement and tensions. The aim is the same, the centre is the same. We simply use different tools. (WTA, Kamińska).

The intro phase ${ }^{1}$ of butō training includes endurance conditioning, which aims to bring the body to the point of extreme exhaustion and crisis. Another important element is mindfulness training, which usually involves the zero walk or other

1 The first phase of training is usually referred to as a "warm-up," yet I deliberately choose not to use this term in order to avoid associations with dynamic exercises that serve to "warm the body up." 
concentration-enhancing practices. The Polish butō dancers resort to traditional techniques, such as Zazen, walking mediation, Hatha, Ashtanga and Kundalini Yoga, kum nye, tai chi chuan, aikishintaiso, aikido and African dance, combined with modern methods/techniques, which tend to be founded on the traditional systems, e.g. Noguchi Taiso, the ISTA training, contemporary dance techniques, contact improvisation, Body Mind Centering and Labyrinth Meditation.

\section{Endurance Training}

The first objective of training practice is to test one's stamina. Training usually starts from a classical warm-up workout geared to improving the body's physical preparedness, fitness and energy flow. It is accompanied by exercises serving to activate individual body parts and stretch muscles and joints. Equally important is the ability to relax the muscles and to accurately evaluate one's body in terms of flexibility, strength and balance. The workout also includes gravitation exercises which are supposed to help feel gravitation precisely and teach the dancer how to use its force. Dancers explore limits to their endurance by, for example, bouncing in one place for a long time, repeating fall-and-rise sequences, and long-distance running. In some variants, the idea is to reach the limit of fatigue and, even, to exceed that limit. All this aims to push the body into a psychophysical crisis.

During endurance conditioning, the physical, biological, neurobiological and biochemical functions of the practitioner's body undergo changes. To understand how the body reacts to exhaustion, we must realise what stages it goes through when subjected to heightened and sustained effort.

In the first stage

there is a delay in how physiological functions adapt to the effort. In this period, oxygen use falls short of the total oxygen demand and evacuation of carbon dioxide is similarly delayed. This ultimately leads to a series of disturbances characteristic of the so-called dead point. [...] Several subjective outcomes are also felt, such as decreased self-perceived wellbeing, considerable fatigue, sometimes muscle pains, a lowered ability to perceive external events, a longing to stop working, etc. They go hand in hand with objective symptoms of decreased physical capacity, e.g. a lowered ability to work, worsened breathing effectiveness (i.e. shallow and accelerate breath rhythm), a decreased intake of oxygen from ventilation air and a very intense return of carbon dioxide. (Mieszkowski n.d.).

However, if the effort is continued, "adaptive mechanisms are mobilised, capacity increases and the disorders disappear" (Mieszkowski n.d.). This phase is called a "second wind." 
The second wind commences the period of functional stabilisation (stable state) characterised by a balance between oxygen demand and use, biochemical processes of decomposition and synthesis and between the production and excretion of carbon dioxide. The functional balance [...] represents the organism's adaptation to the physical effort. (Mieszkowski n.d.)

As a result of intense physical activity, the system produces and secretes certain chemical substances into the blood.

The substances whose concentration and/or activity change while physical effort is performed are called markers of exertion. To emphasise that they are not physiological, physical or other indicators, we refer to them as biochemical markers. This undoubtedly sizeable group of indictors includes selected enzymes, hormones, electrolytes and some proteins from the acute-phase protein class. (Sobiech 2000)

With this severity of fatigue, what is referred to as the runner's high sets in.

[The runner's high] is a euphoric state that appears in prolonged physical exertion. Characterised by increased resistance to pain and fatigue, [...] it involves the sense of happiness and joy which washes over the entire body. It is due to this process that, having run for 40-60 minutes, [...] we stop feeling acute muscle pain, our minds clear, and we discover deep-buried energy resources, which make it possible to continue training. (Czajkowski 2011)

There are three main theories that explain the aetiology of this phenomenon. The oldest of them points to endorphins, endogenous opioids that bind to our brains' opiate receptors. ${ }^{2}$ This unusual state appears after 45-60 minutes, when breathing is still difficult and the muscles are using their stored glycogen. Hypoxia causes stress, which can result in a heightened secretion of endorphins. In 2001, scholars at Nottingham Trent University questioned this theory, claiming that the euphoric state was brought about by another substance, i.e. by phenylethylamine, which is closely related to amphetamine. The latest theory (2004) put forward by researchers at the Georgia Institute of Technology in Atlanta and the University of California attributes the euphoria-triggering function to cannabinoids, specifically to anandamide. "The researchers have found that muscle pain and prolonged physical stress activate the endocannabinoid system, which causes intoxication and euphoria in athletes. The system can also be activated by massage" (Czajkowski 2011).

2 Other triggers of endorphin secretion are threat, hypoxia, deep meditation, acupuncture, sex and chocolate.

3 The substance is also found in chocolate. 
No matter whether only one of these theories is correct or whether euphoria is in fact caused by various mechanisms, people who exercise intensively report this state, using a variety of expressions, such as considerable mood improvement, increased endurance and resistance to pain, the mind's control over the body, etc.

Bringing the body and/or the mind to the point of utter exhaustion through rigorous psychophysical training is one of the techniques buto dancers use to achieve the state of total presence. ${ }^{4}$ Physically exhausted and/or mentally resigned, the performer stops acting as an ego (i.e. stops processing data consciously and rationally) and sheds his/her everyday identity. As Nario Gōda, a butō critic, says: " $[\mathrm{O}]$ nly by throwing off the body and transcending suffering can true dance be created, and [...] Butō begins with the abandonment of self” (Klein 1988: 34). Only then can an internal metamorphosis begin and be consistently sustained.

\section{Mindfulness Training}

Another crucial aim of training is to enhance mindfulness. To this end, butō dancers employ not only elements of various psychosomatic disciplines depicted earlier, ${ }^{5}$ but also one of the so-called butō techniques referred to as zero walk or hokōtai (walking body).

As asserted by all of the artists, the main part of mindfulness training is focusing on breathing, or in other words unblocking energy flows by exercises targeting the diaphragm, the centre and belly power, i.e. the so-called hara point. Breathing exercises are followed by sensory sensitisation (i.e. increasing exteroceptive and proprioceptive awareness), meditation and contemplation practices. This combination leads to a re-modelling of perception. In butō, this process is called erasing or voiding the body.

Mindfulness training specifically includes the already mentioned butō technique called zero walk (cf. "Terms"). The dancer adopts the zero position, referred to also as a neutral position or auto-balance. ${ }^{7}$ Fully relaxed, s/he only flexes somewhat the muscles of the slightly bent legs, tucks in the tailbone and lowers the centre of gravity (pelvis) a bit. Dropping freely along the body, the arms are limp and relaxed. The feet have full contact with the surface (one can also imagine one is standing on a ball). At the same time, the dancer starts to

4 I will discuss this in more detail later in this chapter.

5 See Chapter 3, sections devoted to individual artists.

6 Often spelt in English as hokohtai; cf. Fraleigh, Nakamura 2006: 107-108, 151.

7 The description is based on guidelines given during workshops by, for example, Sumako Koseki, Kayo Mikami, Sylwia Hanff and Krzysztof Jerzak. 
look in a specific way, adopting unfocused perception, also called diffused vision. $\mathrm{S} /$ he stares straight ahead without focusing on any object. To do this, s/he can perform the following exercises: s/he stretches the hands in front, clenches the fists, protrudes index fingers upwards and, retaining the same gesture, slowly moves the hands apart, all the time looking at the thumbs until they reach the boundary of the field of vision. Then s/he lowers the hands.

As a result of these efforts, a specific state of mind is induced in which the dancer as a psychophysical being intensely experiences the totality of the floating world without focusing on any particular object. Having achieved this state, the dancer starts to move and walk very slowly. The relaxed feet (toes not upturned) slide over the floor in tiny steps. A similar gait appears in the Japanese Nō theatre, where it is linked to the masked actor's changed perception of reality. In fact, the kamae posture (lowered centre of gravity, body slightly bowed forward) and the suriashi walk (gliding movements with feet never lifted off the ground) were earlier part of the mai dance within the ritualistic tradition of kagura.

Having mastered the zero position, the butō dancer finds it easier to become an "empty receptacle." Natsu Nakajima explains that in butō, the dancing and moving are done by "something" rather than "someone": "I don't dance, my body moves and dances. My body is moved" (Nakajima 1998: 49).

Aleksandra Capiga-Łochowicz relates that the marionette was the most frequent figure in her training sessions with Morita Itto. Rhizome Lee describes exactly the same practice when he talks of the kugutsu body (Rhizome Lee 2010). The dancer is supposed to allow his/her body to be moved. ${ }^{8}$ This is also the aim of techniques used in various spiritual disciplines: whirling dances (dervishes), shaking (shakers) or very slow walking (kinhin in Zen Buddhism). Fraleigh calls the state attained in and through such practices the "receptive unconscious" (Mond-Kozłowska 2010: 80). In this context, she evokes both Zen meditation and the Christian ascetic practice of kenosis. Kenosis designates deprivation in the sense of "liberation by means of varied ascetic techniques from all external obstacles that separate the human being from his/her true self" (Mond-Kozłowska 2010: 80).

8 A similar idea of the actor as an empty receptacle can be found in Europe in the writings of Heinrich von Kleist and Gordon Craig. In Kleist, the actor would be replaced by a marionette which, split between a doll and a deity, would reflect the infinity and inexpressibility of being. Craig elaborated on Kleist's vision in an essay entitled "The Actor and the Über-Marionette" (1970), envisaging the performer (actor, dancer) being turned into a Super-Marionette rather than replaced by a puppet. 
"Walking" in butō can legitimately be called walking meditation. What is the difference between a common, quotidian state of inaction and the state of mindfulness achieved by meditation practices (e.g. mindfulness meditation, open presence meditation, contemplation)? "Experiments designed to watch the brain watch itself - imaging techniques combined with mindfulness techniques to study different kinds of awareness - are producing some of the most provocative images of the mind and its previously unappreciated powers" (Boleyn-Fitzgerald 2010: 112). Researchers at Toronto University (Canada) and Emory University in Georgia (US) used the fMRI scanner to study two operative models of consciousness: narrative consciousness and experiential (sensory) consciousness. ${ }^{9}$ The former is bound up with an augmented sense of self-referentiality (past, present, ideas, plans, assessments, value-judgments, self-reference) and the activity of what is called the default network (resting network or "dark network"), i.e. "the collection of circuits that come online when we're engaged in mind-wandering or ruminative thought and that hibernate when we are focused on more present-centred, goal-directed activity" (BoleynFitzgerald 2010: 113-114). The latter - i.e. experiential focus or present-moment awareness - comprises "mechanisms of momentary consciousness [...] which may represent core aspects of self-experience achieved earlier in development and may have evolved in earlier animal species" (Farb, Anderson, Segal, qtd. in: Boleyn-Fitzgerald 2010: 114). Linked to the arousal of other areas of the brain, this kind of consciousness enables the human being to be actually here and now. In the experiments mentioned above, the researchers found that mindfulness training improved the ability to choose consciously from which self-awareness to act: the narrative or the sensory one.

\section{Total Presence}

Both kinds of training practices used in the intro phase result in modifying the ways the body works neuro-physiologically, hormonally, perceptually, affectively, emotionally, motorically and energy-wise. The state that is produced in effect is called total presence ${ }^{10}$ or the butō-body state $\left(b u t \bar{o}-t a i^{11}\right)$. Total presence is a

9 For the description of the experiment, see Boleyn-Fitzgerald 2010: 113-115.

10 Total presence sounds very apt to me also in the context of my own experiences in Zazen meditation and butō training. I borrow this term from Sylwia Hanff and Tomasz Bazan.

11 Butoh-tai is the popular English spelling of the word, used for example by Toshiharu Kasai. 
unique state of mind which is at the same time the fundamental aim of butō training and a starting point for further psychosomatic explorations. It essentially involves an extraordinary awareness of being grounded in reality and a very intense sense of being here-and-now. There is no one standard method that generates this state, and to achieve it dancers employ a wide range of practices and techniques described in the sections devoted to endurance conditioning and mindfulness training. As there is no one definitive way to total presence, there is no one standard definition of it either.

To describe the experience of total presence, the Polish butō-ka resort to a heterogeneous terminology borrowed from different disciplines, such as psychology, psychoanalysis, religious studies, cultural anthropology and others. Admittedly, they all point to an extraordinary mode of appreciating impressions from the body and from the environment, a changed reception of stimuli and a transformed manner of information processing (thinking, decision-making, etc.). However, practices serving to alter self- and reality-perception can bring about diametrically different body-mind states, e.g. calmness and agitation. To convey their experience of total presence, the butō dancers rely on a varied lexicon, in which the key coinages are:

1. enhanced consciousness, hyperconsciousness, ecstasy;

2. flow, peak experience;

3. space awareness, body consciousness, being here-and-now, alertness, preparedness, openness, sensitivity;

4. grounding, focus;

5. passive perception, diffused focus, dispersed attention;

6. contemplative experience, zero state, neutral state, erased, empty body-mind, body as an empty receptacle, suspended reflection, control, calculation and decision-making, suspended individual, personal identity, return to infancy, non-differentiating consciousness;

7. trance. $^{12}$

A useful, expository tool to explore this phenomenon is offered by the "cartography of ecstatic and meditative states" developed by Roland Fischer (Fischer 1971:2). Fischer connected two types of arousal of the autonomic nervous system (ANS) to particular states of the body-mind, and then presented the spectrum of ecstatic and meditative states in a graphic schema (see Figure 1).

12 The most important of these notions (flow, peak experience, contemplative experience, zero state and trance) are defined in "Terms." 


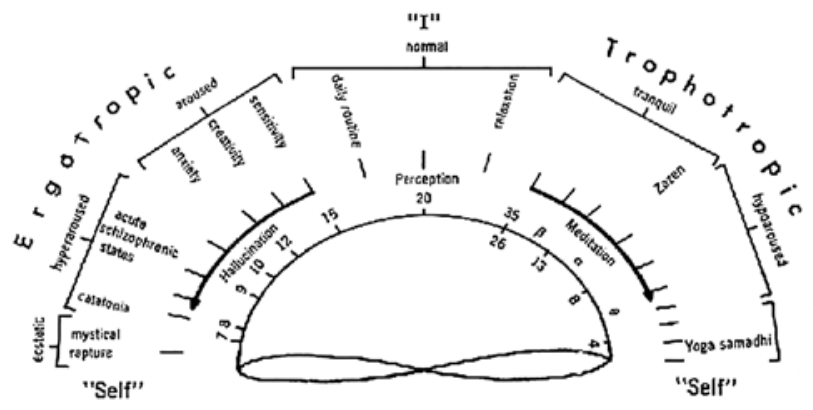

Source: www.wisebrain.org/papers/MapofMedEcstaticStates.pdf [Accessed 23 April 2012]

The states reported by the Polish butō-ka can be found across Fischer's map, with (1), (2) and (3) located in the left-hand part, (4), (5) and (6) in the right-hand part, with trance (7) straddling the two halves of the map as it consists in synchronising both arousal types. This helps understand (or, better, "feel" or "imagine") what kind of body-mind state the artists are trying to capture in words.

Activation of the ergotropic system (i.e. arousal of the sympathetic nervous system SNS, part of the ANS), which is controlled by the left hemisphere, involves such symptoms as energy flow, accelerated pulse, increased blood pressure, sweating, pupil dilation, desynchronised brainwaves, considerable muscle strain, glucose release into the blood, and the secretion of stimulating hormones such as cortisol and epinephrine into the blood. Activation of the sympathetic system serves to mobilise the body to undertake action which requires considerable effort (the "fight or flight response")

Activation of the right hemisphere-controlled trophotropic system (i.e. arousal of the para-sympathetic nervous system PNS, part of the ANS) takes place in situations when there is an overwhelming threat which cannot be opposed. It causes the state of "freezing and resignation" accompanied by the "release of anaesthetising endogenous opioids and changes such as a decreased heart rate, lowered blood pressure, loss of muscle tone and the state of indifference and resignation called dissociation in people" (Sakson-Obada 2009: 78-79). Appended reactions include relaxation, a decreased heart rate, reduced sweating, pupil constriction, synchronisation of brainwaves and increased secretions of insulin, oestrogen and androgen (cf. Schechner 2006: 194). ${ }^{13}$

13 For details of this process, see Schechner 2006: 194-197. 
Briefly, the arousal of the sympathetic nervous system generates states of excitation and ecstasy, sometimes accompanied by hallucinations, while the arousal of the para-sympathetic nervous system causes relaxation, tranquillity and deep meditation.

Trance, in turn, is associated with changed sensitivity to stimuli and altered perception of the self and the environment. In traditional rituals and contemporary practices (such as rave parties and artistic performances), trance has a common neurobiological foundation. Richard Schechner describes two research experiments aimed at investigating trance. In one of them, electroencephalography (EEG) was used to measure alpha, beta and theta brainwaves, while in the other, changes in blood chemistry (the concentration of neuroactive substances) were examined. In the study, the arousal of neuronal circuits of the central nervous system was reported, including increased concentrations of noradrenaline, which acts as a stimulant, and increased a-endorphin levels, an opioid that relieves pain and causes euphoria (cf. Kawai et al., qtd. in Schechner 2006: 196).

This indicates that, in a state of trance, the sympathetic and para-sympathetic nervous systems are aroused at the same time. After a period of oscillation, the systems' functions are attuned. In the synchronisation phase, a specific state of mind appears which defies any linear, organised description. As Fischer concludes, the experience of unity results from the integration of cortical and subcortical activity, and the intensity of the sensation can be conveyed only via metaphors.

The Polish butō dancers talk of two kinds of unique experiences. One group is associated with mindfulness, openness and "enhancement" of perception or awareness, breeding excitement, rapture and ecstasy (the left-hand side of Figure 1). The other group comprises experiences depicted as relaxation, calmness, concentration, focus and meditation, which gradually remove everyday identities and produce an erased, empty body (the right-hand side of Figure 1).

\section{Following}

In the stage of following, dancers explore stimuli from within and without their bodies. The state described as total presence is characterised, among others, by exceptional sensory sensitivity, including extero- and interoception. Due to such heightened receptivity, impulses which are drowned in the "daily buzz," nontypical impressions and, even, terrifying sensations find their way into one's consciousness. Also, feelings that once accompanied repressed or forgotten events can return alongside all the resources accumulated in individual and species development (ontogenesis and phylogenesis, respectively) and stored in the body memory. 
Usually, mindfulness training smoothly transitions into the stage of following, which an external observer could call dance improvisation. The state of mindfulness is used in psychosomatic exploration, in which various body-mind states are tested and perception is experimented with by, for example, activating rarely used receptors (sensory sensitisation), investigating capacities of the body and examining various qualities of movement (resonance, spread, emptiness). Intuition and imagination are given precedence in order to use the inner resources and open up to the unexpected. Particularly important in following is the activation of body memory (cellular, procedural memory), which will be discussed in the next section.

However, the most important aspect of this phase of practice is following as such, i.e. following both the stimuli from the sense receptors and all the spontaneously emerging states, feelings and images. Following is based on the simultaneity of sensation and reaction (sensorimotor unity). As movement appears simultaneously with inner sensation/impression/agitation, it reflects all perception motilities. It is because of total presence that experiencing and responding are not separated by reflection (i.e. the intellect's attempt to control body movements) and its appended socially entrenched mechanism which tells us to censor certain ways of moving.

Motor reactions are supposed to be spontaneous (not reflected on, non-volitional), non-habitual and organic. This involves transgressing the body code (habitual ways of bodily comportment), overcoming bodily automatisms, transcending schemes of movement, surrendering to energy flows (movement is a symptom of the flow) and expanding movement through the use of elements which are untypical and usually avoided. Movement starts from various levels (e.g. bones, tissues, cells, etc.), and it can easily be involuntary (ideomotor). Through movement, in which flow and resonance appear, dancers can relate to other bodies and objects.

\section{Body memory}

The Polish butō dancers often refer to the concept of body memory. Body memory is understood in two ways: first, as an ability to automatically reproduce movement sequences; and, second, as a record (not only of movement) at a level which our reflective (declarative) memory cannot access. As movement sequences are not choreographed in butō, the latter concept is applicable. Addressing body memory, the dancers talk about activating what has been inscribed in their bodies.

Body memory is discussed in some detail by Olga Sakson-Obada. Although her study explores neurophysiological patterns of body functioning disturbed by earlier trauma, I will summarise her major findings below, because post-traumatic disorders in body functioning overlap to some extent with sensations experienced in "ecstatic and meditative states" (cf. "Total Presence"; Fischer 1971), e.g. specific 
arousals of the autonomic nervous system and the inability to interpret experiences cognitively (cf. Sakson-Obada 2009: 69-77).

Sakson-Obada focuses on the somatosensory aspect of trauma, drawing on Bruce Perry's theory of memory types, which distinguishes "four kinds of memory encoded in different structures of the brain" (Sakson-Obada 2009: 82): state memory, motor memory, emotional memory and cognitive memory. These various kinds of memory can be activated when the person is exposed to particular stimuli (cf. Sakson-Obada 2009: 82-83).

The human brain is hierarchically structured and contains relatively simple structures which function without interventions of consciousness (e.g. brain stem and midbrain), more complex structures (the limbic system of hippocampus and amygdala) and highly intricate structures involved in conscious thinking (the cortex). "Within each structure, the memory of an experience can be stored as a neuronal activity pattern" (Sakson-Obada 2009: 82). Thus, at each level, a different type of memory is found and, going from lower-order to more complex structures, inputs are analysed in different ways, triggering different responses in the body. Among Perry's four memory types, state memory, located in the brain stem "encodes blood pressure, heartbeat rhythm and breath frequency at the traumatic moment" (SaksonObada 2009: 84). In the midbrain, motor-vestibular memory stores information about the body's arrangement and orientation. Emotional memory, situated in the limbic system, preserves emotional states, and cognitive memory, tied to the cortex, records experiences in words and combines the remembered impressions in memory clusters. Aspects registered in each memory type can be activated by a stimulus associated with a deep sensation which causes such inscription (so-called state-specific or state-bound memory) (cf. Kasai 2009a).

However, the most complex cognitive memory is not always activated in such situations, as a result of which consciousness receives only disjoined and unintelligible signals about the responses of the brain stem, the midbrain and the limbic system. Various somatotherapeutic methods are used to activate respective levels of memory and, in this way, to recover memories which cannot be accessed by cortical activity (i.e. by conscious attempts to recall things).

How memories are accessed when recalling traumatic events has been studied by Bessel van der Kolk: "Initially, experiences are recollected[...] as isolated states comprising one modality (vision, hearing, smell, touch or affect) which, when intensified, extends memory onto the remaining modalities" (SaksonObada 2009: 85).

By triggering specific body states (e.g. in trance or hypnosis; cf. Sakson-Obada 2009: 81), it is possible to reproduce experiences stored in procedural memory 
which have been recorded in a distorted form or not recorded at all in declarative memory (cf. Sakson-Obada 2009: 81). In this way, specific somatosensory sensations, the functioning of the senses (e.g. the elimination or raising of sensation thresholds) and emotional states are "recalled." Consequently, it is possible to return to the states of consciousness which are "[...] directly connected to physiological body-mind states such as sleeping, sleep deprivation, fasting, oxygen deprivation, nitrogen narcosis, alcohol, psychotropic agents in general, or various dancing, religious training of various kinds, or sensory deprivation, hypnosis, etc." (Charles Tart, qtd. in Kasai 2009a: 26). This facilitates recollecting experiences from the pre-verbal period, involved in a range of specific states of consciousness in the pre-natal and periparturient phases and in infancy (as in non-differentiating or neonate consciousness mentioned by the butō dancers).

\section{Somatosensory Changes}

The retrieval of inputs registered in body memory can trigger unusual, even terrifying or disgusting somatic experiences (see the next section). To describe the changes in the self-experience of the body while "recalling the body state during a trauma experience" (Sakson-Obada 2009: 78), Sakson-Obada talks of somatomorphic dissociation (cf. Sakson-Obada 2009: 69-77). (In the case of intense buto training, the reproduced body state can be associated with any meaningful and intense past experience.)

Extraordinary somatic experiences are caused by "changes involved in the arousal of sympathetic and para-sympathetic nervous systems." ${ }^{14}$ Because, unlike animals, humans have not developed a defence mechanism against sustained excitation, it does not go away when its stimulus disappears. Unreleased autonomic system arousals "activate neuronal circuits constituting state memory at the moment of a traumatic experience [or another equally intense past event]." The uncontrolled cycle of arousal (the response of the sympathetic system) and resignation (the response of the para-sympathetic system) "causes disturbances in body functions." This neurophysiological theory explains disorders that accompany the states of consciousness altered as a result of a single rather than a chronic stimulus, such as disturbed pain sensitivity (changed pain thresholds) and distorted vision, hearing and perception of sensations from the body (somatosensory disorders). Psychologists have also observed that "an altered state of consciousness 'switches in' $[\ldots]$ and abolishes the capacity to represent one's experiences symbolically

14 Throughout this paragraph, the sensations are described based on Sakson-Obada 2009: 78-87. 
(verbally)." In such circumstances, fragments of memories are retrieved which can trigger "bizarre, isolated somatosensory sensations or strong emotions." People can feel "haunted" or "possessed" by incomprehensible experiences. Memories are usually activated by stimuli that correspond to the original trauma situation (or any meaningful past situation that involved strong and unusual sensations). This can engender chronic arousal and, concomitant, the hyper-excitability of the para-sympathetic autonomic nervous system. As a result, stimuli are perceived as disproportionately powerful. Extreme, overwhelming affective states (emotions) set in, including fury, aggression, shame, terror, sadness, anxiety and dysphoria (sorrow coupled with unease), combined with passiveness, a sense of engulfing emptiness and emotional withdrawal. Such numbness is associated with analgesia (the reduced ability to feel pain) and anhedonia (the inability to feel pleasure). Self-perception changes as well, affected by depersonalisation, derealisation, inner incongruity and somatisations (medically ungrounded somatic disease symptoms, such as changes in the field of vision, pain and paresis). These sensations can be accompanied by alexithymia, i.e. difficulty in verbalising emotions caused by the inability to symbolise them.

In the case of trauma work, this kind of experience, inaccessible in states of regular consciousness, can by triggered in hypnosis (in order to "work it through"). In my view, butō training considerably resembles self-hypnosis and is also capable of activating memory linked to a particular body-mind state (i.e. statebound memory). Somatosensory changes caused by rehearsing an intense past experience can be used by butō dancers as resources for further creative work. In stage performances, such resources will make up the dance's texture.

\section{The Object}

Butō dance is associated with specific aesthetics and/or poetics. Its signature features are ugly movements (crawling or walking on crouched, twisted legs), the body's ugliness and diseased looks (flaking rice-flour or plaster make-up, disfigured grimaces) and a general sense of wasting and ruin (old, tattered clothes). Such aesthetics can be explained in various ways. ${ }^{15}$ In my view, its most important source lies in organic factors stemming from the specific way of processing sensations

15 For example, such aesthetics are construed as an attempt to represent the fatigued bodies of poor inhabitants of Japan's backward, rural regions, where Tatsumi Hijikata was born. It is also explained as related to the tragedy of Hiroshima as an attempt to render the bodies damaged by the radioactive radiation (as suggested, for example, by Akira Kasai). 
stirred in butō training. I would argue that the exploration and deployment of body memory paired with the retrieval of repressed (and, as such, undesirable) experiences and feelings contribute to the precedence of such a stage aesthetics model rather than any other. Only such aesthetics can fully reflect the concealed "contents" of our (non-)memory.

To explain what kind of contents can be released, I will draw on theories proposed by developmental psychology and psychoanalysis.

"In psychoanalysis, the body is a key factor in the formation of the subject. The subject is in the body and is, at the same time, the body, but this body is purified, organised, socialised even" (Bakke 2000: 20). Across the stages of development, the human being processes his/her bodily sensations, which undergo socialisation and inculturation. ${ }^{16}$ In the neonatal period (especially throughout the first seven weeks of life), experiences from within the body are felt with particular intensity, with the body's surface (the skin) being sensitised only later. In this period, the body self obtains its first, still incoherent representations, which are later unavailable to conscious memory. In the first two years of life, the child acquires a sense of the limits of its body, in this way developing the "skin ego" related to the establishment of "an inner - mental - space where sensations can be processed safely and intelligibly," and builds the "realness of its inner states." In the third stage of development, which commences around the 15th-18th month of life, the child creates "a coherent representation of its body integrated with the psychological self, a representation that founds reflective self-awareness." As the child's own reflection becomes an object of perception (the so-called reflective function), the interpretation and symbolisation of sensations and emotions can commence. This takes place during what has come to be known as the mirror phase.

At this stage in subjectivity development, the subject establishes a relationship with the environment as the two do not make up a chaotic, undifferentiated whole anymore. From now on, an imaginary anatomy is built in the subject. [...] The imaginary body form emerges only in conformity with the [cultural] context, which Lacan calls the imaginary and symbolic orders. As a result, the biological body is always mediated by the two orders. (Bakke 2000: 22)

Prior to the mirror stage, the human being is an internally undifferentiated, vaguely demarcated, diluted and fraying "uncoordinated aggregate, a series of parts, zones, organs, sensations, needs and impulses" (Grosz 1990: 33) - a body in pieces, devoid of an ego. As such, the child's body is closer to what Lacan calls the real, i.e. that which has not been mediated by culture yet.

16 Throughout this paragraph, cf. Sakson-Obada 2009: 38-42. 
The real is a natural (inborn) sphere of plenitude and fulness which Lacan refers to as "the lack of lack." It is not limited in any way, it knows neither divisions nor discriminants, and it forms a continuum of "raw material," with demarcations, boundaries and antinomies coming forth only later. [This sphere is] that which is entirely concealed but all the same is there. (Bakke 2000: 36)

Monika Bakke also explains that the real "cannot be directly experienced the way it is; it can only by experienced via strategies of the imaginary and symbolic orders. For the real is that which cannot be assimilated and represented; it is the sphere of psychosis, the stage of complete disintegration and the lack of identity while regressing into it is a constant threat to every subject" (Bakke 2000: 38). Importantly, what Bakke means here are abrupt and uncontrolled "regressions."

To construct a coherent subjectivity, the individual must first of all create and retain a clear image of his/her body boundaries. In confrontation with the individual's own bodiliness, the abject is demarcated, encompassing everything that is repulsive, impure, disgusting and linked to the body's "materiality and uncontrolled physiology" (Bakke 2000: 25). The abject is part of the pre-discursive, semiotic sphere (of the bodily, palpable, but as yet non-subjective), anchored in unconscious processes, whereas the culturally "cleansed" subject is ideally located in the symbolic sphere (of the verbal and the rational). Julia Kristeva distinguishes three types of the abject: oral (food-related), anal (excrement-related) and genital (sexual difference-related) (cf. Bakke 2000: 25-26).

An array of mechanisms is used to bracket the abject off from the socially capable subject. The symbolic confronts the semiotic only through "madness, sacredness and poetry" (Bakke 2000: 27) as "[1]iterature, poetry and art sublimate the abject and make it acceptable, whereby it is tamed and brought closer to us" (Bakke 2000: 27). Because the abject and abjection (i.e. a disgust and abhorrence of the repulsive) are generally unwelcome in and for subjectivity, they have become an object of interest for avant-garde artists. Abject art is explored by Hal Foster in The Return of the Real: The Avant-Garde of the End of the Century (1996). The performative strategies he enumerates include (1) identification with the abject; and (2) representing "the condition of abject in order to provoke its operation to catch abjection in the act, to make it reflexive, even repellent in its own right" (Foster 1996: 157). In art, abjection comes in a variety of shapes, for example, as infantilism (undiscriminating, non-evaluating and all-accepting consciousness), innocent perversion, anal eroticism, fascination with mimicry and psychasthenia (cf. Foster 1996: 159-166), and involves "the breaching of the body, the gaze devouring the subject, the subject becoming the space, the state of just similarity" (Foster 1996: 165). 
What butō dancers actually seek is re-immersion in the real and contact with the abject. This sphere, a sphere of disintegration and demise of subjectivity, is a lasting fascination for them. Although structured training produces certain frameworks, it also promotes experimentation with perception, in which the guidance of an experienced butō-ka is indispensable, at least at the beginning, because

Disintegration of the body image may [...] cause the subject to regress to the condition from before the imaginary order, that is, to the archaic, uncoordinated and non-selfsame body in pieces. The return to the order of the real is fraught with psychotic fantasies of decomposition and being controlled by the external, objective world. (Bakke 2000: 23-24)

In training, butō dancers employ various techniques for altering body-mind states in order to go back to the pre-verbal phase. They unite with sensations from the body and react to stimuli directly (unreflectedly). They neither generate representations nor engage in analyses at the symbolic (intellectual, verbal) level. They can be said to revert to non-differentiating, neonate consciousness - to the condition of an aggregate where no differences exist yet, the abject has not emerged and everything just "is." Such a strategy of a "return to the embryonal state" was often applied by Kazuo Ono. As such, it is also a common fixture in the training practices of Ōno's heirs and their students, e.g. Atsushi Takenouchi. Tatsumi Hijikata was rather preoccupied with the abject and fascinated with the liminal moment when the body becomes a subject by entering the sphere of culture and first differentiations - notably self vs. not-self - appear. He was particularly interested in the factors involved in becoming a socialised person which culture actually taboos, in the parts of the self which are subject to abjection. This is probably the source of the abject aesthetics of Ankoku butō.

Because most of the Polish dancers studied butō with various teachers, their practice intertwines strands of butō philosophies picked up and developed by students of (heirs to) both Hijikata and Ōno.

\section{Embodiment}

In this stage, dancers use various mental images to generate movement. Sequences of such images which Hijikata proposed to his dancers are called $b u t \overline{-}-f u$, or butō notation. Mental images are communicated (and noted) by means of words which catalyse metamorphosis. Images can be stimulated from the outside, inspired by matter, objects and/or situations which dancers did or could experience. At the same time, images can be inspired from within performers' bodies by themes and 
pictures "extracted" from them (in the processes described above) as well as by specific states of mind which induce chains of association. Operatively separated from the mind, the body is treated as an empty receptacle or a shell which takes on a form that corresponds to a given mental image. All kinds of images undergo ideokinetic processing when embodied and incarnated in motion/action in ways unique to each performer. Mutations of these images trigger movement which observers perceive and define as dance.

The Polish butō dancers work with various kinds of mental images. They can be concrete and metaphorical images from Hijikata's butō-fu or individually constructed images aligned with the dancer's bodily and mental process. A mental image to be embodied can also be derived from a situation, a theme (e.g. a state of consciousness), an object/thing that the dancer embodies (which s/he "becomes" by uniting with it) and any organic or inorganic matter "embedded" in the body. Additionally, mental images can also arise in the body itself: its arrangements, positions and images recovered from body memory.

\section{Butō-fu and Omoi}

After 1972, Hijikata developed a technique of communicating images through words. Contrary to popular opinion, speech (word use) is an important component of Ankoku butō. It was, in fact, Hijikata's most characteristic technique for working with the body-mind.

Caught up in words, clothed in them, the body came to function as one of the butō signs (butō-fu), which Hijikata called also imaginary wordings and used in his practice with dancers to compose choreographies. [...] As a result [dancers] could become everything and anything, from a pebble to a hail cloud; they could embody the universe. [...] Dancers were not supposed to imitate a thing; they were to become this thing. Embodiment was possible only after the body had been stripped of its individuality and personality [...] Becoming aware of their physicality, dancers learned to use their bodies as tools. And repeating exercises over and over again, they could control their bodies physically and mentally. (Capiga 2009: 53)

This is how Aleksandra Capiga-Łochowicz describes Hijikata's method (relying also on his untranslated papers) while Yōko Ashikawa states directly: "Hijikata wrote dance" (in Hoffman, Holborn 1987: 9). Ashikawa remembers that over the ten years she worked with Hijikata, every day was doused in drum beats and torrents of words. Hijikata, of course, spoke Japanese, a language ideally cut out for such work as its adverbs are often onomatopoeic. "We simply could not dance without words," recalls Capiga-Łochowicz (Capiga 2009: 53), and Kurihara insists emphatically: "For Hijikata the body is a metaphor for words and words 
are a metaphor for the body" (Kurihara 2000: 15). In his talk Wind Daruma (published in 1985), Hijikata explains: "I studied the gestures [...]. Then I put them all inside my body" (Hijikata 1985: 75). In this way, the body was forced into constant transfigurations.

In Hijikata's day, the idea of embodying mental images was not a novelty in Japan. There is a Japanese term omoi which "means thought, concept, image, intention, etc. It is difficult to give a clear-cut definition of the word, but the central idea is concerned with what you have in your mind whether intentionally or not, " as Kasai explains in his "Choreographing a Butoh dance piece" (Kasai 2009b).

In the same paper, Kasai recounts a butō workshop with Semimaru, a butō dancer from the Sankai Juku group, in which Semimaru told a story based on a series of omoi to provoke the trainees to perform various non-typical movements. Diverse omoi are also embodied in the Nō theatre and in koan practice characteristic of some schools of Zen Buddhism. In Nō, embodiment is a rudimentary stage version of divine possession (kamigakari) (cf. Żeromska 2010a: 37-38) and commemorates a dance in honour of "Kasuga Daimyōjin, a deity who revealed himself as an old man, okina, and danced beneath a pine tree [...] in the grounds of the shrine" (Żeromska 2010a: 231), which has been interpreted as the Nō theatre's symbolic descent into the human world. Instead of deities, Nō actors' bodies incorporate "images of people, animal limbs, parts of waterfalls, spirals of tree-trunks, the quivering of twigs, a branch swirled away by the river" (Rodowicz 2009: 9), in other words infinitely varied manifestations of the world. Jadwiga M. Rodowicz refers to this as an "ancient capacity to incarnate a throng of living beings which are transferred from the prehistory of the memory of the human species inside the actor's body" (Rodowicz 2009: 9). Phylogenetic memory is revived, which is metaphorically called "a space inhabited by ancestors."

Choosing the title for her study of the Nō theatre, Rodowicz opted for Boski dwumian. Przenikanie rzeczywistości w teatrze nō [A Divine Binomial: Interpenetrating Realities in the No theatre], in which she describes an ancient vision of the world in which the human being and the world unite in harmonious, constant communication. Her central focus is "the indivisible and living binomial one world in which the living commune with the dead" (Rodowicz 2009: 10), where the boundaries between the human and reality are vague, while the human is "not an individual, but a stream, a bundle, a chord with a pulsating heart at the centre [...]. Each of his feelings, each of his body parts and each piece of his life emulate shapes already created and preserved: plants, animals, mountains, rocks, waterfalls" (Rodowicz 2009: 11). 
As Rodowicz describes it, the two worlds are clinched in constant oscillation, which demands double-layered perception from the audience. The protagonist's shite's - silence at the climactic moment of the plot of the No drama makes room for another reality which lies beyond our reach as a rule. Motokiyo Zeami discusses the same process, insisting that "in the actor's action, the most important part is the moment of suspension, of non-action (senu hima) amidst singing and movement" (qtd. in Rodowicz 2009: 172). In the shadow of this enigmatic silence, sensual images and forms arise which are literally embodied by the actor. A world evoked by previous actions comes into being.

Communication between these two layers of reality in the No theatre is guarded by what Rodowicz calls binomial objects, in and through which a third space is produced where the actor is a vehicle between the everyday space and the space of mystery. The archaic capacity of showing the concealed space through the body enables the performer to traverse the two parallel, mutually resonating realities. The human being consists both of what $\mathrm{s} /$ he is and of what s/he can be. Having crossed the threshold between the two realities, the human being can enter a liminal space and become a "dead body standing," as Hijikata depicted one of Ankoku butō's key figures. In butō, the function of a binomial object is taken over by the dancer's body, which "becomes a text, a record of human experience discovered through movement" (Jerzak 2009). Butō dancers use mental images in order to awaken the memory of the dormant body. "Memory is iconic; it is roused by traversing the space along the trail of word-evoked images [...] memory feeds on the image spellbound in a word" (Rodowicz 2009: 126).

Omoi are also used in koan practice by masters of Rinzai, one of the Zen schools of Buddhism. ${ }^{17}$ Koan practice includes disciplines analogous to those used in butō training. The Zen practitioner achieves total presence by means of special techniques, such as adopting an appropriate position (Zazen sitting) and abdominal breathing (called also belly breathing or diaphragmatic breathing), in which the breath is turned towards the hara point, located below the navel. In shikantazy, which is used in Soto, another Zen school, the practitioner achieves a specific state of mind and then follows whatever emerges as a result of meditative focus.

In Rinzai, however, the practitioner repeats the koan (a question or a riddle, cf. "Terms") assigned by the teacher (sensei) or, more precisely, "takes it into

17 All information on koan practice comes from Małgorzata Braunek, Roshi of the White Plum Sangha, a Kanzeon Zen school, in Poland, imparted during the Dharma Speeches and face-to-face conversations (daisan, dokusan), as well as from my own practice at this school (from 2005 till now). 
the body." This aims to achieve transformation and identification with the koan (becoming the koan). The practice itself can thus be called embodying the koan. Only by "embedding" the koan in the body-mind can the practitioner actually experience it. As an effect, s/he identifies with the koan, becoming one with it. Instead of understanding, the process requires experiencing. It is emphasised in koan practice that the mind - and, thus, the person - contains the full range of possibilities and can be manifested in any given way. The human being is a vehicle, or rather a vessel, of all potential sensory manifestations. The ability to embody/ incarnate koans is directly related to the awareness of how the human mind works. Reality (that is, all forms: both what we consider a subject and what we consider an object) is a manifestation of the mind (WMB). Butō dancers, instead of koans, embed any mental image in their body-minds.

\section{Ideokinesis}

The technique of embodying imaginary wordings is neither Hijikata's original invention nor a distinctive feature of Japanese culture. In fact, it has been used across cultures for millennia. ${ }^{18}$

In the 20th century, the practice came to be referred to as ideokinetics. Ideokinetics can be defined as consciously inducing physical and biological changes by means of mental images. Of course, a "mental image" as used here designates not only visual representations but also derivatives of other sense modalities. Mental images can be divided into direct (literal; e.g. the arm's movement at the joint) and indirect (metaphorical; e.g. an eagle spreading its wings to fly). Direct images are used first of all in sensorimotor training for athletes and in physiotherapy of locomotor organs. Used in such settings as well, indirect images can also be employed by dancers and performers as elements of improvisation both in workshop practice and on stage. Another viable classification divides mental images into abstract and concrete groups (Cf. Hawkins 1991). Concrete images concern concrete activities, such as parting glued-together hands, while abstract images refer to intangible things, e.g. emotions, visions of a force that pulls one, etc. As a matter of fact, Hijikata's butō-fu consists of both concrete and abstract varieties of indirect images.

Ideokinesiology, that is, a science that explores possible applications of mental images to improve muscle patterns (cf. Bernard 2006), was developed by Mabel E. Todd, Barbara Clark and Lulu Sweigard in the 20th century. Quoting Todd, Sweigard claims that "concentration upon a picture involving movement results in

18 For a brief history of the discipline, see Franklin 2012: 23-33. 
responses in the neuromusculature as necessary to carry out specific movements with the least effort" (Sweigard 1978: 6). Sweigard defines ideokinesis as "repeated ideation of a movement without volitional physical effort" (Sweigard 1978: 187). In this case, the aim is not actually to reflect an image automatically through the body movement.

Since the 1970s, several studies have contributed to a theoretical model of ideokinesis. A survey of findings about mental stimulation through motor imagery was published by Bibianna Bałaj of the Catholic University of Lublin. ${ }^{19}$ She reports that as early as in 1885 Salomon Striker found that the "simulation of an activity mobilises the same processing resources which are used to perform this activity" (Bałaj 2007: 231). Contemporary neurobiological research has corroborated Striker's finding. The time-spans of simulated and real movements are similar, "the vegetative responses linked to physical effort change in the same way" (Decety, qtd. in Bałaj 2007: 231), and similar regions of the brain are activated. Brain simulation can be automatic (looking at a person) or consciously triggered (imagining how we would feel in a given situation). Thus, the imagination also has an adaptive function: imagery-based motor training causes similar changes in brain functioning, and "research indicates that imagery-based training effectively improves motor skills" (Bałaj 2007: 245).

How does it work? The brain is connected to the body (e.g. muscles) by bidirectional neural pathways. Neurons are divided into sensory, motor and inter-neuronal (which mediate in communication between the former two types). Sensory neurons collect information about sensory stimuli, transmit it to the brain and provide stimuli for reflexes, while motor neurons transmit information from the brain to the muscles, causing them to contract: "electrochemical activity is shot down the axon, the neuron's lengthy arm" (Franklin 2012: 36). To create visual mental images, the body relies on neuronal pathways linked to seeing, yet in this case the process has an opposite direction: the stimulus comes from an upper organ to the optical cortex, where it is recognised (Franklin 2012: 39). Through movement, our body unconsciously reflects live images created in the mind. However, it takes sensory training and sensory sensitisation to create vivid and complete mental images in the mind.

Even before a decision to perform a movement is consciously made, the brain is engaged in preparing the motor processes (mapping them): it mobilises the network of action-representing neurons, which transmit information to prepare motor (muscle) response. This process is called the excitation of motor potential.

19 Currently affiliated with the Nicolaus Copernicus University in Torun. 
Of course, this does not always produce movement. The brain usually sends a message which stops the movement from "spilling over" from the imagination. To prevent muscle activity, the cortex activates specialised amino acids. However, "the signal that halts motor activity while imagining can be selectively blocked" (Bałaj 2007: 231).

In practice with mental images aimed at initiating movement, such as those used in butō, we focus on the movement which has indeed "spilled out." As early as in the 19th century, mental images and intents were studied for their impact on the unconscious initiation of movement and other bodily responses. The term "ideomotor response" was first used by William Benjamin Carpenter in 1840. It denotes micro-movements and motions performed under the influence of the imagination and outside the person's awareness. A related term - ideodynamic response - refers to all reactions of the body, not only motor reactions, including for example the secretion of fluids (e.g. salivating at the thought of a lemon). An image arising in the mind triggers a series of responses which are reflected in bodily (e.g. motor) processes.

As explained by Jeanne Achterberg, an American body-mind scholar, our bodies' movements are initiated by both brain hemispheres. The left hemisphere controls deliberate and voluntary activities, making sure that the body hears and obeys verbal commands "quite well, except in the case of injury or pathology." The right hemisphere, though associated mainly with image- and representationproduction, also affects body activities, "by sending thought pictures to the appropriate muscles; for example, by imaging a hand opening like a flower [...] No thought, no emotion, is without biochemical, electrochemical activity; and the activity leaves no cell untouched (Achterberg 1985: 123-124, 127).

Embodying/incarnating images is underpinned by these principles, which need not be (and indeed rarely, if ever, are) explicated by butō dancers but, anyway, tacitly underpin their practice. In improvisation, butō dancers employ the body's potential of ideomotor and ideodynamic responses: "various mental experiences and abstract thinking influence motor activity, including the contractions and tension of skeletal muscles and body posture" (Mond-Kozłowska 2010: 76). Using (direct, indirect, abstract and concrete) mental images, butō dancers initiate body movements. They deliberately and purposefully produce images or focus on images found in the external world or in their body memory. They can also rely on the notation of mental images created by Hijikata (butō-fu). Their movements and body poses reflect the images. Mental images, including verbally mediated ones, are a basic instrument of transformation in butō dance. 


\section{Transformation in the Dancer and the Audience}

As shown in previous chapters, butō dancers relinquish all formal aesthetic and semiotic codes. Central to their practice is an act of transformation itself (cf. Fraleigh 2010; and "Sondra Horton Fraleigh: Butō as an Alchemical Process" in Chapter 2 in this volume): dancers become what the viewer sees them as presenting. The "emptiness" produced by discarding the identity is filled with concrete representations. By means of images, the outer world is brought inside the emptied-out body and transforms alongside the body. In training practice, transformation is the ultimate goal of a performer's inner process.

The experience of total presence, which is a key experience belonging to the category of altered states of consciousness, is projected onto the audience and sensed by their bodies. In the warm-up stage of training, buto dancers rely on an array of techniques to achieve this state. The techniques include endurance conditioning, which leads the body to a point of utter exhaustion and crisis, as well as mindfulness training, usually based on the zero walk. Both types of practice change the ways the body works across its various - neurophysiological, hormonal and, consequently, also perceptual, emotional and energy - functions. In the subsequent stage of following, dancers enhance their sensory receptiveness and explore the resources stored in their body memory along the trajectory of individual (ontogenetic) and species (phylogenetic) development. The subsequent embodiment phase involves employing mental images to mobilise movement. Butō dancers fill "the shell of the body" with movement, using Tatsumi Hijikata's butō-fu (butō notation) and images created from the material "inscribed" in the body. Mental images (representations) are processed idiokinetically as they are embodied and incarnated in motion/action/dance.

Butō is quintessentially about undergoing the process of transformation outlined above. Continual psychophysical transformations already formed the core of butō practice in the original, classic style of Ankoku butō. Hijikata "sought to capture amorphous life, evading stiff patterns" (Capiga 2009: 55). His aim was to make dancers "erase" their everyday, human, socialised forms.

His basic idea was that the body's animating spirit metamorphoses into other existences, leaving the empty physical shell to respond to place and environment [...]. Since Butoh is an individual art without universal form, it is important for each Butoh dancer to find his own reality of how the body currently lives - his own form of life. (Tachiki 1999: 33) 
The Polish butō performers pursue the same goals.

Transformance (performance of transformation) is part of many various cultural performances. In butō, transformation involves applying an array of techniques discussed in previous chapters. Although there is no general, universal or standardised butō method, it is possible to list a number of specific techniques which best promote goal achievement across the stages of transformative practice.

\section{Performative Training}

Erika Fischer-Lichte explores performance as a shared act in which "performers" designate both the participants conventionally known as "artists" (actors, dancers, etc.) and those called "viewers" (the audience) in classical aesthetics. Artists and viewers reciprocally modify their actions (cognitive interaction, mutual stimulation). Performativity characteristically involves a sustained, reciprocal process of interaction between the participants: "the autopoietic feedback loop [which] is generated and kept in motion not just through visible and audible actions and attitudes of actors and spectators but also through the energy circulating between them. This energy is no phantasm [...] but is indeed physically perceptible" (Fischer-Lichte 2008b: 59).

In this process, performers are first and foremost phenomenally present in that they do not represent anything other than themselves and here-and-now reality, while the materiality and "palpability" of their bodies overrides their signifying function.

Performers' phenomenal bodies emit special radiation which is perceived by the bodies of other participants/viewers. In many cases, the stream of energy seems veritably to emanate from the performing body to engulf the audience and visibly increase their energy. This makes the artist present here-and-now in an especially intense way. At the same time, viewers who receive such an energy stream experience their own presence also in very special and particularly intense ways. [...] [Performers] rely on special techniques and practices to master space and channel the audience's attention entirely onto their bodily presence. (Fischer-Lichte 2008a: 67).

Characteristic of the phenomenal body is a special kind of "here-and-now" presence: the body is obtrusively present, autotelic and non-intentional in refusing to be a vehicle of any meanings. During the performance, "the phenomenal body of every participant with its typical physiological, affective, energy and motor states directly affects the phenomenal bodies of other participants, triggering in them specific physiological, affective, energy and motor states" (Fischer-Lichte 2008a: 67).

On the other hand, the semiotic body as a vehicle of meaning refers to something beyond itself to which the body only "points." 
Stage performance is a result of the interpenetration of the semiotic body and the phenomenal body. This involves a bodily process, in which "the phenomenal body can continually create as a specific thing and, at the same time, generate its specific meanings. The actor in a special way puts on display his/her phenomenal body, which tends to be experienced as a fact of his/her presence and, simultaneously, as a dramatic character" (Fischer-Lichte 2008a: 67).

Who is it that experiences the "specific" presence of the phenomenal body in private performance that is butō training? In training, dancers working with their body-minds are at the same time subjects and objects of the act. They are doers and observers, putting themselves "on display." They are, as Jerzy Grotowski put it: "a pecking bird and a watching bird."

Inebriated with being in time, busy pecking, we forget to let the watching part of ourselves live. [...] Feeling watched by this other part of the self (the one that seems to be beyond time) offers a different perspective [...], it is neither others' gaze in ourselves nor judgment; it is like an impassive gaze: silent presence illumines all things like the sun, that is all. In each of us, the process can be completed only in the context of this impassive presence. (Grotowski 1990: 216).

In Japanese Nō and Kyōgen theatres, actors use a similar technique of looking, referred to as riken-no ken, i.e. sight of detached perception (Żeromska 2010a: 329) or viewing from a distance. To achieve this, the actor must be engaged and detached at the same time. The Kyōgen actor Yoshi Oida recalls that, instructed by his teacher, he tried to develop such a view from the outside, convinced that the observation point should be located somewhere among the audience. It took him several years to realise that the point was situated behind him: "I watch myself acting from somewhere behind my head.' Okura [teacher] smiled and said, 'Yes, that's right. Your true self watches you from behind" (Oida, Marshall 1992: 41).

In butō, this happens not only during a stage performance, for body and mind are also operatively separated in training. The butō dancer's consciousness dwells within the body (for example, exploring his/her body memory or identifying with images - figures, objects, phenomena) and outside it at the same time, from where it watches these processes; "If I am not here, it's all right, but I must always look at myself from above, I watch. In Hijikata's formulations, an eye watching from above, or eyes watching from the side recur time and again. In order to disperse that consciousness somehow. It's not a lack of consciousness, it's an entirely different consciousness" (WTA, Pastuszak). Therefore, it can be concluded that the dancer him/herself experiences the special presence of his/her own phenomenal body. 
As Fischer-Lichte insists, body and mind are functionally inseparable: "The mind can be seen only as it is embodied in a particular body. In performance, it is impossible to think of an individual as a being consisting of body and mind; rather, an individual must be viewed as an embodied consciousness, an embodied mind" (Fischer-Lichte 2008a: 67).

The body vs. mind dichotomy is abolished by presence, and the performer's phenomenal body shows itself to the audience as an embodied mind. The phenomenal body is thus a functional corporal-mental unity. Fischer-Lichte relies on a radical concept of presence proposed by Hans-Thies Lehman, in which presence should be understood as:

A process of consciousness - but one that is articulated through the body and sensed by the spectators through their bodies. In my view, presence represents a phenomenon which cannot be grasped by such a dichotomy as body vs. mind or consciousness. In fact, presence collapses such a dichotomy. When the actor [performer, dancer] brings forth their body as energetic and thus generates presence, they appear as embodied mind. The actor exemplifies that body and mind cannot be separated from each other. Each is always already implied in the other. [...] Through the performer's presence, the spectator experiences the performer and himself as embodied mind. (Fischer-Lichte 2008b: 98-99)

During a performance, a bodily process takes place in which "the phenomenal body can continually create as something specific and, at the same time, generate its specific meanings" (Fischer-Lichte 2008a: 67). The question for us is whether the dancer generates "specific" meanings also in private performance (training), and if so, how this happens.

In training, the butō dancer adopts the "viewer" role. In private performance, s/ he reaches the inputs recorded in the body memory and retrieves them by bodily re-enactment. What is it that this bodily re-enactment comes down to? The artist has no access to the complete "text" that makes up the blueprint of the current stirrings ( $\mathrm{s} /$ he often cannot fathom the complex cortical cognitive memory). For this reason, what happens is certainly not a "staging," in which the body would be a stage; rather what happens is performance, that is, performative generation of meanings. Incited by the retrieval of forgotten and repressed contents, the extraordinary states of body and mind appear to the artist first of all as concrete sensations and, at the same time, accumulate all later contexts (that is later than the "remembered" experience), becoming a source of several "associations, representations, thoughts, memories and feelings" (Fischer-Lichte 2008b: 226). As such, the process should not be classified as simple, linear reproduction.

In embodying mental images an opposite process takes place, as mentally created, presupposed contents (representations, images, omoi) get embedded in the artist's body and are consequently desemanticised. The artist does not 
attempt either to understand or to interpret these images, treating them instead "as something $[\ldots]$ The things signify what they are or as what they appear. To perceive something as something means to perceive it as meaningful. Materiality, signifier, and signified coincide in the case of self-referentiality" (Fischer-Lichte 2008b: 141). The mental image of "an eagle's wing" becomes an eagle's wing, transforming the dancer's arm into a wing, and the dancer him/ herself into an eagle (though a dead bird with a broken wing or, even, Pegasus can also be embodied).

Summing up, the practices of retrieving resources from body memory and of embodying images belong to the order of presence. In the classical order of representation, perception is goal-oriented, while in the order of presence, the oscillating perception turns the viewer's attention alternately to the phenomenal co-presence of performers and to his/her own unpredictable association chains. As "perception turns into an entirely emergent process" (Fischer-Lichte 2008b: 150), meanings arise and fluctuate. Similar things happen in the following and embodiment stages of butō training. In following, various somatic sensations (in the phenomenal body) trigger chains of associations (in the semiotic body), which induce further sensations. In embodiment, images (meanings) breed sensations, which induce further associations.

Oscillating between the phenomenal order and the semiotic order (associations), the audience open up both to neurobiological empathy and to their private reception contexts. As Fischer-Lichte elucidates, such oscillation engenders liminal experiences in the viewer, such as states of in-betweenness, instability and suspension of all frameworks (rules, norms, orders). As a result, the viewer is put into a crisis situation. "Unsettling self-, other- and world-perception, the crisis is often coupled with very strong emotions, feelings and changes in physiological, energy, affective and motor states [...] Liminality is experienced first and foremost as a transformation of the body" (Fischer-Lichte 2008a: 700).

\section{Co-Experiencing}

The transformation experience appears at both stages of creative butō practice, i.e. in training (private performance) and on stage (public performance). In training, transformation is the goal of the performer's inner process. On stage, the goal is defined as a simultaneous experience of transformation in the dancer and in the audience. To activate the transformation process in the audience, performers rely on specific strategies of stage-presence. Through body movements, they reveal to the audience their here-and-now process of inner transformation, in this way triggering the audience's empathy at the biological level. 
The idea is that the butō dancer's movement is not controlled by volitional factors. As Nakajima puts it, the body does not dance but "is danced" (Nakajima 1998: 49). For this reason, choreography in butō cannot be based on preconceived, fixed movement sequences. In directing the performance, the dancer can employ material generated in experiments during training. However, as some butō dancers insist, transformation takes place in each performance; it is not play-acted or faked. Although butō dance is sometimes classified as dance theatre, strategies used in butō are more akin to performance art and body art than to mimetic stagings of another reality. In butō, the presence of the phenomenal body is in the foreground, while the semiotic layer is created by the audience on the basis of their own associations. Admittedly, the butōka functions in two worlds simultaneously, but these worlds are not the phenomenal body (actor) space and the semiotic body (character) space. The dancer is a performer undergoing constant de-identification and, at the same time, is an observer of him/herself.

The audience must also abandon their everyday cognitive habits and let go of the idea of an unambiguous interpretation of stage events. Because the brain does its best to prevent perceptual chaos, it makes every effort to recognise familiar shapes and patterns. Most associations are, consequently, habitual and acquired. The mind clings to a particular representation, and to use it to construct one interpretation of on-stage events is misleading in butō because the artist weaves a butō show out of the texture of his/her own experiences, subjective representations of reality and non-reflective body actions. Consequently, the audience build their own subjective narratives of the artist's experiences. For this reason, interpretation and critique of a butō performance can only refer to the audience's (rather than the dancer's, director's or choreographer's) construct of it.

The desired reception model involves non-evaluative, non-intellectualising taking-in. In buto dance, like in performance art, there is also a characteristic relationship with the audience, underpinned by bodily co-participation, in which reception mutates into co-experiencing (cf. Bester 2009: 83). Similarly to body art, buto entices the audience to experience the dancer's bodiliness. Direct confrontation with the performer's body takes place at the pre-reflective, neurophysiological level. The dancer and the audience affect each other and share in the transformation process, but the states and contents involved can vary widely because, like the dancer, every viewer bears his/her own unique "record in the body." Experiences of different spectators can be entirely incompatible, resulting from the unconscious activation of completely different resources. 


\section{Neurobiological Empathy}

The starting point and foundation of performer-audience interaction is the body with all its biological and physiological processes and the mirror neuron system, which makes bodily empathy possible. Changes that take place in our bodies (also while experiencing a performance) are registered by proprioceptors and interoceptors. They inform us about alterations in the state of our body-minds, both physical (muscle tension, body posture, etc.) and physiological ones (changes in heartbeat, sweating, salivating, etc.).

The somaesthetics senses are often divided into exteroceptive (relating to stimuli outside the body and felt on the skin), proprioceptive (initiated within the body and concerned with the orientation of the body parts relative to one another and the orientation of the body in space), and visceral or interoceptive (deriving from internal organs and usually associated with pain). (Shusterman 2008: 2)

They provide stimuli which, in turn, stir emotional reactions and further somatic changes (e.g. temperature changes, excessive salivation, etc.). As a result, reception turns, as mentioned, into co-experiencing, pre-reflective bodily being here-andnow with the performer, based on neurobiological empathy.

How does such empathy come about? When we do things, neurons are activated in certain areas of the brain. The same neurons are activated when we watch somebody do the same thing or even imagine doing it (in both cases a similar electro-physiological response takes place in the body; Przybysz 2008: 68). This process is explained by the activity of the mirror neuron system, as "proposed in a theory developed in the 1990s by a Parma-based team of Italian neurobiologists (Giacomo Rizzolatti, Vittorio Gallese, Luciano Fadiga and Leonardo Fogassi)" (Przybysz 2008: 68). The mirror neurons are "cells of double - motor and perceptual - activity" (Przybysz 2008: 68). Since the 1990s, several studies on mirror neurons using electro-physiological (EEG, magnetoencephalography (MEG), transcranial magnetic stimulation (TMS) and neuroimaging (PET and fMRI) methods have been carried out internationally (cf. Rizzolatti, Fabbri 2008). They have found that mirror neurons enable us not only to imitate other people's actions, but also to understand people's intentions and to empathise with others.

"Tania Singer of University College London has shown that some areas in the brain are aroused both when experiencing pain and when watching pain being inflicted on others" (Przybysz 2008: 69). This happens because when we watch a person who is intensely experiencing a sensation (here: pain), "we unconsciously simulate the activity of this person’s organism” (Przybysz 2008: 70).

The simulation theory explains why the audience feel (rather than only understand) the butō performer's psychophysical state. Moreover, the arousal 
of particular brain areas and concomitant biochemical changes in the body can trigger an analogous somatic response, e.g. increased body temperature and/or secretion of fluids. ${ }^{1}$ Vilayanur S. Ramachandran believes that, in this way, the mirror neurons "dissolve the barrier between self and others." For this reason, he refers to them as "empathy neurons" or "Dalai Lama neurons" (cf. Ramachandran 2006). As argued by Ramachandran and William Hirstein, "an artist is an 'unconscious neuroscientist' while a work of art is a 'super stimulus" which excites functional modules in the viewer's brain" (Markiewicz, Przybysz 2007: 114).

Apparently, neurobiological empathy is the most important process which the butō dancer seeks to "graft" in the spectator's body-mind. As such, neurobiological empathy can be a key to understanding the on-stage butō process.

1 In in the context of my argument on ideokinetics above, I described this phenomenon as an ideodynamic response. 


\section{Conclusion}

Butō dance was founded in Japan in the second half of the 20th century. Although its originator Tatsumi Hijikata envisaged the typically "Japanese" body of the dancer as central to butō, ever since the 1980s the dance genre has spread triumphantly across theatre stages worldwide, enacted also in and by non-Japanese bodies. "Though Butoh was born in Japan [in 1959], its impulse is international, with the potential to eradicate barriers and discriminations" (Akira Kasai Five-Day Butoh Workshop... 2005), insists Akira Kasai, a world-reputed Japanese butō dancer and choreographer. Butō's transcultural potential shows both in the universality of its psychosomatic training and in the ease with which the genre lends itself to hybridisations.

Throughout this book, I have described the phenomenon of butō in Poland, outlining a model of training used by Polish dancers. Thereby, I have attended both to the universalisation and globalisation of the originally Japanese dance style as well as to the Polish cultural context of the 1990s, a decade of radical changes in art and culture, preceding the rise of butō in Poland. The vigorous development of buto art in Poland at the threshold of the 21st century was fostered by several factors. Firstly, in the 1990s, critical art appeared, which - drawing on body art familiarised the audience with radical actions in which the performer's living (and naked!) body is both a subject and an object. Secondly, artists gained access to international contemporary dance laboratories, which triggered the development of experimental dance styles. And, thirdly, Eastern body-mind disciplines became very popular in Poland.

In my research, I focused on (1) body-mind disciplines used by the Polish butō-ka and integrated in training with (2) techniques characteristic of butō. The Polish buto dancers' training practices include a varied array of methods and techniques derived from different sources. Some of them are methods and techniques explored mainly for their application in stage performances and developed within such performing arts as classical dance, contemporary dance, dance theatre, physical dance, ritual dance, non-European dance, ethnic dance, dance improvisation, contact improvisation, rhythmic gymnastics, corporeal mime and vocal techniques. Another very important source of techniques and methods is to be found in what are referred to as mind-body or body-mind disciplines, including Hatha Yoga, Kundalini Yoga, Ashtanga Yoga, Eastern martial arts (aikido, aikishintaiso, Chinese styles of Lang and Vietnam Dao), tai chi and capoeira combined with methods developed in the 20th century in the 
West (e.g. Body Mind Centering, ideokinesis, relaxation techniques, etc.) and in Japan (Noguchi Taiso). The Polish artists working with butō also explore bodybased and movement-focused therapeutic methods, such as dance therapy, dance movement therapy (DMT), socio- and somato-analytical psychotherapy as well as skills and experiences gained from their art degree courses and individual collaboration with visual artists.

The Polish buto dancers creatively employ practices which they find particularly relevant to their development as artists. They integrate these practices with buto techniques they have learned both practically in workshops with several Japanese artists and theoretically from the literature, including writings by Hijikata, the founder of Ankoku butō, and his followers. The group of Japanese dancers whose workshops have shaped the Polish artists' idea of body-mind practices used in butō notably includes Atsushi Takenouchi, Daisuke Yoshimoto, Morita Itto, Mika Takeushi, Denise Fujiwara, Yumiko Yoshioka, Ko Murobushi, Min Tanaka, Kan Katsura, Minako Seki, Seisaku Kachi, Yuri Nagaoka, Yoshito Ōno, Yoko Muronoi, Carlotta Ikeda, Tadashi Endo and Yuko Kawamoto. The Polish dancers have also studied butō in workshops taught by Western butō dancers, such as Joan Laage (US), Susana Akerlund (Sweden), Marie-Gabrielle Rotie (UK) and Imre Thormann (Germany). ${ }^{1}$

The inventive synthesis effected by the artists produces what can be labelled integrated butō training: elements of various body disciplines and practices are embedded into a framework provided by butō training. The basic aim of training is to undergo a mental and bodily transformation which is triggered by modifying the body's physiological, affective, motor and energy states. This multi-layered transformation is "grafted" onto the audience through intense, immediate copresence of bodies. Techniques used in integrated butō training are instruments and catalysts of the transformation.

At the beginning, I identified and produced an account of the latent (hidden in action) ways of defining the body, the body self and, finally, the body-mind, because understanding the body and mind as a unified whole is a key to exploring the processes and procedures involved in butō training. Subsequently, I re-traced the stages that make up the processual structure of private butō performance. I distinguished three major training phases: intro, following and embodiment. The intro phase includes endurance training (which causes changes in body chemistry, inducing the so-called runner's high) and mindfulness training (promoting contemplativeness and receptivity through butō's signature exercise,

1 For more information, see "Biographical Notes" in this volume. 
i.e. the zero walk). Both types of training are supposed to produce the butō body (buto-tai), i.e. the state of total presence. To show the wide range of altered states of consciousness which the artists associate with butō-tai, I drew on Roland Fisher's "cartography of the ecstatic and meditative states" (1971). In the second phase (following), the dancer explores stimuli from within and without the body, e.g. his/her own sensory arousals and the inputs stored in body memory, which I explained building on neurophysiological frameworks. The dancer follows his/ her own sensations, and movement can appear spontaneously. At the core of the third phase (embodiment) lie ideokinetic and ideodynamic responses. Working with the body responding to images has been part not only of Japanese theory and practice (omoi in the Nō theatre and koan practice in Zen Buddhism) but also of 20th-century European ideokinesiology. As such, the employment of images mediated by Hijikata's butō-fu (butō notation) seems to be universal.

Thus-constructed training helps the dancers perform a comprehensive physical, biological and mental - act of self-transformation. The butō-ka modify the functioning of their own (apparently also autonomic) nervous system and impact their bodies' affects, representations and motorics. Importantly, the transformation also extends onto relations and communication. The major goal to be achieved in stage practice is a simultaneous transformative experience for all the participants in the events, as the performer's transformation is supposed to trigger a transformation process in the viewer. To this end, the dancers employ various strategies and through bodily acts reveal their here-and-now inner transformation to the audience, which arouses the audience's neurobiological empathy. I explained this phenomenon within the paradigm of social cognitive studies and the mirror neuron theory. The transformation process is "grafted" into the viewer's body through exciting empathy, which is fostered by the intense co-presence of performers and viewers.

Such training has a crucial function in devising performances and affects the aesthetics of stage productions. The art of butō calls for further aesthetic and critical studies which can build on the findings and insights outlined in this book.

Today, it is very challenging, if not entirely impossible, to demarcate a boundary between theatre (which is largely post-dramatic and uses performance arts abundantly), artistic dance (which is both dramatised dance theatre and minimalist experimentation, more resembling performance and happening than dance theatre) and varied, heterogeneous performance art. For this reason, I chose the universal category of bodily presence as the axis of my research and argument. In 21 st-century art, bodily presence is central to theatre, dance and performance practices. 



\section{Appendix 1: Terms}

African dance. Based on the triad of rhythm, music and dance, it has first of all practical relevance. Afro-Caribbean and Afro-Brazilian possession cults derive from Africa. An important element of the philosophy underlying African dance is that it refers to foetal experiences of living in the environment of continual syncopal sounds provided by the foetus's and the mother's heartbeat rhythms. The body finds itself in sustained interaction with the environment, which is explored through inner bodily states as the body and the world form a system of communicating vessels (cf. "somatic modes of attention" - Csórdas 1993).

Aikido. $A i$ is harmony and balance; $k i$ is spirit and energy; $d \bar{o}$ is a path, a method, a way and teaching. Aikido is a Japanese martial art codified by sensei Morihei Ueshiba at the turn of the 19th century. The founder of aikido based his system on a combination of traditional Japanese martial arts. Aikido emphasises the moral and psychological aspect of practitioners' actions and their responsibility for another person's health and life throughout training and combat. The actual term aikido was first used in 1944. In Poland, the first aikido group was founded in 1976. Using one's $k i$ is central to mastering aikido techniques. $K i$ is often translated as "power of breath," "life force," "energy" and sometimes even "soul." Timing, distance and focus (calmness) of mind and body are particularly important. Most teachers locate $k i$ at the hara point (cf. Centre). Because $k i$ is increasingly frequently associated with the spiritual sphere, aikido tends to be referred to as "Zen in movement."

Aikishintaiso. As ai is harmony, $k i$ is energy, shin is the mind, tai is the body and so is practice, the term could be translated as "body gymnastics for improving its functioning." It is an integral part of aikido. The practice was founded by the already legendary teacher Koichi Tohei, who emphasised its relevance and used a basic set of exercises in training. Although aikishintaiso is just a starting point for martial arts practice, it can also be approached as an independent health discipline and practice. Regularly applied, it re-invigorates the body, removing physical blocks and opening up new possibilities.

Archetype. In his works on the collective unconscious, Carl Gustav Jung defines archetypes - vehicles of representations shared by the entire humanity - as its major components. The pre-images appear in culture as symbols. Through symbols, abundant in art, dreams and fantasies, people access knowledge inscribed 
in archetypes. Key to complete development, the individuation process involves confronting archetypes.

Authentic movement. A method initiated and developed by Mary Whitehouse, a dancer and pioneer of dance and movement therapy. Authentic movement originates in inner feelings and does not depend on any specific dance technique. Movements are supposed to be free, that is, unfettered by intellectual speculation, rational decisions and volition. Authentic movement is a type of dance improvisation also used in therapeutic settings.

Auto-balance, zero position, neutral position. In butō, it is the starting point for body motions, for example in zero walk practice. The body is naturally relaxed and, at the same time, fully grounded.

Body Mind Centering (BMC). A somatic education method developed by Bonnie Bainbridge Cohen. BMC helps understand how the mind is expressed through the body in movement. The aim of the practice lies in "discovering the relationship between the smallest level of activity within the body and the largest movement of the body, aligning the inner cellular movement with the external expression of movement through space. This involves identifying, articulating, differentiating, and integrating the various tissues within the body, discovering the qualities they contribute to one's movement, how they have evolved in one's developmental process, and the role they play in the expression of the mind" (Cohen 2012: 1). One of the basic BMC techniques is developmental movement, in which primary movement patterns are used. One of the fundamental aspects of $\mathrm{BMC}$ is developing an awareness of body layers, starting from cells, skeleton, ligaments and muscles, to organs, glands, the nervous system, fascia and body liquids, ending with the interactions among all these systems. The method improves mindfulness and helps consciously draw movement from various body levels.

$B \boldsymbol{u} \boldsymbol{t} \bar{o}-f u$. In Japanese, $f u$ means a chronicle or a history. Butō-fu is a notation put together by a choreographer or a butō dancer and used to build movement in a butō performance. Tatsumi Hijikata's classic butō-fu is still used by some continuators of his style.

Butoh Kaden. A book accompanied by audio-visual resources (DVD-ROM) published in 1988 by Yukio Waguri, a dancer from a group founded and led by Tatsumi Hijikata. It presents Hijikata's method developed for Ankoku butō: sequences of imaginary wordings included in the classic buto-fu.

Centre. It corresponds to the body's gravity centre located in the lower part of the torso, approximately five centimetres below the navel. "Grounding in the 
centre" and "drawing movement from the centre" are emphasised by the founders and students of several methods and disciplines. It is important, for example, in African dance, in various Japanese disciplines (where it is referred to as the hara point) and in most body-mind disciplines.

Contact improvisation (CI). A special technique for improving skills in group improvisation, developed by the American dancer and choreographer Steve Paxton (1972). Contact improvisation focuses both on the physical components of movement, mind states and absolute presence which foster creative responses to whatever is happening at the moment. $\mathrm{CI}$ is a symbiosis of Western experiences in dance and movement (modern dance, gymnastics, etc.) and Eastern approaches to the living system of body-mind (e.g. Eastern martial arts). Including lifts, falls and acrobatic movements, CI requires the mastery of basic techniques and skills, contact with (one's own and the partner's) body, cooperation with the partner, strength, suppleness and sustained alertness. Part of CI is so-called small dance, i.e. apparent motionlessness in which the body actually performs miniscule movements. In small dance, like in butō, dancers tend to use images (ideokinesis), which are typically related to the body's anatomy, biology and physiology (skeleton, expanding lungs, energy flow).

Contemplative experience. An experience produced in mediation-like practice. Toshihiko Izutsu in "The Metaphysical Background of the Theory of Noh: An Analysis of Zeami's 'Nine Stages"' - a chapter in his 1981 book The Theory of Beauty in the Classical Aesthetics of Japan - distinguishes consecutive stages, or levels, along which the contemplative field evolves. In the first stage, the observing subject relinquishes regular perception, which involves cognitive focus on a selected object, and expands the observation field to perceive a boundless multitude of objects with their mutual interconnections and associations (dispersion of attention). The cognitive act transforms into an awareness of presence. In the second stage, the two components - i.e. the field and the awareness of the field become indistinguishable and are mutually harmonised. In the third stage, awareness of contemplation disappears, entirely absorbed by the field. The field is luminous and non-existent awareness manifests itself in a negative fashion as a black point in the middle of the field. In the fourth and final stage, even the field vanishes as all forms are engulfed in total darkness, which paradoxically morphs into limitless, dazzling light. The nothingness experienced at this moment is regarded by Izutsu as true reality.

Contemporary dance. A dance style that emerged at the beginning of the 20th century, based on classical dance (ballet) ideas, yet without its rigid principles. 
It includes all forms of non-classical Western artistic dance (e.g. modern dance, dance theatre, etc.). Even though in contemporary dance a broad array of techniques can be used to create movement, most contemporary dancers have a background in ballet. Contemporary dance uses body weight, breath, swings, etc. The first technique of modern dance was developed by Martha Graham, who studied movement by drawing on her knowledge of body physiology gleaned from the literature collected by her father, who was a neurologist. Her dance technique system came into being in 1928-1938. In the Graham technique, dancers come to understand the motor capacities of their bodies and, consequently, acquire complete awareness and control of muscles and joints in movement, whereby they are not supposed to exceed the natural limits of their bodies. According to Graham, dance is based on effort and the constant interaction of two opposing factors: contraction and release. The important principles are continuity of movement, fall, recovery, and increasing and diminishing dynamics. In modern dance, movement is based on the natural dynamics of the body. Modern dancers move while lying, kneeling, sitting and standing.

Corporeal mime. Dramatic corporeal mime is a kind of physical theatre. Etienne Decroux, the art's pioneer and reformer, spent decades (1930-1991) developing a new technique based on the absolute coordination of breathing, energy and movement rather than on external mirroring.

Dance improvisation. Dance performance with an open-ended structure created in real time without any prior choreography. Among many various improvisation methods are, for example, Gaga, contact improvisation and authentic movement.

Dodecaphony. Greek: dōdeka - twelve, phōne - sound; a twelve-tone, atonal technique of composing music in which there is no tonal centre as all twelve sounds of the octave arranged in a tone row are given approximately the same importance.

Expressionist dance (Ausdrücktanz). A dance style inspired by the ideas of Expressionism and developing mainly in 1910-1930 which rejected ballet aesthetics and technique for the sake of emotional expression. As its founders did not devise one codified movement language, most artists developed their own styles and methods. Its chief representatives were Mary Wigman (the founder of expressionist dance), Kurt Joss and Harald Kreutzberg.

Flow. Explored by Mihaly Csikszentmihalyi, an American scholar of Hungarian descent, in his Flow: The Psychology of Optimal Experience (1990). Csikszentmihalyi defines flow as a focused state of complete absorption in the activity/situation at 
hand, precluding boredom or unease. Flow resembles peak experience to a degree because it involves being entirely immersed in what one is doing and unaware of anything other than the action itself. In the flow state, a person can be conscious of his/her actions but not of this consciousness itself. At the core of the experience is the blurring of the boundary between the self and the activity.

Gaga. A movement language developed by Ohad Naharin, the founder and choreographer of Israel's Batsheva Dance Company. Gaga originated over twenty years ago, when after a serious back injury Naharin resolved to use selfobservation to enhance his awareness of the body in motion. He compiled his findings into a movement language and pedagogy. Today, Gaga is one of the most popular methods for dance improvisation.

Harmolodics. Developed by the jazz musician Ornette Coleman, harmolodics is a musical philosophy and method which claims that (1) every instrument has its own "voice" and, as such, should use its most natural sound scale, irrespective of conventional tonalities; (2) instruments find themselves in a democratic relationship that overcomes patterns and divisions.

Hokōtai, see Zero walk.

Individuation, see Archetype.

Intuitiveness. Non-reflective activity in conformity with intuition. Intuitiveness helps reach resources inaccessible to consciousness.

Koan. A problem or a question based on a paradox, used in Zen Buddhism. Looking for and finding an answer to the question is supposed to help the meditating person achieve enlightenment. The Japanese word koan means literally a "public record" and is derived from the Chinese gongan, denoting a "legal precedence." Koans consist of fragments of sutras, homilies, students' questions and their masters' answers or have the form of a single paradoxical question. Koans point to ultimate truth but defy logical thinking and can be solved only by achieving deeper insight and uniting with "their spirit." Koan practice is one of the basic techniques used in the Rinzai Zen School.

Martial arts. Modes of bare-handed combat, sometimes using melee weapons. All martial arts are learned by training which usually includes self-control and selfdefence exercises, improves the condition and capacity of the body and reduces fear. The guiding idea of martial arts is personal and spiritual development. The term "martial arts" was first translated into a Western language in 1920, in a Japanese-English dictionary, Takenobu, based on the Japanese word bu gei or 
bu jutsu. The definition was taken directly from the Chinese notion of $w u s h u$, meaning literally a martial/military art/discipline and collectively denoting all Chinese fighting methods.

Method. A codified set of techniques serving a defined aim. While there is no universal method in butō, certain specific techniques recur commonly in butō practice.

Mind-Body Disciplines. Psychophysical practices engaging body and mind. As responses to stimuli are at the same time bodily and mental, every action is a psychosomatic act. All practices involve a patent or latent inner process (cf. Somatic education).

Mover. Designating a person who moves on stage, the term covers a broad range of artistic stage movement.

Mugennō. Dream Nō or fantastic Nō; a drama which features an apparition, a spirit, a ghost or a deity as the protagonist. The category was coined by theoretician Sanari Kentarō in the 20th century.

Neuroaesthetics. A cognitive discipline that scientifically studies phenomena of perception and knowledge of artworks. An interdisciplinary field, neuroaesthetics draws on traditional sciences, such as psychology, physiology and neuroscience, to identify the neurobiological sources of aesthetic experiences, as neuroaesthetics scholars insist that art-making and art appreciation depend on the activity of the areas of the brain involved in perception. The field was pioneered by Semir Zeki and Vilayanur S. Ramachandran, who claim that artists have a tacit knowledge of the neurophysiology of perception and emotion, on which they usually unconsciously rely in creating artworks.

Neurophenomenology. A scientific research programme aimed at explaining issues of consciousness, mind and experience in a pragmatic way. It combines neurosciences (a third-person perspective) with phenomenology (a first-person perspective) and emphasises the embodied condition of the human mind. Neurophenomenological studies overlap partly with research of such disciplines as neuropsychology, biopsychology and psychological phenomenological studies. The term was coined by Charles D. Laughlin, John McManus and Eugene G. D'Aquili in 1992 and was specified by the neuroscientist Francis Varela in the second half of the 1990s.

Noguchi Taiso. A system of body workout developed in Japan by Mihizo Noguchi in the second half of the 20th century. It draws heavily, for example, on the Chinese 
method of meridian practice and is underpinned by the idea of an "unconscious subject." In Noguchi Taiso movements are fluid, musculoskeletal comfort is emphasised, and the body is experienced as a lump smoothly surrendering to the force of gravity. The body is supposed to transform into, metaphorically speaking, a water bag with freely floating bones, muscles and tissues. Overall relaxation is combined with tiny tensions in some body parts, and energy flows induced in this way make the body optimally flexible. Noguchi taught his classes at the same time that Tatsumi Hijikata was working at Tokyo's Asbestos Studio. Currently, Noguchi Taiso is used by many butō dancers in order to learn how to move with maximum economy and use the force of gravity. Basic exercises improve bodily receptiveness and perfect the skill of self-perception of body-mind, which helps grasp what is actually going on with other body-minds.

Peak experience. A unique experience type described by the American humanist psychologist Abraham Maslow in Toward a Psychology of Being (1962). Peak experiences are states of exceptional clarity and fulness, which often change the person's further functioning. Among the most important features of peak experience are a sense of being in an exceptional and complete situation dissociated from human motivations, as well as experiencing non-evaluative perception, opulent sensations, disinterestedness, transcendence of ego, disentanglement from time and space, the idea the everything is perfect, receptivity, a mixture of astonishment, terror, humility and dazzlement, the perception of all aspects of an object simultaneously, functioning beyond language, non-classifying perception and unity of things polarised in regular states of consciousness. Such perception of the world also entails altered self-perception: in peak experiences, the person feels more integrated, merges with the world, goes beyond him/herself, crosses his/her personality, becomes "a river without a dam," feels graceful, at ease, happy and elated, shakes off control, inhibitions and fears, is unreserved, effusive, spontaneous, impulsive, creative and present here-and-now, neither desires nor strives for anything, has pure intentions and his/her expression becomes poetic.

Performance. In its two basic senses, it can designate two things. First, it is any performative form of a closed, repeatable and reproducible structure (as opposed to open-ended improvisation), synonymous with a staging, a stage production and a show. In dance, a performance can be both directed (given a pre-determined general structure and course) and choreographed (given pre-composed forms of on-stage actions). Second, as Richard Schechner defines it, performance is every instance of "showing doing," that is, "doing" which is underlined, pointed to and displayed. The essence of stage performance lies in action and interaction with the audience, which produces an autopoietic feedback loop (as Erika Fischer- 
Lichte insists). The term is popularly used to refer to a special kind of artistic event which should correctly be called performance art. Performance art is a distinctive kind of art practice which became popular in the 1960s and includes artistic manifestations that originate in experimentation within both performing and visual arts.

Performer. A person that participates in a performance. Dancers and artists as well as viewers and "random passers-by" can be performers.

Phowa. A Tibetan Vajrayāna practice of transference of consciousness associated with the death bardo (a posthumous state of consciousness, a realm where our consciousness goes after death).

Physical theatre. Questioning the utility of conventional theatrical and dance figures and movement codes, physical theatre is based on natural human movements and founds its techniques on bodily conditions. In this way, it constantly creates a new physical idiom. Informed by the idea of the organic, psychosomatic unity of the human being, it is based on improvisation and an exploration of the possibilities afforded by the body.

Postmodern dance. Developed vigorously in the 1960s and 70s, mainly in the US. It arose in response to compositional and aesthetic constraints of modern dance. Its most important, indeed distinctive, feature is discarding dancing technique for the sake of everyday modes of movement. Postmodern dance proponents have insisted that all movement is dance and all people are dancers. Eminent postmodern dance artists include Merce Cunningham, Robert Ellis Dunn, Simone Forti, Anna Halprin and the Judson Dance Theater.

Practitioner. A person who practices something, an expert or a student using an set of techniques or a defined method

Pre-expressivity. The pre-expressive state refers not only to phenomena that chronologically precede expression, but also to those that are ontologically and temporally simultaneous with performing (expression). The concept was developed within the anthropology of theatre founded by Eugenio Barba, an intercultural research project focused on performative traditions. The practical study of techniques used by performers (conducted within the International School of Theatre Anthropology - ISTA) helps identify their universal underlying principles. On this model, the pre-expressive manifestations are a relevant, though frequently neglected, aspect of the performer's art. The appreciation of the performer's presence at the pre-expressive level is referred to as pre-interpretation. 
Qualia (singular quale). Subjectively perceived or phenomenal qualities of sense experiences, such as hearing sounds, feeling pain and seeing colours. Qualia are properties of sensory experiences. As knowable, qualitative traits of that which is given, they can recur in various experiences and, as such, are a kind of universals. "The quale is directly intuited, given, and is not the subject of any possible error because it is purely subjective" (Lewis 1956: 121).

Resonance. A term often used by butō dancers and theoreticians (e.g. Rhizome Lee, Yumiko Yoshioka, Toshiharu Kasai, etc.) to capture how relationships among objects evolve. The dancer resonates with his/her inner stirrings and, further in practice, with other objects (body parts as relative to one another, things, animals, etc.). Through movement and mutual resonance, the body flexibly adjusts to the changing environment. Butō practice is quintessentially about sustained resonance (a reciprocal interaction loop) between bodies and objects. In the study of techniques used in Ankoku butō, Kayo Mikami defines the analogous process as a "relationship."

Somatic education. A mode of working with the body-mind underpinned by the idea that body and mind - or body and psyche - are an inseparable whole (psychosomatics); represented, for example, by Wilhelm Reich (character armouring theory) and his heirs: Alexander Lowen and John Pierrakos (bioenergetics, body therapy, somatotherapy). Currently, the most popular methods classifiable as (psycho)somatic education include: the Alexander Technique, Bartenieff Fundamentals, Body Mind Centering, the Feldenkrais Method, Hanna somatic education, ideokinesis, sensory awareness, Trager psychophysical integration, eurythmics and Skinnerac releasing.

Somatotherapy. A psychotherapy school introduced and developed by R. Meyer. Also referred to as body psychotherapy and body psychoanalysis (mainly in France). It integrates several approaches and techniques, such as rebirthing, Gestalt, vegetotherapy, Ericksonian hypnosis and others. Somatotherapeutic interventions use touch, scream, all bodily expressions and their analysis. Somatotherapy is based on physiological principles endorsed by contemporary medicine and psychology. However, it goes beyond the psychosomatic approaches to disease which are focused chiefly on symptoms to be removed. Rather, it studies the connections between spirit and body and represents an integrated take on the body, in which the totality of the human organism and all its aspects are attended to. Admittedly, somatotherapy uses symptom-oriented techniques (massage, relaxation, etc.), but it treats contact with and through the body first of all as a way to explore and solve conflicts. As such, it does not eliminate emotions 
and symptoms that disturb contact, but rather intensifies them to provoke their exposure and unblocking as well as a realisation of their causes. (https://www. eneteia.pl/o-nas/czytelnia/slowniki-encyklopedie/cz_slownik_somatoterapii/ Accessed 17 March 2018)

\section{Suriashi, see Zero walk.}

Technique. A procedure for action that serves to achieve a pre-defined aim. The same techniques can be used in various methods and, at the same time, different techniques can help achieve the same aim.

Trance. Richard Schechner in his Performance Studies: An Introduction (2002) lists hypnotic, psychotic, hallucinatory, possession, ecstatic and shamanistic trances. Trance possession occurs worldwide in ritual performances across cultural traditions. Ritual trance in Japan is discussed by Estera Żeromska in Japoński teatr klasyczny. Korzenie i metamorfozy [Classical Japanese Theatre: Roots and Metamorphoses] (2010), focusing on kamigakari (dance of divine possession) performed by the miko-mai; collective ecstasy during the onbashira-matsuri, the tree trunk festival; and odori-nembutsu, a dancing prayer in which fixed movement sequences, recitations and sounds are repeated until ecstasy is achieved.

Transformance, performance of transformation. A performance type whose aim is the inner transformation of the performer. The role of the audience can be adopted by the performer him/herself. Transformance is the core of butō training.

Yoga. One of the six orthodox (Vedic) systems of Indian philosophy and a collection of spiritual disciplines. It goal is liberation by means of proper practices (body training, observance of an ethical code, focus, meditation and asceticism). Yoga is preoccupied with relationships between body and mind. In the West, yoga is popularly understood as a group of physical and mental exercises practised chiefly for health-related purposes (especially Hatha Yoga). The most disseminated type of yoga in the West is Hatha Yoga, developed by Bellur Krishnamachar Sundararaja Iyengar. Hatha means "force." Hatha Yoga is based on body postures called asanas, six cleansing processes ( $k r i j a)$ and breath control (pranajama). Also considerably widespread is Ashtanga Yoga, a traditional form of Hatha Yoga, including a system of exercises based on vinyasa, i.e. movement sequences synchronised with breathing. Ashtanga means "eight," which alludes to the eight components of yoga (jama, njama, pranajama, asana, pratjahara, dharana, dhjana, samadhi). In turn, Kundalini Yoga is an intensive practice that aims to awaken inner energy and experience the body as an energetic whole. It is a method of tantric yoga in which the fiery life force located at the base of the 
spine (Kundalini) is to be skilfully aroused. When Kundalini power is awakened from its dormant state, it spirals up through chakras along the body's vertical axis at the spine until it settles at the "thousand-petaled chakra" above the head. The goal of the practice is ultimate liberation.

\section{Zero position, see Auto-balance.}

Zero walk. The basic technique in butō, which consists in moving with one's knees slightly bent and centre lowered, associated with very slow motion, diffused vision and meditative calmness of mind. It derives from the Japanese Nō theatre, where the actors used suriashi, a gliding movement in which the feet were not lifted off the ground (suriashi was an element of mai dance included in the ritual tradition of kagura). A somewhat similar Zen practice, i.e. walking meditation, is called kinhin. 



\section{Appendix 2: Biographical Notes}

Akerlund Susana/SU-EN (born in 1966 in Sweden). She lived in Japan from 1986 to 1994 and studied butō dance for five years under Tomoe Shizune, the artistic director of Hakutobo butoh-ha, founded by Tatsumi Hijikata. She also danced with the affiliated group Gnome, with Yōko Ashikawa, Hijikata's student, as a teacher and a choreographer. She also studied various Japanese body disciplines and martial arts (she is a certified Jiuta-mai dancer). In her work as an artist, she focuses on the dehumanising human body that takes in forms and qualities of matter. Drawing inspiration from conceptual and performance art, she investigates the modern human body's relationship to nature and explores the "Nordic body" as analogous to Hijikata's "Japanese body." In 1997, she founded a butō school in Haglund (north of Uppsala), a site for workshops, explorations and artistic projects. (www.suenbutohcompany.net)

Amagatsu Ushio (born in 1949 in Yokosuka, Kanagawa Prefecture, Japan). Choreographer and dancer, artistic director of Sankai Juku (set up in 1975). Based in Paris since 1982, Sankai Juku are famous for their signature upside-down hangings. Amagatsu co-founded Dairakudakan (1972). Since 1997, he has also worked as an opera director. (Sankai Juku: www.sankaijuku.com, Dairakudakan: www.dairakudakan.com)

Artaud Antonin (1896-1948). Theatre theoretician and practitioner. In the 1920s, he was associated with French Surrealists, yet he parted company with them in the belief that Surrealist ideas should be practised rather than just proclaimed. His vision of theatre was directly inspired by a Balinese theatre's performances (1931) and the time he spent with the Tarahumara people in Mexico (1936). He described his ideas in a series of poetic essays, manifestoes and letters published in France in the volume entitled Le Théâtre en son Double (The Theatre and Its Double) in 1938. He called for reclaiming the original transformative power of performative arts. The book was published in Japan in 1965. Artaud was an unfulfilled practitioner as schizophrenia robbed him of his powers, thwarted the pursuits to have his vision enacted on stage and caused his psychophysical decline, ending in his premature death in a mental institution. Artaud's ideas of theatre were formative both for performance arts and for physical theatre.

Ashikawa Yōko. Tatsumi Hijikata's favourite student and chief dancer for twenty years (from the mid-1960s). An heir to his Ankoku butō method, she handed down 
Hijikata's buto-fu technique to new generations of dancers. In the 1980s, she was artistic director of the Gnome company.

Bartenieff Irmgard (1900-1981). German dancer, choreographer and therapist; student of Rudolf von Laban. The so-called Bartenieff Fundamentals are a set of simple exercises aimed at developing awareness and connectivity through improving coordination and fitness.

Endo Tadashi (born in 1947). Dancer, choreographer and director of the ButohCenter MAMU and the Butoh-Festivals MAMU in Göttingen, Germany. In 1989, he met Kazuo Ōno, whose art deeply affected his artistic explorations. Endo works with Nō, Kabuki and butō as well as various Western theatre forms. $\mathrm{He}$ is interested in how tensions between oppositions can be expressed through the body. He traces the body's transformations along life cycles and seeks to embody the Japanese concept of $m a$ (emptiness, in-between space). (www.butoh-ma.de)

Fujiwara Denise (born in 1954 in Toronto). Choreographer, dancer, actress and educator. As a child, she practiced modern rhythmic gymnastics. She studied dance at York University and co-founded the T.I.D.E. (Toronto Independent Dance Enterprise). She started her career as an artist in the late 1970s, developing individual projects. In 1994, Natsu Nakajima choreographed her solo show Sumida River. In her art, Fujiwara focuses on human nature and pre-verbal body functioning. Currently, she runs the Fujiwara Dance Inventions. Since 1997, she has served as artistic director of the CanAsian Dance Festival. She works also for theatre, television and film. (www.fujiwaradance.com)

Ikeda Carlotta (born Sanaé Ikeda in Fukua, Japan). Involved in dancing ever since childhood, she began to study formally classical dance techniques only at nineteen years of age (in Tokyo). Later, she adopted the pseudonym Carlotta Ikeda as a tribute to Carlotta Griss, a 19th-century Romantic dancer. She developed a fascination with butō dance when watching Tatsumi Hijikata's subversive, violent and "bizarre" performances. With Ko Murobushi, she co-founded Ariadone, whose 1987 performance was the first butō production to be shown in Europe. In her dance shows, she combines radical aesthetics redolent of sadomasochistic practices with subtle, fleeting images. Her key concern is the body's capacity for continual and immediate metamorphosis. (www.ariadone.fr)

Ishihara Rui Takayuki (born in 1976 in Kyoto). Currently based in Warsaw. He worked as an actor and visual artist. He was inspired to take up dance by Min Tanaka and Kazuo Ōno (butō), Megumi Nakamura (classical and modern ballet), 
Simone Forti (postmodernism) and many other artists devoted to exploring the movement-body connections within various arts disciplines.

Iwata Miho (born in 1962 in Ichinomiya-shi, Japan). She studied architecture at the University of Kyoto and Polish Studies at the Jagiellonian University in Cracow, Poland. Based in Cracow since 1986. In 1991, she met the butō dancer Daisuke Yoshimoto and later studied Kazuo Ōno's and Min Tanaka's art. She embarked on her solo butō career in 1994. Iwata develops all elements of her performances herself, from choreography to stage design. She collaborates with many artists as a member of the Otwarta Pracownia [Open Studio] and Improvising Artists \{i.a\}.

Kachi Seisaku. Student of Tatsumi Hijikata and Yōko Ashikawa, member of Hakutobo butoh-ha.

Katsura Kan (born in Tokyo). Founder and practitioner of Zen Butoh. In 1979-1981, he worked with Byakkosha. He is devoted to the idea of global butō, but cherishes the dance's classical elements as well. He develops solo performances and collaborates with many artists as a choreographer. He founded the international company Katsura Kan \& Saltimbanques. For twenty-eight years, he has worked with, as he puts it, "minority dancers" across the world, in remote corners of Africa, Europe and South-Eastern Asia. His explorations and performances in Indonesia, Thailand, Singapore, Hawaii and other locations have been funded from grants of the Japanese Fund. (www.katsurakan.com)

Kasai Akira (born in 1943). Initially, he studied classical and modern dance, but in 1963, when he met Kazuo Ōno and Tatsumi Hijikata, he became fascinated with butō. In 1979, he gave up dancing to study eurythmics and anthroposophy in Germany. Six years later, he returned to Japan, where he developed an individual dancing style and became artistic director of the Tenshikan company. (www. akirakasai.com)

Kasai Toshiharu/Morita Itto (born in 1952). He was introduced to butō by Semimaru (of Sankai Juku) in 1988 and adopted the artistic alias of Morita Itto. First, he performed with Kobuzoku Arutai and in 1996 he co-founded GooSay with Mika Takeuchi in Sapporo. He explores butō as a method of body-mind integration and spiritual healing. He is the director of the Sapporo Dance Movement Institute, a certified dance therapist and Clinical Psychology Professor at the Sapporo Gakuin University, where he does research into somatic psychology (psychosomatics) and body desocialisation. (www.ne.jp/asahi/butoh/ itto/ittomorita/index.htm) 
Kaseki Yuko (born in w Tokyo). She studied butō with Anzu Furukawa in 1990-1993 and later joined his group Dance Butter Tokyo. In 1995, she cofounded the cokaseki group with the dancer and producer Mark Ates in Berlin. She collaborates with many artists and travels across Europe, Japan, Canada, Mexico and the US with her performances and workshops. In her stage performances, she uses butō, contemporary Western dance techniques and performance arts. Her art is often compared to dream visions. (cargocollective.com/yukocokaseki)

Kawamoto Yuko. Born in the 1970s. Artistic director of the Tokyo-based Shinonome Butoh (1999). She has studied and performed with Yukio Waguri, a student of Tatsumi Hijikata. In her art, she explores image-based inner transformation processes. The Shinonome group abandoned Ankoku butō's signature dark aesthetics to create a new type of butō. (www. shinonomebutoh. com)

Laage Joan (born in 1948 in Wisconsin). American dancer, choreographer and educator. She studied butō under Kazuo Ōno and Yōko Ashikawa. She performed with Ashikawa's Gnome and participated in workshops taught by Min Tanaka, Sankai Juku, Akira Kasai, Harupin Ha, Masaki Iwana and SU-EN. In 1989, she choreographed her first group performance in Taipei. In 1991, she founded Dappin Butoh. She taught workshops and performed in Poland in 1996 and 2000. In 2004, she moved to Cracow, where she taught classes in stage choreography and dance composition for the Artystyczna Alternatywa [Artistic Alternative]. In 1995, she started to perform as Kogut [Rooster]. Laage is also a butō researcher and completed a PhD project on Embodying the Spirit: The Significance of the Body in the Contemporary Japanese Dance Movement of Butoh in 1993. She is a certified practitioner of the Laban Movement Analysis and Bartenieff Fundamentals. (seattlebutoh-laage.com)

Laban Rudolf von (1879-1958). Hungarian dancer, choreographer and dance theorist. The Laban Movement Analysis is a language and a framework for describing, analysing and understanding movement as based on four principles: shape, effort, space and body.

Maro Akaji (born in 1943 in Sakurai, Nara, Japan). Founder and artistic director (since 1972) of Dairakudakan, a legendary butō dance company which expanded the butō style, adding elements of spectacle to it. Maro was an important artist of Angura (underground), a Japanese avant-garde theatre movement. Currently known not only as a dancer, but also an actor and artistic director. (www. dairakudakan.com) 
Mishima Yukio (1925-1970). Japanese writer who focused on the chasm between Japanese tradition and the modern world. His literature and socio-political engagements inspired Tatsumi Hijikata.

\section{Morita Itto, see Kasai Toshiharu.}

Murobushi Ko (born in 1947 in Tokyo). In 1968, he started to study butō under Tatsumi Hijikata, soon after that performing with him. For a while, he became a yamabushi (mountain hermit) but later returned to the stage. He co-founded Dairakudakan, set up a butō-devoted periodical (Hageshii Kisetsu) in 1974, cofounded with Carlotta Ikeda a women's butō company called Ariadone, for which he did the choreography, and then established another group, Sebi. In 1978, he visited Europe with Ariadone, showing the first butō performance in this part of the world. His style is grounded in intensive physical explorations. (www.komurobushi.com, www.komurobushi.com)

Muronoi Yoko (born in Yokohama). Dancer, musician and video-artist. She learned butō with Akira Kasai, while studying at Tokyo's Waseda University. In 1982-1984, she collaborated with Nobuo Harada's Seiryukai and has performed solo since 1985. (www.tokyo-seiryukai.jp).

Nagaoka Yuri (born in Tokyo). She studied classical dance and at twelve years of age joined the Hiraoka Shiga Dance Company to learn modern ballet. As a teenager, she came in contact with butō. In 1997, she started to perform and teach workshops in America, Europe and Asia. She starred in Masaki Iwana's film Shureitachi (Vermilion Souls). Since 2005, she has performed and taught workshops with her butō teacher Seisaku Kachi as the Butoh Company Dance Medium. (yurinagaokabutoh. blog.shinobi.jp)

Nakajima Natsu (born in 1943 in Sakhalin). In the 1950s, she studied at the Masa Tsuchiya Classical Dance Academy and the Masami Kuni Dance Academy. In 1962, she joined the Kazuo Ohno Dance Institute. In the 1960s, she danced in productions directed and choreographed by Tatsumi Hijikata. In 1969, she founded the Mutekisha company in Tokyo. She has performed internationally and won several awards for her art. (www.geocities.jp/mutekisha/index1-e.html)

Ōno Yoshito (born in 1938 w Tokyo). A member of the Ankoku Butoh company, he performed with Tatsumi Hijikata in Kinjiki, the first ever butō show, in 1959. In 1969, he gave his first solo performance and then stopped performing. In 1985, he returned to the stage in a performance with his father Kazuo Ono and has directed his performance since 1986. He is director of the Kazuo Ohno Dance Studio. (www.kazuoohnodancestudio.com/english/yoshito) 
Rotie Marie-Gabrielle (born in 1967 in Pembrokeshire, UK). She studied fine arts and dance. In 1992, she started to learn butō, practising with several artists both in Japan (where she did a research project) and in Europe. Among her teachers are Akiko Motofuji, Ko Murobushi, Masaki Iwana, Kazuo and Yoshito Ōno, Carlotta Ikeda and Kim Itoh. She has collaborated with many butō artists, such as Ko Murobushi and Atsushi Takenouchi. Since 2000, she has created numerous productions shown across Europe. She also designs stage costumes. (www.rotieproductions.com)

Seki Minako (born in 1945 in Nagasaki). Dancer of the third butō generation. Since 1985, she has danced with the Dance Love Machine, a company with which she came to Europe in 1986. She settled in Berlin and in 1987 co-founded (with Yumiko Yoshioka) the Japanese-German troupe Tatoeba. She is interested in oneiric poetics. Since 1996, she has worked on her own and participated in several collaborative artistic projects. (www.minakoseki.com)

\section{SU-EN, see Akerlund Susana.}

Takenouchi Atsushi (born in 1962 in Matsuzaka, Japan). He started dancing butō in Hokkaido in 1980, when he joined Hoppo Butoh-ha, one of the most important buto companies. In 1984, as part of the company, he performed in Takazashiki, choreographed by the founder of butō Tatsumi Hijikata. He also danced with Kazuo and Yoshito Ōno. Today, he works with his own variety of butō, which he refers to as Jinen Butoh. He has developed many solo projects focused on the themes of nature, earth, pre-history, time, space and circumstances. In 1996-1999, he performed in Japan, and in 1999 he started travelling in Europe and Asia, showing his Jinen Butoh programme entitled Sun and Moon, teaching workshops and performing for the public. Since 2002, when he received a grant from the Japanese government, he has lived in Europe, collaborating with actors and dancers from France, Italy and other countries. He offers workshops for professional performers, amateurs, parents and children, people with disabilities and their instructors. On many occasions, he produces performances with his trainees. Invited by different municipal culture centres, he has travelled to Poland a few times and visited Warsaw, Poznan, Szczecin, Wroclaw, Lublin and Olsztyn. (www.jinen-butoh.com)

Takeushi Mika (born in 1966). Dancer and certified dance therapist. In 2002, she founded the Butō Institute in Sapporo. She performs with the GooSay Ten and with Morita Itto. (www.ne.jp/asahi/butoh/itto/mika/mika-e.htm) 
Tanaka Min (born in 1945 in Tokyo). Since the early 1970s, he has lived at the rural Body Weather Farm, where he runs intensive workshops in body disciplines and butō and organises the annual Dance Hakushu summer festival. With his group, he has performed at theatres, museums, in the streets, fields, forests, gardens, deserts, rivers and even the ocean. He has collaborated internationally with several artists. His main inspiration is Tatsumi Hijikata's Ankoku butō, which he has re-worked in his own, unique way. The motto of his art is exploring the origins of dance. His art practices are best defined as site-specific dance. (www. min-tanaka.com)

Thormann Imre (born in 1966 in Bern, Switzerland). He has practised many martial arts (aikido, kung fu, tai chi and taekwondo). In 1990, he obtained a certificate as an Alexander Technique teacher. He lived in Tokyo, where he studied butō with Kazuo Ōno and Michizo Noguchi (who founded his own training method). Since 1993, he has performed in solo butō shows. In 2002, he founded a butō school called Bodygarage in Tokyo. After thirteen years, he returned to Europe and settled in Berlin, where he now lives, dances and teaches butō and Noguchi Taiso. (www.bodytaster.com)

Waguri Yukio (born in 1952 in Tokyo). In 1972, he became the main dancer of the Ankoku Butoh company led by Tatsumi Hijikata. He still performs and teaches workshops in and outside Japan. In 1988, he published Butoh Kaden, a book with a DVD-ROM, presenting Hijikata's key buto-fu. Currently, he is artistic director of the Kohzensha Butoh Company (www. otsukimi.net/koz).

Yoshimoto Daisuke (born in 1941). He graduated in arts from the Theatre Faculty, Nippon University, in 1967. At the age of forty, he started to dance butō. He collaborated with such artists as Kazuo Ōno, Hisaya Iwaki and Yukihiko Sakai. In the 1990s, he came to Poland several times, showing a series of performances about death. In 1997, Wroclaw's Centre of Studies of Jerzy Grotowski's Work and of the Cultural and Theatrical Research (present-day Jerzy Grotowski Institute) held a butō dance festival, with Yoshimoto as a programme consultant. (www. butoh-ultraego.com)

Yoshioka Yumiko (born in 1953). She was among the first members of Ariadone. Together with Minako Seki, she founded the dance group Tatoeba: Théâtre Danse Grotesque and, later, her current group TEN PEN CHii Art Labor with the visual artist Joachim Manger (1994). She designs pioneering installations in which butō dance (performance) is combined with visual arts (technology). (www.ten-penchii.de) 



\section{List of Photographs}

Photo 1: Paweł Dudziński, photo Gabriel Obolewicz .................................... 143

Photo 2: Paweł Dudziński, photo Piotr Mazurek .......................................... 143

Photo 3: Paweł Dudziński, Incantation 2, photo Michał Popiel-Machnicki ............................................................................... 144

Photo 4: Justyna Jan-Krukowska, Water \& Fire Ritual, photo Kamil Zaremba ...................................................................... 144

Photo 5: Justyna Jan-Kurkowska, A Lady's Dressing Table, photo Kamil Zaremba ....................................................................... 145

Photo 6: Justyna Jan-Kurkowska, A Lady's Dressing Table, photo Kamil Zaremba ..................................................................... 145

Photo 7: Sylwia Hanff, 8 Deserts, photo Arkadiusz Rączka ........................ 146

Photo 8: Sylwia Hanff, 8 Deserts, photo Arkadiusz Rączka ......................... 146

Photo 9: Sylwia Hanff, The Ocean’s Dreams, photo Marta Przybyło ......... 147

Photo 10: Krzysztof Jerzak, Straw-butō, photo Monika Cichocka ................ 147

Photo 11: Krzysztof Jerzak, Straw-butō, photo Monika Cichocka ............... 148

Photo 12: Krzysztof Jerzak, Aite, photo Barbara Songin ................................ 148

Photo 13: Amareya Theatre, Haiku for Three Bodies, photo Jerzy Nowak .... 149

Photo 14: Amareya Theatre, The Empty Home, photo Jerzy Nowak ........... 149

Photo 15: Amareya Theatre, Anatomical Theatre, photo Jacek Sobociński ... 150

Photo 16: Amareya Theatre, Xenos, photo Agnieszka Kubińska .................. 150

Photo 17: Aleksandra Capiga-Łochowicz, Improvisation 2008, photo Andrzej Janikowski

Photo 18: Aleksandra Capiga-Łochowicz, Improvisation 2009, photo Andrzej Janikowski

Photo 19: Aleksandra Capiga-Łochowicz, Improvisation 2010, photo Andrzej Janikowski

Photo 20: Aleksandra Capiga-Łochowicz, Improvisation 2010, photo Andrzej Janikowski

Photo 21: TO-EN, Melange, photo Małgorzata Taraszkiewicz ...................... 153

Photo 22: TO-EN, Melange, photo Małgorzata Taraszkiewicz …………...... 153

Photo 23: TO-EN, Embers, photo Małgorzata Taraszkiewicz ........................ 154 
Photo 24: TO-EN, Embers, photo Małgorzata Taraszkiewicz 154

Photo 25: Irena Lipińska, line, photo Paweł Pych .......................................... 155

Photo 26: Irena Lipińska, DNACE, photo Kailai Chen ................................... 155

Photo 27: Irena Lipińska, DNACE, photo Kailai Chen ................................... 156

Figure 1: Roland Fischer's cartography of ecstatic and meditative states. Source: www.wisebrain.org/papers/MapofMed EcstaticStates.pdf [Accessed 23 April 2012] 


\section{Bibliography}

Akira Kasai Five-Day Butoh Workshop at PSU, July 26-30. 2005. https://www. pdx.edu/syndication/akira-kasai-five-day-butoh-workshop-psu-july-26-30. Accessed 10 July 2014.

Achterberg, Jeanne. 1985. Imagery in Healing. Boston: Shambala Publications.

Artaud, Antonin. 1958. The Theatre and Its Double. trans. Mary Caroline Richards. New York: Grove Weidenfeld.

Aslan, Odette, Beatrice Picon-Vallin \& Ushio Amagatsu. 2002. Butō(s). Paris: CNRS Editions.

Bakke, Monika. 2000. Ciało otwarte. Filozoficzne reinterpretacje kulturowych wizji cielesności. Poznań: Wydawnictwo Naukowe Instytutu Filozofii Uniwersytetu Adama Mickiewicza.

Bakthin, Mikhail. 1984. Rabelais and His World. trans. Helene Iswolsky. Bloomington: Indiana University Press.

Bałaj, Bibianna. 2007. "Umysłowa symulacja $\mathrm{z}$ wykorzystaniem wyobraźni motorycznej. Przegląd teorii i badań.” In Piotr Francuz (Ed.), Obrazy w umyśle. Studia nad percepcja i wyobraźnią. Warszawa: Wydawnictwo Naukowe "Scholar." 231-248.

Banes, Sally. 1992 “Is It All Postmodern?” The Drama Review, 36. 59-62.

Barba, Eugenio. 1999. Land of Ashes and Diamonds: My Apprenticeship in Poland. Aberystwyth: Black Mountain Press.

Barba, Eugenio \& Nicola Savarese. 2005. A Dictionary of Theatre Anthropology: The Secret Art of the Performer. 2nd edition. trans. Richard Fowler et al. London and New York: Routledge.

Barrek, Małgorzata. 2009. Butō i problem cielesności. MA thesis supervised by Dr Mirosław Kocur, Institute of Cultural Studies, University of Wroclaw.

Berestecka, Anna. 2009. "Butoh - nagie ciało w przestrzeni sceny." Autoportret, 19. 26-29.

Bernard, André. 2006. "An Introduction to Ideokinesis." André Bernard, Wolfgang Steinmüller \& Ursula Stricker, Ideokinesis: A Creative Approach to Human Movement and Body Alignment. Berkeley: North Atlantic Books. 3-6.

Bester, Katarzyna. 2009. "Konstrukcja i dekonstrukcja widza w teatrze interkulturowym.” In Agata Dąbek \& Joanna Jaworska-Pietura (Eds.), Publiczność (z)wymyślana. Kraków: Księgarnia Akademicka. 73-86.

Bester, Katarzyna . 2010a. "Butō - od nazwy do istoty." In Dariusz Kosiński (Ed.), Lektury dramatyczności. Kraków: Księgarnia Akademicka. 299-328. 
Bester, Katarzyna . 2010b. "Elegia o Hijikacie." Teatr, 12. 72-73.

Boleyn-Fitzgerald, Miriam. 2010. Pictures of the Mind: What the New Neuroscience Tells Us about Who We Are. Upper Saddle River, New Jersey: FT Press.

Bremer, Józef. 2001. Problem umyst-ciało. Wprowadzenie. Kraków: WAM.

Bykow, Fiodor. 1988. "Lao Tsy i traktat Tao Te King." In Marian Dziewisz (Ed.), Taoizm. Kraków: Biblioteka Pisma Literacko-Artystycznego. 27-38.

Capiga, Aleksandra. 2009. Bunt ciała. Butoh Hijikaty. Kraków: Muzeum Sztuki i Techniki Japońskiej Manggha.

Capiga-Łochowicz, Aleksandra. 2011. "Taniec butoh jako droga do integracji ciała i umysłu." Kultura Enter, 35. [n.p.].

Carlson, Marvin. 2001. Performance: A Critical Introduction. London and New York: Routledge.

Chanczewska, Emilia. 2004. "Integracja w terapii tańcem. Kwiaty na chodniku." http://www.pzgszczecin.internetdsl.pl/prasb_01.html. Accessed 21 June 2014.

Coelho, Abel. 2008b. "Ankoku Butō and Altered States of Consciousness." http:// www.docstoc.com/docs/48073529/Butoh-and-Trance-ruinedmap-dancecompany-shuddering. Accessed 19 June 2014.

Cohen, Bonnie Bainbridge. 2012. "An Introduction to Body Mind Centering." https://www.semanticscholar.org/paper/1-A-N-I-NTRODUCTION-TO-BODY-M-IND-C-ENTERING-\%C2\%AE-by-CENTERING-cohen/8f023bca0 ecf0bf8e58a34601e9297d20d8a63b6. Accessed 12 April 2018.

Craig, Gordon. 1908. “The Actor and the Über-Marionette." Mask, 1(2). 3-16.

Csikszentmihalyi, Mihaly. 1990. Flow: The Psychology of Optimal Experience. New York: Harper and Row.

Csórdas, Thomas J. 1993. “Somatic Modes of Attention." Cultural Anthropology 8(2). 135-156.

Czajkowski, Albert. 2011. “Uwaga! Bieganie uzależnia! Czyli czym jest euforia biegacza.” http://nektarnik.pl/2011/01/uwaga-bieganie-uzaleznia-czyli-czymjest-euforiabiegacza. Accessed 26 September 2011.

Davidson, Donald. 2002. Essays on Actions and Events. Oxford: Clarendon Press.

Deflem, Mathieu. 1991. "Ritual, Anti-Structure, and Religion: A Discussion of Victor Turner's Processual Symbolic Analysis." Journal for the Scientific Study of Religion, 30(1). 1-25.

Dewey, John. 1991. The Later Works: 1925-1953. Volume 1: 1925. Carbondale: Southern Illinois University Press.

Dewey, John . 2005. Art as Experience. New York et al.: Penguin Books. 
Dudziński, Paweł. 2004. Rytuat intuitywny. Metoda artystyczna Teatru Performer. Zamość: Stowarzyszenie Teatr Performer Instytut Sztuki Nowej.

Dudziński, Paweł . 2006. "Rytuał intuitywny a sztuki performatywne." In Magdalena Gołaczyńska \& Ireneusz Guszpit (Eds.), Teatr - przestrzeń - ciało dialog. Poszukiwania we współczesnym teatrze. Wrocław: Wydawnictwo Uniwersytetu Wrocławskiego. 177-189.

Dudziński, Paweł . 2008. "O malowaniu dla Guinnessa i Teatrze Performer." Interview by Teresa Madej. 15 May 2008. http://www.zamosconline.pl/text. php?id=2118\&rodz=kul/. Accessed 20 June 2011.

Eguchi, Osamu. 1988. "My View of Hoppō Buto-ha." Susan Blakely Klein, Ankoku Butō: The Premodern and Postmodern Influences on the Dance of Utter Darkness. New York: Cornell University East Asia Series. 89-91.Fischer, Roland. 1971. "A Cartography of the Ecstatic and Meditative States." Science, 174. 897-904. http://wisebrain.org/papers/MapofMedEcstaticStates.pdf. Accessed 24 March 2012.

Fischer-Lichte, Erika. 2008a. "Czym jest przedstawienie w kulturze performansów? Próba definicji.” Didaskalia, 88. 65-71.

Fischer-Lichte, Erica. 2008b. The Transformative Power of Performance: A New Aesthetics. trans. Saskya I. Jain. New York: Routledge.

Foster, Hal. 1996. The Return of the Real: The Avant-Garde of the End of the Century. Cambridge, MA, and London, UK: MIT Press.

Fraleigh, Sondra Horton. 1996. Dance and the Lived Body: A Descriptive Aesthetics. Pittsburgh: University of Pittsburgh Press.

Fraleigh, Sondra Horton. 1999. Dancing into Darkness: Butoh, Zen, and Japan. Pittsburgh: University of Pittsburgh Press.

Fraleigh, Sondra Horton. 2010. Butoh: Metamorphic Dance and Global Alchemy. Urbana, Chicago, and Springfield: University of Illinois Press.

Fraleigh, Sondra \& Tamah Nakamura. 2006. Hijikata Tatsumi and Ohno Kazuo. Oxon: Routledge.

Francuz, Piotr (Ed.). 2007. Obrazy w umyśle. Studia nad percepcja i wyobraźnią. Warszawa: Wydawnictwo Naukowe „Scholar”.

Franklin, Eric. 2012. Dynamic Alignment through Imagery. 2nd edition. Champaign: Human Kinetics.

Fret, Jarosław. 2000. “Teatr fizyczny Lloyda Newsona.” In Ewa GuderianCzaplińska \& Grzegorz Ziółkowski (Eds.), Teatr: ciało i cień. Materiały z sympozjum młodych teatrologów, Poznań 1999. Poznań: Uniwersytet Adama Mickiewicza. 131-8. 
Gōda, Nario. 1988. “On Ankoku Butō.” Susan Blakely Klein, Ankoku Butō: The Premodern and Postmodern Influences on the Dance of Utter Darkness. New York: Cornell University East Asia Series. 79-88.

Gołaszewska, Maria. 1985. Zarys estetyki. Warszawa: PWN.

Grabowska, Jadwiga \& Szymajda Joanna. 2009. "Raport o tańcu współczesnym w Polsce w latach 1989-2009." http://www.kongreskultury.pl/library/File/ RaportTaniec/taniec_raport_w.pelna\%281\%29.pdf. Accessed 10 June 2009.

Grosz, Elisabeth. 1990. Jacques Lacan: A Feminist Introduction. London: Routledge.

Grotowski, Jerzy. 1990. “Performer.” Jerzy Grotowski, Teksty z lat 1965-1969. Wrocław: Wiedza o Kulturze. 214-8.

Grotowski, Jerzy. 2007b. “Techniki aktorskie.” Interview with Jerzy Grotowski by Denis Bablet. Jerzy Grotowski, Ku teatrowi ubogiemu. Wrocław: Instytut im. Jerzego Grotowskiego. 197-207.

Hanff, Sylwia. 2009. "Wywiad z Sylwią Hanff, tancerką butoh." http://www. suwalki.info/articles2.php?id=135. Accessed 19 June 2014.

Hanff, Sylwia . [n.d.]. "Aktor obdarty ze skóry." HTL, http://limenbutoh.net/ index.php?option $=$ com_content \&task=blogsection \&id $=11 \&$ Itemid $=36$. Accessed 12 March 2011.

Hannerz, Ulf. 1996. Transcultural Connections: Culture, People, Places. London and New York: Routledge.

Harpham, Geoffrey Galt. 1982. On the Grotesque: Strategies of Contradiction in Art and Literature. New York: Princeton University Press.

Hawkins, Alma. 1991. Moving from within: A New Method for Dance Making. Pennington: A Capella Books.

Hijikata, Tatsumi. 2000b. "From Being Jealous of a Dog's Vein." The Drama Review, 44(1). 56-59.

Hijikata, Tatsumi . 2000c. "Inner Material/Material." The Drama Review, 44(1). 36-42.

Hijikata, Tatsumi . 2000e. “To Prison.” The Drama Review, 44(1). 43-48.

Hijikata, Tatsumi . 2000 f. "Wind Daruma." The Drama Review, 44(1). 71-79.

Hoczyk, Julia. 2009a. Japoński taniec butō. Historia i charakterystyka gatunku, MA thesis supervised by Prof. Leszek Kolankiewicz, Akademia Teatralna im. Aleksandra Zelwerowicza, Warszaw.

Hoczyk, Julia. 2009b. “O cielesności w japońskim tańcu butō.” NowyTaniec. $P L$, http://www.nowytaniec. pl/czytelnia/Julia_Hoczyk_O_cielesnosci.pdf. Accessed 4 January 2010. 
Hoczyk, Julia. 2013b. “Wytańczyć niewysławialne.” In Jadwiga Majewska (Ed.), My, taniec. Antologia polskiej krytyki tańca po 1989 roku. Tarnów: Centrum Sztuki Mościce. 127-133. http://kultura.lublin.eu/wiadomosci,1.1236. Wyta\%C5\%84czy\%C4\%87_niewys\%C5\%82awialne.html?locale=pl_PL. Accessed 1 July 2014.

Hoffman, Ethan \& Mark Holborn. 1987. Butoh: Dance of the Dark Soul. New York: Aperture Foundation.

Ichikawa, Miyabi. 1988. "A Preface to Butō [Butō Josetsu]." Susan Blakely Klein, Ankoku Butō: The Premodern and Postmodern Influences on the Dance of Utter Darkness. New York: Cornell University East Asia Series. 69-71.

Iwabuchi, Keisuke. 1988. “The Paradigm of Butō.” Susan Blakely Klein, Ankoku Butō: The Premodern and Postmodern Influences on the Dance of Utter Darkness. New York: Cornell University East Asia Series. 73-77.

Izutsu, Toshihiko. 1981. The Theory of Beauty in the Classical Aesthetics of Japan. The Hague, Boston and London: Martinus Nijhof Publishers.

Jabłońska, Małgorzata. 2008. "Dramaturgia ciała. Zarys projektu badawczego na przykładzie analizy praktyk cielesnych OPT Gardzienice." Konteksty. Polska Sztuka Ludowa, 1(280). 129-135.

Jabłońska, Małgorzata. 2009. “Ciała ikon. O recepcji dialektycznego związku cielesności i wizualności w spektaklach Ośrodka Praktyk Teatralnych 'Gardzienice.”' In Agata Dąbek \& Joanna Jaworska-Pietura (Eds.), Publiczność (z)wymyślana. Relacje widz-scena we wspótczesnej praktyce dramatopisarskiej i inscenizacyjnej. Kraków: Księgarnia Akademicka. 155-174.

Jan-Krukowska, Justyna. 2009. Dzieło jako narzędzie pracy nad sobą. Paper delivered at the Carpe Diem. Arteterapia $w$ edukacji i rozwoju człowieka conference held by Instytut Kształcenia Ustawicznego Nauczycieli i Studiów Edukacyjnych Dolnośląskiej Szkoły Wyższej. Wrocław, 14-15 January 2009 (courtesy of the author).

Jan-Krukowska, Justyna. [n.d.]. Body Weather, HJK, http://www.justbody.eu/ butoh.html. Accessed 24 June 2010.

Jan-Krukowska, Justyna. [n.d.]. Ciało i obiekt. Kluczowe odkrycia w procesie pracy $z$ ciałem i przedmiotem, HJK, http://www.justbody.eu/cialo_i_obiekt. html. Accessed 24 June 2010.

Jan-Krukowska, Justyna. [n.d.]. Kobiece Rytuały. Rytuał. Uzdrawianie. Wspólnota, HJK, http://www.justbody.eu/?page_id=151. Accessed 24 June 2010.

Janicka, Ewa. 2012. Transkulturowy charakter japońskiego tańca butō. Unpublished PhD dissertation supervised by Dr Hab. Juliusza Tyszka, Adam Mickiewicz University in Poznań, https://repozytorium.amu.edu.pl/jspui/ bitstream/10593/3511/1/E.Janicka\%20PHD.pdf. Accessed 15 June 2014. 
Janik, Jerzy A. 2011. “Zjawiska (fakty) emergentne.” PAUza Akademicka. Tygodnik Polskiej Akademii Umiejętności, 111. 3.

Janikowski, Grzegorz. 2008. “Tańcząc w stronę korzeni.” Kultura Enter, 2. http:// kulturaenter.pl/tanczac-w-strone-korzeni/2008/12/. Accessed 19 June 2014.

Jerzak, Krzysztof. 2009. A Butō Dance Workshop Information Leaflet. 21-22 November 2009.

Jędrzejczak, Łukasz. 2010. O powstawaniu doznań mistycznych. Podejście neurokognitywne (Studia z Teorii Poznania i Filozofii Języka, vol. 4). Olsztyn: Instytut Filozofii Uniwersytetu Warmińsko-Mazurskiego.

Karkou, Vassiliki \& Patricia Sanderson. 2005. Arts Therapies: A Research-Based Map of the Field. Edinburgh: Elsevier Churchill Livingstone.

Kasai, Toshiharu. 1999. "A Butoh Dance Method for Psychosomatic Exploration." Memoirs of the Hokkaido Institute of Technology, 27. 309-316.

Kasai, Toshiharu. 2000. "A Note on Butoh Body." Memoirs of the Hokkaido Institute of Technology, 28. 353-360.

Kasai, Toshiharu. 2001. Mind-Body Learning by Butoh Dance Method, paper delivered at the 36th Annual Conference of American Dance Therapy Association. 11-14 October 2001. Sheraton Capital Center Hotel, Raleigh, North Carolina, USA, http://www.ne.jp/asahi/butoh/itto/method/adta21. htm. Accessed 15 March 2011.

Kasai, Toshiharu. 2005. "The Arm-Standing Exercise for Psychosomatic Training." Bulletin of the Faculty of Humanities, Sapporo Gakuin University, 77. 77-81.

Kasai, Toshiharu. 2009a. "New Understandings of Butoh Creation and Creative Autopoietic Butoh - From Subconscious Hidden Observer to Perturbation of Body-Mind System." Bulletin of the Faculty of Humanities, Sapporo Gakuin University, 86. 21-36.

Kasai, Toshiharu. 2009b. "Notes on Butoh Dance." http://www.ne.jp/asahi/ butoh/itto/method/kasait/k--note.htm. Accessed 15 March 2011.

Kasai, Toshiharu. 2009c. Q and A: My Butoh Practice and How I Integrate It into My Therapeutic Work, a talk at the Central School for Speech and Drama University of London, 2 November 2009. http://toshi-kasai.info/london_ central_speech-drama.pdf. Accessed 12 November 2010.

Kasai, Toshiharu \& Kate Parsons. 2003. "Perception in Butoh Dance." Memoirs of the Hokkaido Institute of Technology, 31. 257-264.

Kawa, Magdalena \& Alicja Kawka. 2008. "Butoh jest jak wirus." Opornik, 36(9). http://hf.org.pl/ao/index.php?id=787. Accessed 29 September 2009. 
Kawai, Norie et al. 2001. "Catecholamines and Opioid Peptides Increase in Plasma in Humans during Possession Trances." Cognitive Neuroscience and Neuropsychology, 16(12). 3419-3423.

Keene, Donald. 2001. "Realizm i nierzeczywistość w teatrze japońskim." In Krystyna Wilkoszewska (Ed.), Estetyka japońska. Antologia. Kraków: Universitas. 89-108.

Kirby, Michael. 1975. "Post-Modern Dance." The Drama Review, 19. 3-4.

Klein, Susan Blakely. 1988. Ankoku Butō: The Premodern and Postmodern Influences on the Dance of Utter Darkness. New York: Cornell University East Asia Series.

Klein, Susan Blakely. 2008. Ankoku Butoh (or Buto): Dance of Utter Darkness. ICU Core Course Ramune to Anime (Fall 2008), https:/eee.uci.edu/ clients/sbklein/THEATER/07-ICU/EA120-10a-07-outline.htm. Accessed 17 March 2010.

Kleist, Heinrich von. 1970. About Marionettes. trans. Michael Lebeck, New York and Mindelheim: Three Kings Press.

Kocur, Mirosław. 2003. Butoh, czyli teatr tańca, curatorial text for Maciej Rusinek's photography exhibition Butoh - królestwo poezji ciała, at the Manggha Museum of Japanese Art and Technology, Kraków, May 2003.

Kowalczyk, Izabela. 2000. "Spory o sztukę lat 90." http://magazynsztuki.eu/ old/archiwum/teksty_internet_arch_all/archiwum_teksty_online_11.htm. Accessed 9 June 2014.

Kowalczyk, Izabela. 2006. "Sztuka krytyczna - wybrane zagadnienia." http:// www.culture.pl/baza-sztuki-pelna-tresc/-/eo_event_asset_publisher/eAN5/ content/sztuka-krytyczna-wybrane-zagadnienia. Accessed 9 November 2011.

Kozyra, Agnieszka. 2004. Filozofia zen. Warszawa: PWN.

Kudliński, Tadeusz. 2006. "Dziady w 13 Rzędach.” In Janusz Degler \& Grzegorz Ziółkowski (Eds.), Misterium zgrozy i urzeczenia. Przedstawienia Jerzego Grotowskiego i Teatru Laboratorium. Wrocław: Instytut im. Jerzego Grotowskiego. 139-140.

Kurihara, Nanako. 2000. "Hijikata Tatsumi: The Words of Butoh." The Drama Review, 44. 12-28.

Laage, Joan. 1993. Embodying the Spirit: The Significance of the Body in the Contemporary Japanese Dance Movement of Butoh. Danton: Texas Woman's University.

Lao, Tzu. 1997. Tao Te Ching. trans. Arthur Waley. Ware: Wordsworth Editions Limited. 
Lewandowski, Roman. 2008. "Miho Iwata. Niewidzialne miejsca." http://www. baltic--gallery.art.pl/archiwum/miho_iwata. Accessed 4 February 2014.

Lewis, Clarence Irving. 1956. Mind and the World-Order: Outline of a Theory of Knowledge. New York: Dover Publications.

Małecki, Wojciech. 2009. "Somatoestetyka a normy ciała." Kultura Współczesna, 1(59). 8-18.

Markiewicz, Piotr \& Piotr Przybysz. 2007. "Neuroestetyczne aspekty komunikacji wizualnej i wyobraźni.” In Piotr Francuz (Ed.), Obrazy w umyśle. Studia nad percepcja i wyobraźniq̨. Warszawa: Wydawnictwo Naukowe „Scholar”. 111-149.

Maslow, Abraham. 1962. Toward a Psychology of Being. New York: Van Nostrand.

Mazurek, Maciej. 1994. “Obrazy przepływającego świata.” Dekada Literacka,9(92). http://dekadaliteracka.pl/index.php?id=3200/ Accessed 16 December 2009.

McKenzie, Jon. 2011. Performuj albo... Od dyscypliny do performansu. trans. Tomasz Kubikowski. Kraków: Universitas.

Melanowicz, Mikołaj. 1994. Literatura japońska. Volume. 1: Od VI do połowy XIX wieku, Warszawa: PWN.

Merleau-Ponty, Maurice. 2001. Fenomenologia percepcji. trans. Małgorzata Kowalska \& Jacek Migasiński. Warszawa: Fundacja Aletheia.

Mieszkowski, Piotr. [n.d.], Fizjologia a bieganie, http://www.eioba.pl/a/1k7p/ fizjologia--a-bieganie. Accessed 19 June 2014.

Mikami, Kayo. 1997. Tatsumi Hijikata. An Analysis of Ankoku Butoh Techniques. Unpublished $\mathrm{PhD}$ dissertation at the Faculty of Humanities, Ochanomizu University, Tokyo (courtesy of the author).

Mikami, Kayo. 2002. "Deconstruction of the Human Body from a Viewpoint of Tatsumi Hijikata’s Ankoku Butoh." http://w01.tp1.jp/ a150397531/etude/ deconst.html. Accessed 16 January 2010.

Mond-Kozłowska, Wiesna. 2003. “Ciało-znak / Teatr fizyczny." Alma Mater, 51. http://www3.uj.edu.pl/alma/alma/51/01/13.html. Accessed 5 October 2009.

Mond-Kozłowska, Wiesna. 2010. Przekraczanie sztuki $w$ metafizycznym doświadczeniu tańca. Fenomenologia egzystencjalna w filozofii tańca Sondry Horton Fraleigh. Kraków: Ignatianum.

Nakajima, Natsu. 1998. “Butoh - pomiędzy teatrem a tańcem.” trans. Joanna Ostrowska. Opcje, 3(22). 48-51.

Nancy, Allison (Ed.). 1999. The Illustrated Encyclopedia of Body-Mind Disciplines. New York: Rosen Publishing Group. 
Niemczycka, Magdalena. 2005. Butoh: wydzieranie ciemności z ciała. MA thesis supervised by Dr Hab. Mirosław Kocur at the Institute of Cultural Studies, University of Wrocław.

Nishida, Kitarō. 1993. Last Writings: Nothingness and the Religious Worldview. trans. David A. Dilworth. Honolulu: University of Hawaii Press.

Oida, Yoshi \& Marshall Lorna. 1992. An Actor Adrift. London: Methuen.

Paduch, Ewa. 2009. "Moda na antybalet." http://www.iwoman.pl/na-serio/ ludzie/moda\%3Bna\%3Bantybalet,54.0.449334.html. Accessed 3 April 2010.

Pastuszak, Katarzyna Julia. 2010a. Ankoku butō Hijikaty Tatsumiego teatr ciała$w$-kryzysie. PhD dissertation supervised by Dr Hab. Michał Błażejewski, University of Gdańsk.

Pawlik, Jacek Jan. 2008. “Źródła, symbolika i znaczenia tańca afrykańskiego.” Konteksty. Polska Sztuka Ludowa, 1(280). 32-39.

Pędzich, Zuzanna. 2009. "Psychoterapia Tańcem i Ruchem w Polsce i na świecie.” In Zuzanna Pędzich (Ed.), Psychoterapia tańcem i ruchem. Teoria i praktyka w terapii grupowej. Warszawa: Arteer. 11-34.

Piotrowski, Piotr. 1998. "Wytrącić z automatyzmu myślenia." interview by Maciej Mazurek. Znak, 12. 146-160.

Piotrowski, Piotr. 1999. Znaczenia modernizmu. W stronę historii sztuki polskiej po 1945 roku. Poznań: Rebis.

Polzer, Elena. 2004. Hijikata Tatsumi's from Being Jealous of a Dog's Vein. MA thesis supervised by Dr Klaus Kracht, Humboldt-Universität zu Berlin, Philosophische Fakultät III, Institut für Japanologie.

Przybysz, Piotr. 2008. "Inni w naszych głowach.” Charaktery, 2. 66-71.

Ramachandran, Vilayanur S. 2006. "Mirror Neurons and the Brain in the Vat." http://edge.org/3rd_culture/ramachandran06/ramachandran06_index.html. Accessed 15 April 2011.

Rhizome, Lee. 2010. Behind the Mirror: A Butoh Manual for Students. http:// subbody.net/14pdf/BUTOH_MANUAL_FOR_STUDENTS.pdf. Accessed 24 July 2011.

Rizzolatti, Giacomo \& Maddalena Fabbri Destro. 2008. "Mirror Neurons." Scholarpedia. http://www.scholarpedia.org/article/Mirror_neurons. Accessed 24 February 2011.

Rodowicz, Jadwiga. 2009. Boski dwumian. Przenikanie rzeczywistości w teatrze $n \bar{o}$. Wrocław: Instytut im. Jerzego Grotowskiego.

Roquet, Paul. 2003. Towards the Bowels of the Earth: Butoh Writhing in Perspective. MA thesis supervised by Prof. Lynne Miyake and Prof. Laurie 
Cameron, Pomona College, http://ibtheatre.wikispaces.com/file/view/ TowardstheBowelsoftheEarth.pdf. Accessed 22 September 2011.

Sakson-Obada, Olga. 2009. Pamięć ciała. Ja cielesne $w$ relacji przywiązania $i w$ traumie. Warszawa: Difin.

Schechner, Richard. 2006. Performance Studies: An Introduction. 2nd edition. New York: Routledge.

Shusterman, Richard. 2000a. Performing Live: Aesthetic Alternatives for the Ends of Art. Ithaca and London: Cornell University Press.

Shusterman, Richard. 2000b. "Somaesthetics and the Care fo the Self: The Case of Foucault.” The Monist, 83(4). 530-551.

Shusterman, Richard. 2007. “Życie, sztuka i filozofia. Intymne wyznania Richarda Shustermana o filozofii, życiu, sztuce, ciele i duszy oraz wielu innych sprawach wysłuchane przez Adama Chmielewskiego." Richard Shusterman, O sztuce $i$ życiu. Od poetyki hip-hopu do filozofii somatycznej. trans. and ed. Wojciech Małecki in collaboration with Adam Chmielewski. Wrocław: Atla 2. 11-29.

Shusterman, Richard. 2008. Body Consciousness: A Philosophy of Mindfulness and Somaesthetics. Cambridge: Cambridge University Press.

Sier-Janik, Barbara. 1995. Historia tańca postmodern. Zarys problematyki twórcy i techniki. Warszawa: Centrum Edukacji Artystycznej.

Smith, Nancy Stark. 2006. "Harvest: One History of Contact Improvisation." A talk given at the International Contact Festival Freiburg, Germany 2005. Contact Quarterly: The Place Issue, 32(2). Summer/Fall. https:// contactquarterly.com/cq/unbound/view/harvest-a-history-of-ci\#\$. Accessed 27 February 2018.

Sobiech, Krzysztof. 2000. "Przydatność markerów biochemicznych w ocenie monitoringu wysiłku fizycznego." http://www.czytelniamedyczna.pl/1582. przydatnosc-markerow-biochemicznych-w-ocenie-monitoringu-wysilkufizycznego.html. Accessed 26 September 2011.

Sokołowska, Joanna. 2008. "Inspiracje - improwizacje - intuicja. Sztuka performance Pawła Dudzińskiego.” O.pl. Polski Portal Kultury. http:// magazyn.o.pl/2008/inspiracje-improwizacje-intuicja-sztuka-performancepawla-dudzinskiego. Accessed 15 June 2011.

Staż $w$ Teatrze ZAR. [n.d.]. http://www.grotowski-institute.art.pl/index.php? option=com_content\&task=view\&id=919. Accessed 22 February 2012.

Sweigard, Lulu. 1978. Human Movement Potential: Its Ideokinetic Facilitation. New York: Dodd, Mead, and Co..

Tachiki, Akiko. 1999. "Absolute Butoh (A report of Ex...it!' '99, a symposium and dance exchange project held in Schloss Brollin)." Ballett International/Tanz Aktuell, 11.32-33. 
Tanaka, Min. 1986. "Min Tanaka. Farmer/Dancer or Dancer/Farmer: An Interview by Stein Bonnie Sue." The Drama Review, 30(2). 142-151.

Taniec lasu. [n.d.]. "Information about the Production by Teatr Chorea." http:// www.chorea.com.pl/spektakle/taniec-lasu/. Accessed 21 June 2014.

Tanizaki, Junichirō. 2005. Pochwała cienia. trans. Henryk Lipszyc. In Krystyna Wilkoszewska (Ed.), Estetyka japońska. Kraków: Universitas.

Taranienko, Zbigniew. 1997. Gardzienice. Praktyki teatralne Włodzimierza Staniewskiego. Lublin: Test.

Tart, Charles. 1969. Altered States of Consciousness. New York: Wiley.

Tung-chi, Lin. 1947. "The Chinese Mind: Its Taoist Substratum." Journal of the History of Ideas, 8(3). 259-72.

Turner, Victor. 2008. The Ritual Process: Structure and Anti-Structure. New Brunswick and London: Aldine Transaction.

Tyborowska, Beata. 2009. "Modern Dance." http://dance.pl/Modern_dance, artykul,32.html. Accessed 6 October 2009.

Viala, Jean \& Nourit Masson-Sekine. 1988. Butoh - Shades of Darkness. Tokyo: Shufunotomo. Vyas, Nisha. 2009.

"The Use of Imagery and Visualisation in Contemporary Dance." http:// www.indefocus.com/articles/featured-articles/222-the-use-of-imageryandvisualisation-in-contemporary-dance. Accessed 3 December 2010.

Walkowiak, Izabela. 2009. Kostium $w$ tańcu butō. Unpublished MA thesis supervised by Dr Hab. Mirosław Kocur, Institute of Cultural Studies, University of Wrocław.

Wańtuch, Anna. [n.d.]. "Butoh i Judson Dance Theater jako przedstawiciele tańca postmodern." http://www.teatrtancadf.pl/pliki/obrazy/postmodern. pdf. Accessed 20 February 2011.

Welsch, Wolfgang. 2002. "Rethinking Identity in the Age of Globalization: A Transcultural Perspective." Aesthetics \& Art Science, 1. 85-94. www.uni-jena. de/welsch/papers/W_Welsch_Rethinking_Identity.pdf. Accessed 29 January 2018.

Wielechowska, Katarzyna. 2004. "Indyjska teoria 'rasa': propozycja dla współczesnego teatru.” In Krystyna Wilkoszewska (Ed.), Estetyka transkulturowa. Kraków: Universitas. 365-374.

Wilk, Sandra. 2011. “O ryżu, ziemi i walce człowieka.” http://www.rp.pl/ artykul/648104.html. Accessed 4 July 2014.

Wojnicka, Iwona. 2011. Butoh DO 1200 kilometrów (courtesy of the author).

Yamamoto, Kiyokazu. 1978. "Kara’s Vision: The World as Public Toilet." Canadian Theatre Review, 20. 28-33. 
Zamorska, Magdalena. 2010c. “Transkulturowość butō. Japonia, Welsch i pytania o tożsamość." Kultura - Historia - Globalizacja, 6. http://www.khg.uni.wroc. $\mathrm{pl} /$ ?type=artykul\&id=98. Accessed 4 December 2011.

Żbikowski, Tadeusz. 1988. “Prawie wszystko o tao.” In Marian Dziewisz (Ed.), Taoizm. Kraków: Biblioteka Pisma Literacko-Artystycznego.

Żeromska, Estera. 2003. Maska na japońskiej scenie. Od pradziejów do powstania teatru nō. Warszawa: Trio, Biblioteka Fundacji im. Takashimy.

Żeromska, Estera. 2010a. Japoński teatr klasyczny. Korzenie i metamorfozy, vol. 1. Warszawa: Trio.

Żeromska, Estera. 2010b. Japoński teatr klasyczny. Korzenie i metamorfozy, vol. 2. Warszawa: Trio.

Żukowska, Aneta. 2009. "Butō, czyli w poszukiwaniu naturalnego ruchu." http:// www.edukacyjnykrakow.pl/?cget=artykul\&from=298. Accessed 23 September 2010.

\section{Interviews}

Koseki Sumako. 2009. In Conversation at a Butō Workshop within the Work in Progress Arts Meeting. 28 February -5 March 2009. Srebrna Góra, Poland.

WAC: Interview with Aleksandra Capiga-Łochowicz by the Author. 12 July 2010. Kraków.

WIL: Interview with Irena Lipińska by the Author. 2 June 2010. Wrocław.

WJK: Interview with Justyna Jan-Krukowska by the Author. 2 June 2010 and 10 March 2011. Wrocław.

WKJ: Interview with Krzysztof Jerzak by the Author. 21 November 2009. Wrocław.

WMB: Interview with Małgorzata Braunek „Jiho” by the Author. November 2009. Kazimierz Dolny.

WSH: Interview with Sylwia Hanff (Sylwia Stępniak) by the Author. 10 August 2010. Wolimierz.

WTA: Interview with the Amareya Theatre (Katarzyna Julia Pastuszak, Agnieszka Kamińska, Aleksandra Śliwińska) by the Author. 5 August 2010. Gdańsk.

WTB: Interview with Tomasz Bazan by the Author. 5 July 2010. Lublin.

WTE: Interview with To-En (Anna Brałkowska) by the Author. 17 May 2010. Poznań. 


\section{Internet Websites}

AA: Artystyczna Alternatywa. Art Studio, Tab: Kurs choreografii scenicznej. http://www.art.krakow.pl. Accessed 15 September 2010. "Currently: Hurtownia Ruchu. Studio Tańca.” Tab: Kurs choreografii scenicznej. http:// hurtowniaruchu.pl. Accessed 4 July 2014.

AAK: Akademia Aikido Kobayashi, http://aikido-kolo.pl/aiki.html. Accessed 15 May 2011.

AAT10:AlternatywnaAkademiaTańca2010.http://www.starybrowarnowytaniec. $\mathrm{pl} /$ aat2010. Accessed 21 June 2011.

BIW: Iwona Wojnicka’s Blog. http://iwonakimu.blogspot.com. Accessed 4 May 2011.

Bushido: http://www.bushido24.pl/, tab: Style chińskie i wietnamskie. Accessed 21 June 2014.

DMT: Instytut DMT. Polski Instytut Psychoterapii Tańcem i Ruchem. http:// www.instytutdmt.pl. Accessed 13 April 2011.

HJK: Justyna Jan-Krukowska, JustBody. http://www.justbody.eu. Accessed 21 June 2014.

HTA: Teatr Amareya. http://teatramareya.pl. Accessed 21 June 2014.

HTL: Teatr Limen. http://limenbutoh.net/index.php. Accessed 21 June 2014.

HTMP: Teatr Maat Projekt. http://www.teatrmaat.pl. Accessed 18 July 2009.

KAAK: Krakowska Akademia Aikido Kobayashi Hirokazu. http://www.aikidokaak.pl. Accessed 3 December 2009.

Kana: Stowarzyszenie Teatr Kana. http://www.kana.art.pl. Accessed 28 November 2010. LeTHAL: http://www.lethalco.com. Accessed 4 July 2014.

Modliszka: Polskie Towarzystwo Kung Fu Modliszki. http://www.tanglangmen. com. Tab: Teoria i technika. Accessed 10 April 2010.

Solo Projekt 2011: http://www.starybrowarnowytaniec.pl/event/332. Accessed 15 March 2012.

Stary Browar Nowy Taniec: http://www.starybrowarnowytaniec.pl. Accessed 15 July 2011; Current websiste: http://www.artstationsfoundation5050.com/ live/taniec/aktualnosci/. Accessed 15 June 2014.

SRBSH: Subbody Resonance Butoh School Himalaya. http://www.subbody.net. Accessed 4 July 2014.

SU-EN Butoh Method: http://www.suenbutohcompany.net/. Tab: Workshops. Accessed 30 May 2010. 
Vietvodao: http://www.vietvodao.q4.pl/index.php?p=historia. Accessed 21 June 2014.

https://www.eneteia.pl/o-nas/czytelnia/slowniki-encyklopedie/cz_slownik_ somatoterapii/. Accessed 17 March 2018

\section{Further Reading}

Barbe, Frances. 2002. The Way of Butoh and Contemporary Choreography: Reflective Writing on Choreographic Research. http://www.kent.ac.uk/arts/ research/pdfs/TheWayofButohandContemporaryChoreographybyFrancesBa rbe2002.pdf. Accessed 21 June 2011.

Bergmark, Johannes. 1991. "Butoh. Revolt of the Flesh in Japan and a Surrealist Way to Move" Mannen paa gatan, 1, http://www.surrealistgruppen.org/ bergmark/butoh.html. Accessed 12 July 2014.

Braid, James. 1855. The Physiology of Fascination, and the Critics Criticised. Manchester: John Murray.

Coelho, Abel. 2008a. A Compilation of Butoh Exercises. Honolulu: University of Honolulu, Department of Theatre and Dance.

Cohen, Selma Jeanne (Ed.). 2004. International Encyclopedia of Dance. New York and Oxford: Oxford University Press; Butō entry, http://butohdance. blogspot.com/2008/04/but-in-international-encyclopedia-of.html. Accessed 6 April 2008.

Csikszentmihalyi, Mihaly \& Isabelle Csikszentmihalyi Isabella. 1999. "Adventure and the Flow Experience.” In John C. Miles \& Simon Priest (Eds.), Adventure Programming. State College, PA: Venture Publishing. 153-158.

Czajkowska, Joanna. 2009. "Notes from a Meeting with Joanna Czajkowska Conducted by Anna Królica." 15 January 2009. Mała Litera Club, Łódź, put down and edited by Witold Mrozek, http://www.nowytaniec.pl/?p=827. Accessed 9 October 2009.

Damasio, Antonio. 1994. Descartes' Error: Emotion, Reason, and the Human Brain. New York: Penguin Putnam.

Gallese, Vittorio. 2003. “The Roots of Empathy: The Shared Manifold Hypothesis and the Neural Basis of Intersubjectivity." Psychopathology, 36. 171-180.

Hijikata, Tatsumi. 2000a. "Fragments of Glass." Interview with Suzuki Tadashi. The Drama Review, 44(1). 62-70.

Hijikata, Tatsumi. 2000d. "Plucking Off the Darkness of the Flesh." Interview by Shibusawa Tatsuhiko. The Drama Review, 44(1). 49-55.

Pastuszak, Katarzyna Julia. 2014b. Interview with Steve Buchanan in the catalogue of the Gdańsk Dance Festival 2014. Gdańsk: Klub Żak. 52-54. 
Przemiany/Transformations. [n.d.]. Leaflet accompanying Przemiany/Transformations by the To-En Butoh Company.

Rizzolatti, Giacomo \& Michael A. Arbib. 1998. "Language Within Our Grasp." Trends in Neurosciences, 21(5). 188-194.

Shigenori, Nagatomo. 1992. Attunement through the Body. Albany: SUNY Press. Shizuto, Masunaga. 1987. Zen Imagery Exercises: Meridian Exercises for Wholesome Living. Tokyo: Japan Publications.

Shizuto, Masunaga. 1997. Meridian Exercises: The Oriental Way to Health and Vitality. trans. Stephen Brown. New York: Japan Publications.

Stein, Bonnie Sue. 1986. "Butoh: Twenty Years Ago We Were Crazy, Dirty, and Mad." The Drama Review, 30(2). 107-126.

Tsuno, Kaitarō. 1978. "The Tradition of Modern Theatre." Canadian Theatre Review, 20. 9-18.

Yuasa, Yasuo. 1987. The Body. Toward an Eastern Mind-Body Theory. ed. and trans. Nagatomo Shigenori \& Thomas P. Kasulis. New York: SUNY Press.

Yuasa, Yasuo. 1993. The Body, Self-Cultivation, and Ki-Energy. New York: SUNY Press.

Zarrilli, Phillip. 2009. Psychophysical Acting: An Intercultural Approach after Stanislavski. London and New York: Routledge. 



\section{Index}

A

Achimowicz, Anna 141

Achterberg, Jeanne 186, 221

Åkerlund, Susana 124, 196, 211, 216

Akira, Kasai 20, 33, 177, 195,

213-215, 221

Amagatsu, Ushio 20, 29, 100, 108, 211,221

Andō, Mitsuko 28, 237

Artaud, Antonin 52, 58, 72, 211, 221

Ashikawa, Yōko 30, 33, 47, 114, 125, $126,181,211,213,214$

Aslan, Odette 29, 100, 221

Aughterlony, Simone 137

B

Bałaj, Bibianna 185, 186, 221

Bakhtin, Mikhail 25

Bakke, Monika 178, 179, 180, 221

Banes, Sally 36, 221

Barba, Eugenio 23-25, 38, 72, 95, 110, 206, 221

Barrek, Małgorzata 53, 221

Bartenieff, Irmgard 12, 139, 207, 212, 214

Bataille, Georges 52

Bazan, Tomasz 12, 14, 63, 101, 103-114, 170, 232

Beardsley, Aubrey 29

Berestecka, Anna 25, 221

Bester, Katarzyna 28, 51, 52, 192,

221, 222

Boleyn-Fitzgerald, Miriam 16, 170, 222

Brałkowska, Anna 14, 124, 126, 128, 232
Braunek, Małgorzata 183, 232

Bremer, Józef 158, 159, 222

Burden, Chris 37

Burrows, Jonathan 137

Bykow, Fiodor 103, 222

C

Czajkowski, Albert 167, 222

Chanczewska, Emilia 86, 222

Chopin, Fryderyk 52, 139, 140

Capiga-Łochowicz, Aleksandra 14, 28, 31, 51, 52, 114-124, 151, 152, $169,181,219,222,232$

Carlson, Marvin 35-37, 222

Clark, Barbara 184

Carpenter, William Benjamin 186

Coelho, Abel 45, 222, 234

Cognard, André 83

Coleman, Ornette 203

Craddock, Takami Mochizuki 40

Csikszentmihalyi, Mihaly 202, 222, 234

Csórdas, Thomas 94, 199, 222

D

Davidson, Donald 159, 222

Decroux, Etienne 202

Deflem, Mathieu 75, 222

Deleuze, Gilles 39

Derrida, Jaques 52

Dewey, John 160, 222

Duczyński, Zygmunt 81

Dudziński, Paweł 14, 56-64, 108, 143, 144, 219, 223, 230

Durkheim, Émile 84 
E

Eguchi, Osamu 22, 28, 33, 34, 223

Elberfeld, Rolf 46

Endo, Tadashi 75, 196, 212

F

Fischer, Roland 171-174, 220, 223

Fischer-Lichte, Erika 13, 14, 65, 188-191, 205, 223

Flicker, Jean Daniel 40

Forti, Simone 142, 206, 213

Foster, Hal 179, 223

Fraleigh, Sondra Horton 27, 34, 41, $50,51,131,132,162,168,169$, $187,223,228$

Francuz, Piotr 16, 221, 223, 228

Franklin, Eric 184, 185, 223

Fret, Jarosław 38, 93, 223

Freud, Sigmund 29, 48

Fujiwara, Denise 196, 212

G

Genette, Jean 29

Gibson, Jerome 49

Gōda, Nario 20, 29, 31, 69, 168, 224

Grabowska (Majewska), Jadwiga 11, 224

Graham, Martha 92, 202

Grosz, Elisabeth 178, 224

Grotowski, Jerzy $12,38,53,57,58$, $63,65-67,76,84,85,91,99,108$, $130,133,189,217,224,227,229$, 230

Grzegorczyk, Anna 30

Guattari, Felix 39

Gunji, Masakatsu 25

H

Harpham, Geoffrey Galt 25, 224

Haring, Chris 137

Hannerz, Ulf 55, 224
Hanff, Sylwia 14, 71-81, 107, 108, $110,146,147,168,170,219,224$, 232

Hawkins, Alma 184, 224

Hepburn, James Curtis 16

Herbert, Zbigniew 106

Higler, Ria 137

Hijikata, Tatsumi $11,14,15,19$, $20,22,26-37,41-44,50,52,55$, $61,68,79,83-85,89,91,95-98$, $101,107,108,110,114-116,119$, $120,125,126,129-131,133,135$, $138,177,180-184,186,187,189$, 195-197, 200, 205, 211-217, 223, 224, 227-229, 234

Hilgards, Ernest 49

Hisao, Kanze 23

Hoffman, Ethan 33, 181, 225

Hoczyk, Julia 24, 25, 29, 51, 52, 63, $75,224,225$

Holborn, Mark 33, 181, 225

Honda, Yasuji 21

I

Ichikawa, Miyabi 20, 26, 48, 225

Ikeda, Carlotta 29, 75, 196, 212, 215, 216

Ishi, Baku 33, 34

Ishihara, Rui Takayuki 10, 14, 138, 141, 142, 212

Iwabuchi, Keisuke 25, 32, 225

Iwana, Masaki 75, 214-216

Iwata, Miho 14, 138, 141, 213, 228

Iyengar, Bellur Krishnamachar

Sundararaja 138, 208

J

Jabłońska, Małgorzata 38, 225

Jan-Krukowska, Justyna 14,61 , 64-71, 129, 130, 141, 144, 219, $225,232,233$

Janicka, Ewa 53, 225 
Janik, Jerzy 159, 226

Janikowski, Andrzej 151, 152, 219

Janikowski, Grzegorz 21, 25, 30

Jarret, Keith 118

Jerzak, Krzysztof 14, 81-90, 132,

$147,148,168,183,219,226,232$

Joss, Kurt 202

Jung, Carl Gustaw 48, 84, 199

Juro, Kara 21

K

Kachi, Seisaku 196, 213, 215

Kandinsky, Wassily 60

Kamińska, Agnieszka 14, 90, 91, 92, 94-100, 165, 232

Karkou, Vassiliki 121, 226

Kasai, Toshiharu 20, 41, 45, 46, 115, 120, 170, 207, 213, 215, 226

Kaseki, Yuko 214

Katsura, Kan 82, 108, 140, 196, 213

Kawa, Magdalena 102, 226

Kawai, Norie 163, 173, 227

Kawamoto, Yuko 75, 196, 214

Kawka, Alicja 102, 226

Keene, Donald 26, 227

Kirby, Michael 36, 227

Klein, Susan Blakely 19-22, 24-29, $31,35,40,168,223-225,227$

Klein, Yves 56, 57

Kleist, Heinrich von 169, 227

Kocur, Mirosław 34, 221, 227, 229, 231

Koseki, Sumako 15, 39, 132, 168, 216, 232

Kowalczyk, Izabela 11, 227

Kozyra, Agnieszka 39, 227

Kreutzberg, Harald 33, 202

Kubiak, Beata 91

Kudliński, Tadeusz 84, 227

Kunio, Yanagita 21
L

Laage, Joan 47, 62, 95, 114, 140, 196, 214, 227

Laban Rudolf von 121, 139, 140, 212,214

Lacan, Jacques 178, 179, 224

Lama, Dalai 194

Lang, Wang 105

Lao, Tzu 103, 105, 227

Laughlin, Charles D. 204

Lautréamont, Comte de (Isidore Lucien Ducasse) 29

Lee, Rhizome 14, 41, 43, 44, 138, 139, 169, 207, 229

Lehman, Hans-Thies 190

Leśnierowska, Joanna 12, 136

Lewandowski, Roman 141, 228

Lewis, Clarence Irving 158, 207, 228

Lipińska, Irena 10, 12, 14, 129-131, 133-138, 155, 156, 220, 232

M

Małecki, Wojciech 55, 161, 228, 230

Maro, Akaji 20, 214

Markiewicz, Piotr 194, 228

Marshall, Lorna 189, 229

Maslow, Abraham 48, 205, 228

Masson-Sekine, Nourit 19, 31, 231

Masumura, Katsuko 28

Matoian, Patrick 82

Mazurek, Maciej 27, 228, 229

McManus, John 204

McKenzie, Jon 13, 228

Melanowicz, Mikołaj 24, 228

Mercé, Antonia 33

Merleau-Ponty, Maurice 162, 228

Mieszkowski, Piotr 166, 167, 228

Mikami, Kayo 15, 33, 41, 97, 165, 168, 207, 228

Mishima, Yukio 19, 21, 215

Mond-Kozłowska, Wiesna 37, 63, $93,162,169,186,228,239$ 
Morenz, Siegfried 102

Morita, Itto 45, 82, 95, 115-117, $169,196,213,215,216$

Murobushi, Ko 75, 95, 97, 98, 196, 212, 215, 216

Muronoi Yoko 82, 196, 215

$\mathbf{N}$

Nagaoka, Yuri 95, 196, 215

Naharin, Ohad 203

Nakajima, Natsu 20, 30, 169, 192, 212, 215, 228

Nakamura, Megumi 142, 212

Nakamura, Tamah 50, 131, 132, 168,223

Nanako, Kurihara 41, 227

Nancy, Allison 12, 161, 228

Newson, Lloyd 38, 223

Niedziałkowski, Stefan 73, 138, 139, 140

Niemczycka, Magdalena 53, 229

Nieoczym, Ryszard 65-67, 70

Nishida, Kitarō 39, 49, 229

Noguchi, Michizo 45, 49, 81, 83, $86,90,97,116,132,138,161,165$, $166,196,204,205,217$

O

Oida, Yoshi 189, 229

Osterwa, Juliusz 60

Orowiecka, Katarzyna 141

$\overline{\mathbf{O}}$

Ōno, Kazuo 14, 19, 20, 27-29, 33, $34,41,47,52,62,69,75,84,85$, $89,131,141,142,180,212-217$

Ōno, Yoshito 15, 27, 41, 96, 196, 216

$\mathbf{P}$

Paduch, Ewa 28, 31, 117-120, 122, 123, 229

Parsons, Kate 35, 45-47, 117, 226
Pastuszak, Katarzyna Julia 14,15 , 19, 32, 38, 51, 52, 90-92, 96, 98, $99,124,189,229,232,234$

Paxton, Steve 71, 93, 201

Pawlik, Jacek Jan 94, 229

Pędzich, Zuzanna 121, 229

Piasecka, Elżbieta 141

Picasso, Pablo 60

Picon-Vallin, Beatrice 29, 100, 221

Piotrowski, Piotr 11, 229

Pleyer, Peter 137

Pollock, Jackson 56, 57, 60

Polzer, Elena 34, 229

Prantel, Sebastian 77

Przybysz, Piotr 193, 194, 228, 229

$\mathbf{R}$

Ramachandran, Vilayanur S. 194, 204, 229

Ramasike, Tebby W.T. 40

Rodowicz, Jadwiga 182, 183, 229

Rodowicz, Tomasz 140

Roquet, Paul 19, 31, 229

Rotie, Marie-Gabrielle 95, 196, 216

$S$

Sade, Marquis de 29

Sakson-Obada, Olga 162-165, 172, 174-176, 178, 230

Savarese, Nicola 23-25, 221

Schad, Isabelle 137

Schechner, Richard 13, 172, 173, 205, 208, 230

Schumacher, Michael 137

Schütz, Alfred 46, 48

Seki, Minako 82, 95, 196, 216, 217

Shihan, André Cognard 82

Shizune, Tomoe 125, 126, 211

Shizuto, Masunaga 235

Shuji, Terayama 21

Shusterman, Richard 55, 160-162, 193, 230 
Sier-Janik, Barbara 36, 230

Smith, Nancy Stark 94, 230

Sobiech, Krzysztof 167, 230

Sokołowska, Joanna 57-60, 62, 63, 230

Stanislavski, Konstantin 89, 235

Stein, Bonnie Sue 28, 235

Stuart, Meg 137

Sweigard, Lulu 184, 185, 230

Szymajda, Joanna 11, 224

$\hat{\mathbf{S}}$

Śliwińska, Aleksandra 14, 90-92, 98, 99, 232

\section{T}

Tachiki, Akiko 187, 230

Tadashi, Suzuki 21, 234

Takaya, Eguchi 28, 33, 34

Takenouchi, Atsushi 63, 69, 70, $75,79,82,95,99,107,114,122$, $129-133,137,138,140,142,180$, 196, 216

Takeuchi, Mika 40, 45, 95, 115, 213

Tanaka, Min 20, 28, 47, 67-70, 129, 141, 142, 196, 212-214, 217, 231

Tanizaki, Junichirō 29, 231

Taranienko, Zbigniew 38, 103, 231

Tart, Charles 176, 231

Thormann, Imre 82, 83, 196, 217

Todd, Mabel E. 184

Tomaszewski, Henryk 73

Turkowski, Janusz 81, 83

Turner, Victor 75, 222, 231

Tyborowska, Beata 92, 93, 231

Tyszka, Juliusz 53, 225

U

Ueshiba, Morihei 82, 199
W

Wach, Anita 104

Waguri, Yukio 15, 35, 41, 50, 95, 96, 200, 214, 217

Wańtuch, Anna 36, 231

Walkowiak, Izabela 53, 231

Welsch, Wolfgang 38-40, 231, 232

Whitehouse, Mary 200

Wieczorek, Stanisław 138

Wigman, Mary 34, 202

Witkiewicz, Stanisław Ignacy

(Witkacy) 60

Wojnicka, Iwona 14, 52, 138-140, 231, 233

V

Varela, Francis 204

Viala, Jean 19, 31, 231

$\mathbf{Y}$

Yamada, Biskup 20, 130

Yamamoto, Kiyokazu 22, 231

Yoneyama, Kunio 20, 28

Yoshimoto, Daisuke 15, 28, 62, 70, $75,81,82,95,97,107,108,112$, $130,133,137,138,141,196,213$, 217

Yoshioka, Yumiko 95, 97, 98, 131-133, 137, 196, 207, 216, 217

$\mathbf{Z}$

Zaides, Arkadi 137

Zambrano, David 137

Zarilli, Philip 38

$\dot{\mathbf{Z}}$

Żbikowski, Tadeusz 102, 106, 232

Żejmo, Katarzyna 14, 69, 138, 139

Żeromska, Estera 16, 19, 21, 23, 26, $182,189,208,232$

Żukowska, Aneta 32, 118, 120, 123, 232 
